\title{
Daniela Rippl
}

\section{Žiznetvorčestvo oder \\ die Vor-Schrift des Textes}

\author{
Eine Untersuchung \\ zur Geschlechter-Ethik \\ und Geschlechts-Ästhetik \\ in der russischen Moderne
}

Verlag Otto Sagner München · Berlin - Washington D.C.

Digitalisiert im Rahmen der Kooperation mit dem DFG-Projekt „Digi20“

der Bayerischen Staatsbibliothek, München. OCR-Bearbeitung und Erstellung des eBooks durch den Verlag Otto Sagner:

http://verlag.kubon-sagner.de

() bei Verlag Otto Sagner. Eine Verwertung oder Weitergabe der Texte und Abbildungen, insbesondere durch Vervielfältigung, ist ohne vorherige schriftliche Genehmigung des Verlages unzulässig. 


\title{
SLAVIS̈TISCHE BEITRÄGE
}

Begründet von

Alois Schmaus

\author{
Herausgegeben von \\ Peter Rehder
}

\author{
Beirat: \\ Tilman Berger - Walter Breu - Johanna Renate Döring-Smimov \\ Walter Koschmal · Ulrich Schweier - Miloš Sedmidubský - Klaus Steinke
}

BAND 387

\section{VERLAG OTTO SAGNER MÜNCHEN 1999}




\section{Daniela Rippl}

\section{Žiznetvorčestvo \\ oder \\ die Vor-Schrift des Textes}

Eine Untersuchung zur

Geschlechter-Ethik und Geschlechts-Ästhetik in der russischen Moderne

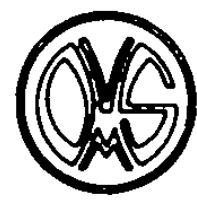

VerLag OtTo SAgner

MÜNCHEN 1999 


\section{9.}

3990

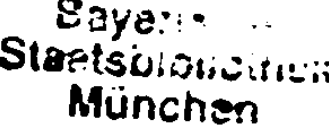

ISBN 3-87690-752-7

(c) Verlag Otto Sagner, München 1999 Abteilung der Firma Kubon \& Sagner

D-80328 München

Gedruckt auf alterungsbeständigem Papier

$$
99 P 87690
$$




\section{Danksagung}

Die vorliegende Dissertation wurde durch ein Promotionsstipendium der Deutschen Forschungsgesellschaft im Rahmen des Graduiertenkollegs Geschlechterdifferenz und Lıteratur an der Ludwig-Maximilians-Universität München ermöglicht; sie wurde im Wintersemester 1994/95 als Dissertation angenommen und im gleichen Jahr als Microfiche veröffentlicht. Mein besonderer Dank gilt den Betreuem dieser Arbeit Frau Professor Dr. Johanna-Renate Döring-Smirnov und Herm Professor Dr. Aage A. Hansen-Löve, die mir in ausführlichen Gesprächen wertvolle Hinweise und Anregungen zur Bewältigung der Themenstellung gaben. Mein Dank gilt ebenso Frau Professor Dr. Ina Schabert für die wissenschaftliche Beratung, die sie mir während meiner Teilnahme am Graduiertenkolleg zuteil werden ließ, sowie Professor Dr. Peter Rehder für die Aufnahme der Arbeit in die Reihe "Slavistische Beiträge". 


\section{Inhalt}

Vorwort 11

Einleitung $\quad 15$

1. ZiznetvorČestvo oder die Vor-Schrift des

Textes: Geschlechter-Ethik und Geschlechts-

Ästhetik in der russischen Moderne 15

2. Rekonstruktion der religionssymbolistischen

Genealogie: Aufbau und Kapitelübersicht 26

3. Kulturpoetik - Psychopoetik - Genderpoetik:

Theoretische Überlegungen zur Diskursanalyse 33

4. Forschungsbericht:

Feministische Konzepte der Literatur-

wissenschaft

38

Kapitel I:

Gnostische Kunstreligion als Triebökonomie

Der Gebrauch der Lust im Silbemen Zeitalter

4. Sophiologische Diätetik:

Vladimir Solov'evs Sinn der liebe 
5. Eros pontifex:

Zinaida Gippius' Metaphysik der Liebe

6. Sophia-Projektion und schreibende Muse:

Zinov'eva-Annibals Dreiundreißig Mißgeburten

\section{Kapitel II:}

Gottesverlangen und Minnedienst

Der hysterische Mann im Silbernen Zeitalter

7. Ein theurgischer Zeugungsakt:

Andrej Belyjs Silberne Taube

8. Idealisierte und/oder perhorreszierte

Weibs-Bilder:

Aleksandr Bloks Kult der.Schönen Dame

9. Ver-/Entstellung der Frau:

Ljubov' Dmitrievnas Wahrheit und Dichtung

\section{Kapitel III:}

Höfische Liebesspiete - Tödliche Inszenierungen

10. Mimesis und Mimikry:

Das symbolistische žiznetvorčestvo

11. Eine Tragikomödie der Heterosexualität:

Die symbolistische ménage-à-trois 
12. Text-à-trois:

Valerij Brjusovs Feuriger Engel

13. Der Tod der Muse:

Renatas Ende

199

\section{Kapitel IV:}

\section{Liebesverluste}

Sankt-Petersburg - Petrograd - Leningrad

205

14. Der Petersburger Text:

Ein männlicher Stadttext

15. Die Erotik der Autor-Stadt:

Konstantin Vaginovs Ziegenlied 



\section{Vorwort}

Nachdem der russische Präsident Michail Gorbacev die Ära Perestrojka und Glasnost' eingeleitet und damit auch wioder die Archive zugänglich gemacht hatte, konnten endlich jene Texte wieder gedruckt werden, die als kulturelles Erbe der Öffentlichkeit solange vorenthalten worden waren, wie z.B. die Texte der russischen Religionsphilosophen und Symbolisten, um die es in der vorliegenden Arbeit geht. Zum ersten Mal nach fast sieben Jahrzehnten konnten die Russen in ihren Buchhandlungen wieder Bücher von Vladimir Solov'ev, Vassilij Rozanov, Nikolaj Berdjaev, Dmitrij Merežkovskij, Zinaida Gippius' - um nur ein paar Namen zu nennen - kaufen. Heute, nach dem Zerfall der Sowjetunion, erfreuen sich diese Texte einer unerwarteten Aktualität, werden doch darin bereits Voraussetzungen zur Reformienung des russischen Staates diskutiert, die auf Konzepten einer neuen Geschlechter-Ethik und Geschlechts-Ästhetik aufbauen.'

Ein paar Jahre vor Gorbacevs Zeit gab es schon einmal den Versuch, die Gedanken der Religionsphilosophen neu zu beleben. Damals, im Jahre 1980 beriefen sich die christlich orientierten Feministinnen Rußlands in ihren Reformienungsbestrebungen auf diese zensierte Tradition innerhalb der russischen Kultur. ${ }^{2}$ Dementsprechend formulierten sie ihre "messianische Aufgabe" in der

\footnotetext{
1 Ein cinschlagiges Beispiel dafur ist dic Publukation des Buches Russkaj éros ili filosofija ljubvi v Rossil (Der nussische Eros oder die Philosophie der Liebe in Rußland), hg von V P. Sestakov. Moskva 1991.

2 Gameunt sind dic Almanache Zenszina i Rossija (Die Frou und Rußland). Rossijanka und Manja Se getioren au den ersten Texten einer feministischen Opposition. die in der Sonvetunion im Hertost 1979 in Selbsnerlag erschienen sind. Diesc Texte gelangten über Umuege nach England. deren Ubersctaing uns Englische führte uioderum zur deutschen Ausgabe Vgl Frauenoffensive. Die Fran und Rußland. Munchen 1980. Die der femunustuschen Opposition angehongen Fraucn Mamonova.
} 
Rechristianisienung Rußlands, um das Land von der totalitären Ideologie zu «erlossen» und damit auch die russische Geschichte "wiederzugebären": "Die Frauen Rußlands haben gleichzeitig die Mission, den Menschen zu sich selbst zurückzubringen, der Gewalt die Liebe entgegenzusetzen, die Macht des kalten, seelenlosen technokratischen Denkens zu Fall zu bringen, sich des Herzens und des Geistes zuzawwenden." ${ }^{3}$ Indem sie den kulturellen Lebenszausammenhang des totalitären Regimes offenbarte, prangerte die feministische Kritik den Verfall von Ehe und Familie und die daraus resultierende Vereinzelung beider Geschlechter an. Schwerpunkt ihrer Kritik bildet der dem Alltagsempfinden zugrundegelegte Verlust von "weiblichen Frauen" und "männlichen Männem". Der Verlust von "weiblichen Frauen" wird in der generellen Identitätslosigkeit der Frau innerhalb des Patriarchats gesehen, dessen phallokratische Auswüchse das "Weibliche" unterdrückt: "Indem sie vor sich selbst davonläuft, irt sie in den Ecken einer ihr fremden Kultur herum, denn die Werte bleiben am Mann ausgerichtet. Die Frau wird von der Gesellschaft gezwungen, sich selbst ebenfalls danach einzuschätzen, wie ähnlich sie dem Mann geworden ist. ${ }^{14}$ Die "Verweiblichung des Mannes" hingegen wird von der feministischen Kritik einerseits als Resultat einer spezifischen Form des "Mutterns" interpretiert, andererseits als Folge der administrativen und ideologischen Unterdrückung, die den "männlichen" Unternehmungsgeist hemme.

Malachouskaja, Cicenko, Gonceva und Vosnescriskaja muBten zuzschen 1980 und 1981 die Sowjetunion verlassen

3 Frauenoffensive Die Fran und Rußland, 1980, op.cit., S 176.

4 Ebd., S. 41 ff.

5 Vgl Nancy Chodorow. The Reproctuction of Mothening. Psychoanalysis and the Sociology of Gender, Berkeley 1978. De nussischen Femunustunnen berufen sich zwar nicht auf die Autonn, aber das, was sie ausfuhren. entspneht dem von thr gepragten Termunus ,Muttern“ Unter diesem Phänomen versteht Chodorow eine unmaßige und hystensehe Sinnischkett in der Erzachung, die dem Kind schadet 
Aus der besprochenen Lektüre lassen sich zwei Aspekte ableiten, die für die Frage der Geschlechter-Differenz innerhalb der russischen Kultur paradigmatisch zu sein scheinen: 1. das Ewig-Weibische (verno bab'e) des russischen Charakters und 2. die Idee des Heiligen Rußlands (svjataja rus') verbunden wird. ${ }^{6}$ Diese Idee begreift die nationale Identität als "messianische" und äußert sich immer wieder zyklisch in Versuchen der kollektiven religiösen und historischen Rettung und geistigen Wiedergeburt Rußlands. Nach Foucault könnten diese Versuche der Rettung und Wiedergeburt am Ende des letzten Jahrhunderts und nach dem Zerfall des Sowjetregimes als "Krankheiten" des nationalen Selbstbewußtseins bezeichnet werden, die in den "Krankheiten der (russischen) Macht" begnündet liegen und in letzter Konsequenz für die "Krankheiten des Körpers"7 verantwortlich sind. Am Anfang dieses Jahrhunderts verstanden die Religionsphilosophen das "dritte Geschlecht" als Überwindung des nationalen Dilemmas, heute begreift man es als seine Ursache. Damit wird die politische Technologie des Körpers und der geschichtliche Prozeß als dessen Selbstenteignung deutlich: Am Ende stand als Resultat des totalitären Regimes der geschlechtslose homo sovietıcus.

Die Frage nach der Rettung und Wiedergeburt Rußlands, wie sie um die Jahrhundertwende formuliert wurde und heute emeut gefordert wird, ist deswegen auch, wie Luce Irigaray es formulierte, als eine Frage der GeschlechterDifferenz zu denken: "Jede Epoche hat Heidegger zufolge, eine Sache zu bedenken'. Nur eine. Die sexuelle Differenz ist wahrscheinlich diejenige unserer Zeit. Diejenige, die uns, wäre sie gedacht, die Rettung bringen würde? Damit das Werk der sexuellen Differenz Wirklichkeit werden kann, ist in der Tat eine

6 Nikolaj Bcrdjacv: Russkij eros ıli filosofia ljubv v Rossil, 1991, op.cit., S. 6

7 Michel Foucault: Überwachen und Sirafen Dic Geburt des Gefangnisses. FrankfurtMain 1976 
Umwalzang des Denkens und der Ethik notwendig. Alles in der Beziehung zwischen Subjekt und Diskurs, Subjekt und Welt, Subjekt und Kosmischem, zwischen Mikro- und Makrokosmos muß neu gedacht werden. Alles, und als erstes das Faktum, daß das Subjekt sich immer männlich bestimmt hat, auch wenn es vorgab, universell oder neutral zu sein: der Mensch. ${ }^{.8}$ In Anlehnung an dieses Zitat schlage ich vor, die Texte, die Gegenstand dieser Arbeit bilden, als Beiträge zu einer neuen Geschlechter-Ethik und Geschlechts-Ästhetik zu lesen, die die Grundlage für eine neue Lebensform bildeten.

8 Lucc Ingaray Hihuque de la differance sexuelle, Pans 1984. Zit. nach Hihik der sexuellen Differenz. FrankfurdMain 1991, S 12. 


\title{
Einleitung
}

\section{Lebensschöpfung oder die Vor-Schrift des Textes: Geschlechter-Ethik und Geschlechts-Ästhetik in der russischen Moderne}

\author{
Arbeiten heißt, anderes zu denken, als \\ das, was man vorher dachte \\ Michel Foucault ${ }^{9}$
}

Žıznetvorcestvo, Lebensschöpfung, so heißt das Programm des russischen Religionssymbolismus ${ }^{10}$, einer literarischen Weltanschauung, die im Zeitalter der ersten Revolution, der Februarrevolution im Jahre 1905, Rußland durch ein neues religioses Bewußtsein, eine "neue innere Kirche"1" zur Rettung und Wiedergeburt verhelfen wollte.

9 Michel Foucault Eine (jeschichie der Wahrhell, Munchen 1987, S. 6

10 Nach der typologischen Periodisienung der russischen Moderne von A A Hansen-Love wer-den dre Phasen des Symbolismus unterschieden. I S I = die diabolische Phase des Frih-symbolismus der 90er Jahre des 19. Jahrhunderts (auch bezeichnet als "Dekadenz"). gegliodert in die beiden "Programme" des Asthetismus und Panasthetismus. 2 S II = der mythopoetische Symbolismus der ersten Jahre nach 1900, 3 S III = der grolesk-kamevaleske Symbolismus nach 1906 Vgl. A. A Hansen-Love. Der Russische Symbolismus Sysiem und Entfaltung der poetischen Motrue, Wien 1989. Dieser Typologie entsprechend getion der Religionssymbolismus der zueiten Phase an, da es sich ber der Motabildung aber jeweils um Transformationen der vorhergehenden Phase handelt. werden im Verlauf der Dissertation auch Motive aus den anderen Phasen besprochen

II Vgl in drescm Zusammenthang N.A Berdjaev Samopoznanie. Pans 1949 und N Zemov The Russian Religious Renaissance of the Twenneth ('entury, New York 1963 
Die Repräsentanten dieser literarischen Weltanschauung verstanden ihre Texte als Medium für die Enthüllung einer geistigen Wahrheit, die den uneingeweihten Leser mit mystischer Intuition und metaphysischem Einblick erfullen sollte. Davon leiteten sie eine neues Verhalten und "eine neue Lebensart"12 ab, die als Grundlage für ein neues gesamtgesellschaftliches Bewußtsein und damit auch für eine neue Gesellschaft angesehen wurde: Eine literarische Weltanschauung, die als gnostische Kunstreligion bzw. Religionskunst mystische und metaphysische Konzepte für die Realisierung einer Heilsvorstellung und letztendlich einer politischen Utopie einsetzte, um ein wiedergeborenes Rußand, einen neuen Staat zu erschaffen.

"Sinnbild des neuen Zeitalters" war der deutsche Philosoph Friedrich Nietzsche, in dessen Schatten sich die Symbolisten ausnahmslos bewegten. Von ihm übernahmen sie das geistige Fundament, mit dem sie das menschliche Verhalten und den Alltag neu zu bestimmen suchten: der Übermensch. Er trat an die Stelle des alten Gottes. ${ }^{13}$ Die Lebensschöpfung, das ziznetvorcestvo, ist im Kontext des Nietzsche-Kultes und der (jottsuche (bogotzkatel'stvo) im finde-siècle Rußlands als Gegenbewegung zu Materialismus, Positivismus, Rationalismus, Utilitarismus etc. entstanden. Es resultierte, wie die Textanalysen zeigen werden, in einer spezifischen Semiotik des Verhaltens, die auf der Ästhetisienung bzw. Theatralisienung des Lebens als Kunst (und umgekehrt) basierte. ${ }^{14}$ Ziel der vorliegenden Arbeit ist es, das ästhetische Problem der Be-

12 Alexander Edkind Fins des Inmogglichen. Die (jeschichie der Psychoanalyse in Rußland. Lapzag 1996. S. 54 "Eingewerhte pflegten al sagen, es handeke sich am chesten um cine nouc Letonsart"

13 Ebd S. 52 Vgl. auch Maria Deppermann "Nictzsche in Rußland", in. Niezzsche Sirucien, Bd 21, 1992.S $211-252$.

14 Irina Papemos Sudic (hernyshersky and the Age of Realism. A Sinuty in the Semuoncs of Behonor, Stanford 1988 hat dieses Problem an Comsevskuj und scancm Werk untersucht 
ziehung zwischen Kunst und Leben - der innerste Kern des symbolistischen żznetvorCestvo - unter der Perspektive der Geschlechter-Differenz zu untersuchen. Gerade die Suche nach neuen Lebensformen war begleitet von kontroversen Diskussionen über Sexualität, "ein politischer Gegenstand im späten imperialistischen Rußland." ${ }^{15}$ Es wurde an Konzepten gearbeitet, die das Verhältnis von Mann und Frau, Ehe und Familie neu formulieren und damit auch das sexuelle Verhalten im weitesten Sinne regulieren sollten.

Wie Foucault dargelegt hat, konstituieren sexuelle Kategorien und Normen sowohl ein System von Machtbeziehungen, die den sozialen Körper konfigurieren, als auch eine Denkweise über Macht und ihre Weise, diese durch das Medium des Körpers selbst zu organisieren. Foucault argumentiert, daß in dem Übergang von alten traditionellen Regimen zur kapitalistischen Gesellschaft die Regulierungs- und Straffunktionen des absoluten Staates in die Hände von Ärzten, Kriminologen, Pädagogen und Juristen übergehen. Auf diese Weise werden Macht und Persönlichkeit transformiert und mit ihnen der Gebrauch und die Bedeutungen von Sexualität. ${ }^{16}$ Ein ähnlicher Übergangsprozeß, wenn auch viel langsamer, vollzog sich im Rußland der Jahrhundertwende. ${ }^{17}$ Zugang zu politischer Macht zu bekommen wie überhaupt politisch etwas zu verändern, war unter dem zaristischen Regime äußerst schwierig. Urbanisierung und Industrialisienung wichen von der westlichen Erfahrung in vielerlei Hinsicht ab,

15 Laura Engelstein. The Keys 10 Happiness. Sex and the Search for Modernity in Fin-de-Siecle Reussia. Princeton 1992. S. 1

16 Michcl Foucault: Histoire de la sexualité. I: La volonté de sawoir, Pans 1976 Zusammengefaßt nach der deutschen Ubersetzung Der Wille zum Wissen Sexalitat und Wahrhell I, FrankfurtMain 1991 .

17 Daher sind Foucaults Thesen. ure Engelstein nehug behauptet. nur bedingt applizuerbar, dern der Kontext war in Rußland cin anderer Vgl Engelstein. 1992. op.cit., S. 3 
genauso wie kulturelle Entwicklungen: "Rußland produzierte seine eigene Version westlicher Tradition, auf sexuellem, wie auf allen anderen kulturellen Gebieten." $^{18}$

Einer der eigenwilligsten und umstrittensten Denker dieser Zeit war der Publizist und Religionsphilosoph Vasilij Rozanov (1856-1919), der sich selbst als Nachfolger Dostoevskijs betrachtete und von seinen Zeitgenossen mit Nietzsche verglichen wurde. ${ }^{19}$ Ähnlich wie Freud in Westeuropa untersuchte Rozanov die Beziehung der Kultur zur Sexualität. ${ }^{20}$ Er verherrlichte den Geschlechtsakt als Moment der Aneignung von Weisheit und brach damit die strikte Tabuisienung der Sexualität in der russischen Kultur auf. Offen schrieb Rozanov darüber, wie sich Mann und Frau am besten sexuell verhalten sollten. ${ }^{21}$ In seiner fundamentalen Kritik an der orthodoxen Ausübung des Christentums machte er die Russisch-Orthodoxe Kirche verantwortlich für überholte Familienstrukturen, die noch immer auf dem mittelaiterlichen domostroj

18 Engelsteun. 1992. op.cit., S. 3

19 Ebd das Kapitel zu Rozanov "Sex and the Ant-Semite Vasilij Rozanov's Patrarchal Erocicism", S. 299-334, S. 303 Engelsten analysiert Rozanovs anusernitisches Denken in Bezug auf Sexualitit Sie zeigh. daB Rozanov im Unterschiod au Weininger, dessen (jeschlecht und ('haraker in RuBland genauso popular war we Nictzsches Also sprach Zarathustra, dic jüdische Kultur nucht als weiblich und desuegen als verachtenswert betrachtete. sondern um Gegenteil thre sexuclk Potenz und phallische Orenterung hervortob und die "Mannlischket des Alten Testaments" der "Verweiblichung des Chnstentums" vorzog

20 Alexander Etkind. 1996. op cit., S. 58. "Rozanov stand Fraud in victem nahe. was de Bezuchungen von Sexualitat und Kultur angingen, de beide als pnmar betrachteten Auch uber deren Wochselseitugkeit waren sie sich enug Je mehr en Mensch sich sexuell verwiklicht, desto wenuger Energien bleaben thm fur anderweitige Vernichtungen. umgekehrt waren de Kulturheroen aller Zetten und Vöker Menschen mit cigenwilligem, oftmals schwach ausgepragtem Sexualteben | ... | Der posituve, kulturstuftende Sim sexuelker Tabus. der fur den strengen. verschlossenen Freud so sehr von Bodeutung war, mußte Rozanov [... | zutiefst fremd bleiben "

21 Nachdem der Text (ledinennoe (Solltana) veroffenticht war, crhuelt Rozanov Arrest Man beschuldigte thn der Pornographe Vgl. Andrej Sinjavskij Opassic hist'ja Rozanowa (Rozanovs Venwehte Blatter), Pans 1982. S 29 
basierten und damit einem sexuellen Puritanismus folgten. ${ }^{22}$ Rozanov rehabilitierte das "Geschlecht" (er gebrauchte das Wort Sexualität nicht), indem er es von der Sünde entkoppelte. ${ }^{23}$ Für ihn war das "Geschlecht" ohne Sünde, weil es so von Gott ausgedacht war. Deswegen formulierte Rozanov das "Geschlecht" als "göttlichen Ort des Menschen."24 In den Aufsätzen Semejnij vopros $v$ Rossij (Die Familienfrage in Rußland) von 1903 und $V$ mire nejasnogo i nerešennogo (In der Welt des (Inklaren und (Inentschiedenen) von 1904 entwickelte Rozanov eine neue „Physiologie der Ehe ${ }^{\prime 25}:$ "Er regt an, Neuvermählte die ersten Wochen bis zum Eintritt der Schwangerschaft in der Kirche, vielleicht in einem Seitenbau, verleben zu lassen, möglichst aber in einem Gotteshaus des Südens, das mit seiner Kuppel nicht den Himmel metaphorisch abbildet, sondern ihn metonymisch ebenso zu den Sternen öffnet wie den Boden zu Pflanzen. Sein Vorschlag, die körperliche Vermählung im Kontakt zu Gott und Schöpfung am selben Ort zu feiem wie die geistliche, in der Kirche einen "Ehe-Palast" zu errichten, emtete Entrüstung sogar in den Religiös-Philosophischen Versammlungen. Dabei ging es Rozanov darum, die Alltagskultur mit der Religion, mit der Bindung zu Gott zu versöhnen." 26

22 Domostroj, en altrussisches Hausbuch aus dem 16. Jahhindert, ist cin cinzigartuges Denkmal des patnarchalischen Sitten- und Moralkodex' der altrussischen Familie Aus der Perspektive eines mit grenzenloser Macht ausgestatteten Hausvaters urd das eruunschte Verhaten der Familienangetiongen und Bediensteten geschilden Es unterweist den Mann. whe et sich als gottesfurchtiger Chnst zu vertalten hat und wie er dreses Verhalten an sein "Weib" weiterautragen hat. "Der Mann lechre sein Weib. we sie Gott at Gefallen und ihrem Manne au Willen sei, wie sie das Haus und alles Wirtschaftsgerat in guter Ordnung halte und jegliche Arbeit zul vernchten wisse. wie sie die Dienerschaft unterveise und was sie selbst tuc "Zit nach der Ubersetzung von Klaus Muller, Altrussisches Housbuch. Darmstadt 1989, S 7.

23 Alcxander Etkund, 1996, op.cit, S 55

24 Andre Sinjavskij, 1982. op cit., S. 33/34.

25 Der Grund fur Rozanovs intensive Ausscinandersetzung lag wohl in seiner ersten unglucklichen Ehe mut der chemaligen Gelicbten Dostoevskujs. von der er sich nicht scheiden lassen konnte. weil sie nicht in de Schendung cinvilligte Vgl. Sinjavskij. 1982. op.cit. S 27

26 Rauner Grubel "Prckärc Gange zurschen Leben. Kunst und Religion Vasily Rozanovs religiose. 
Rozanov sah in einer neuen „Physiologie der Ehe“ die Voraussetzung für einen besseren Staat. Im Gegensatz zur kirchlich verordneten Keuschheit und Ehelosigkeit war er der Meinung, eine glückliche Ehe könne sexuellen Perversionen vorbeugen. Konträr dazu entwickelte er in seiner Streitschrift Ljudi lunnogo sveta (Mondlichtmenschen) einen androgynen, Männliches und Weibliches in sich vereinigenden Menschen und verteidigt die homosexuelle Liebe. ${ }^{27}$ Zusammenfassend kann man sagen, Rozanov hat in den unterschiedlichen Formen der sexuellen Liebe den Schlüssel zu Kultur und Literatur generell gesehen. Davon leitete er u.a. Lermontovs Dämonismus ab, Gogol's infermale Welt (alle schönen Frauen sind Hexen) oder Tol'stojs Darstellung der Liebe als absolutes Leid. ${ }^{28}$

Im Gegensatz zu Rozanovs Verherrlichung der Sexualität, die an die Verherrlichung der Familie gebunden war, äußerte sich Vladimir Solov'evs (18531900) religionsphilosophische Vorstellung von der geschlechtlichen Liebe als mystische Verschmelzung mit der Sophia. Dabei verband er die uralte gnostisch-mystische Idee einer weiblichen göttlichen Hypostase mit der apokalyptischen Vorstellung von einem "Dritten Reich" des Geistes, in dem die Geschlechter-Differenz wie alle kulturellen und existentiellen Polaritäten und Widersprüche in der All-t:inheıt verschmolzen sind. In seinen Vorlesungen über das (jottmenschentum ${ }^{29}$ formuliert der Religionsphilosoph als utopischen Ent-

soziale und literansche Häresie", in Wiener Slowistischer Almanach. Sonderband 41, Wicn 1996. S 103-146. S. 125

27 Vasilij Rozanov. Ljuct lunnogo sueta. Metafizika chnstiansma Menschen des Mondlichtes. Eine Metaphysik des ('hnstentums, Sankt-Pctcrburg 1911

$28 \mathrm{Vgl}$ Sestakovs Einfuhnung au Russkuj éros ili filosofija ljubvn v Rossi, Moskau 1991, S. 9

29 Vladumir Solov'ev "Ctenija o Bogoxelovotestre", in .Xxbramie Soćinent] III-IV [Sankt-Petcrburg 1873-1905], Nachdruck Brusscl 1966, S 3-163 
wurf eines neuen Menschentyps und einer neuen Gesellschaft den Gottmenschen (bogocelovek), der sowohl den Logos des Vaters als auch das Materielle der Sophia in sich vereinigt, dessen Androgynität folglich den ausweglosen Kampf der Geschlechter, wie ihn Nietzsche postulierte, beenden sollte. Dabei sollte in letzter Konsequenz die Zerrissenheit des Christentums in der vollständigen Harmonie von West- und Ostkirche transzendiert werden:

$V$ božestvennom organizme Christa dejstvujušce edinjašcee nacalo vyrazajuščee soboju edinstvo bezuslovno-suščego, očevidno est' Slovo ili Logos.

Edinstvo vtorogo vida, edinstvo proizvedennoe, v christianskoj teozofii nosit' nazvanie Sofii [. .] Sofija est' telo Božie, materija Božestva, proniknutaja nacalom božestvennogo edinstva Osuščstuljajuš̌zij v sebe ili nosjaščij eto edinstvo Christos, kak cel'nyj nastojašxij božestvennyj organizm - universal'nyj $i$ individual'nyj vmeste - est' $i$ Logos i Sofija [ ] Govorit' o Sofij, kak o sušrestvennom elemente Božestva, ne znacit', s christianskoj tocki zrenija, wodit' novych bogov. Mysl' o Sofii vsegda byla v christianstve, bolee togo - ona byla ešce do christianstva ${ }^{30}$

Das einheitsstiftende Wirkprinzip im gottlichen Organismus Christi, das Prinzip, welches die Einheit des absolut Seienden zum Ausdruck bringt, ist offenbar das Wort oder der Logos

Die Einheit der zweiten Art, die hervorgebrachte Finheit, tragt in der christlichen Theosophie den Namen Sophia [ . ] Die Sophia ist der Leib Gottes, ist die vom Prinzip der gottlichen Einheit durchdrungene Materie der Gottheit. Christus, der diese Einheit in sich tragt und sie verwirklicht, ist als ganzheitlich-göttlicher Organismus - universal und individuell zugleich -, sowohl Logos als auch Sophia [...] Von der Sophia als wesenhaftem Element der Gottheit zu sprechen, heißt vom christlichen Standpunkt aus nicht, neue Gotter einzufuhren Den Sophiagedanken hat es im Christentum immer gegeben. mehr noch - es gab ihn bereits vor dem Christentum ${ }^{31}$

Solov'evs Nachfolger ist der Religionsphilosoph Nikolaj Berdjaev. Er knüpft an dessen Theorie zur Geschlechtsliebe an und entwickelt daraus seine Schrift zur Metaphysik des (jeschlechts und der Liebe. ${ }^{32}$ Berdjaev

\section{Ebd S 115}

31 Wladimur Solowjow "Vortesungen uber das Gortmenschentum", Gesammette Werke Band I. München 1978. S 670

32 Nikolaj Berdjacv Melafizika pola I ljubv, in Pereval, 1907. Nr 5, S 7-16 und Nr 6. S. 24-36 
vertrat die Meinung, die Grundlage einer jeden Religion sei das Geschlecht: „Nastojaščaja religija, misticeskaja żizn' vsegda orgiasticna, a orgiazm, mogucaja sila żizni, svjazan s polovoj poljarnost'ju. Polovaja poljarnost' est' osnovnoj zakon žizni i možet byt' osnova mira." (,Die echte Religion, das mystische Leben ist immer orgiastisch. Der Orgiasmus ist eine mächtige Gewalt des Lebens, die mit der geschlechtlichen Polarität verknüpft ist. Die geschlechtliche Polarität ist das grundlegenste Gesetz des Lebens und vielleicht sogar die Grundlage der Welt." $)^{33}$

Leitmotive seines weiteren Schaffens sind zwei Themen, die Berdjaev im Sinn der Kunst (smysl tvorČestva) von 1916 ausarbeitet: 1. Die erotische Energie stellt eine ewige Quelle der Kunst dar (deswegen kann man die Kunst nicht ohne die Eigenarten der Liebe verstehen) und 2. die Erotik ist mit der Schönheit verbunden, deswegen bezeichnet der Eros die Suche und den Weg zum Schönen. ${ }^{34}$ An dem Werk Dostoevskijs arbeitet Berdjaev seine "Überlegungen über den Eros" weiter aus. In dem Buch Die Weltanschauung Dostoevskijs (mirosozercanie Dostoevskogo) von 1923 unterscheidet er zwei Liebeskonzeptionen, die die Poetik des Autors bestimmen und damit auf ihre Weise auch den russischen Charakter erklären: Dostoewskijs Helden lieben entweder aus Wollust oder aus Mitleid. Aber besonders detailliert beschreibe Dostoevskij die Liebe aus Wollust, die immer zur Zerstörung des Menschen führe.

Neben Berdjaev haben Lev Karsavin, Boris Vyšeslavcev und Dmitrij Merežkovskij über Dostoevskijs Liebeskonzeption geschrieben. Karsavin nennt Fedor Pavlovic Karamazov "einen Ideologen der Liebe". ${ }^{35}$ In seinen Peters-

33 Berdjacv un cuncm Bnef an seune aukunftige Frau Zit nach Russkj eros ili filosofii ljubv v Rossii, 1991, op cit., S 11

34 Ebd S. 11

35 Lev Karsavnn "Fodor Pavionc Karamazov kak idoolog ljubvi", un: NaCalo. Pctrograd 1921 
burger Nachten begründet er eine Geschlechter-Ethik und Geschlechts-Ästhetik, die auf einer dialektischen Vorstellung, der "Zweieinheit der Liebe" aufbaut und Geist und Körper, Verstand und Gefühl, Männlichkeit und Weiblichkeit vereinigt. ${ }^{36}$ Ausgehend von Solov'evs und Berdjaevs Gedanken zur Sexualität und zur Philosophie der Liebe entwirft Vyšeslavcev seine Ethik des verwandelten Éros (1931), in der er, der Tradition des christlichen Platonismus verbunden, neueste psychologische und psychoanalytische Erkenntnisse diskutiert. ${ }^{37}$ Hauptbestandteil dieser Geschlechter-Ethik ist Vyšeslavcevs Polemik mit der Psychoanalyse Freuds. Vyšeslavcev billigt Freud zu, er habe zwar unbewußte sexuelle Instinkte in Kunst und Religion aufgedeckt, ihren wahren Sinn jedoch nicht aufgedeckt, weil sein Ideensystem Sublimierungsmechanismen überhaupt außer acht läßt. In seinem Aufsatz Dostoevskij über die Liebe und Unsterblıchkelt zeigt er die Parallele zur Geschlechter-Ethik Solov'evs und zur Literatur des Silbermen Zeitalters im allgemeinen auf. ${ }^{38}$

Im sechsten Kapitel von Die Religion Tol'stojs und Dostoevskıjs beschreibt Dmitrij Merežkovskij in der Gegenüberstellung von Tol'stojs Anna Karenına und Dostoevskijs .Jüngling zwei Liebeskonzeptionen, die als paradigmatisch für das Silherne Zellalter anzusehen sind: die Heiligsprechung und die Dämonisierung der Liebe. ${ }^{39}$ Auf jeden Fall wird an diesen Untersuchungen deutlich, daß Dostoevskijs Einfluß auf die Texte der Symbolisten von entscheidender Bedeutung war. Aus Solov'evs Androgyniekonzept, einer geistigen Körperlichkeit und der "Gottmenschlichkeit“ der Liebe entwickelt Zinaida Gippius in ihren theoretischen Schriften Kritik der Liehe (1900), Verliebtheit

36 Ders. Noctes Petropolitanae. Petrograd 1922.

37 Bons Vyseslavocv: Enka preobražennogo erosa. Pans 1931.

38 Ders. "Dostoevsku o ljubvi i bessmerti", in: Sovremennue zapiska. Pans 1932. S. 208-304

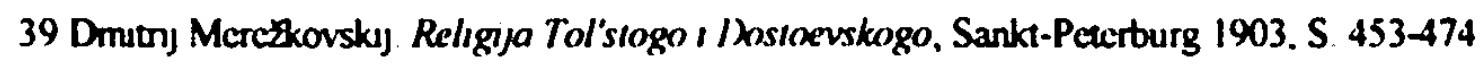


(1908), Über die Liebe (1925), Züge der Liebe (1928) und Arithmetik der Liebe (1931) eine Metaphysik der Liebe, «Eros Pontifex».

Generell kann man in der russischen Religionsphilosophie des fin-de-siècle zwei entgegengesetzte Liebeskonzeptionen unterscheiden. Die erste geht von Solov'ev aus, die zweite von Pavel Florenskij. Diese wird von Ivan Il'in und Sergej Bulgakov weiterentwickelt. Während Solov'ev und seine Nachfolger im Geiste des Platonismus stehen, orientieren sich Florenskij und seine Nachfolger auf die mittelalterliche Charitas und der damit verbundenen christlichen Ethik von Ehe und Familie. Florenskij betrachtet die Liebe als Träger einer metaphysischen Wahrheit, die zu Gott führt. Auf diese Weise ist die Liebe kein individueller, persönlicher Akt, sondern eher ein Geburtsprozeß, ein Prozeß der Verschmelzang aller Liebenden mit dem göttlichen Wesen. ${ }^{40}$ Sergej Bulgakov bezeichnet das Geschlecht als den Anfang der Sünde im Menschen. In Svet nevecemij von 1917 kritisiert er Solov'ev als "Ideologen eines dritten Geschlechts" und als "geistigen Don Juan", der die Sexualität nicht besiegt. sondem sie in seiner Propagienung des Eros ästhetisiert. ${ }^{41}$ Auch der persönliche, intime Charakter, den Solov'ev seiner Lehre über die Sophia verleiht die Idealisienung des Kwig Weıblıchen - kritisiert Bulgakov wegen seiner doppeldeutigen Ausrichtung auf Himmel und Erde. ${ }^{42}$ Die Idealisierung der Frau in der hermetischen Tradition Rußlands (in den unterschiedlichen Sekten) ${ }^{43}$ und

40 Pavel Florenskj]: Solp i unverzdenie istıny, Moskva 1914

41 Sergej Bulgakov. Sivet Neveternij. Sozercanija i umozrenija. Moskva 1917, S 295-305

42 Dicse gab der Schniftstellern Anna Smuth den AntaB. sich als Solov'evs ewige Freundin ausaugeben Vgl ders "Vladimur Solov'ev I Anna Smidt", in Tichie dumy, Moskva 1918. S 94-98

$43 \mathrm{Vgl}$ in diesem Zusammenhang Aage A Hansen-Love "Allgemenc Haretk., russische Sekten und ithe Literansierung in der Moderne. in Wiener. Nlawistischer Almanach. Sonderband 41, Wien 1996. S.171-294 
der Romantik (etwa bei Gogol') ${ }^{44}$, die Überkompensation des idealisierten Weiblichen beim jungen Dostoevskij (in dessen Bruder-Schwester-Ideal) und seine vielschichtige Gynaikophobie der späteren Jahre ${ }^{45}$, Nietzsches DionysosKult, sowie Solov'evs Sophiologie als weibliches Weltprinzip sind für die Auseinandersetzung mit den Texten der Religionssymbolisten von entscheidender Bedeutung. Vjaceslav Ivanov machte aus Nietzsches Dionysos-Kult eine Art Privatreligion. ${ }^{46}$ Dmitrij Merežkovskij (1865-1941) und seine Frau Zinaida Gippius' (1869-1945) entwickelten die "Religion des Dritten Testaments" als metaphysische Lehre der All-Einheit. ${ }^{47}$ Aleksandr Blok (1880-1921) und Andrej Belyj (1880-1934) konzentrierten sich auf die Idee der persönlichen Inkarnation der Sophia. ${ }^{48}$ Alle diese Einflüsse werden in den einzelnen Textanalysen konkret besprochen, denn sie bereiten im Ansatz jene "ideale Voraussetzung" der kollektiven Ungespaltenheit zwischen den Geschlechtern

\begin{abstract}
44 Wre Hansen-Love dargelegt hat basien Gogol's Idealisienung des Weiblichen auf seiner Beschäftigung mit der deutschen Asthetik (im Geiste Winckelmanns), der erotisch-mystischen Minne der Hummelskonigin des katholischen Mittelatters und der ostkirchlichen Sophiologie und schlägt sich neoder in enem erhabenen und ideaken Frauenbild. das mit der Kunst gleichzusetzen ist. Die Schönhent der Frau wird daber selbst aum feminisicrten Kunst-Schonen Gleichzeitig wird die Angst vor dem Nichts in ein perhortesziertes Weibsbild umgeleitet Vgl Aage A Hansen-Love. "Gogol. Zur Poetik der Null- und Locrstelle", in: Wiener Slowishscher Almanach, Band 39, Wien 1997, S 183-303, S. 212, sowie Natascha Drubek-Meyer Gogol's eloquenna corporis. Eimverleibung. Identitat und die (irenzen der Fiknion, (im Druck)
\end{abstract}

$45 \mathrm{Vgl}$. Aage A Hanscn-Löve "Der Diskurs der Konfession", in Fjodor Dostoewskaj. Der Hïngling. Munchen 1988. S 874-911.

$46 \mathrm{Vgl}$. Alexander Edkund. 1996. op.cit., den Abschnita "Die Religion des Diomysos", S. 62-68.

$47 \mathrm{Vgl}$ Temura Pactumuss Znnaida Hippius. An Intellectual Profile, Carbondale etc 1971, S. 103166

48 Zum Verhaltmis der Sophiologic und dem Dialektischen Matenalısmus siche Bons Grons. "Weishert als weibliches Weltepnizip Die russische Sophologic des Wladimir Solowjevi", in: Weisheit, hg von Aleida Assmann. München 1990, S 345-355, S 353. Grows weist daraufhin. daß die Parallelitit der Sophiologic und des Dialckuschen Materialismus durch thren gemeinsamen Ursprung in der Philosophe des deutschen Idealismus erklart werden kann Zu dem Einfluß der Sophoologie auf die Literaturthoone Bachtuns siche Rauner Grubels Vorwort a Michail Bachtun Die Asthethk des Wortes. Frankfurt 1979, S. 70ff und Hansen-Love. 1996, op.cit., S 196 
vor, die von den Symbolisten als "Drittes Geschlecht" gepriesen wurde und das zum Künstlergeschlecht par excellence avancierte.

\section{Rekonstruktion der religionssymbolistischen Genealogie:}

\section{Methodischer Aufbau und Kapitelübersicht}

Die vorliegende Dissertation glieden sich in vier Kapitel. Sie untersucht Texte von 1898 bis 1927, konzentriert sich aber auf das erste Jahrzehnt dieses Jahrhunderts. Diese Einteilung scheint eine evolutionäre Dimensionierung der Konzeptionen des Symbolismus nahezulegen, ist aber nicht beabsichtigt. Vielmehr geht es um die Rekonstruktion dieser spezifischen Genealogie, deren Problematik auch in theoretischer Hinsicht aufgezeigt werden soll. Im ersten Kapitel werden am Beispiel von Vladimir Solov'evs Sinn der Liebe, Zinaida Gippius' Metaphysik der liehe und I.ydia 7.inov'eva-Annibals Vorstellung der lesbischen Liebe Konzeptionen des Silbernen Zeltalters ${ }^{49}$ vorgestellt, die auf einer gnostischen Kunstreligion basieren und eine keusche Wollust "vor-schreiben", die die Fortpflanzung ausschließt. Die Texte dieser Zeit sind generell unter der Prämisse von Literatur als "Religionsersatz" bzw. "Ersatzreligion" zu verstehen. Sie übernehmen religiöse Funktion, das heißt, sie bieten ein soteriologisches Modell an, ein Erlösungsmodell als Alternative zum herkömmlichen, das die im modernen Bewußtsein abgespaltenen Traditionen des Religiösen kreativ nutzt: „Aus der Sicht der kirchlich-dogmatischen "O r t h o d o x i e" könnte man zu der

49 Der Beginn des 20 Jahrhunderts wird in der russischen Literatur als. Silbermes Zettalier bezeschnet im Unterschuod zum (ioldenen Zeltalter am Anfang des 19. Jahrhunderts als Bezeichnung der Puskin-Epoche 
Auffassung kommen (und dies ist in der religionsphilosophischen Debatte der Jahrhundertwende vielfach geschehen), daß der Symbolismus die Kunst an jene pragmatische Position in der Kultur rückt, wo traditionellerweise die häretischen Religions- und Ideologiesysteme beheimatet waren (also in der Sphäre der Subkultur, der Folklore, der kulturellen Peripherie etc.) Die romantische wie die symbolistische Mythopoesie ersetzt das die religiösen Urbedürnisse des modernen Menschen nicht mehr befriedigende System kirchlich institutionalisierter Religiosität und den gesamten Komplex des "Glaubens" als eines voluntaristischen Akts durch die Reaktivierung des Mythisch-Mystischen und der ihm eigenen Sub- und Antikultur. Damit soll der dem Bewußtsein und seiner Rationalität antagonistisch entgegenwirkende Willensakt des "Glaubens" ("credo quia absurdum") durch die im Unbewußten wurzelnde E v i d e n z, also das Aufscheinen und "Aufsteigen" des Mythischen ersetzt werden. “50

Wichtig fur den Untersuchungsgegenstand dieser Arbeit ist der Aspekt, daß das literarische Religionssystem der Symbolisten die von der traditionellen Vaterreligion verdrängte, weibliche Seite der Religion reaktivierte. Als Erlösungsmodell gedacht, sollte es die in der Christologie dominant gewordene Fremderlösung durch einen schöpferischen Kunstakt ersetzen, dessen Projektion in männlichen bzw. weiblichen Erlösergestalten personifiziert wurde: „Während im SI der Projektionsakt selbstwertig (also ästhetisch autonom) wird, nimmt er im Religionssymbolismus des SII gleichsam "Fleisch" an bzw. wird in maskulinen oder femininen Erlösergestalten personifiziert. Auffällig ist, daß im SII vor dem Hintergnund der kanonisierten neutestamentarischen Motive der Fremderlösung (durch Jesus Christus) das heterodoxe Modell der Selbster-

50 Aage A Hansen-Love: Kunstreligion und Religionskunst Dieser Text liegt mir als Typoskript vor 
lossung (des Künstlermenschen als Neuer Dionysos) dominiert. Dieses Konzept, das im religiösen Wahn des Automessianismus gipfelt, setzt einerseits die mystisch-hermetische (bzw. nach C.G. Jung alchemistische) Tradition der Selbsterlösung fort und entwickelt andererseits das im dekadenten Frühsymbolismus etablierte Bild des Dichter-Demiurgen, der einer Fremderlösung nicht bedarf. “ ${ }^{\text {¿SI }}$ Dem urchristlichen Verständnis entsprechend vereinigten die Symbolisten in ihren Texten die inkarnierte göttliche Sophia mit dem Logos des Vaters. Daraus resultierte eine Verlagerung der Geschlechterzuordnung, die der sektantischen Idee des Transsexualismus entspringt: "Das Herz bzw. die Anima des sich opfernden Mannes erscheint als Braut, die sich mit dem Himmlischen Bräutigam auf mystisch-erotische Weise vereint." 52 Solov'ev imaginierte eine Vereinigung mit der himmlischen Sophia, seiner ewigen Freundin, die männliche Züge trägt, während Zinaida Gippius' sich als Braut Christi dachte, die weibliche Züge trägt. Die Textanalysen zeigen, daß die Liebessemantik beider Schriftsteller durch deren virtuelle Androgynie, d.h. der Verweiblichung des Mannes im Falle Solov'ev bzw. der Vermännlichung der Frau im Falle Gippius bestimmt ist. Im Falle Zinov'eva-Annibals wird einerseits der Problemkreis der Homoerotik aufgegriffen, andererseits die Suche nach einem genuin weiblichen Ort in der Literatur. Diese Suche kristallisiert sich innerhalb des ausgewählten Textes gerade durch die Gegenüberstellung von Sophia-Projektion (das Problem des "die Frau schreibenden Mannes") und schreibender Muse heraus.

Im zweiten Kapitel wird das Phänomen der männlichen Hysterie an den jüngeren Symbolısten Aleksandr Blok (1880-1921) und Andrej Belyj (18801934) untersucht. Bloks Kult der Schönen Dame (Prekrasnaja IDama) und

51 Aage A Hanscn-Love "Zur psychopoctuschen Typologic". in Wiener .Nawisnscher Almanach Sincerband 31, Wien 1992, S 195-288. S 220 
seine Dekonstruktion im Mythos der Unbekannten (Neznakomka) ist ein Beispiel dafür. An ausgewählten Gedichten aus dem lyrischen Zyklus der Verse von der Schönen Dame (Stichi o Prekrasnoj Dame) von 1901 und 1902 wird deutlich, daß es sich bei der männlichen Hysterie um die Maskerade eines effeminierten Mannes handelt, die paradigmatisch für das symbolistische žınetvorcestvo ist. Als Gegenstimme dieses Kultes der Schönen Dame, der die Festschreibung der Frau im Leben und in der Kunst offenbart, ist ein autobiographischer Text mit dem signifikanten Titel Dichtung und Wahrhett zu sehen. Er wurde von Bloks Ehefrau, Ljubov' Dmitrievna Mendeleeva-Blok, geschrieben und ist Zeugnis für die offenkundige Ver-/Entstellung der Frau und die Stelle der Frau als Entstellung fur die symbolistische Theorie. ${ }^{53}$

Belyjs erster Roman Serebrjany golub' (Die Silberne Taube), der auf ironisch-groteske Weise die Vision einer zweiten Parusie Christi ad absurdum führt und damit rückwirkend die Mythisierung der Häretik innerhalb des Symbolismus ins Lächerliche zieht, offenbart ebenso ein strukturelles Moment der Hysterie. In den Veitstänzen Andrej Belyjs, die die Ekstatik der SektantenTänze widerspiegeln, zeigt sich der hystenische Körper des Schriftstellers, der sich als Wortkörper im Text fortsetzt: Die Kreisbewegungen des Tanzes sind signifikant für die literarische Struktur dieses Romans. In diesem Kapitel wird gezeigt, daß gerade die männliche Hysterie das Konzept der Androgynität im Silbernen Zeitalter belebte und damit letztendlich die Festschreibung von Geschlechterstereotypen weiterverfolgte. ${ }^{54}$

52 Ebd.

53 Diesc Formulierung übernehme ıch von Bettıne Mehnke „Die Verstellung und dic schone Summe", in: Raum und Verfahren, hg von Jorg Huber und Alois Martin Muller, Basel. Frankfurt/Main 1993

$54 \mathrm{Vgl}$ in diesem Zusammenhang Goorges Didi-Hubcrmann Die Erfinchung der Hystene Die photographische Klinik won Jean-Martin ('harcot. Munchen 1997, S. 366 
Im dritten Kapitel steht das žınetvoržestvo als Text-Vor-Schrift zur Diskussion. Untersucht wird seine Auswirkung auf die Textproduktion und auf das Verhalten von Mann und Frau innerhalb des symbolistischen Zirkels. Valerij Brjusovs historischer Roman (ognennyj angel (Der feurige Engel) von 1908 offenbart die zirkuläre Semantik (knužkovaja semantika) des ziznetvorčestvo, einem zirkulären (Text-)begehren, das dem Wunsch nach "kollektiver Schöpfung" entsprechen sollte. In der Art des sektantischen Kollektivismus, der nur Brüder und Schwester kennt und hinter die monogame Ehestruktur zurückgeht, entstanden komplizierte Dreiecksbeziehungen, die als Resultat des ZiznetvorCestvo zu sehen sind. Sie sind weiteres Anzeichen für die Ästhetisierung bzw. Theatralisierung des Lebens und damit des Verhältnisses von Mann und Frau und verweisen auf den performativen Charakter des gesamten žiznetvorčestvo: "Das Buch des Lebens muß gelebt werden, nicht gelesen; genau diese Theatralisienung des Textuellen, diese Verwandlung des kontemplativen und distanziertaufschiebenden "sozercanie" in das žiznetvorčestvo bildet den Kem der symbolistischen Lebens-Kunst in der Moderne." 55

Die Religionssymbolisten substituierten die religiöse Trinität, die Dreiheit der göttlichen Personen in Dreiecksbeziehungen, die paradigmatisch für die Polarisienung von Leben und Kunst wurde. Dreiecksbeziehungen solcher Art fưhrten sowohl die älteren Symbolisten Zinaida Gippius, Dmitrij Merežkovskij, Vjaceslav Ivanov und Valerij Brjusov, als auch die zweite Generation der Symbolisten, die sogenannten jüngeren Symbolisten Aleksandr Blok und Andrej Belyj. Auf welche Weise der jeweils "Dritte"' im Bunde in ein bereits existierendes Verhältnis integriert wird und welche Auswirkungen dies auf den Schaffensprozeß nimmt, bildet ein wichtiges Kriterium in diesem Kapitel. In der

$55 \mathrm{Vgl}$ Aage A Hansen-Löve. 1996, op.cit. S. 213. 
Textanalyse wird dargelegt, welche Funktion das "Gesetz des Dritten" für die Poetik des literarischen Textes einnimmt und welchen Einfluß umgekehrt der literarische Text auf die reale Frau nahm, in diesem konkreten Falle auf Nina Petrovskaja, eine der "Musen" des Symbolismus. Wenn die männliche Hysterie sich im Silbernen Zettalter als "Maskerade eines effeminierten Mannes" offenbart und mit der Selbstzensur bzw. Verleugnung des Begehrens einhergeht, kann man die weibliche Hysterie als "Maskerade der Weiblichkeit" bezeichnen, die der Enteignung des Begehrens durch den (hysterischen) Mann entspringt.

Im abschließenden Teil der Dissertation wird ein spezifisches Phänomen der russischen Literatur vorgestellt: Der Petersburger Text, ein männlicher Stadttext, der weibliche Züge trägt. Die Petersburger Intelligencija als das geistige Zentrum Rußlands problematisierte zu Beginn des 20. Jahrhunderts immer bewußter ihre eigene kulturelle und damit geschlechtliche Identität. Das Unbehagen an der russischen Kultur wurde durch den Zitatcharakter der Stadt Petersburg - die die Kulisse ihrer Texte, den Schauplatz für die Erscheinung des Ewigen Weiblıchen und der Schönen Dame bildet - ausgelöst. Petersburg als Mythos, "geschaffen von der männlichen Hand Peters des Großen, der in einem gewaltsamen Akt der Selbstkolonialisierung die weibliche Seele Rußlands versklavte und sie der Geometrie des westlichen Denkens unterwarf", erschütterte das Verhältnis der Intelligencija zu ihrem eigenen Ursprung und verstärkte die Einsicht ihres Schaffens als Zitat von Zitaten. ${ }^{56}$ Nicht umsonst stehen Wiedergeburtsphantasien als zentraler Stimulus für die Textproduktion der Symbolisten. Sie sind begleitet von einem Auslöschen des mütterlichen Kör-

56 Bons Groys: "Petersburg/Petrograd/Leningrad Eine Stadt und thre Namen", in: Petersburger Trunume, Hg. von Wolfgang Lange, Munchen 1992. S. 291-302. S. 294. 
pers, der Verneinung des weiblichen Ursprungs schlechthin bzw. der Übertragung aller Vaterfunktionen auf die Mutter, die dadurch ambivalent wird.

Ein Text aus der Avantgarde - Kozlinaja pesn' (Das Ziegenlied) von Konstantin Vaginov (1899-1934) - thematisiert diese Suche der Intelligencija nach kultureller und geschlechtlicher Identität. Als Petersburger Autor und Angehöriger der alten Petersburger Intelligencija steht Vaginov selbst am Ende dieser langen Tradition innerhalb der russischen Literatur und Kultur. Er schreibt den Petersburger Text zu Ende und schreibt ihn gleichzeitig von seinem Ende her. Als letztes "Petersburger Märchen" und Abgesang auf die alte Kultur, wie Vaginov Kozlınaja pesn' resigniert bezeichnet, leitet er die Todesstunde der Petersburger Intelligencija ein. Dieser Text gehört zu jenem Werkkorpus der russischen Moderne, die vor dem Hintergnund eines doppelten Paradigmenwechels als Ergebnis der sogenannten Kunstrevolution von 1910/13 und der Oktoverrevolution von 1917 entstehen. ${ }^{57}$ Der vollkommene Traditionsbruch und ganzheitliche kulturelle Systemwandel wird zum Ausgangspunkt für jene narrativen Verfahren, die in der Textproduktion dieser Zeit eine Konfrontation von Symbolismus und Avantgardismus bedingten. Die Frage danach, auf welche Weise sich die Umwertung und Umwandlung des symbolistischen Kunstmodells des Automessianismus bzw. der Autosoteriologie in ein Modell der grotesken Soteriologie vollzog (wie am Beispiel von Vaginovs Kozlınaja pesn' gezeigt wird), bildet in diesem letzten Kapitel die Argumentationsbasis, an der die Frage nach der Semiotik des Verhaltens unter der Perspektive der Geschlechter-Differenz diskutiert wird. Eine große Rolle bei der Bewertung dieser Frage spielt die politische Realität der in den zwanziger Jahren forciert be-

57 Felix Philipp Ingold "Kunsttext und Lebenstext Thesen und Beispick aum Verhaltmis zurschen Kunst-Werk und Altiags-Wirklichkett um russischen Modemismus", in Welt der .Stoven. 1981, 26, S $37-61$ 
triebenen Angleichung der Geschlechter zum Aufbau der sozialistischen Gesellschaft. Sie basierte auf einem Konzept des "Postgeschlechtlichen", insofem sie den geschlechtslosen homo sovieticus propagierte.

\section{Kulturpoetik - Psychopoetik - Genderpoetik: \\ Theoretische Überlegungen zur Diskursanalyse}

Eine genderpoettsche Lektüre, wie sie für die ausgewählten Texte dieser Dissertation vorgeschlagen wird, um die Semiotik des Verhaltens im Silbernen Zeitalter unter der Perspektive der Geschlechter-Differenz zu untersuchen, schließt eine kulturpoetische und psychopoetische Lektüre mit ein. ${ }^{58}$ Die kulturpoetische Lektüre setzt mehrere Spezifika der russischen Kultur voraus: 1. Die Geschichte der russischen Kultur als "eine Geschichte des Verlustes und der nachfolgenden Versuche, das Verlorene wiederzugewinnen." ${ }^{59} 2$. Die Idee des nussischen nationalen Selbstbewußtseins, das seit dem Mittelalter eng verbunden war mit einem christlichen Messianismus, hervorgerufen durch den besonderen Widerstand des alten Rußland gegenüber der asiatischen Steppe und den langen kriegerischen Auseinandersetzungen mit den Stämmen des Ostens. Allein die geographische Lage, zwischen dem europäischen Westen und dem asiatischen Osten, hat die Rolle des alten Rußlands als "messianische", als Verteidigerin Europas vorherbestimmt. Die Lehre von "Moskau als dem dritten Rom", die als Idee vom heiligen Rußland in das russische nationale Bewußtsein eingegangen ist, entwickelte das messianische Thema weiter. Nach dem Sturz von Konstantinopel (dem "zweiten Rom") blieb Rußland als einzige

58 Der Begniff wird nach Stephen Groenblatts "Grundaige ciner Poetuk der Kultur" verstanden Vgl Schmulage Riten. Betrachrungen zwischen Welibildem. Berlin 1991, S 107-122.

59 M.A Maslin: Russkaja ldeja (Die nussische Idee), Moskau 1992. S 4. 
orthodoxe Bewahrerin der christlichen Tradition zurück. In dieser Idee ist der Wille zur kollektiven religiösen und historischen Rettung nicht nur des russischen Volkes, sondem der Orthodoxie im allgemeinen ausgedrückt. 3. Die prinzipielle Gespaltenheit bzw. Doppelung der russischen Kultur - sei es in offizielle und inoffizielle Kultur, in Eigenes als slavjanofil'stvo (Slavophilentum) und Fremdes als zapadnicestvo (Westlertum) - und darüber hinaus an die ständige Reflexion Kulturschaffender über die Frage des russischen nationalen Selbstbewußtseins, die mit der Beginn der Moderne in Bezug zur GeschlechterDifferenz diskutiert wurde. Aus dem Bewußtsein seiner prinzipiellen Mangelposition, die Rußland als rückständiges Land (als das Unbewußte des Westens) gegenüber dem Westen (als das Über-Ich Rußlands) einnimmt, werden kulturelle Leerstellen aufgefüllt und in der Folge als nationales Eigenes diskutiert. ${ }^{60}$ Der Versuch, Rußland im Text wiederzugewinnen, mit dem Text die Gespaltenheit der eigenen Kultur zu überwinden ist zentrales Anliegen der Autoren, die im Rahmen dieser Arbeit untersucht werden und spiegelt ihr textuelles Umgehen mit Geschlechter-Differenz umso nachhaltiger wieder. Diese wird topographisch diskutiert, was sich am Phänomen des Petershurger Textes zeigen läßt. In Anlehnung und Erweiterung von Laqueurs Konzeption der Unterscheidung eines lim-(jeschlecht-Zwet-(ieschlechter-Modells könnte man in diesem Zusammenhang von einem lim-Kultur-Modell bzw. einem Zwet-KulturenModell sprechen, da der religionssymbolistische Diskurs der Gespaltenheit bzw.

60 Bons Groys "Rossija kak podsoznanic zapada", in Wiener. Slawishischer Almanach (23), 1989, S 199-214. Slavjanofil'sno (Slawophilentum) und zapactnicesno (Westlertum) sind zuci unterschedliche Denknchtungen det russischen Intelligencija, dxe um Zolotoj wek ((ioldenen Zeitalter) der russischen Litcratur in der Mitte des 19 Jahrhunderts entstanden sind Obwohl beide Ruchtungen in der Tendenz grundierschioden waren - die erstere akzentuierte die russische Frage auf die nationale Eigentumlichkeit Rußlands. die zweite auf die Rezeption westlicher Erfahrungen - ging es beiden um eine gesuge Renaussance Rußlands 
Doppelung der russischen Kultur unterliegt. ${ }^{61}$ Diese bedingt als literarisiertes Modell in der Textproduktion der Symbolisten eine Auflösung bzw. Verdoppelung der Geschlechter-Differenz: die Verweiblichung des Mannes und die Vermännlichung der Frau. Sie bestimmt in den vorliegenden Fällen das Psycho(patho-)gramm der Autoren, deren Projektionsakt das verlorene Liebes-Objekt die tote bzw. wiederzugebärende russische Kultur - automessianisch bzw. autoerotisch substituiert. Rußland wird zum introjizierten Objekt, mithilfe dessen sich die abstrakten Autoren im zwetgeschlechllichen Wort erst konstituieren. ${ }^{62}$ Der Akt des Schreibens wird dabei zum auto(r)soteriologischen bzw. auto(r)erotischen Akt, der den Geschlechtsakt substituiert bzw. travestiert und in den vorliegenden Textanalysen in einem triebökonomischen Zusammenhang problematisiert wird. ${ }^{63}$ Die psychopoetische Lektüre fußt auf Hansen-Löves Typologie der Russischen Moderne. Darin sind die von Freud differenzierten Grundstörungen der Melancholie, Neurose und Psychose zu Modellen inner- und intrapsychischer Korrelationen abstrahiert und werden dem künstlerischen Modell des Symbolismus und der Avantgarde zugeordnet. Dementsprechend verweist der Frühsymbolismus auf den melancholisch-narzißtischen Typus, während der mythopoetische Symbolismus auf den neurotischen Typus und die nachsymbolistische Avantgarde in ihrer futuristisch-archaistischen Ausprägung auf den psychotischen Typus verweisen. Wichtig furr die Themenstellung der

61 Thomas Laqueur. Auf den Leib geschneben. Die Inszenierung der (jeschlechier von der Annke bis Freud. FrankfurtMaun/New York 1992

62 Diese Uberlegungen basieren auf den Thesen von Johanna Renate Donng-Smimov. Vgl in diesem Zusammenhang "Das zuergeschlochtliche Wort Dec Autonsienung der Korrespondentun in zwer BriefWerken der nussischen Romantik", in Aulorschafi Genus und (jente in der Zell um 1800, Munchen 1994, S. 77-87, S 84

63 Auto(r)erotik läßt sich in diescm Fall mut Auto(r)messtanusmus bzu Auto(r)sotenoloigje gleichsetzen aufgrund der Erousienung des religionssymbolıstuschen Diskurses, we er von den Sịmbolisten gefuhrt wurde 
Arbeit ist der Einfluß, den die Psychoanalyse auf die Textproduktion der Symbolisten nahm. In keinem anderen europäischen Land wurden die Texte Freuds so schnell und intensiv rezipiert und übersetzt. ${ }^{64}$ Besonders aufschlußreich ist die Tatsache, daß Freuds Schriften den oben genannten Autoren teilweise bekannt waren und sie diese wiedenum auf ihre Weise literarisierten. Daß Freud seine Analysen zum Teil der Lektüre russischer Literatur verdankte, birgt eine interessante Wechselwirkung und impliziert eine besondere Dynamik der Textproduktion auf beiden Seiten. ${ }^{65}$ Die Symbolisten schrieben somit eine Art psychoanalytischen Metatext. Freud wiedenum setzte sich mit Dostoevskijs Werk und Merezkovskijs Voskresšı bogı auseinander und verfaßte daraufhin seinen eigenen Leonardo da Vinct. ${ }^{66}$ Vergleicht man das symbolistische žzznetvorCestvo mit westlichen Modellen der gleichen Zeit, so findet die Jungsche Animakonzeption ihre russische Entsprechung bei Vjaceslav Ivanov, während Freuds Sublimierungskonzept bei Belyj und Blok dominiert. Wenn man bei Ivanov-Jung von einem Orpheus-Komplex sprechen könnte, dominiert bei Blok und Belyj der Ödipus-Mythos in allen möglichen Schattienungen und Verdunkelungen. Die psychopoetische Lektüre beinhaltet auch, dieses intertextuelle Phänomen mithilfe der kritischen Theorien zur Psychoanalyse, wie sie im Rahmen der Genderforschung entstanden sind, darzustellen. ${ }^{67}$

64 Magnus Ljunggren "The psychoanalytuc breakthrough in Russia on the eve of the First World War", in Russian Isterature and Psychoanalysis, Hg Daniel Rancour-Laferncre. Amsterdam. Phuladelphia 1989, S 173-193

$65 \mathrm{Vgl}$ in desem Zusammenhang Alcxander Etkund. 1996, op cit S 101-133

66 Freud zahlt Mcrezkovskujs leonarde da Vincl zu seinen Licblingsbuchern Vgl. Sarah Kofman Die Kindheit der Kunst Hine Interpretaitum der lireudschen Asthenk. Munchen 1993, S 18

67 Die Sudic von Igor Smimov Na pull k teoni literatury (Auf dem Weg zu einer Theone der lsterarur). Amsterdam 1987, stelt eine knusche Auscinandersctaung mit dem Poststnukturahismus dar und bildet fur das Gegenlesen der Texte aus dem Feld der gender snudies eane hulfreiche Folic Smimov erortert un seiner Arbett die verschuodenen Theonen zeitgenossischer Schulen uber Literatur und fuhrt sie aus den Definitionen einzelner literanscher Subsysteme heraus Dabeı werden unterschwedliche Typen 
In Kombination mit den genannten kultur- und psychopoetischen Konzepten wird eine genderpoetische Lektüre als Wiederlesen der Art und Weise verstanden, wie Geschlechter-Differenz im Silbernen Zettalter diskursiviert wurde, das heißt, mit welchen thetorischen Effekten "Weiblichkeit" und "Männlichkeit" im literarischen Text produziert wurde. ${ }^{68}$ Das bedeutet, daß die Identitäten der Geschlechter nichts natürlich Gegebenes sind, sondern sozial und sprachlich von jedem einzelnen der Symbolisten immer neu aufgenommen und in Szene gesetzt werden. Damit offenbart sich die Unterscheidung von biologischem und sozialem Geschlecht als kulturell konstruierte Ideologie. Scheinbar feststehende Kategorien wie Natur, Kultur und Körper werden genauso hinterfragt wie die von Weiblichkeit und Männlichkeit. Die genderpoetische Lektüre vollzieht sich unter der Perspektive des Religionssymbolismus als einer sekundären Stilformation, deren semiotische Struktur auf einer Mystifikation als Stilisienung der symbolistischen Ästhetik beruht und im Zeichen eines kulturellen Paradigmenwechsels entstand. ${ }^{69}$ In der Folge davon generierte sich gemäß der symbolistischen Auffassung von der Welt als einem Text ein neuer Welttext, ein Metatext, indem kollektive Phantasmen über Weiblichkeit und Männlichkeit verhandelt werden. ${ }^{70}$ Die Poetik des Symbolismus ist folglich eine Metapoetik der Verschleierung bzw. der Maskienung, denn ihr liegt ein Signifikationsverhältnis zugrunde, bei dem das Signifikat immer entzogen bleibt. Sie

der kunstlerischen Rode in threr ersten Annaherung betrachtet

$68 \mathrm{Vgl}$ Barbara Vinken (Hg.): Dekonstruknver Feminismus. Literaturwissenschaft in Amerika, Frankfurt/Main 1992.

$69 \mathrm{Vgl}$ in diescm Zusammenhang "Uber Geschichte. Geschlocht und cinge damit ausammenhangende Denkverbote Ein Gespräch mit Génevieve Fraisse gefuhrt von Eva Hom", un: Neue Rundschau, Frankfurt 1993, 4, S 46-56

$70 \mathrm{Vgl}$ in diesem Zusammenhang dic Studie von Enka Greber "Mystufikatuon und Epochenschwelle (Cenubina de Gabriak und dic Knsc des Simbolismus", in: Wiener Slawishischer Almanach 32, 1993. S $175-206$. 
erzeugt damit genau jenen Diskurs des Mangels, jenes negative Spiegelbild, furr das das Weibliche traditionsgemäß steht. Auf diese Weise symbolisiert sie auch den Ort der Frau, den es nicht gibt bzw. nicht geben soll: Das Nichts als Ort der Nicht-Begegnung, in dem es gemäß Lacan auch "kein Geschlechtsverhältnis" gibt. $^{\text {"1 }}$ Der thetorischen Logik entsprechend ist jedoch jeder Verschleierung eine Entschleierung (obnaženie), eine Demaskierung inhärent, deren tropologische Mechanismen das eigene Repräsentationsmodell zum Sturz bringen, was die Krise des Symbolismus im Jahre 1910 belegt und in der Folge den Postsymbolismus einleitete.

\section{Forschungsbericht}

Feministische Konzepte der Literaturwissenschaft

Feministische Literaturwissenschaft versteht sich als interdisziplinärer Forschungszweig, der gender als die fundamentale, organisierende Kategorie von Erfahrung setzt und ihre Aufgabe und ihr Ziel darin formuliert, sowohl etablierte literarische Strategien zu reinterpretieren, als auch den männlich geprägten literarischen Kanon zu revidieren. Praktiziert wird eine Lektüre, in deren Mittelpunkt die Analyse der Geschlechtsidentität steht, wie zum Beispiel die Untersuchung von männlichen und weiblichen Figuren im literarischen Text und ihre Funktion im narrativen Prozeß, sowie die Codierung männlichen und weiblichen Begehrens.

Einen entscheidenden Ansatz für eine feministische Lektüre innerhalb der slavistischen Forschung lieferte Olga Matich, die eine Typologie der Ge-

71 Jacques Lacan Radiophonte Televiston. Weunhumberlin 1988. S 66 
fallenen Frau in der russischen Literatur des 19. Jahrhunderts mit Ausblick auf die Moderne erstellte. ${ }^{72}$ Ein anderes Beispiel ist Joe Andrew, der aus feministischer Perspektive die Klassiker der russischen Romantik, sogenannte Metsterwerke des russischen Literaturkanons, die in dem Zeitraum von 17801863 entstanden sind, reinterpretiert hat. Andrew konzentriert seine Untersuchungen auf Fonvizin, Karamzin, Puškin, Lermontov, Gogol', Turgenev und Čemy̌̌evskij. Er geht von einem Literaturverständnis aus, das Texte als Elemente ideologischer Prozesse innerhalb einer Gesellschaft begreift, in der zentrale Themen des Patriarchats verarbeitet werden. ${ }^{73}$ Weitere Forschungsergebnisse brachte Barbara Heldts Studie The terrible perfection, in der die Slavistin eine Typologie der russischen Heldin entwickelt, die als Zukunftshoffnung fur ein besseres Rußland steht. ${ }^{74}$ Im ersten Teil ihrer Arbeit untersucht sie die Variation dieses Themas in Werken des russischen Realismus und klassifiziert Motive der starken und schwachen Frau, die besonders auf die Textproduktion von Tol'stoj und Cechov zutreffen. Im zweiten Teil setzt sie sich mit dem Phänomen weiblicher Autorschaft am Beispiel von Marina Cvetaeva auseinander. Inès Muller de Morogues untersucht das Frauenbild und

72 Olga Matich "A Typology of Fallen Women in Ninetoenth Century Russian Literature", in: Amenican Coninbution to the ninth international congress of Slovists, Ohio 1983, S. 325-345. Matich erstellt en verstufiges Modell der Opferrituale als literansierte Grenaiberschreitung, die aum Paradigma der Gefallenen Frau in der russischen Literatur des 19. Jahrhunderts werden:

$$
\begin{aligned}
& \text { 1. weibliches Opfer/mannlicher Opferer } \\
& \text { 2. weibliches Opfer/mannlicher Erloser } \\
& \text { 3. weibliche Erloserin/mamnliches Opfer } \\
& \text { 4. weiblicher Opferct/mannliches Opfer }
\end{aligned}
$$

73 Joe Andrew Women in Russian literature 1780-1863, New York 1988

Ders: "Not daring to desire: Male/Female and Desire in Narrative in Puškin's 'Bachcisarajskij Fontan"', in: Russian literature XXIV (III), 1988, S 259-275

Ders : "The Blind will sec". Narrative and Gender in Taman', in Russian Ljteramure XXXIII), 1992. S. 449-477

74 Barbara Heldt The ternble perfection Women and Russian Lsterature. Bloomington 1987 
die Perspektive des Weiblichen im Werk von Nikolaj Leskov. ${ }^{75}$ Jane Langan analysiert in Icon versus myth pornographische Motive und Verfahren im Werk Dostoevskijs. ${ }^{76}$

Eine ganz neue Perspektive brachte Theresa de Lauretis, die Jurij Lotmans Theorie der Sujettypologie hinterfragte. ${ }^{7}$ Sie weist daraufhin, daß die Basiskette der Narrativik, von der aus alle Geschichten konstruiert sind, in erster Linie männlich ist. Die elementare Sequenz im Mythos kann dabei auf eine Kette reduziert werden: Eingang in einen geschlosssenen Raum und Heraustreten aus ihm (diese Kette ist nach beiden Seiten hin offen und kann endlos multipliziert werden). Insofem ein geschlossener Raum als Käfig, Grab, Haus, oder als Frau - und dementsprechend mit Merkmalen wie Dunkelheit, Wärme, Feuchtigkeit assoziierbar - interpretiert werden kann, wird der Eingang in diesen Raum als Tod, Empfangnis, Heimkehr empfunden. De Lauretis argumentiert, Lotmans Sicht sei männlich und nicht universal, da Frauen eine mögliche Variante des geschlossenen Raumes bildeten. Männer überquerten die Grenze dieses geschlossenen Raumes, um wiedergeboren aus ihm herauszutreten. Frauen dagegen stellten als Antagonisten ein Attribut der narrativen Topologie dar. Sie repräsentierten das Hindemis, das vom Held überwunden werden müßte. Gemäß Lotman könne der Held nur männlich sein, denn das Hindemis sei morphologisch weiblich. Lotman entwerfe den Helden als mythisches Subjekt, als aktives Prinzip der Kultur, als denjenigen, der Unterscheidungen treffe,

75 lnis Muller de Morogues Le problem feminin et les portaits de femmes dans l'oeuvre de Nikolaj Leskov, Bern/FrankfurtMain/Now York/Pans 1991

76 Janunc Langan "Icon versus myth Dostowskij. fomunism and pornography", in Religion and Isterature 18, 1986/1, S 63-72.

77 Theresa de Lauretis bezicht sich in threr Studic Alice doesn't. Feminism. Semuotics. ('inema. Bloomungton 1984. S 103-157, auf Lotmans Schrift "Der Ursprung des Plots um Licht seiner Typologe" ("The Ongen of Plot in the Light of Typology"), in Poencs Taday, Vol I, Nos 1-2 (Autumn 1979: (61-184) 
Differenzen schaffe. Das Weibliche hingegen sei nach Lotmans Typologie unfahig zur Transformation. Es sei Element des Sujetraums, Topos, Widerstand, Matrix, Gegenstand. Dabei sei die Begehrensstruktur von einer männlichen Perspektive konstruiert, denn diese sei essentiell ödipal und unterdrücke bzw. bestrafe weibliches Begehren. Die Verbindung zwischen Narrativik und ödipalem Begehren erscheine deswegen unbestreitbar. De Lauretis' schreibt der Sujettypologie - wie sie von Lotman nach Propp formuliert wurde - sadistische Strukturen zu, da sie Verändenungen, Kampf um Stärke, Sieg oder Niederlage provoziere.

Klassifizient man die oben genannten Beispiele aus der der slavistischen Forschung nach paradigmatischen Gesichtspunkten, so kann man sie in die zweite Phase der "Konsolodienung"78 der feministischen Theorie, der "Rekonstruktion weiblicher Kulturgeschichte" ${ }^{179}$, der Entzifferung der "Listen der Ohnmacht" ${ }^{80}$ einordnen, während in der ersten Phase auf die sogenannten "Löcher im Diskurs" ${ }^{81}$ aufmerksam gemacht werden mußte. Die dritte Phase der feministischen Literaturwissenschaft leitet schließlich die Genderforschung (gender studies) ein, die aber ohne ihre feministische Vorgeschichte nicht zu denken ist. An dieser Stelle werden zentrale theoretische Positionen zusammengefaßt, um die Fortschritte der feministischen Theorie zu verdeutlichen. Wie Sylvia Boven-

78 Diese Einteilung in dre Phasen folgt Jane Todds Feminist Literany History A Defence. Oxford 1988.

79 Inge Stcphan und Sigrid Weigel: Die verborgene Frau Sechs Beitrage au einer feminisnschen Literaturwissenschaft. Berlin 1988

80 Claudia Honzeger und Betuna Heintz (Hgg) Listen der Ohnmacht Zur . Sozlalgeschichte weiblicher Widerstandsformen. FrankfurtMain 1981

81 Der Schwerpunkt in den Anfangen der fermistischen Literaurwissenschaft bestand gerade in der Archaologie einer weiblichen Kulturtradituon $\mathrm{Vgl}$ in diesem Zusammenhang "Femunisusche Zugange $>$ Gender Studies< von Walter Erhart und Britta Hermann. in: Ginundzige der Lllerarumwssenschaff. Hgg van Heinz Ludung Amold und Hetnneh Deterng. München 1996 
schen herausgearbeitet hat, gilt ein Grundverständnis des Weiblichen als Natureinheit für fast alle kulturgeschichtlichen und philosophischen Theorien über die Frau. Dieses leitet sich primär aus ihrer biologischen Funktion des Gebärens ab und ist konstitutiv für einen kulturellen Ausschluß der Frau, ihrer Domestizienung einerseits und einer auffäligen Präsenz und Bedeutung des Weiblichen in Kunst- und Literaturproduktion andererseits. ${ }^{82}$ In der synthetischen Rekonstruktion dessen, was aus dem Bewußtsein der patriarchalen Gesellschaft verdrängt wurde, ist das Weibliche als Verkörpenung dieses Verdrängten in üppiger Vielfalt thematisiert und imaginiert worden. Verdrängt, untergeordnet und einverleibt, wird die Frau zum "diffusen Symbol"83. Auf diese Weise wird das Weibliche einerseits zum Sinnbild des Mangels, des Verlustes, in dem sich die Erinnerung an ein Paradies der Naturhaftigkeit und Harmonie aufbewahrt haben. Andererseits kann diese auch zum Schreckbild werden, in dem sich die Furcht vor der Rache für die Unterdrückung und Zerstörung der ungebändigten Naturgewalten und rationalem Kontrollverlust spiegeln. Von diesem double-hınd ist die Okkupation des Weiblichen in der Kunstund Literaturproduktion geprägt. Einerseits wird das Weibliche in seiner Naturnähe als Idealzustand stilisiert, was in einer zunehmend technologisierten Welt zur Utopievorstellung avanciert. Folglich substituieren Kunst und Literatur eine verlorengegangene Einheit. Andererseits zeichnet sich die Okkupation des Weiblichen durch eine Erotisierung bzw. Dämonisienung aus. Das Weibliche existiert im Bewußtsein des Mannes nur als das Andere ${ }^{84}$. Sie ist das "Undiffe-

82 Sylvia Bovinschen Dre imaginierte Weiblichkelt Fxemplansche Intersuchungen zu kulturgeschichilichen und literarischen Prasentanonsformen des Weiblichen. FrankfurtMain 1979. Bovenschen begreift Frauenbilder als Idoologieproduktion - im Gegensatz au Mananne Schuller und Klaus Theueleit de in ihnen psychologisch determunierte Wunsch- und Angstbilder setien

83 Inge Stephan "Bilder und ummer wioder Bilder...", in Die verborgene Frau, op.cit S 19 84 Der Begnff des 'Anderer' wurde von Sumone de Beauvorr un Das andere (jeschlecht (le deuxième 
renzierte, Molluskenhafte, Vorindividuelle, von Natur- und Gattungsgrenzen Bestimmte" $^{\prime 85}$. Als unterworfene Natur, als nichtkulturelle bilden diese Weiblichkeitsmuster die einzige Identifikations- und Intergrationsmöglichkeit für Frauen. Durch diese ist die Frau gleichermaßen "beteiligt und ausgegrenzt" ${ }^{46}$. In der Tatsache, daß die Heldinnen in literarischen Texten so häufig sterben, sieht Schuller eine Konsequenz der Opferung der Frauen im Kulturprozeß, die sich dann auch in den literarischen Diskursen symbolisch fortsetzt. ${ }^{87}$ Die Metapher des 'Splegels' - ebenso dessen Kehrseite und Ränder, seine Zerschlagung und Verdoppelung - ist inzwischen durchaus geläufig zur Beschreibung weiblichen Selbstverständnisses unter der Kontrolle des männlichen Blicks. Das Selbstbildnis der Frau entsteht im Zerrspiegel des Patriarchats. Auf der Suche nach ihrem eigenen Bild muß die Frau den Spiegel von den durch die männliche Hand aufgemalten Frauenbıldem befreien. Noch 1983 konstatiert Weigel resigniert: "Es gibt nur wenige Ansätze, dieses Spiegelverhältnis in der weiblichen Literaturproduktion, in der Schreibpraxis von Frauen zu untersuchen - diesen komplizierten Prozeß von Neu- und Zurückeroberung, Aneignung und Aufarbeitung, sowie Vergessen und Subversion." ${ }^{88}$ Die Verlagerung des Interesses in der

sexe) gepragt und ist seither zum fesuen Bestandtel der feministischen Literaturwissenschaft geworden Beauvoirs Hauptthese lautet Die Verschiodenheit der Geschlechter ist nicht naturbodingt sondem kulturbodingt Gerade durch das 'Andersscin' der Frau, betont Beauvorr, und insbesondere durch thre Fahigkett Leben at gebaren. erfahrt der Mann und sein Selbstbewußtsein eine standige Bedrohung Deshalb belegt der Mann dic Frau ummer weeder mit Bildern und Begniffen. um ihre Exustenz au bannen und somit cuner moglichen Gefahr der Umkehnung des Subjekt-Objekt-Verhalmisses al begegnen

85 Sylva Bovenschen. Die imaginierte Weiblichkeit, op cit. S. 31

86 Signd Weigel "Der schiclende Blick Thesen aur Geschichte weiblicher Schreibpraxis", in Die verborgene lirau. Sechs Beitrage zu einer feministischen Literatumissenschafi. Berlin 1983.

87 Mananne Schuller "Literarische Szenenen und ihre Schatten Orte des Weiblichen in literanschen Produktoonen", Ringvorlesung Fran und Wissenschafi. Marburg 1979, S 79-103

88 Sylva Bovenschen "Uber de Frage gibt es eune weibliche Asthetu?? In Frouen Kunst Kulturgeschichte. Astherik und Kommunikation 25. (1976), S 60-70 Sylvia Bovenschen motuviert ihre Fragestellung mut der so ganz anderen Erfahrungsweise der Frau. die auch andere Imaginationen und Aus- 
feministischen Theorie von Aussagen über 'Mann/Frau' zu Momenten der Weiblichkeit in der Schrift ist Luce Irigaray und Hélène Cixous gemeinsam: "Denn ebensowenig wie es mir darum geht, aus der Frau das Subjekt und Objekt einer Theorie zu machen, kann das Weibliche subsumiert werden unter irgendein Genre: die Frau. Das Weibliche läßt sich mit keinem Eigennamen, keinem Begriff, auch nicht mit dem der Frau bezeichnen." Theorie von der Frau auf, sondem verschaff dem Weiblichen seinen Ort innerhalb der Geschlechter-Differenz. Ihre Methode, den Ort des Weiblichen wiederzufinden, besteht in der Durchquerung der Diskurse, der philosophischen und der psychoanalytischen (z.B. ihr Buch Speculum als Durchquenung der Freudschen Theorie und deren Kritik), in welchen sich im Innem das Weibliche als Mangel, als Fehler definiert findet. Diese Durchquerung geschieht allerdings - gegen das Modell des "Onto-Theo-Logischen" gerichtet - im weiblichen Stil: "Dieser 'Stil' oder diese 'Schrift' der Frau legt vielmehr Feuer an die fetischisierten Worte, die angemessenen Termini, die wohlkonstruierten Formen. Dieser Stil privilegiert nicht den Blick [...], sondern dieser Stil widersteht jeder fest gefügten Form, Figur, Idee, Begrifflichkeit und läßt sie explodieren." Cixous' und Irigarays Thesen die Gefahr der "fehlenden historischen Differenzierung dessen, wie die Frau nach dem männlichen Bild sein soll, wie sie ist, und wie sie sein könnte, d.h. die fehlende Unterscheidung von Frauenbild, Frau und Utopie. Auf diese Weise wird das Weibliche als ewig Weibliches festge-

drucksweisen erwarten laßt. S. 76. "Gibt es cinc ueibliche Asthetik" Ganz gewzB, uenn dic Frage das asthetasche Sensonum und die Formen des sinnlichen Erkennens betnffi. sicherlich nucht, wenn danunter cine aparte Vanante der Kunstproduktion oder eune ausgeklugelte Kunstthoonc verstanden uird."

89 Luce Ingaray Das (jeschlecht, das nicht eıns ist, Berlin 1979, S. 162.

90 Ebd S. 162 
schrieben, während in einer Revision der männlichen Ordnung sich das Männliche am Stoff des Weiblichen gesundet."

Mit Judith Butlers (jender Trouble (Das Unbehagen der (jeschlechter) beginnt ein neuer Abschnitt innerhalb der feministischen Theorie. ${ }^{92}$ Butler arbeitet eine performative Theorie der Geschlechter aus. Damit setzt sie genau an jenem Punkt ein, wo sich die traditionelle feministische Theorie totgelaufen hat und wo sich ihr theoretisches Dilemma am nachhaltigsten niederschlägt, stellt sie doch den Gegenstand der feministischen Theorie generell infrage - nämlich 'die Frau' als 'das Subjekt' des Feminismus, sowie die Unterscheidung Geschlecht (Sex) und Geschlechtsidentität ((jender). Spätestens seit Laqueurs Studie zur Inszenierung der (jeschlechter von der Antike bis Freud, seiner Konzeption des EinGeschlecht bzw. Zwet-(jeschlechter-Modell war die Unterscheidung zwischen sex und gender fragwürdig geworden. ${ }^{93}$ Butlers Hauptthese lautet: Ganz gleich, ob man die Frau als das ausgeschlossene Andere nach Beauvoir oder das Andere des Figenen nach Irigaray begreift, der Bezug auf die Substanz des Weiblichen oder auf die Frau als Subjekt der Befreiung läuft Gefahr, gerade die Verhältnisse zu reproduzieren, die den Ausschluß herstellten. Butler schreibt: "Das feministische Subjekt erweist sich genau durch dasjenige politische System diskursiv konstruiert, das seine Emanzipation ermöglichen soll. Dies wird dann zum politischen Problem, wenn gezeigt werden kann, daß dieses System die geschlechtlich bestimmten Subjekte entlang einer differentiellen Herrschaftsachse hervorbringt oder von vorneherein als männlich definierte Subjekte produziert. In beiden Fällen ist der unkritische Appell an ein solches

\footnotetext{
91 Signid Weigel "Der schiclende Blick", in Die verborgene Frau, op cit . S 162.

92 Judith Butler Das Unbehagen der (ieschlechter, Frankfurt/Man 1991

93 Thomas Laqueur. Auf den Leib geschneben. Die Inszeniening der (jeschlechier won der Annke bis Freud. FrankfureMain/New York 1992
} 
System zum Zweck der Frauenemanzipation offensichtlich widersprüchlich." 94 Es wäre allerdings zu einfach, wolle man behaupten, Butler rechnete mit den inzwischen zu den Klassikem zählenden Studien der feministischen Theorie ab: Sei es Beauvoirs l'autre sexe (Das andere Geschlecht), Irigarays Le sexe qut n'est pas un (Das Geschlecht, das nicht eins ist), Speculum de l'autre femme (Splegel des anderen (jeschlechts) oder Kristevas Konzeption des mütterlichen Körpers. Butler sieht ihre Hauptaufgabe darin, die "gnundlegenden Kategorien des Geschlechts, der Geschlechtsidentität und des Begehrens als Effekte einer spezifischen Machtformation zu enthüllen." ${ }^{95}$ Hierbei verpflichtet sie sich einer Genealogie, die in der Tradition Nietzsches und im Anschluß daran von Foucault jene "politischen Einsätze erforscht, die auf dem Spiel stehen, wenn die Identitätskategorien als Ursprung und Ursache bezeichnet werden, obgleich sie in Wirklichkeit Effekte von Institutionen, Verfahrensweisen und Diskursen mit vielfältigen und diffusen Ursprungsorten sind." 96 Diese sieht Butler im Phallogozentrismus und in der Zwwangsheterosexualität. Beide Phänome stehen im Mittelpunkt ihrer Studie. Sie zentriert sie, um sie zu dezentrieren.

Butler untersucht drei unterschiedliche Diskursgebiete, um eine Genealogie der (ieschlechterkategorıen zu erstellen. Dabei behandelt sie die Subjekte von Geschlecht, Geschlechtsidentität, Begehren und unterzieht den Status der Frau(en) als Subjekt des Feminismus einer erneuten Betrachtung. Sie untersucht strukturalistische, psychoanalytische und feministische Darstellungen des Inzesttabus auf ihre Verwendbarkeit für eine Darstellung der komplexen geschlechtlich bestimmten "Identitäten" und setzt sich mit der Konstruktion des mütterlichen Körpers bei Julia Kristeva auseinander, um die impliziten Normen

93 Judith Butler, 1991, op cit., S 17

95 Ebd S. 9 
aufzuzeigen, die die kulturelle Intelligibilität des Geschlechts und der Sexualităt in ihrem Werk anleiten. ${ }^{97}$ Wichtig in diesem Zusammenhang ist die Frage nach der Verknüpfbarkeit der Stofflichkeit des Körpers mit der Performativität des sozialen Geschlechts und dem Verhalten der Kategorie des "Körpergeschlechts" innerhalb einer solchen Beziehung. Butler resümiert, daß eine mehr oder weniger stillschweigende Ausschlıeßungsoperation festlegt, was in die Grenzen des Körpergeschlechts eingeschlossen wird. ${ }^{98}$ Ihre Studie ist im Kontext des Dekonstruktiven Femınısmus anzusiedeln, der eine Lektüre vorschlägt, die Geschlechtsidentität, Identifikation und Repräsentation in den Mittelpunkt stellt, aber nicht mehr unter der Perspektive der traditionellen feministischen Theorie, die die Frau als soziosexuelles Opfer in den Blick nahm, sondern den Zusammenhang von "natürlichem" Geschlechtsunterschied und symbolischer Ordnung denkt und zwar als tropologischen Zusammenhang von Figuration und Defiguration. ${ }^{99}$ Dieses Konzept wird innerhalb der feministischen Theorie kontrovers diskutiert. Es gilt vielen als "prekäres Bündnis" ${ }^{100}$.

Comell verweist dagegen auf die positive Wirkung, die die Dekonstruktion der feministischen Theorie gebracht hat. Damit meint sie Derridas Eingriff in die psychoanalytische Theorie Lacans. ${ }^{101}$ Er zeige nämlich "die Nichtrückfuihrbar-

96 Ebd (Hervorhebung der Verfasserin)

97 Ebd S loff

98 Diess. Körper von Gewicht. Die diskursiven Grenzen des Geschlechis. Berlin 1995

99 Dekonsinukiver Feminismus Literaturwissenschafi in Amenka, hg von Barbara Vinken, FrankfurtMain 1992 und Bettine Menke "Dic Verstellung und dic schone Stumme", in Roum und Verfahren. hg von Jorg Huber und Aloss Martun Müller, Base/Frankfurt/Maun 1993

$100 \mathrm{Vgl}$. in diesem Zusammenhang den Aufsatz von Seyla Benhabib "Femunusmus und Postmoderne Ein prekares Bundnis", in: Der. Sirelt um Differenz. Feminismus und Postmoderne in der Ciegenwart. Hgg. Seyla Benhabib/Judith Butler/Drucilla Comell/Nancy Fraser, Frankfurt/Main 1993, S 9-31

101 Nach Rorty sollte man zwe Bedcutungen von Dekonstruktuon unterscheiden "Im ersten Sinne bezieht sich das Wort auf die philosophischen Vorhaben von Jacques Dernida Bei dieser Auffassung ist die Zerschlagung der Unterscheidung zwischen Philosophie und Literatur unerlaßlich fur die Dekon- 
keit von Geschlecht (sex) und Sexualität auf die auferlegten Strukturen der

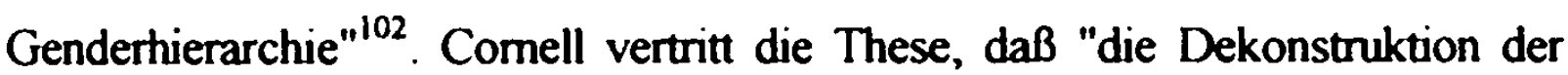
konventionellen Strukturen der Gender-Identität als entweder biologisch nötige oder kulturell erwünschte, nicht nur nicht die Realität des Leidens der Frau auslöscht, sondern im Gegenteil die Bejahung von weiblicher sexueller Differenz als einer Differenz fordert, die nicht reduzierbar ist auf die herrschende Definition des Weiblichen innerhalb der Hierarchie der Gender, als das andere des Mannes oder als sein Spiegelbild. Sexuelle Differenz wird also mit anderen Worten nicht ausgelöscht; im Gegenteil werden die rigiden Strukturen der Gender-Hierarchie, die Frauen entwertet und sie mit den patriarchaischen Konventionen dieser Hierarchie gleichgesetzt haben, in Frage gestellt" ${ }^{103}$. Comell plädiert für zwei Typen mit gleichwertigen Rechten, als einer möglichen Form mit Geschlechter-Differenz umzugehen. Dabei unterstreicht sie, wie

struktion Derndas philosophisches Unterfangen fuhrt ene Entwicklungslinic fort, wober Heideggers Unterscheidungen zwischen Denkern und den vieten Schreiberlingen von Dernda jodoch abgelectnt werden. Ebenso venurft Dernda den von Nietzsche verachteten und von Heidegger mederhergestellten phulosophuschen Professionalismus Damut uzrd Dernda alkerdings in die Richtung einer "allgemeinen. undifferenzerten Textualitat" gelenkt In seinem Werk dient de Unterscheidung zwischen Philosophie und Literatur bestenfalls als Teil einer Leiter, die uir loslassen konnen. sobald wir auf ihr comporgestregen sind Daneben gibt es jodoch cine zweite Bedeutung von Dekonstruktion. in der sich dieser Ausdruck auf eune Methode der Texunterpretation bezicht Woder diese noch sonst cine sollte man Dernda unterstellen, der ebenso we Heidegger schon die bloße ldoe der Methode geningschatzt " Vgl Richard Rorty "Doconstruction and Circumvention", in Fissays on Heidegger and Others Philosophical Papers, Bd 2. Cambndge 1991, S 66-82 Dr Ubersetzung: "Dekonstruicren und Auswerchen", in Eine Kultur ohne Zentrum Vier philosophische Essays, Stuttgan 1993, S 104-147, S. 105 Rorty verweist auf Heideggers Konzeption der Methode als Spielart des Verfahrens Er plädient fur die Idoc eunes nahtlosen. undifferenzienten aligemeinen Texts. der de Polemuk um de Untersecheidung zwschen Phulosophe und Litcratur innertalb des Poststrukturalismus auf jene Weise umgeht, indem er dic Philosophic als litcrarische Gattung begreift, und sie somvt auf seine Weise dekonstrusert Er stura sie von threm crhabenen RoB, denn sobald die Philosophic aufhort, ein Rochtferugungsdiskurs zul sein, verlien sic thre rasson d'eire. Rortys Textauffassung ist methodologisch wesentlich fur das Untersuchungsobjckt diescr Arbett

102 Drucilla Cornell "Gender, Geschlocht und gleichueruge Rochte", in: Der Sireit um die Differenz. op.cit, S 80-104, S 80

103 Ebd S 82 
wichtig Derridas Dekonstruktion für die feministische Theorie ist, denn gerade in ihr wird die sexuelle Differenz anerkannt. Gleichzeitig betont sie die "Notwendigkeit einer psychoanalytischen Theorie im politischen Denken ganz allgemein und besonders im feministischen Denken"104. Sie macht darauf aufmerksam, daß der Lacanismus als Darstellung der Gender-Differenzienung erklärt, warum es zu einer Hierarchie kommt, in der das Weibliche verworfen wird. Durch seine Anerkennung der konstitutiven Kraft der Sprache venunmöglicht er jeden Versuch, Geschlecht, Geschlechtlichkeit und Gender-Identität auf eine vorgegebene Natur oder Anordnung von Trieben zu gründen, so wie es Freud getan hat. In der Annahme einer phantasmatischen Identifikation, daß den Penis haben, bedeutet, den Phallus zu haben und damit die Basis der patriarchalischen Kultur bildet, rechtfertige er die Hierarchie der Gender. ${ }^{105}$ Derrida hingegen, so Comell, unterstreiche die politische und ethische Bedeutung der Tatsache, daß gelebte Sexualität nie völlig mit der auferlegten Gender-Identität übereinstimme. Comell legt dar, warum gerade die postmoderne Philosophie, insbesondere Derridas Möglichkeit einer "neuen Choreographie der sexuellen Differenz", die die performative Macht der Sprache, in der und durch die Gender-Identität konstituiert wird, die Veränderung und die Neuinterpretation

\section{Ebd S 86}

105 Ebd S 88-89. Dicse Einsicht ist allerdings nicht neu. $V_{g l}$ in dicsem Zusammenhang Samuel Webers Ruckehr zu Freud Jacques lacans Entstellung der Psychoanalyse, Wien 1990, S. 123. "Der Phallus, sofern seine Zirkulation durch das vaterliche Verbot, das das Gesetz des Signifikanten eunfuhr, geregelt wird, erscheint necht als das Produkt einer besonderen Kultur, sondem als die strukaurale Moglichkeitsbedingung des subjektiven Zugangs zu jeder Kultur und au den Tauschsystemen. die sie konstituieren" $\mathrm{Vgl}$ ebenso den Aufsatz von August Ruhs "Dic Schnft der Seele Einfuihnung in dic Psychoanalyse nach Jacques Lacan", un: Psyche 3 1980, S 885-909, S 905 Ruhs weist mit Weber darauftun. daß Freud endeutug am Phallokratismus festhält und der Phallus fur unn kulturbestummend ist: "Der Einbruch des Phallus als Signufikant des Signifikanten in die intrapsychische Okonorne eroffinet dem Subjckt durch die standige Verueisung auf etwas anderes. aber auch durch die Verknupfung mit cincen Signifikat (das mannliche Geschlechtsorgan) den Weg au euner Vielzahl von Objekten und Objektansprichen. die es das ganze Leben begleiten werden " 
der derzeitigen Strukturen von Gender-Identităt, die das Weibliche abwerten und Heterosexualität als Norm setzen, ermöglicht, so wichtig ist für die Emanzipation beider Geschlechter: Die Dekonstruktion arbeitet am Entzug einer falschen Legitimation, derjenigen, die die derzeitige Gender-Hierarchie bedingt, indem sie die Dimension einer Philosophie des Politischen annimmt. ${ }^{106}$ Allerdings formuliert Cornell zumindest in einem Punkt einen Unterschied zwischen sich und Derrida. Sie besteht darauf, von der sexuellen Differenz auszugehen, um das Weibliche durch das Wiedererzählen und die Remetaphorisierung des Mythos zu affirmieren: "Wenn wir die breite Intervention der Macht der Refiguration durch Mythos, Metapher und, in der Tat durch Phantasie und Fabel nicht zulassen, so kann es uns passieren, daß wir an der Ablehnung des Weiblichen teilhaben. Wir müssen in der gleichen Zeit, in der wir versuchen, aus der Geschlechterhierarchie auszubrechen, die sich endlos durch die Wiedereinsetzung einer rigiden Geschlechtsidentität wiederholt, eine Komplizenschaft mit den Mechanismen einer patriarchalen Gesellschaft vermeiden, die nicht anders kann, als den Wert des Weiblichen zu verleugnen." 107

Comells Bedeutung für die feministische Theorie liegt darin, daß sie, ähnlich wie Butler dies tut, auf die Wichtigkeit der richtigen Verwendung des Begriffs Performativität beharrt. ${ }^{108}$ Beide verwenden den Begriff der Perfor-

$106 \mathrm{Vgl}$ in diescm Zusammenhang (iemeinschafien. Positıonen zu eıner Phulosophie des Polinschen. hg von Joscph Vogl. Frankfurt/Maun 1993

107 Drucilla Comell "Das femunususche Bundnis mut der Dekonstrukuon", in: Dekonsinukaver Feminismus, op cit., S 279-319, S 313 Deeser Aufsatz wilt sıch in zwer Teile. Im ersten Tel. den sse "Dic dekonstruktuve Allegone der Frau" bettelt, spncht Cornell von der revolutionaren Macht des Weiblichen. die sie im unendichen Spiel der Frau mit der Kastration und im weiblichen Schreiben als Prozeß der Resulisienung des simulacrums Frau verwirklicht sicht Im zweiten Tel "Gerechugkent und der Ruf des Anderen" beschaftugt sie sich mut dem was sic Derndas "unausloschliche Spur des Utopismus im polituschen und ethuschen Denken" nennt

108 Butlers poststrukturalistische Neudefinition der diskursiven Performativitat deutet diesen Begnff 
mativităt nach Austins How to Do Things with Words, nach Derridas Signature. Event, Context und Paul de Mans Begriff der Metalepsis, wie er in seinen Aufsätzen zu Nietzsche in den Allegorien des Lesens formuliert wird. ${ }^{109}$ Butler definiert eine performative Handlung als eine solche, die das, was sie benennt, hervorruft oder in Szene setzt und so die konstitutive oder produktive Macht der Rede unterstreicht: "In dem Maße, wie ein Performativ eine vorgängige Intention 'auszudrücken' scheint - einen Täter hinter der Tat - ist diese vorgängige Handlungsfähigkeit nur lesbar als Efffekt dieser Äußerung. Damit ein Performativ funktionieren kann, muß es aus einem Satz sprachlicher Konventionen schöpfen und diese Konventionen, die traditionell funktioniert haben, rezitieren, um eine gewisse Art von Effekten hervorzurufen." 110

Das vorgestellte Konzept des Dekonstrukaven Femınısmus erklärt Männlichkeit und Weiblichkeit als Iffekte symbolischer Anordnungen. Darin wird die Opposition von männlich und weiblich als Effekt kultureller Anordnungen, als thetorischer Fffekt im Sinne einer neuen Rhetorik lesbar: "Die dekonstruktive feministische Theorie vollzieht sich als Lektüre der symbolischen Anordnungen, in denen Geschlechtsidentitäten konstituiert werden, und sie ist als Lektüre dieses Funktionierens, in der der Schein der Substantialität ausgeht, dekonstruktıv.

als Macht des Diskurses. Wirkungen durch standige Wiederholung zu produzieren In diesem Zusammenhang stellt sic dic Frage, wie die Beschrankungen solcher Produktion, die Zuange. unter denen eune solche Produktion erfolgt, verstanden werden mussen "Sind es soziale und polsusche Grenzen, die der Resıgnufizierbarkcit von sozalem Geschlocht und von Rasse gesetzt sind, oder liegen diese Grenzen strenggenommen außerhalb des Sozzalen" Sollen wir dieses "Außen" als das versteten, was sich der diskursiven Ausarbeitung auf Dauer uidersetzt. oder ist es eine veranderliche Grenze, die von bestummten polituschen Investutionen gesetat und versetza uird?", in Korper won Gewicht, 1995, op cit., S. 45

109 Paul de Man Allegonen des Iesens, Frankfurt/Main 1988

110 Judith Butter. "Für cin sorgfaluges Lesen", in. Der. Sireit um Differenz, op cit S 122-132, S 123 
Sie ist ein Re-Reading, Wi(e)derlesen im doppelten Sinne des Emeut- und Gegenlesens dieser Konstruktion." 111

Die dekonstruktive feministische Theorie vollzieht sich folglich als eine Strategie der Lektüre, die die "metaphorische Fehl-Lektüre" dekonstruiert und zwar auf eine solche Weise, indem sie das Weibliche dort ansiedelt, wo sich Metapher und Metonymie ständig ineinander verschieben, innerhalb einer Rhetorik des screen: "Lesen als Gegen-Lesen macht das Dispositiv metaphorischer Fehl-Lektüre und damit erst das Weibliche lesbar: in der oder als die Dekonstruktion der konstitutiv asymmetrischen Oppositionen. Das 'Andere' - als solches immer schon integriert - träte allein auf als ein radikal dezentrierender Widerstand, der exzentrische Rest, der von spekulären Bezugnahmen nicht eingeholt werden kann, und insofern als das 'an sich' Un-Repräsentierbare. Das Weibliche 'ist' dann die Spannung und Unentscheidbarkeit zwischen figurativ und literal, Metapher und Metonymie, zwischen verschiedenen Modi der Verhehlung und Verstellung: "112

Die oben vorgestellte Theorie-Geschichte und Theorie-Entwicklung der feministischen Literaturwissenschaft, von ihren Anfängen als Frauenstudien bis zur zeitgenössischen postfeministischen (ienderforschung, verfolgte zwei Ziele: Erstens sollte sie die Verlagenung des Erkenntnisinteresses von frauenspezifischen Themen auf die generellen Konstruktionsmechanismen von sozialem wie biologischem Geschlecht aufzeigen und zweitens sollte gezeigt werden, daß gerade der Eklektizismus der methodischen Verfahren zur Produktivität der feministischen Literaturwissenschaft beigetragen hat. ${ }^{113}$

III Bettune Mchnke "Dic Verstellung und des schoine Summe", op cit S 68

112 Ebd S. 78ff

$113 \mathrm{Vgl}$. in diesem Zusammenhang Ehrar/Hermann. 1996, op cit., S. $498 \mathrm{f}$ 


\title{
Kapitel I:
}

Gnostische Kunstreligion als Triebökonomie.

Der Gebrauch der Lust im Silbernen Zeitalter

\author{
Der Mann glaubt zu schöpfen - \\ er glaubt-glaubt-glaubt, \\ er schöpft-schöpft-schöpft.
}

Er schöpft-schöpft-schöpft die Frau.'

1 Jacques Lacan Encore Das Seminar Buch XX. Weinheim/Berlın 1986. S 141 


\section{Sophiologische Diätetik:}

\section{Vladimir Solov'evs Smysl ljubvi (Der Sinn der Liebe)}

Die wahre Zukunft an der wir arbeiten mussen. ist die universale Bruderlichkeit. die aus der unversalen Vaterschafi durch eine bestandige moralische und soziale Sohnschaft hervorgeht. ${ }^{2}$

In der geschichts- und religionsphilosophischen Abhandlung Smysl ljubvi (Der Sinn der Liebe) von 1892-1894 entwirft Vladimir Solov'ev (18531900 ) in fünf zusammenhängenden Aufsätzen eine Geschlechter-Ethik, die eine "wahrhaft verstandene und wahrhaft verwirklichte Geschlechtsliebe" (S. 255) propagiert und diese als Voraussetzung für die Schaffung einer "absoluten idealen Persönlichkeit" (S. 227) begreift. ${ }^{3}$ Dabei unterscheidet er fünf Wege der Geschlechtsliebe. Der erste Weg, der "satanische"

2 "Die nussische Idee", in Wladimir Solowjew, Hg. Wladimır Szylkarskı. Frciburg/i Brsg 1953, Band III. S. 30-91, S 81. "Die russische Idec" in Sobranie Socmem Vladimira Sergeevica Solov'eva (Gesamtonusgabe der Werke von Vladimir Sergeevt .Solov'ev), (crstmalıg Sankt-Pcterburg 1873-1900], Nachdruck Brussel 1966. Band XI. S 89-118. S. 114. "Istinnaja budušČnost' relovecestva, nad kotoroj nam nadležt potrudit'sja. cst' vselenskoc bratstvo. ischodjaščc iz vselenskogo otcestva, Crez neprestannoc moral'noc i social'noe synovstvo."

3 "Smysl ljubvi" im folgenden mit SL abgekurzt, wird zituert nach: Sobranie Socinenij, [18731900], Nachdruck Bruissel 1966. Band VII. S 3-62 Alle folgenden russischen Textzitate zu Solov'ev entstammen dieser Ausgabe Alle deutschen Textzitate entstammen der Gesamtausgabe der Werke von Wladımır Solowjew, Hg. Wladımır Szy'lkarskı. Frciburg/i. Brg 1953, Band VII, S. 201272. Eine Weiterentwicklung von Solov'evs Geschlechter-Ethik findet sich in der Moralphilosophie Oprandanie dobra (Die Rechtfertigung des Guten) von 1897, sowie in der 1898 verfaßten Schrift Ziznennaja drama Platona (Das Lebensdrama Platons) 
("satanskij put"') ist gleichzusetzen mit käuflicher Liebe, mit Prostitution. Der zweite Weg, der "tierische" ("životnyj put"'), ersetzt in Solov'evs Augen nur die physische Befriedigung. Der dritte Weg ist der gute, menschliche Weg, nämlich der eheliche. Da der Mensch aber immer nach etwas höherem strebt, wird dieser Weg durch einen vergeistigten Weg ersetzt, der Geist und Körper verbindet. Alle diese Wege, der satanische, tierische, menschliche und engelsgleiche führen, denn der Mensch erlebt darin die Geschlechtsliebe als passiv. Allein der fünfte, der "gottmenschliche" Weg ist ein Weg der Erhöhung ("voschoždenija"), in der sich die Geschlechtsliebe wahrhaftig verwirklicht und damit den Tod überwindet.

Solov'ev begründet diese Geschlechter-Ethik mit der Tatsache, daß "die Aufgabe der Liebe niemals bewußt gestellt und deshalb auch niemals in gehöriger Weise gelöst worden ist" (S. 228). Er klagt eine Begriffsnorm ein, die festlegt, was geschlechtlichen Beziehungen gezieme (S. 240). In diesem Zusammenhang kritisiert er die in seinen Augen willkürliche Pathologisierung geschlechtlicher Beziehungen, wie sie in den Schriften Krafft-Ebings Psychopathı sexualis und Binets Le fétichısme en amour als Abweichungen von der Norm dargestellt werden:

Eta anomalija polucila nazvanie fetišizma $v$ ljubvi. Nenormal'nost' takogo fetišizma sostoit, orevidno $v$ tom. čto tast' stavitsja na mesto celogo, prinadležnost' na mesto sušcnosti No esli vozbuzdajušxie fetišista volosy ili nogi sut' Casti Žnskogo tela, to ved' samo eto telo vo vsem svoem sostave est' tol'ko Cast' Zenskogo sušCestva, i odnako ze, stol' mnogoxislennye ljubiteli ženskogo tela samogo po sebe ne nazyvajutsja fetišistami, ne priznajutsja sumasšedšimi i ne podvergajutsja nikakomu leceniju $V$ そem že tut, odnako, razliðie? Neuželi v tom, čto ruka ili noga predstavljajut men'šuju poverchnost', neželi vse telo? (S. 35)

Diese Anomalien haben die Bezeichnung Liebes-Fetischismus erhalten Das Abnorme eines solchen Fetischismus besteht offensichtlich darin, daß ein Teil an die Stelle des Ganzen gesetzt wird, ein Zubehor an die Stelle des Wesens Wenn aber die den Fetischisten erregenden Haare oder Fuße Teile des weiblichen Korpers sind, so ist doch 
auch dieser Körper selbst, in seinem ganzen Bestand, nur ein Teil des weiblichen Wesens; indessen werden die so zahlreichen Liebhaber des weiblichen Körpers an sich nicht Fetischisten genannt, nicht als vernickt anerkannt und keinerlei Krankenbehandlung unterworfen Worin besteht denn hier der Unterschied? Doch nicht etwa darin, daß eine Hand oder ein Bein eine kleinere Oberflache aufweist als der ganze Körper? (S. 242)

Solov'ev behauptet dagegen, daß "man keinerlei festes Kriterium zur Unterscheidung finden kann, was auf geschlechtlichem Gebiet normal und was unnormal ist" (S. 245), denn seiner Meinung nach könnte man die gesellschaftlich akzeptierte Prostitution genauso als Abart der geschlechtlichen Beziehung darstellen. Er führt drei Aspekte auf, die das sexuelle Verhalten des Menschen bestimmen: die animalische Natur des Menschen, das soziale Gesetz in Form des bürgerlichen Ehemodells und der geistige Aspekt. Die Tatsache, daß in der zeitgenössischen Gesellschaft alle drei Aspekte nicht vereint gelebt werden, sondern getrennt, sieht Solov'ev in der Klassengesellschaft begründet.

Wie im weiteren gezeigt wird, basiert Solov'evs Geschlechter-F.thik auf der religionsphilosophischen Grundidee der All-Einheit (Vse-edinstvo), die bestimmt ist durch die Dreieinigkeit Gott-Christus-Sophia. Deren Ziel ist die Verwirklichung einer dreifaltigen Utopie, der theosophischen, theokratischen und theurgischen Verwirklichung des Gottesreiches auf Erden, der "Genesis von Himmel und Erde" (S. 13/214, "roždenija neba i zemli"). Ausgehend von der Wiederherstellung der Ganzheit des Menschen, die für Solov'ev gleichbedeutend mit der Wiederherstellung des Ebenbildes Gottes im Menschen ist und den "Beginn der Verkörperung des wahren idealen Menschentums" (S. 27/231, "načalom voplošcenija istinoj ideal'noj celovečnosti") darstellt, kann der "wahre Mensch in der Fülle seiner idealen Persönlichkeit" nicht nur 
Mann und nicht nur Weib sein, sondern muß die "höhere Einheit von beidem sein" (S. 227):

Osuscestvit' eto edinstvo, ili sozdat' istinnogo celoveka, kak svobodnoe edinstvo muźskogo i Ženskogo načala, sochranjajušxich svoju formal'nuju obosoblennost', no preodolevšich svoju suščstvennuju rozn' i razpadenie, - éto i est' sobstvennaja bližajzaja zadaca ljubvi (S 24)

Diese Einheit zus verwirklichen oder den wałsen Menschen als freie Einheit des männlichen und weiblichen Prinzips zu schaffen, die beide ihr formales Sondersein bewahren, aber ihre wesenhafte Verschiedenheit und ihr Geschiedensein überwunden haben. das ist die eigentlich nachste Aufgabe der Liebe (S 227).

Damit formuliert Solov'ev die Aufgabe der Geschlechtsliebe als metaphysische, deren zentrales Anliegen die Überwindung der niederen Welt der Stofflichkeit, der Zeit und des Todes in einer höheren Welt der Geistigkeit und Ewigkeit darstellt. Dieser Wunsch nach Transzendenz äußert sich als Überwindung der Geschlechter-Differenz in der All-Einheit, die gleichzusetzen ist mit der androgynen Idealvorstellung eines dritten Geschlechts. ${ }^{4}$ Der „Sinn der Liebe“ besteht für Solov'ev dabei, auf der Grundlage des Glaubens die "Neuerstehung und Verewigung des individuellen Lebens", die "Rechtfertigung und Rettung der Individualität durch die Opferung des Egoismus" (S. 217) zu erwirken, deren Voraussetzung die Umwandlung des Weltalls im Sinne der alleinigen Idee darstellt. Im geschichtlichen Prozeß führt der Weg

\footnotetext{
4 Wesentlich fur Solov'evs Sophienlehre war der Einfluß der Kabbala und der Geheimlehren. die in der Solov'evforschung als crste Quelle benannt werden Vgl in diesem Zusammenhang Edith Klum: Natur. Kunst und liebe in der Philosophie Vladimir Solov'evs, Berlin 1965, S. 25ff Auch der Einfluß der deutschen Mystik, vor allem Jakob Bohmes und seiner Lehre von der androgynen Natur Adams und Christus, sowic in der Nachfolge Franz von Baaders Saize der erotischen Philosophie pragten Solov'evs Sophienlehre Aber auch Schellings "Philosophie der Offenbarung" nahmen Einfluß auf Solo'vevs theologisch-philosophische Spekulationen Vgl hierzu Ludolf Müllet Vadimir Solov'ev und der Protestantismus, Freiburg 195!, S 93-125, sowie Olga Matich "Androgyny and the Russian Religious Renaissance", in Anthony $M$ Mhkoun (Hg.). Westem Philosophical Systems in Russian Literature, Los Angeles 1979, S 165-175 Siche auch Konstantun Mocul'skij Vladimir.Solov'ev. Žzn'i ucenie, Panz 1936, S $205 \mathrm{ff}$.
} 
dahin über die allmăhliche Ablösung hin zur Herstellung des solidarischen Ganzen, zu der wahren "syzygischen Einheit" (S. 270) als mystischer Leib des Kosmos, der für Solov'ev die vollkommene harmonische Verbindung der Menschen untereinander heißt, geprägt durch die "Wechselwirkung der Liebe" (S. 259), nicht durch Herrschaft und Unterordnung. Die geschichtliche und kosmische Verwirklichung dieser Idee sieht Solov'ev in der historischen Kraft, die er der Sophia als "Körper Gottes" zumißt. Diese Kraft der Sophia ist in der Lage, das vollkommene Gute als unteilbare Organisierung der dreieinigen Liebe auf der Erde zu realisieren. In diesem Sinne ist die wahre Liebe eine aufsteigende und eine absteigende (amor ascendens und amor descendens, S.255).

In der All-Finheit ist die Gespaltenheit der materiellen Welt als Krankheit der modernen Zivilisation überwunden, denn in ihr als Symbol des mystuschen Leibs der Ungeschiedenheit ist die doppelte Undurchdringlichkeit des stofflichen Seins in der Zeit und im Raum immer schon aufgehoben. In diesem Sinne repräsentiert die Wiederkehr der Ewigen Weıhlichkeit, wie sie von Solov'ev projiziert wird, die Voraussetzung für die Erlösung aus dem "Sein als Zustand des Zerfalls, ein Sein, das in die einander ausschließenden Teile und Momente zerstückelt ist" (S. 262). Sie bildet den Nährboden jener religionsphilosophischen Idee Solov'evs, die psychoanalytisch gesprochen mit dem Prozeß der "Unbewußtwerdung", der Ich-Auflösung im mütterlichen Leib, dem Rückzug in die pränatale Geschlechtslosigkeit bzw. Doppelgeschlechtlichkeit gleichzusetzen ist oder im hermetischen Diskurs die Rückverwandlung des Kultur- in den Naturmenschen bedeutet. Gerade die Vereinnahmung der Ewigen Weiblıchkelt durch den männlichen Philosophen bzw. 
seine Feminisierung mit der Betonung auf der All-Einhelt offenbaren Phantasmen über Wiedergeburt, Rettung und Auferstehung, die sich über den mütterlichen Körper definieren oder wie Luce Irigaray es formuliert: "Vielleicht werden Jahrhunderte vergehen müssen, bis der Mann in der Lage sein wird, den Sinn seines Werks, seiner Werke zu deuten: das endlose Konstruieren von Substituten seines vorgeburtlichen Aufenthalts."

Das Konstruieren eines vorgeburtlichen Aufenthalts entspricht bei Solov'ev der Geburt des Geistes im Leib. Diese zweite Geburt, die geistige Geburt ist die wahre Geburt. Sie ersetzt den eigentlichen Geburtsvorgang durch eine körperliche Transformation, die dem pneumatischen Geist-Prinzip und der Idee der Transsexualität des sektantsvo entspricht. Damit wird die Geschlechterzuordnung verlagent und die Trennung der Geschlechter aufgebrochen:

No razdelenie polov, ne ustranjaemoe ich vnešnym $i$ prechodjašxim soedineniem $v$ rodovom akte, - eto razdelenie meždu mužskim i žnskim elementom celoveðeskogo suštestva est' uže samo po sebe sostojanie dezintegracii i nacalo smerti Prebyvat' $v$ polovoj razdel'nosti znaxit' prebyvat' na puti smerti, a kto ne chozet ili ne možet soijti s etogo puti. dolźen po estest vennoj neobchodimosti proijti ego do konca Kto podderživaet koren' smerti, tot neizbežno vkusit i ploda ee. Bessmertnym možet byt' tol'ko cetyj Cetovek, i esli fiziologixeskoe soedinenie dolźno byt' zameneno iztinnym soedineniem, a nikak ne vozderžaniem ot vsjakogo soedinenija, t.e. nikak ne stremleniem uderžat' in statu quo razdelennuju, raspavšujusja, i sledovatel'no, smertnuju Celoveceskuju prirodu (S 33)

Die Trennung der Geschlechter aber - die durch ihre außere und vorubergehende Vereinigung im Geschlechtsakt nicht beseitigt wird-, diese Trennung zwischen dem männlichen und weiblichen Element des menschlichen Wesens ist schon an und fur sich ein Zustand der Desintegration und der Anfang des Todes Im geschlechtlichen Getrenntsein verharten, bedeutet, auf dem Weg des Todes verharren, wer aber diesen Weg nicht verlassen will oder kann, der muß ihn mit naturlicher Notwendigkeit bis zum Ende gehen Wer die Wurzel des Todes unangetastet laßt, der muß unvermeidlich auch seine Frucht zu schmecken bekommen Unsterblich kann nur der ganze Mensch sein, und

5 Luce Ingaray Die Eshik der sexuellen Differenz. FrankfurdMain 1991, S 19 
da die physiologische Vereinigung die Ganzheit des menschlichen Wesens nicht wiederherstellen kann, so muB die verkehrte Vereinigung durch die wahre ersetzt werden, keineswegs aber durch eine Enthaltung von jeder Vereinigung, das heiBt keineswegs durch das Bestreben, die getrennte, zerfallene und folglich sterbliche menschliche Natur in statu quo zu erhalten (S. 239)

Die wahre Vereinigung von Mann und Frau beruht dementsprechend nicht auf einer sexuellen, die immer mit dem Tod gekoppelt ist, sondern auf einer geistigen Vereinigung. Dabei trennt Solov'ev die Sexualität vom Körper und die Fortpflanzung von der Sexualität: "Gewöhnlich wird angenommen, daß der Sinn der geschlechtlichen Liebe in der Vermehrung der Gattung besteht, der sie als Mittel diene. Ich halte diese Ansicht für falsch" (S. 201), denn "Kinderzeugung ist nicht die eigentliche Sache der Liebe" (S. 226). Der wahre Sinn der liehe besteht für Solov'ev in der wahren, geistigen Liebe als Triumph über den Tod, denn Sexualität bedeutet immer die Erfahrung der Sterblichkeit:

Istinnaja ze duchovnaja ljubov' ne est' slaboe podražanie i predvarenie smerti, a toržestvo nad smer'ju, ne otdelenic bessmertnogo ot smertnugo, veCnogo ot vremennogo, a prevraščenie smertnogo $v$ bessmertnoe, vosprijatie vremennogo $v$ vě̌noe Ložnaja duchovnost' est' otricanie ploti, istinnaja duchovnost' est' ee pereroždenie. spasenie, voskresenie (S 40)

Die wahre geistige Liebe aber ist nicht eine schwache Nachahmung und Vorwegnahme des Todes, sondern ein Triumph uber den Tod, nicht die Trennung des Unsterblichen vom Sterblichen, des Ewigen vom Zeitlichen. sondern die Verwandlung von Sterblichem in Unsterbliches, die Aufnahme von Zeitlichem in Ewiges. Die falsche Geistigkeit ist die Verneinung des Leibes, die wahre Geistigkeit ist dessen Wiedergeburt (S 248)

Um Sterbliches in Unsterbliches zu verwandeln, um die ewige Wiederholung des Todes zu umgehen, ersetzt Solov'ev den physiologischen Prozeß des Gebärens durch einen geistig-pneumatischen. Folglich wird die Wiedergeburt des Leibes nur erreicht, wenn der mit der "Potenz einer unendlichen Vollkommenheit" ausgestattete Mann, dessen schöpferisches Wirken darin be- 
steht, ahnlich wie Gott das Weltall und Jesus Christus die Kirche geschaffen haben, das Material, das er in der Person des Weibes vorfindet, umzusetzen in ein ideales Material. Auf diese Weise kann er die Vergöttlichung der Menschheit verwirklichen, das Ebenbild Gottes im Menschen wiederherstellen, denn die Idealisierung des niederen Wesens ist zugleich die beginnende Realisierung des höheren:

Celovek dlja svoego tvorČeskogo dejstvija imeet v lice ženšciny material, emu samomu ravnyj po stepeni aktualizacii, pered kotorym on pol'zuetsja tol'ko potencial'nym preimužestvom pocina, tol'ko pravom ob ob-jazannost'ju pervogo saga na puti $k$ soveršenstvu, a ne dejstvitel'nym soveršenstvom (S 41)

Der Mann hat fur sein schopferisches Wirken in der Person des Weibes das Material, ein Material, das ihn selbst dem Grade der Aktualisation nach gleich ist, vor dem er nur den potentiellen Vorzug der Initiative, nur das Recht und die Pflicht auf dem Wege zur Vollendung nicht aber die wirkliche Vollendung voraus hat (S. 249)

Die wahre, geistige Liebe gibt dem Menschen schöpferische Kraft, die ihn dazu befähigt, das weibliche Material gottgleich zu gestalten. Solov'ev integriert hier die Geschichte des Bildhauers Pygmalion, der sich in eine von ihm selbst geschaffene elfenbeinerne Mädchenstatue verliebt. Auf Bitten Pygmalions ließ Aphrodite sie lebendig werden und Pygmalion nahm sie zur Frau. Ebenso wie der Bildhauer Pygmalion schafft sich der Philosoph Solov'ev seine ideale Frau:

Konkretnaja forma etogo voobraženija, ideal'nyj obraz $v$ kotoroj ja oblekaju ljubimoe lico v dannyj moment, sozdaetsja, konežno mnoju (Hervorhebung von mir, D.R ), no on sozdaetsja ne iz nicego, i sub-ektivnost' etogo obraza kak takogo, tee javljajušcegosja teper' i zdes' pered očami moej duši, niskol'ko ne dokazyvaet sub'ektivnogo, t.e dlja menja liš' sušcestvujuščego, charaktera samogo voobražaemogo predmeta Esli dlja menja, nachodjaščegosja po siju storonu transcendentnogo mira, izvestnyj idealnyj predmet javljaetsja tol'ko kak proizvedenie moego voobraženija, eto ne mešaet ego polnoj dejstvitel'nosti v drugoj vyš̌ej sfere bytija. I chotja naša real'naja žizn' nachoditsja vne êtoj vyš̌ej sfery, no naš um ne sovsem đužd ej, i my možem imet' nekotoroe umozritel'noe ponjatie o zakonach ee bytija (S.L., S 44) 
Die konkrete Form dieser Einbildung, die ideale Gestalt, in die ich die geliebte Person im gegebenen Augenblick einkleide, wird natürlich von mir geschaffen (Hervorhebung von mir, DR.) und die Subjektivitat dieser Gestalt als solcher, das heißt der jetzt und hier vor den Augen meiner Seele erscheinenden Gestait, beweist nicht im geringsten den subjektiven Charakter des eingebildeten Gegenstands selbst Wenn fur mich, der ich mich diesseits der transzendentalen Welt befinde, ein gewisser idealer Gegenstand nur als Erzeugnis meiner Einbildung erscheint, so stort das seine volle Realitat in einer anderen, hoheren Sphare des Seins nicht. Und obwohl unser reales Leben sich außerhalb dieser hoheren Sphare befindet, so ist sie in unserem Intellekt doch nicht ganz fremd, und wir konnen einen gewissen spekulativen Begriff von den Gesetzen ihres Seins haben (S. 253)

Das auf diese Weise idealisierte Weibs-Bild entspricht einem weiblich gedachten Gott. Solov'ev beschreibt hier eine Technik der Liebe, die über die erotische Vereinigung mit der Sophia erfolgt und auf diese Weise die Gottwerdung des Menschen verspricht. Es ist eine Technik, die versucht, etwas Jenseitiges zu transportieren, etwas, was man nicht verstehen, aber wiederholen kann. Dieses Jenseitige entspricht einer idealen, entkörperlichten Welt, in der die Endlichkeit aufgehoben ist:

No imenno dlja togo, ctoby Bog' različalsja bezuslovno ot našego mira, ot našej prirodoj, ot etoj vidimoj dejstvitel'nosti, neobchodimo priznat' v Nem svoju osobennuju

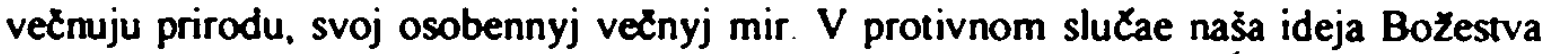
budet skudnee, otvlezennee, neželi naše predstavlenie vidimogo mira ${ }^{6}$

Doch eben daza, daß Gott sich unbedingt von unserer Welt, von unserer Natur, von dieser sichtbaren Wirklichkeit unterscheide, ist es notwendig, inm seine besondere ewige Natur, seine besondere ewige Welt zuzuerkennen Andernfalls ware unsere Idee von der Gottheit durftiger und abstrakter als unsere Vorstellung von der sichtbaren Welt ${ }^{7}$

Das Einzigartige an dieser Geschlechter-Ethik ist die Einheit zwischen Lehre und Leben, die Solov'ev unabdingbar vorlebte: seine "himmlische“

6 Vladimur Solov'ev: "Ctenija o Bogocelovexestve", in Sobranie Socinenij III-IV |Sankt-Peterburg 1873-1905] Nachdruck Brussel 1966, S. 3-163, S. 115

7 Vladimir Solov'ev "Vorlesungen über das Gottmenschentum". In (iesammelte Werke, Band I, München 1978, S. 670 
Liebesbeziehung mit der Sophia. ${ }^{8}$ Da er sich nur mit ihr vermählt fühlte, ist er nicht in der Lage ,irdische Liebesbeziehungen“ einzugehen:

V istorii poezii, mistiki, umozrenija Vladimir Solov'ev javljaetsja edinstvennym, kotoryj ne tol'ko imel poeticeskie i filosofskie sozercanija otnositel'no Sofii, no pripisyval sebe ešce $i$ liðnye $k$ nej otnošenija, prinimajušcie erotiðeskij charakter. Poetomu zemnuju ljubov' on ošcuščal dlja sebja, $v$ obščem, kak nekotoroe padenie ili izmenu On ne mog sdelat'sja otcom ili mužem, ibo curstivoval sebja kak by obručennym [ $\ldots]^{9}$

In der Geschichte der Poesie. der Mystik, der geistigen Spekulation ist Vladimir Solov'ev der einzige, der nicht nur poetische und philosophische Betrachtungen uber die Sophia machte, sondern ihr auch personliche Beziehungen zuschrieb, die erotischen Charakter annahmen Deswegen betrachtete er fur sich die irdische Liebe im Grunde als Niedergang oder Verrat Er konnte weder Vater noch Ehemann werden, denn er fuhlte sich, als ob er vermählt wäre [. ]

8 Aufschlußreich in diesem Zusammenhang ist ein biographisches Detail. das der Entstehung des Textes Der Sinn der Liebe unmittelbar vorausgeht Solov'cv wollte cine Licbesbezichung mit der verheirateten Sofja Michajlovna Martynova emgehen, die er als Inkarnation der himmlischen Sophia, seiner ewigen Freundin auserwahlt hatte Nicht nur dieser Versuch. auch alle anderen Versuche scheiterten. $\mathrm{Vgl}$ in diesem Zusammenhang Konstantin Mołul'skij. Madimir Solov'ev. Zizn'i ucenie, Panz 1951, S. 197ff.

9 Sergej Bulgakov "Vladimir Solov'ev I Anna Smidt" [1918], in Russkaj eros ili filosofija ljubvi v Rossin (Der russische tiros oder die Philosophie der Liebe in Ku/3land), Moskva 1991, S. 315-320, S 315/316. Bulgakov weist darauf hin, daß im Unterschied al anderen Mysukem wie Bohme. Baader. Saunt-Marun oder zu Dichtem wie Goethe. Shelley und Petrarca, denen der Philosoph Frauenhaß unter der Maske der Androgynitat vorwirf Solov'ev eıne mystısche Liebesbeziehung mit der Sophia pflegte. Dic Quelle der Solov'evschen Sophıologic ist dic Kabbala (Schechina entspncht der Sophia) Allerdings ist die Apotheose der irdischen Ehe und die geheiligte Kinderzeugung. wie sie die Kabbala lehrt. der mystischen Erotik Solov'evs vollkommen fremd

Solov'evs Sophiologic blicb nicht ohne Wirkung auf reale Frauen. denn die Sophia war nicht nur ein metaphysisches Wesen. sondem konnte, wie oben dargelegt. konkrete, irdische Zuge annehmen. Begegnungen fustlegen und Nachrichten hinterlassen Diese Einheit zuischen Solov'evs Lehre und seinem Leben - die Personifizicrung der Sophia als seine ewige Freundin - wurde in dem Moment problematisch, als sich die Mistikerin Anna Śmidt (1851-1905) als diese ausgab. Sie lebte in Niznij Novgorod. wo sie als Journalistun arbeitete und mystische Traktate uber die Kirche und das Dntte Testament schricb Solov'ev verkehrte mit Anna Smidt brieflich und crkannte die außergewohnlıche Begabung. die diesen Schriften zugnundelag Dadurch fühlte er sich von ihr gleichermaßen angezogen und abgestoßen, denn auf der einen Seite beuunderte er das Talent dieser Frau. auf der anderen Seite konnte er in thr nur seinen Doppelganger erkennen Anna Smidt. die sich beharrlich als Inkamation sciner ewigen lireundin (veenaja podruga) stılisierte. Wurde von ihren Zeitgenossen großtenteils als negative Erscheinung aufgenommen und fur halbwahnsinnig gehalten Siche hierzu Konstantın Mocul'skıj, 1951, op.cit. S 262ff und Sergej Bulgakor in 7ichye dumy' (Sille (iedanken), |zucrst Moskau 1918| Pans 1976, S 77ff 
Solov'evs philosophisch-künstlerisch geschaffenes Liebesobjekt ist nur auf dem Wege des endlosen Aufschubs, als sein abwesender Bezugspunkt erreichbar. Interessant ist dabei die Tatsache, daß das Wunschbild (bzw. Angstbild) des Weiblichen das Selbstbild des Philosophen und das wiederum die Idealisienung bzw. Herabminderung des Weiblichen determiniert. Dieser Proze $B$ wird besonders deutlich in einem Akrostychen aus dem Jahre $1892^{10}$ :

\section{SAFO}

Skazocnym Cem-to povejalo snova

Angel' ili demon mne $v$ serdce stucitsja?

Formu prinjat' moe Cuvstvo boitsja.

O, kak bessil'no cholodnoe slovo!

Slovo nezdešnich šepot strannyj.

Aromat japonskich roz.

Fantasticnyj i tumannyj

Otgolosok vešnych grez

Etwas wehte mich erneut an,

Klopft ein Engel oder ein Damon an mein Herz?

Mein Gefuhl furchet sich Form anzunehmen

O, wie kraftlos ist das kalte Wort!

Seltsames Gemurmel jenseitiger Worte.

Duft japanischer Rosen

Phantastisch und neblig

klingt das Echo frühlingshafter Traume

10 Alle folgenden Textzitate entstammen der Ausgabe Biblioteka poeta. Vladimir Solov'ev

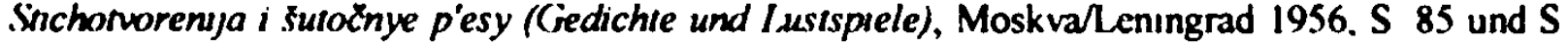
$154 \mathrm{ff}$ 
Madonnoj byla dlja menja ty kogda-to

Almaznoju radugoj lik tvoj gorel,

Tainstvenno vsjo v tebe bylo i svjato.

Rydal ja u nog tvoich tysjacekrat $i$

Edva udavit'sja s toski ne uspel,

No skryls'ja kuda-to tvoj obraz krylatyj.

A vmesto nego ja Matrenu uzrel

Maijskaja roza davno uže otpeta.

Avgust I avgust izcez.

Tol'ko kak lysina starogo Feta.

Rošca tvoja tak pečal'no razdeta.

El'ju odnoju krasujetsja les

Novoj prirode sozustvenno vtorja,

Ach, ty Matrenoju sdelalas' s gorja

1

Eine Madonna warst Du einst fur mich.

Wie ein diamantener Regenbogen leuchtete Dein Antlitz

Geheimnisvoll war alles in Dir und heilig.

Schluchzend lag ich tausendmal zu Deinen Füßen und

Kaum ist es mir gelungen, die Trauer zu ertranken

Schon verbarg sich Dein geflugeltes Antlitz

Und stattdessen erblickte ich nur noch Matrena

Die Mairose ist schon lange abgesungen.

August . Auch der August verschwand

Genau wie die Glatze des alten Fet

ist auch Dein Hain traurig kahl geworden,

Nur durch einen einzigen Tannenbaum wird der Wald noch verschont

In der Natur mitleidig widerhallend,

wurdest Du vor Kummer zur neuen Matrena

(Interlinearubersetzung von mir, D R ) 
Das Gedicht, dessen Liebessemantik den Regeln der ,höfischen Liebe“ folgt, zeigt Solov'evs Dichotomisierung der Frau als "Heilige" ("Safo"), als "himmlische Göttin" ("svetloe božestvo") und als "femme fatale" ("Matrena"). " Der primäre Prozeß der Identifizierung wird von einem sekundären der Herabminderung bzw. Entwertung abgelöst. Aus dem Bildhauer, der die ideale weibliche Gestalt schaffen will, wird ein einfacher Steinmetz:

Vy byli dlja menja, prelestnoe sozdan'e,

Eto dlja skul'ptora mramora kusok.

No sloman moj rezec $v$ usilennom staran'e.

A glybi kamennoj on odolet' ne mog!

Ljubit' vas tout-de-même? Vot strannaja zateja!

Kogda ze kto ljubil negodnyj material?

O svetlom božestve, ljubov'ju plameneja,

$O$ suetlom botestue nad vami ja mectal

Teper' utešu vas! Pigmalioni redki,

No est' kamenotes v primete $u$ menja

Iz mramora skam'ju on sdelaet $v$ besedke

I budet otdychat' ot trudovogo dnja.

(Mart 1893)

Sie waren fur mich ein wunderbares Geschopf,

Genauso wie fur den Bildhauer ein Stuck Marmor,

Aber mein Meißel ist durch die kraftvolle Anstrengung gebrochen.

Er konnte den steinernen Block nicht überwinden!

Sie trotzdem lieben, das ist ein seltsames Unterfangen,

Wenn fur den der liebt, das Material unbrauchbar ist

Als helle Gottheit, vor Liebe brennend.

Als helle (jotthet habe ich won Ihnen getraumt

Jetzt troste ich Sie! Pygmalions gibt es selten,

Aber ich habe jetzt einen Steinmetz im Auge

Aus dem Marmor macht er eine Bank in der Gartenlaube

Und wird sich darauf vom Arbeitstag ausruhen

II Vgl in dicsem Zusammenhang Kapitel III der Disscrtation 
Das auf diese Weise imaginierte Weibs-Bild steht für Solov'evs Vision einer transzendenten, einer anderen Welt (mir inof) als Voraussetzung der angestrebten All-Einheit (vse-edinstvo). Sie hebt die Individualität des Menschen insofern auf, da alle Menschen Bestandteil der All-Einheit sind und auf diese Weise nur aus dieser hervorgehen können:

I vot pervyj, osnovnoj zakon esli $v$ našem mire razdel'noe $i$ izolirovannoe suščestvovanie est' fakt $i$ aktual'nost', a edinstvo - tol'ko ponjatie $i$ ideja, to tam naoborot, dejstvitel'nost' prinadležit edinstvu, ili tocnee, vseedınstvu, a razdel'nost' i obosoblennost' sušcestrujut tol'ko potencial'no i sub'jektivno A otsjuda sleduet, ¿̌to bytie étogo lica v transcendentnoj sfere ne est' individual'noe $v$ smysle zdešnego real'nogo bytija. Tam, t.e $v$ istine, individual'noe lico est' tol'ko lux, zivoj i dejsvitel'nyj, no ne razdel'nyj lux odnogo ideai'nogo svetila - vseedinoj suščnosti. Eto ideal'noe lico, ili olicetvorennaja ideja, est' tol'ko individualizacija vseedinstva, kotoroe nedelimo prisutstvuet $v$ každoj iz étich svoich individualizaciej Itak, kogda my voobrazaem ideal'nuju formu ljubimogo predmeta, to pod êtoj formoj nam soobščaetsja sama vseedinaja suš̌nost' (S.L., S. 45)

Und dies ist das erste grundlegende Gesetz Wenn in unserer Welt das getrennte und isolierte Dasein Tatsache und Aktualitat ist, so besitzt dort umgekehrt die Einheit, oder genauer die All-Einheit Wirklichkeit; die Getrenntheit und Isoliertheit dagegen existieren nur potentiell und subjektiv. Hieraus aber folgt, daß das Sein dieser Person in der transzendenten Sphäre kein individuelles im Sinne des hiesigen realen Seins ist. Dort, das heißt in der Wahrheit, ist die individuelle Person bloß3 ein lebendiger und wirklicher Strahl, aber ein nicht abtrennbarer Strahl einer idealen Leuchte - der alleinigen Wesenheit Diese ideale Person oder die personifiziente Idee ist nur die Individualisierung der All-Einheit, die unteilbar in jeder dieser Individualisationen anwesend ist Und so teilt sich uns, wenn wir uns die ideale Form dieses geliebten Gegenstandes vorstellen, die alleinige Wesenheit mit. (S 253)

Solovev's Konzept der All-Einheit bedeutet somit eine kollektive Ungespaltenheit der Geschlechter, d.h. die Angleichung von Mann und Frau als mannweıblıches bzw. weibmännlıches Geschöpf (mužeženskoe ıli żenomužskoe sušcestvo), die sich jeweils umgekehrt proportional entsprechen. ${ }^{12}$ In dieser Vorstellung konstruiert Solov'ev die Ewıge Weiblichkeit aber, und das ist

12 Das Konzept der All-tinhelt ist homolog zu Weiningers Androg!nitatsauffassung zu sehen Vgl. das folgende Kapitcl dieser Dissertation "Eros Pontıfex Zinaida Gippius' Metaphysik der Licbe." 
das Widerspruchliche an seiner gesamten Argumentation, als das andere Geschlecht (Beauvoir), als das (jeschlecht, das nicht eins tst (Irigaray) und erzeugt damit genau jenen Diskurs des Mangels, jenes negative Spiegelbild, für das das Weibliche traditionsgemäß steht. ${ }^{13}$ Auf diese Weise symbolisiert Solov'evs Geschlechter-Ethik den Ort der Frau, den es nicht gibt, bzw. nicht geben soll: Das Nichts als Ort der Nicht-Begegnung, in dem es gemäß Lacan auch kein Geschlechtsverhältnis gibt:

Bog kak edinyj, razlicaja ot sebja svoe drugoe, te. vse, cto ne On sam, soedinjaet s soboju eto vse, predstavljaja sebe ego vmeste $i$ zaraz, $v$ absoljutno soveršennoj forme. sledovatel'no, kak edinoe Éto ctrugoe edinstvo, razliznoe, chotja i neotdelimoe ot pervona ̌al'nogo edinstva Božja, est' otnositel'no Boga edinstvo passivnoe, Ženskoe, tak zdes' vecrnaja pustota ( $\boldsymbol{X}_{i}$ staja potencija) vosprinimaet polnotu božestvennoj Zizni No esli v osmove etoj Vexnoj zenstvennosti lezit cistoe niěto, to dlja Boga eto ničto veřno skryto vozprinimaemym ot Božestva obrazom absoljutnogo soveršenstva (S.L., S 44)

Gott, der Einzige, der alles, was nicht Er selbst ist, als sein Anderes (Hervorhebung von mir, D.R.) von sich unterscheidet, vereinigt dies alles mit sich, indem Er es sich zusammen und zugleich in der absolut vollkommenen Form, folglich Eines vorstellt Diese andere Einheit, von der ursprünglichen Einheit Gottes verschieden, wenn auch nicht von ihr abtrennbar, ist in bezug auf Gott eine passive, weibliche Einheit, da hier die ewige Leere (die reine Potenz) die Fülle des göttlichen Lebens empfängt Wenn aber im Grunde dieser ewigen Weiblichkeit das reine Nichts liegt. so ist fur Gott dieses Nichts ewig durch das Bild der absoluten Vollkommenheit verdeckt, das sie von der Gottheit empfangt (S. 254)

In der Wiedervereinigung von Gott und Schöpfung, die sich durch das Wirken der Sophia, der göttlichen All-Weisheit vollzieht, sieht Solov'ev den "Sinn der Liebe“. Über sie wird die Welt transformiert und in den Zustand der All-Einheit zurückgeführt. Dieser Prozeß vergöttlicht den Philosophen, der somit die "theurgische" Tat der Welttransformation vollbringen kann. ${ }^{14}$

$13 \mathrm{Vgl}$. in diesem Zusammenhang Luce Irigaray Das Geschlecht, das nicht eins ist. Berlın 1979 14 Solove'vs Visionen haben nicht nur eine metaphysische und historiosophische Dimension. sondern auch eine mystusche, denn sic sind an den Glauben an cine unmittelbare Begegnung mit 
Gleichzeitig soll diese "theurgische Tat" das Christentum rehabilitieren, denn Rußland ist gemäß seiner messianischen Rolle dazu in der Lage, die ungebrochene Tradition des orthodoxen Christentums mit der pervertierten des Westen zu vereinen. ${ }^{15}$ Solov'ev vereinnahmt für Rußland bzw. für sich selbst die apokalyptische Vision des in die "Sonne gekleideten Weibes"16, das einen Sohn gebären soll, der der Welt ein neues Wort sagt. In diesen Visionen nimmt der künstliche Geburtsvorgang gleichsam Fleisch an. Der Philosoph bringt den neuen Logos auf die Welt, der Fleisch und Wort wieder vereint: "So erweist sich Sophia als der mystische Name für Rußland, "Rossija", die eine mystische Ehe mit dem Antichristen-Westen eingehen soll (der freilich dadurch seines eigenen christlichen Ursprungs bewußt und damit gerettet wird), wobei unter dem Westen eigentlich eher die russische verwestlichte Intelligencija inklusive Solowjow selbst als der reale geographische Westen verstanden wird. Die Sophia ist für Solov'ev die Entdeckung der eigenen weiblichen (russischen, christlichen usw.) Dimension. Die Vereinigung der zwei Hälften des Christentums, d.h. des Westens und des byzantinischen

der himmlischen Sophia gebunden Dieser Glaube schlagt sich am offensichtlichsten in dem Godicht Tn svidanija (Drei Begegnungen) von 1898 nicder und ist in der noch ungebrochenen Tradituon der russischen Orthodoxic verankert. in deren Theologie das ncuplatonische Denken weitervermittelt wird .,Sophia wird in dieser Perspektuve als die weibliche und zugleich matericlle Dimension Christı aufgefaßt. als der verklarte Leib Christ - in der Nahe zur Mutter Gottes und aur Kurche, die auch theologisch als der mysusche Leib Christi gilt. Indem das Materielle in dem verkorperten Logos aber als das noch vor der Weltschopfung in der Person der Sophia prasente weibliche Prinzip gesetzt wird. entsteht de facto eine Erweiterung der gottlichen Trinitat, in die cine neue weibliche Hypostase eingefuhrt wird Die philosophisch-thoologisch-sophiologischen Bemuhungen Solov'evs galten deswegen in erster Linic der Aufgabe, die maximale göttliche Gleichberechugung fur Sopha zu erreichen, ohne eine Position cinzunehmen, dic als haretusch empfunden werden konnte “Zit. nach Boris Groys "Weisheit als weibliches Weltpnnzip Die russische Sophiologie des Wladimir Solowjow", in Weisheit, hg Von Alcida Assmann. Munchen 1990. S. 345-354, S 346ff

15 Dazu ausfuhrlıcher Egbert Munzer. Solov'ev Prophet of Russian-Western Unuty. London 1956. S 135ff 
Rußlands, betrachtet er als die innere mystische Ehe in der Seele des russischen Intelligenzlers zwischen seiner westlichen Kultur und seinem russischen Unbewußten, die ihm die lang ersehnte Ganzheit, die Androgynität, die vse-edınstvo gewährt." ${ }^{17}$ In diesem Sinne repräsentiert das sophiologische Ganze, die All-Einheit nach Solov'ev psychoanalytisch gesprochen einen Übertritt in die symbolische Ordnung ohne die Trennung vom Körper der Mutter wirklich zu vollziehen, um damit jenen ungeteilten $\mathrm{Zu}$ stand zu bewahren, den der Philosoph in Erweiterung der slavophilen sobornost' (Konzılizıtät) an den Begriff der sofijnost' (Sophiezıdat) bindet.

Solov'evs religionsphilosophischer Diskurs rekurriert auf einem dualistischen Denken, in dem das Weibliche als Natur, Körper, Immanenz, Passivităt codiert und dem 'Männlichen', d.h. Gott als Verkörperung von Kultur, Geist, Transzendenz, Kreativität untergeordnet ist. Die synthetische Rekonstruktion der verlorengegangenen Einheit im philosophischen Wunschbild Solov'evs thematisiert damit genau jenen Moment des Eintritts in die Kultur, der sich in dem Verbot der Mutter äußert. Dieser ist bekanntermaßen gebunden an den Übertritt des Kindes aus der präödipalen Phase, aus der MutterKind-Dyade in die triadische Konstellation, den Eintritt in die symbolische Ordnung der Sprache, die durch das "Gesetz des Vates" gekennzeichnet ist. Das Konzept dieser Kunstreligion bzw. Religionskunst konzentriert sich also

16 Boris Groys, 1990, op.cit., S 349

17 Ebd 
auf jenen Vorgang, der im Freud-Lacanschen Diskurs die Entwicklung geschlechtlicher Identität meint: "Die präödipale Phase muß daher als vorgeschlechtlich gedacht werden. Sie geht jeglicher Identität voraus, auch der von Raum und Zeit." ${ }^{\prime 8}$ Allerdings fokussiert Solov'ev nicht den Prozeß der Bewußtwerdung, sondern genau den umgekehrten Prozeß der Unbewußtwerdung, der Ichauflösung im Mutterleib und damit eine Ablehnung einer eindeutig geschlechtlich festgelegten Identität. Diese Ich-Auflösung im Unbewußten ist Voraussetzung für die Wiedergeburt im Text, das, was Kristeva die semiotische chora nennt und was an eine archaische Mutterbeziehung geknüpft ist, die sich als "zweite" Rückkehr der Triebfunktionalität in der symbolischen Ordnung äußert: "[...] das Semiotische muß als Negativität definiert werden, die in das Symbolische eingeschleust wird und seine Ordnung verletzt."19

Der kunstreligiöse Prozeß der Ich-Auflösung des Religionsphilosophen im Text, sein Wunsch nach Wiedergeburt im mythischen Leib, außerhalb von Raum und Zeit als Ausdruck der Verneinung bzw. Verweigerung einer eindeutigen Geschlechtsidentität äußert sich in einer totalen Feminisierung der künstlerischen Projektion, die lust- und angstbesetzt ist zugleich. Phantasmen der Heilung bzw. Zerstückelung, wie sie in der himmlischen Sophia und ihrer Dekonstruktion im apokalyptischen Weib auftauchen, können als Ausdruck jener ambivalenten Wahmehmung des eigenen Selbst gelten, in denen sich der Versuch abzeichnet, die Fragilität der eigenen Ich-Identität in der Zer-

18 Sigrid Wcigel "Das Weibliche als Metapher des Metonymischen", in I Stephan/C Pietzker (Hgg.) Frauensprache und Frauenhteratur' Fur und Wider einer Psychoanalyse literarischer Werke, Tübıngen 1986, S. 108-118. S. 113

19 Julia Kristcva Die Revolution der poetischen Sprache, FrankfurdMain 1978. S 78 
stückelung eines anderen Subjekts abzuarbeiten und diese zu überwinden. Nach Lacan antizipiert das Kleinkind, das sich noch in einem Zustand der Ohnmacht befindet, imaginär die Beherrschung der Einheit des Körpers. Dieser Prozeß vollzieht sich über die Identifizierung mit dem Bild des Ähnliehen als einer totalen Gestalt: Die Identifizierung geschieht und aktualisiert sich in der konkreten Erfahrung, bei der das Kind sein eigenes Bild im Spiegel wahrnimmt. Das Ich, das in seinem (ersten) visuellen Abbild sich als Ganzheit imaginiert hatte, muß sich wieder der Fragilität dieser Einheit stellen. $^{20}$ Analog dazu ist der Selbsterlösungsproze $B$ im kunstreligiösen Modell Solov'evs zu sehen. In dem das andere Subjekt (die himmlische Sophia) als Ganzheit imaginiert wird, kann sich das eigene Subjekt (der Religionsphilosoph) wieder als ganzheitliches spiegeln bzw. erfahren. Dissoziiert sich dieser Prozeß der Selbsterlösung, erfährt auch die Projektion der Erlösergestalt eine Abwertung im Bild des zerstückelten, diabolischen Weibes.

Solov'evs Geschlechter-Ethik basiert auf einem Entdifferenzienungsgedanken, der männliches und weibliches im androgynen Ideal des dritten Geschlechts transzendiert. Dieser geht einher mit einer Mystifikation, denn sie rekurriert auf ein mystisches, d.h. außerirdisches, transzendentes Urerlebnis, das den Philosophen aus dem als Unheil empfundenen irdischen Dasein erlöst. Die Erlösung erfolgt über die Vereinnahmung der Ewıgen Weıblıchkent bzw. über die Feminisierung des Mannes und ist notwendige Voraussetzung für dessen schöpferisches Potential. In diesem Sinne ersetzt der Text die

20 Jacques Lacan "Das Spiegelstadium als Bildner der Ichfunktıon", in: Schrifien Band I. Freiburg 1973, S. 61-71 
körperliche Vereinigung. Er vereinigt den vergöttlichten Helden mit der Muttergöttin und dem Gottvater, denn die Vergöttlichung des Helden kündigt die Rückkehr des in einen Gott verwandelten Urvaters an. ${ }^{21}$ Die Fiktion dieser totalen Verschmelzung des Körpers im Text wird zum Zeichen für Zeitlosigkeit, Transzendenz, Autorschaft. Solov'evs Ethikkonzept beruht damit auf der Vorstellung eines Logos, der durch das virtuell zweigeschlechtliche und damit in letzter Konsequenz geschlechtslose Wort symbolisiert wird, das die Libido auf die künstlerische Phantasie umleitet. Dieser Prozeß entspricht den immer wieder neu ansetzenden Versuchen dessen, was Inge Stephan "Retotalisierung des männlichen Körpers als weibliches Fleisch nennt." 22 Er betrifft nicht nur den Bereich der imaginierten Frauenfiguren, also den Bereich der Frauenbilder im weitesten Sinne, sondern sie berührt das Verhältnis des Autors zur Sprache insgesamt."23 Dementsprechend könnte man Solov'evs Schreiben als Versuch deuten, sich "Weiblichkeit" anzu-

21 Freud beschreibt diesen Zusammenhang in Massenpsychologie und lch-Analyse "Damals mag die sehnsuchtige Entbchrung einen Einzelnen dazu bewogen haben. sich von der Masse loszulosen und sich in die Rolle des Vaters zu versetzen Wer dies tat war der erste epische Dichter, der Fortschrit wurde in seiner Phantasie vollzogen Der Dichter log die Wirklichkeit um im Sinne seiner Sehnsucht Er erfand den heroischen Mythos. Heros war, wer allein den Vater erschlagen hatte. der im Mythos noch als totemistusches Ungeheuer erschien Wie der Vater das erste Ideal des Knaben gewesen war, so schuf jetzt der Dichter im Heros. der den Vater ersetzen will. das erste Ichideal [ . I Der Mythos ist also der erste Schritt. mit dem der einzelne aus der Massenpsychologie austrita | | Der Dichter, der diesen Schritt getan und sich so in der Phantasic von der Masse gelost hatte, weiß nach einer weiteren Bemerkung von Rank doch in der Wirklichkeit zu ihr zu finden Denn er geht hin und erzahlt dieser Masse die Taten seines Helden. die er erfunden hat Dieser Held ist im Grunde keın anderer als er selbst Er senkt sich somit zur Realitat herab und hebt seine Hörer zur Phantasie empor Die Horer aber verstehen den Dichter, sie konnen sich auf Grund der namlichen schnsuchtigen Bezchung zum Unater mit dem Heros identifizieren". in Sigmund Frcud. Studienausgabe XIII, [Frankfurt 1969-1979] Frankfurt 1982. S 152ff

22 Inge Stephan "Die Musen gehoren zu den himmlischen Gestalten. die Mann und Weib nicht kennen" Zur Androgynitatsauffassung in Kunst und Wissenschaft. in. Frauensprache und FranenIteratur? Fur und Wider einer Psychoanalyse Iterarischer Werke, S 119-126. S 125

23 Ebd 
eignen, sie gleichzeitig aber auch zu fürchten: Die Wiederkehr der Ewigen Weıblichkelt steht synonym für den weiblichen Körper der Mutter, der die Züge des Vaters trägt. Das Ergebnis dessen, was Hansen-Löve den neurotischen Typus des Symbolismus nennt, lebt genau aus diesem Paradox. ${ }^{24}$

In der feministischen Theorie wird heute ebenso das Nahen oder die Ankündigung einer anderen Parusie des Göttlichen, wie sie im Mittelpunkt der gnostischen Kunstreligion steht, die Vladimir Solov'ev an der Idee der AllEinhelt und der Sophia als Körper Gottes ausarbeitet, diskutiert:

Das Ende einer Kultur wurde auch dem Tod Gottes entsprechen. Welchen Gottes? Des Gottes, der den transzendentalen Grundstein eines allein von einem Geschlecht gehaltenen Diskurses bildet, einer von einem Geschlecht bestimmten Wahrheit? Das konnte die Ruckkehr eines Gottlichen, eines Gottes ermoglichen [.. ] Die Rufe oder die Außerungen der letzzen Philosophen Nietzsche, Heidegger, in bezug auf den "Tod Gottes" sind Rufe nach einem Kommen oder einer Ruckkehr des Gottlichen im Fest, in der Gnade, in der Liebe, im Denken. Im Gegensatz zur ublichen Interpretation besagen sie nicht das Verschwinden der Gotter, sondern das Nahen oder die Ankundigung einer anderen Parusie des Gottlichen Das setz die Umgestaltung der Welt des Diskurses voraus den Anbruch einer neuen Epoche der Geschichte, des Universums Das Ende der Zeiten und Zugang zu einer anderen Zeit, einem anderen Zeitraum ${ }^{25}$

Solov'ev und Irigaray ist gemeinsam, daß sie angesichts einer zu erwartenden Apokalypse eine neue Ethik der Geschlechter-Differenz ausarbeiten, die eine dritte Ära ermöglicht. Sie führen eine die göttliche Trinität erweiternde, weibliche Hypostase ein, um die Dualität Vater-Sohn aufzubrechen und eine Gleichberechtigung des Weiblichen zu erreichen. Beide favorisieren die Parusie der Ewıgen Weıblıchkelt gegenüber der Parusie Christi als Voraussetzung der Verwirklichung einer vergöttlichten Utopie: der dritten Ära des Okzidents als Zeitalter des Geistes und der Braut, des Paares im Falle Irigarays, des (jottmenschen im Falle Solov'evs. Beiden philosophischen

$24 \mathrm{Vgl} \mathrm{Aage} \mathrm{A} \mathrm{Hansen-Love} \mathrm{"Zur} \mathrm{psychopoctischen} \mathrm{Typologic",} \mathrm{op} \mathrm{eit.} \mathrm{S} \mathrm{195-288}$ 
Diskursen ist eine Mystifikation der Geschlechter-Differenz gemeinsam, die sich als Idealisierung des Weiblichen, als positive Theorie von Weiblichkeit niederschlägt. Im Falle Irigarays erfolgt diese Mystifikation aber unter Berufung auf eine neue Differenz "die als erste ernsthafte historische Bedrohung für die Hegemonie des männlichen Geschlechts anzusehen wäre"26, während sie bei Solov'ev von der Aneignung des Weiblichen als Überwindung von Differenz zeugt.

25 Luce Irigaray Die tihik der sexuellen Differenz. FrankfurdMaın 1991. S 167

26 Naomı Schor "Dieser Essentualismus, der keıner ist Irigaray begreıfen", in Dekonsiruktiver Feminismus, op cit., S 219-247, S. 230 


\title{
5. Eros pontifex:
}

\section{Zinaida Gippius' Metaphysik der Liebe}

\author{
Vex̌noženstvennoe \\ Moljus' i ljublju .. No malo \\ Ljubvi, molitv $k$ tebe \\ Tivom - woej ot nacala \\ Xocu prebyt' v sebe. \\ Ctob serdce tebe otvexalo - \\ Serdce - v sebe samom, \\ Ctob Nežnaja uznavala \\ Svoj cistyj obraz v nem. \\ I budut puti inye, \\ Inoj ljubvi pora \\ Sol'vejg, Tereza, Marija, \\ Nevesta - Mat' - Sestra! ${ }^{27}$
}

27 Zinaida Gippius Stichonorenija i Poemy, II (Collected Poetical Works, Vol II) 1918-1945, Hg von Temira Pachmus, in Slansche Propylaen, Munchen 1972, S. 11

\author{
Das Ewigweibliche \\ Ich betc und ich licbe, aber wenig \\ Licbc. Gebctc zu dir. \\ Der/dic Deınınge - von Anbegınn \\ Will ich unverandert bleiben in mir \\ Damit das Herz dir antwortet - \\ Das Herz - in mir sclbst. \\ Damit ich als Zartiche erkenne \\ Mein reines Bild in ihm \\ Und es werden neue Wege kommen. \\ Einer anderen Zeit Licbe. \\ Sol'vejg. Tereza. Maria. \\ Braut - Mutter - Schwester! \\ (Interlincarubersctzung von mir, DR )
}


In dem als Motto zu diesem Kapitel zitierten Gedicht Das Ewig Weibliche von 1908 preist die Religionssymbolistin und Literaturkritikerin Zinaida Gippius die erotisch-mystische Liebe als höchste Form der Sublimierung, die unter dem Terminus Verliebtheit, "einem nicht fleischlichen, spirituellen Konzept von Erotik" - Eingang in die Debatte um die Wiedergeburt der russischen Spiritualität fand. ${ }^{28}$ Gippius' erotisch-mystisches Liebeskonzept ist im Zusammenhang mit einem geschlechtslosen und lustvollen Androgynentum, einer ,keuschen Wollust“ zu sehen und basiert, wie in der Forschung bereits hingewiesen wurde, auf der "Erlösung vom Geschlechstdualismus und der spirituellen Restituierung einer uranfänglichen Ganzheit"29. Es geht aus von der Verwandlung des Geschlechts (preobraženie pola) durch die doppelte Inversion von mannwetblichem (mužeženskoe) und weibmännlichem (ženemužskoe), die als wahres Geschlecht, als drittes Geschlecht (tretij pol) bzw. "Unisex" ${ }^{30}$ - Vladimir Solov'evs Theorie der All-Einheit weiterentwickelt: Eros pontifex, der priesterliche Eros.

$28 \mathrm{Vgl}$ Erika Greber "Mystik und Lyrik Zinaida Gippius", in Wiener Slawistischer Almanach, Sondertand 41, Wien 1996, S. 147-171, S 153. Wie Greber herausgearbeitet hat, steht Gippius' crousch-mysusche Liebesvorstellung in der Tradition von Bohmes Sophiakonzept (vgl. die Androgynısıcnung des Ewig Weıblichen ("der/dic Deınıge von Anbeginn" in oben zitiertem Gedicht) und in der Tradition der Frauenmystik (vgl die Anspielung auf "Sol'vejg, Teresa. Manja"). Bohme wird in der Genderforschung als Vorlaufer der heuugen feministischen Theologic betrachtet

29 Ebd S. 151

30 Olga Matuch "Zinaida Gippius and the Uniscx of Heavenly Existence". in Welt der Sloven, 19, S. 98-104. 
Im folgenden Kapitel werden zunächst die Hintergründe geschildert, die zur Entstehung der Religion des Dritten Testaments gefüht haben, um in einem nächsten Schritt Gippius' theoretische Schriften über die Liebe im Zusammenhang zur Sexualität und zur Mystik zu diskutieren. Danach wird die Frage untersucht, welche Bedeutung der Transvestismus bzw. das crossdressing für die Frau und für die Schriftstellerin Gippius hatte - ein Aspekt, der bisher in der Forschung weitgehend unbeachtet geblieben ist. ${ }^{31}$ Dabei wird auch der Bezug zum chlystovstvo dargelegt. Damit schließt sich die Frage an, welche Absichten und Möglichkeiten Gippius mit ihren zahlreichen Stilisierungen (z.B. als Kleopatra oder Madonna etc.) verfolgte. Schließlich wird ihre Ehe mit Dmitrij Merežkovskij als Realisierung der Theorie der doppelten Inversion von "mannweiblichem" und "weibmännlichem" Ideal und als Theatralisierung des Geschlechtsverhaltens innerhalb des symbolistischen žiznetvorð̌estvo vorgestellt.

Zinaida Gippius und Dmitrij Merežkovskij verbanden auf originelle Weise die Frage nach dem Platz - der "Leerstelle" des Weiblichen - in der Konfiguration der Geschlechter mit der Frage nach Gott und Religion. In der

31 Vgl. Greber, op.cit. 1996, S 153. Greber verweist auf den gendershifi in Gipplus Lyrik An 166 Gedichten hat sie herausgearbeitet daß Gippius entweder die neutrale oder die mannliche form des Sprechens bevorzuge. die ihr das anerkannte gender der Autorschaft verleihe, aber auch in vielen Gedichten auf die Position des Dazwischen zuruckgreife und damit auch die Diskursivitat von gender vorfuhre $\mathrm{Vgl}$ in diesem Zusammenhang auch A. Gove: "Gender as a Poctic Feature in the Verse of Zinaida Gipppius", in Amencan Coninbution to the Eigth Intemational Congress of Slovists, Zagreb, Ljubljana 1978, Vol.1: Isnguistics and Poetics, hg von H Bimbaum, Columbus, Ohio. S $379-407$ 
Realisierung des oben erwähnten Androgynitätskonzepts prägten sie in einer Art "Doppelkünstlerschaft" die Religion des Dritten Testaments. Diese "gnostische Kunstreligion" sollte die Weichen für eine Synthese von Christentum und Heidentum stellen und das historische Christentum reformieren, das den Geist auf Kosten des Körpers unterdrückt, das geistige Prinzip als das reine, gute, heilige und göttliche über das körperliche Prinzip als das unreine, sündige und dämonische stellt. Die Konzeption des heiligen Fleisches (svjataja plot'), die Fleisch und Geist (dušetelesnost') in sich vereinigt, wurde von Gippius und Merezkovskij als Alternative zum Asketismus des historischen Christentums gedacht. Alle diese Faktoren zusammen mit der Reformierung der Kirche sollten das Fundament legen für den Beginn einer neuen Ära, des Königreiches Gottes auf Erden, des Dritten Testamentes (Tretij Zavet) und verweisen auf die mystischen Ursprünge dieser Kunstreligion: "Das Programm dieser "apokalyptischen" Kirche der zweiten Wiederkunft Christi und des sogenannten "Dritten Testamensts" druckte Merezkovskij auch in der Lichtmetaphorik der mystischen Vereinigung aus: wie zwei elektrische Drähte sollten sich die heidnisch-hellenische Konzeption der Heiligkeit des Fleisches und die christliche Konzeption der Heiligkeit des Geistes verbinden zu einer neuen Ökumene.."32

In ihrer St. Petersburger Wohnung führte Gippius einen literarischen Salon, in der diese Fragen zur Wiedergeburt der russischen Spiritualität und zur Sexualität diskutiert wurden. Die russische intelligencija ${ }^{33}$ ging dort ein

32 Greber, 1996. op cit. S 154. Siche in diesem Zusammenhang auch Olga Matıch Paradox in the Religious Poetry of Zınaida Gippius, Munchen 1972, S 20ff, sowie "The Cause" Hippius Religious Vicws and Activities, in. Temira Pachmuss Zinaida Gippius An Intellecrual Profile. London. Amsterdam 1971, S 103-166

33 Gipplus charakterisin die nussische intelligencija in Bezug auf Rußland in der Geschichte ihres 
und aus: "In diesem Haus machte man wirklich Kultur", schrieb Belyj, "alle haben dort einmal gelernt." ${ }^{34}$ Vertreter der hohen Geistlichkeit, Künstler, Schriftsteller, unter anderem auch die Religionsphilosophen Vladimir Rozanov und Nikolaj Berdjaev, schlossen sich der neuen Religion des Dritten Testamentes an. Im Jahre 1900 gründeten die Merezkovskijs zur Verbreitung ihrer Lehre die Relıgıös-Phılosophısche Gemeinschaft (relıgıozno-filozofskoe obšcestvo), deren sprachliches Organ die Zeitschrift Der neue Weg (Novyj put') war. ${ }^{35}$ Die Gemeinschaft traf sich regelmäßig von 1901 bis 1903 , bevor sie von der Synode verboten wurde. ${ }^{36}$ Engster Vertrauter in der Frage

Tagebuchs (gemeint sind die Petersburger Tagebucher von 1914-1919 [zuerst Munchen 1921] folgendermaßen "Korennyc Zitcli Peterburga, my prnadležali k tomu širokomu krugu russkoj "intelligencii", kotonuju spravedlivo ilı net, nazyvali "sovest'ju i razumom" Rossil Ona ze - 1 to uze konexno spravedlıvo - byla edinstvennym "slovom" i "golosom" Rossii, nemoj, pntajno-moleašcej - samoderžanno Poslc neudavšejsja revoljucu 1905 goda - neudavšejsja potomu, cto samoderzavic ostalos' - intelligencija esli ne usililas', to rasšinlas' Razdiraemaja unutrennymı nesoglasi-

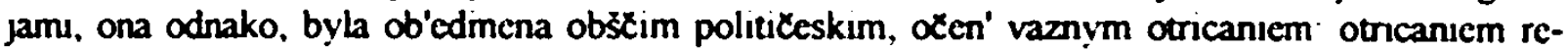
¿ıma Russkaja intelligencija. - cto klass ilı kng. ili sloj (vse slova ne tokny), kotorogo ne znact burbuazeno-demokraticeskaja Evropa, kak ne eszala ona samoderZavija. Sloj, po sravnenıju so vsej tolšej gromadnoj Rossu, $\propto$ 'en' tonkıj, no lıš' v nem soveršalas' koe-kakaja kul'tumaja rabota I on sygral svoju, ocen' ser'eznuju istonecskuju rol' (Als echte St.Petersburger gehorten wir zu jenem Kreis der nussischen "Intelligencija", dic man zurecht oder zu unrecht "Gewissen und Verstand" Rußlands nannte Sic war - und das ist naturlich gerechtferugt zu behaupten - das einzige "Wort" und die cinzige "Summe" des stummen, schweigenden, absolutistischen Rußlands Nach der mißgluckten Revolution von 1905, miBgluckt deswegen. weil sich der Absolutusmus halten konnte, hat sich die Intelligencija. wenn auch nicht verstarkt, so doch ausgedehnt Gespalten durch innere Unstummigkeiten. war sic trotz allem vereint in der allgemeinen polituschen, sehr wichtigen Verneinung der Verneinung des absolutustischen Regimes Die nussische Intelligencija, das ist eine Klasse. oder ein Kreis, oder cine Schicht (alle diese Worte sind nicht genau zutreffend), die das bourgeoise demokratische Europa nicht kennt, genauso wie es die Selbstherrschaft nicht kannte Diese Schicht ist im Vergleich zur nesigen Weite Rußlands sehr dunn, aber nur in ihr vollzog sich eine kulturelle Arbeit Und sie spielte thre sehr ernste historische Rolle), in Zivye lica . Sichi Dnemila (lebendige Gestalten. Gedichte. Tagebucher), Bd 1, Tiflis 1991, S 159-396, S 159

34 "V ctom dome voistınu tvonlı kul'turu Vse zdes' kogda-to uxilis'", in Andrej Belyj Arabeskı [zuerst Moskau 1911], in: Slavische Propylaen. Band 63, Munchen 1969, S 415

$35 \mathrm{Vgl}$ in diesem Zusammenhang I Scherter Die Pelersburger Religios-Phulosophischen Vereinigungen Die Entwicklung des religiosen Selbstverstandnisses ihrer Intelligencija-Mitglieder (I90)1917), Berlin 1973

$36 \mathrm{Vgl}$ Greber. 1996, op cit., S 154 
nach dem Verhältnis zwischen Gott und Geschlecht, des Wichtigsten (glavnoe), wie sie von Zinaida Gippius bezeichnet wurde, war Dmitrij Filosofov, der mit den Merezkovskijs von ungefähr 1905-1920 in einer ménage- $\dot{a}-$ trois lebte. ${ }^{37}$ Gippius sah den Erfolg ihres Unternehmens glavnoe im wesentlichen darin begründet, daß sie gemäß der Dreiheit der göttlichen Personen agierten und sie auf diese Weise substituierten. Ihre Treffen waren von Riten begleitet, die sie auf der Basis der Russisch-Orthodoxen Liturgie und kirchlichen Ritualen feierten: "The first such secret celebration of the Holy Eucharist took place in the Merezhkovskij apartment after Midnight [...] These agapes, which later included some of their followers, must be viewed as part of the turn-of-the-century religious experimentation reflected in the widespread interest in the occult, theosophy and anthroposophy, and various sectarian rituals." ${ }^{38}$

Im Laufe der Treffen innerhalb der Religıös-Phılosophischen Gemeinschaft entwickelte Gippius ihre Theorie von der "dreieinigen Struktur der Welt", in der die Ziffern eins, zwei und drei für die Einheit von Persönlichkeit, Sexualität und Gemeinschaft stehen. Gemäß dieser Theorie steht das Dritte für die Idee von der Konzılızı̈̈t (sobornost') ${ }^{39}$, die als Grundlage für die Religion des Iritten Testaments diente und sich als Weiterentwicklung der Solov'evschen All-Einheit interpretieren läßt:

37 Von seiner Seite wohl mehr ungewollt als gewollt Filosofov versuchte immer wieder, sich von Gippius' charısmatischem Einfluß zu losen, was ithm endlich in der Emıgration gelang Vgl. Temura Pachmuss. 1971, op cit , S 103-166

38 Olga Matich. 1972, op cit. S. 21

$41 \mathrm{Vgl}$ in dicsem Zusammenhang Alexander Etkund: Eros des Unmoglichen Die (jeschichse der Psychoanalyse in Rußland. Leipzig 1996. S 64f 
[...] moja idèe fixe byla "trojstvennoe ustrojstvo mira" Ja ne ponimala, kak možno ne ponimat' takuju javnuju, $\vee$ glaza brosajušcujusja vešc', takuju real'nuju pritom, otraŽennuju vsegda $i$ v našem myšlenii, vo vsech našich dejstvijach, bol'šich - do povsednevnych, $v$ našich Cuvstvach $i-v$ nas samich My togda tak i govorili 1,2,3. Ne simvolizeski, a konkretno, 1 - ne est' li edinstvo našej liđ̌nosti, našego ja? A naša ljubov' celovełeskaja k drugomu "ja", tak to oni ęti "ja", uže dva, a ne odin (priðem edinstvennost' každogo ne terjaetsja) I dalee - vychod vo množestvennost' (3), gde ne terjajutjsa v dolženstvovanii ni 1 , ni 2 . Vot za èto tri, za obš̌̌estvennuju ideju, u nas načlas' bor'ba s DS [.. ] Ja, v moich "naitijach" (inogda bespoleznych, besplodnych, dlja menja, bez nego, - vsegda) govorila emu Casto "Ty slušaeš', no ty izvne slušaeš', a ty êto prodkožno pojmi, togda i vozrałaj!" Tak vot, presledovavšuju menja ideju ob "odin dva - tri" on tak ponjal podkožno, iznutri, êto jasno ona, konę̌no i byla uže $v$ nem. esce ne dochodja poka do soznanija On dal ej vsju polnotu, preobrazil ee v samoj glubine serdca i uma, sdelav iz nee religioznuju ideju vsej svoej zizni i very - ideju Trojcy. prišestvija Inucha ı tret'ejo ('arsna, ili Zaveta Vse ego raboty poslednych desjatiletij imejut etu - i tol'ko etu - glavnuju podosnovu, glavnuju vedušcuju ideju

[ ..] meine idee fixe war die "dreieinige Struktur der Welt". Ich verstand nicht, warum man eine so offensichtliche, formlich ins Auge springende und vor allem eine so reale Sache nicht verstehen konnte, die sich schon immer in unserem Denken widergespiegelt hat, in allen unseren Taten, in den großen wie in den alltaglichen, in unseren Gefuhlen, wie in uns selbst Wir haben damals auch so gesprochen 1,2,3 Nicht symbolisch, sondern konkret, 1 - ist das nicht dic Einheit unserer Personlichkeit, unseres "Ichs"? Und unsere menschliche Liebe zu einem anderen "Ich", so daß diese beiden Ichs schon 2 sind. und nicht eins (obwohl die Einheit eines jeden sich nicht verliert) Und weiter - der Ausweg in die "Vielheit", wo sich weder 1 noch 2 in deren Schuldigkeit verlieren Wegen dieser drei, wegen dieser gemeinschaftlichen Idee begann der Streit zwischen mir und DS >Dmitrij Sergeevix, Gippius Ehemann, D R $<$ [ . . I Ich habe in vielen meiner "Eingebungen" (zuweilen nutzlosen, fruchtlosen fur mich, ohne ihn, immer) oft zu ihm "Du horst mir zwar zu, aber du horst von außen zu, aber dir soll es unter die Haut gehen, dann kannst du immer noch ablehnen'" Jedenfalls ging ihm die mich verfolgende Idee uber "eins - zwei - drei" unter die Haut, das ist klar sie war naturlich schon in ihm, es war ihm nur noch nicht bewußt Er gab ihr ihre ganze Fulle. formte sie um in der Tiefe seines Herzens und Verstands, machte daraus die religiose Idee seines Lebens und Glaubens - die Idee der Dreieinigkeit, der Parusie des Geistes und des dritten Konigreiches oder Testaments Alle seine Arbeiten der nachsten Jahrzehnte haben diese und nur diese Grundlage als fuhrende Idee ${ }^{40}$

40 Zinaida Gippius Dmirrj Merezkovskj] [zuerst Pans 1951]. in. Zivye lica Dnevnika (Ausgabe in in zweı Banden), Tıflıs 1991, Bd II, S 247 
Die Idee der Dreieinigkeit, der Parusie des heiligen Geistes und des Dritten Reiches bilden die Grundlage einer Kunstreligion, mit der die Merežkovskijs eine authentische Verbindung von Kirche und Gesellschaft anstrebten. Doch der elitäre Kreis der Religiös-Philosophischen Gemeinschafi hatte wenig Bezug zur vorrevolutionären russischen Alltagsrealität. Erst die gescheiterte $\mathrm{Re}-$ volution im Jahre 1905 gab den Anstoß zu einer politischen Auseinandersetzung innerhalb der Gemeinschaft. ${ }^{41}$ Von nun ab bemühte sich Gippius in ihre Idee von der dreigeteilten Struktur der Welt das soziale Element als das dritte gemeinschaftsstiftende Element einzubauen. Vor der Revolution hatte sie die Verbindung zwischen Gesellschaft und Religion, Mystizismus und Metaphysik konsequent abgelehnt. ${ }^{42}$ Trotz aller Bemühungen, neue Mitglieder für glavnoe zu gewinnen, scheiterte dieses Unternehmen, nicht zuletzt aus dem Grund der fanatischen Besessenheit, mit der Gippius die Religion des Dritten Testaments und der androgynen Liebe verwirklichen wollte. ${ }^{43}$ Schließlich setzte die Revolution von 1917 dem Traum von der geistigen Wiedergeburt Rußlands ein jähes Ende.

Gippius veröffentlichte ihre literaturkritischen Arbeiten zunächst unter männlichem Pseudonym: Anton Krajnij, Roman Arensky, Lev Pušcin, Genosse

41 Vgl Greber, op.cit, 1996, S 155 Greber macht darauf aufmerksam, daß die Aktuvitaten der Gemeinschaft den vormaligen Ichbezug uberschritten haben und nun gesellschaftsbezogen nach dem mystuschen Modell contemplano et actio agieren

42 Pachmuss. 1971, op.cit S. 124

43 Ebd S 149 
Herman. ${ }^{44}$ Der erste Aufsatz, der hier besprochen wird, wurde unter dem Titel Verlıebtheit 1908 in Sankt-Petersburg erstmalig veröffentlicht. Er behandelt das Thema der idealen sexuellen Vereinigung von Mann und Frau. Gippius bespricht zunächst Merežkovskijs Novyj Babylon (Das neue Babylon), ein Text der Rozanovs In der Welt des (Inklaren und Unentschiedenen (V mire nejasnogo ı nerešennogo) gewidmet ist. Rozanov wollte die Frage der Geschlechtsliebe mithilfe des Evangeliums und in der Anerkennung jenes absoluten Prinzips lösen, durch das Christus das Fleisch heilig gesprochen hat. ${ }^{45}$ Soweit stimmt Gippius mit Rozanov überein, den sie als "Prophet des Geschlechts" und "als genialen Verteidiger und Fürsprecher der Ehe" bezeichnet. Sie widerspricht ihm jedoch darin, daß Ehe und Familie die einzige Form der Realisieng der Geschlechtsliebe darstellen. Nach Gippius stellen Ehe und Familie keine metaphysische Lösung der Frage dar:

Brak (slityj nerazyyvno s detoroženiem) est' odna iz form real'nogo projavlenija pola možet byt' samaja glubokaja. polnaja i velikaja. no vse-taki - odna iz form. cast' pola 1 tol'ko uže rešiv vopros pola prinjatiem ego ("da"), možno na kakichlibo osnovanijach stojat' lið̌no i obš̌estvenno za etu imenno formu Bol'seju ze East'ju brak prinimalsja i prinimaetsja prosto kak pervyj, samyj estestvennyj i praktičskij žitejskij vychod, i "vopros pola", takim obrazom, vovse ne "myslitsja" kak vopros

44 Ebd S 305 Gippius begann thre literarische Kamere als dekadente Autorin 1898 in St Petersburg Siche in diescm Zusammenhang Aage A Hansen-Love Der Russische Symbolismus Sysiem und Entfaltung der Monve, Bd 1, Wien 1989, sowie ders "Zur Typologic des Ertabenen in der russischen Moderne. in Poenca 23. 1991, S 166-216 Alle folgenden Textzitate der Aufsatze „Vljublennost” (..Dic Verliebtheit”). [zuerst Sankt-Petersburg 1908], „O ljubvi“ (..Uber dic Licbe“), [zuerst Pans 1931]. .Anifmetıka ljubvi“" (.Dic Arıthmetik der Licbe"). [zuerst Paris 1931], „O zenach" (,Uber Ehefrauen“). [zuerst Pans 1925]. die in den Jahren von 1908 bis 1931 in verschiedenen Zeitschriften erschienen sınd. uurden der Ausgabe Russkj eros ili filosofija ljubviv Rossiy. Moskva 1991, S 174-215 entnommen

45 Alexander Etkınd,1996, op cit, S 54-59 "Dic Bande des Geschlechts au Goth sind grober als die der Vernunft. selbst als die des Gewissens au thm "Siche auch Johannes, 6, 63 "Wic kannst Du sagen, daß das Fleısch nicht nutzlich ist? Alles Fleısch ist durch den Geıst animiert Es ist der Geist. der das Leben gibt "

46 In „Vlublennost”. [zuerst 1908], 1991, op cit., S 175 
Die Ehe [untrennbar mit der Kinderzeugung verbunden] ist eine der realen Erscheinungsformen der Sexualitat, vielleicht die tiefste, vollste und großte, aber trotz allem - eine der Formen, ein Aspekt der Sexualitat. Und nur nachdem man die Frage der Sexualitat mit "ja" beantwortet hat, kann man auf irgendwelchen Gundlagen, personlichen oder gesellschaftlichen gerade auf dieser Form bestehen Großtenteils wurde und wird die Ehe aber einfach als erster und praktischster alltaglicher Ausweg gewahlt und dadurch ist die "Frage des Geschlechts" nie als Frage "gedacht" worden. ${ }^{46}$

Gippius' Geschlechter-Ethik stellt die traditionelle Ehe als praktizierte Form des Geschlechtsverhältnisses in Frage, weil dieses Konzept an die Fortpflanzung gekoppelt ist und deswegen keine wirkliche Lösung für die Klärung der Frage nach der idealen Vereinigung zwischen Mann und Frau darstellt. Voraussetzung ihrer Konzeption der Ehe ist eine "physische Verwandlung des Leibes": „Dlja togo, ctoby èta novaja tajna novogo braka byla najdena, nužno fizičeskoe preobrazovanie tela. “47 Sie entwirft ein Dreieck, das ihre Idee des sexuellen Aktes in der "heiligen Heirat" veranschaulicht. Es könnte folgendermaßen dargestellt werden:

\author{
Chrostus \\ Healige Heirat \\ Vertindung zu Goll \\ Ich = Mann Indische Heirat $D u=F r a u$
}

Die "heilige Heirat" löst den Dualismus von Körper und Geist auf. Sie basiert auf einer neuen Form der Liebe, einer Art Metaliebe, die Gippius als neue christliche Verliebtheit bezeichnet. Diese ist nur durch Jesus Christus erfahr-

47 Ebd S. 183 
bar, denn nur er hat im Bereich des Körperlichen dieses persönliche Gefühl bestätigt. Folglich kann man das Geheimnis, das der "Verwandlung des Leibes" zugrundeliegt, nur durch Christus erfahren:

Tak že kak mir, Bog, pravda, Žizn' nikogda nami ne mogut byt' poznanny, no liš vse bolee i bolee poznawaemy, tak ne uznaem my i etoj tajny Znanie est' konec, smert' ili porog bezvremen'ja inoj zizni, poznavanie - Zizn' mira dvizenie vo vremeni Christos put', istina i żizn', no snazala put', i ves' put' do konca, a zatem uže istina i żizn'. Esli my ponjali, cto vopros pola - takoj ze velikij i mirovoj, kak rjad drugich, kotorye vexno razrešajutsja i nikogda ne razzešeny, - pozemu on odin dolžen byt' rešen raz i navsegda?

Genauso wie die Welt, Gott, die Wahrheit kann das Leben niemals von uns erkannt werden, sondern kann nur mehr und mehr wahrgenommen werden, denn wir erkennen dieses Geheimnis nicht Wissen bedeutet Ende. Tod oder Ubergang in einen zeitlosen Zustand. Erkennen bedeutet Leben der Welt. Bewegung in der Zeit. Christus ist "Weg, Wahrheit, Leben", aber in erster Limie Weg und der ganze Weg bis zum Ende und dann kommt erst Wahrheit und Leben Wenn wir verstehen, daß die Frage des Geschlechts genauso groß und von Weltbedeutung ist, wie eine Reihe anderer Fragen, die man ewig entscheidet und nie entschieden hat, warum soll dann sie allein entschieden werden, einmal und fur alle Zeiten? ${ }^{48}$

Hierin zeigt sich Gippius' Nähe zur Brautmystik, die in ihrem Falle als "männliche Erlebensweise", aus der "Perpsektive einer maskulinen" persona erfolgt und auf die "Rollenverweigerung und Selbstbehauptung weiblichen Schreibens" hinweist. ${ }^{49}$ Wie Eva Meyer an der Geschichte der Mystikerinnen herausgearbeitet hat, steht die Stilisierung der Mystikerin als Jungfrau für eine Technik der Liebe, die zeigt, daß sich die erotische Vereinigung der Mystikerin mit Gott über das Wort vollzieht. ${ }^{50}$ Das Wort Gottes dringt in den Körper der Mystikerin ein, der dadurch verletzt wird. Die so entstandene Liebeswunde steht für den Liebesakt und verweist damit auf eine andere Lust-

48 In „Vlublennost““, op cit , S 183

$49 \mathrm{Vgl}$ Greber, 1996. op.cit . S. 153

50 Eva Meyer: "Schreiben aus Liebeswut. Mystik und Hysterie", in Frauensprache und FrauenIIteratur? Für und Wider einer Psychoanalyse literanscher Werke, Tubıngen 1986, S 11-17 
erfüllung: Die Mystikerin empfangt die Worte Gottes und trägt sie auf der Erde aus. Die Worte werden zu Fleisch, damit die Mystikerin Gott werden kann. Diese paradigmatische Verwechslung zwischen Wort und Körper zeigt, daß die Mystikerin eine Heilsgeschichte reinszeniert, die dem Körper Erlösung verspricht. Das Fleisch muß sterben, um eine Auferstehung in den Himmel nachvollziehen zu können. In diesem Prozeß richtet die Mystikerin ihr Begehren auf eine Idee von Gott als höchstes und unerreichbares Ideal und auf die Stellung Gottes, des "Vaters als Sprecher, Leser und Schreiber innerhalb des öffentlichen Diskurses, d.h. als Verwender der Zeichen im Gegensatz zum Zeichen- oder Tauschobjekt. " ${ }^{51}$ Gippius übernimmt dieses Konzept und überträgt es auf ihre Metaphysik der Liebe als Voraussetzung einer neuen geistigen Körperlichkeit, die im Kuß, das "heimlichem Zeichen" körperlicher Nähe und Vereinigung, ihre Erfüllung findet.

Genauso wie Solov'ev verneint Gippius den natürlichen Geburtsvorgang und zieht ihm den künstlichen der Textproduktion vor. Vergleicht man Gippius' Liebesdiskurs mit Solov'evs, so lassen sich folgende Gemeinsamkeiten feststellen: Solov'evs Auffassung von der Liebe als metaphysischer Liebe jenseits von Zeit und Tod, von der existierenden organischen Einheit von Geist und Fleisch und von der sexuellen Liebe als einer körperlichgeistigen Erfahrung, die zwei Menschen zu einer idealen und absoluten Persönlichkeit vereinigen kann, bestimmen auch Gippius Konzept. Im ersten Teil des Aufsatzes Ïber dıe Lıcbe, 1925 in Paris erschienen, arbeitet Gippius an den Parallelen von Solov'evs Konzept der All-Einheit und Otto Weiningers in (jeschlecht und (harakter entwickelten Vereinigungstheorie eine Ge-

51 Judith Butler, 1991, op.cit. S. 85 
schlechter-Ethik aus, die als "Die Liebe und der Gedanke" bezeichnet wird und "eine doppelte Brücke zwischen zwei Menschen schlagen soll: von der Männlickeit eines menschlichen Wesens zur Weiblichkeit eines anderen und von der Weiblichkeit zur Männlichkeit eines nächsten. ${ }^{52}$ Gippius folgt Solov'ev und Weininger - wenn sie in einer ersten Stufe die Grenzen der Geschlechter zu flexibilisieren und zu transzendieren scheint, sie in einer zweiten Stufe aber erneut in einem "Idealmann" und einer "Idealfrau" fixiert ${ }^{53}$, deren doppeltgeschlechtliche Persönlichkeit und vergeistigte Körperlichkeit die Voraussetzung ihrer Idee von der idealen, der körperlich-geistigen Liebe bildet. Gippius nennt sie „Eros pontifex“ (,priesterliche Geschlechtsliebe“). Diese Liebe hebt die Gespaltenheit von Mann und Frau auf.

Im zweiten Teil ihres Aufsatzes Üher die Liebe mit dem Titel "Die Liebe und die Schönheit" entwickelt Gippius am Beispiel der Liebeskonzeptionen von Dante, Goethe, Ibsen, Gogol', Dostoevskij, Tolstoj, Bunin eine Geschlechts-Ästhetik, der sie Soluv'evs Vorstellung von "der Schöheit als wahmehmbare Form des Guten und der Wahrheit" zugrundelegt: Solovev nannt das "ästhetisch Schöne" jede wahrnehmbare Darstellung eines Gegenstands oder einer Erscheinung aus der Perspektive ihres endgültigen Zustands oder im Licht einer zukünftigen Welt. Mit anderen Worten - schön ist jenes künstlerische Werk, daß zur realen Verbesserung der Wirklichkeit führt. ${ }^{54}$

52 Zinaida Gippius "O ljubvi (I Ljubov' i mysl', II Ljubov' i krasota)", [zucrst 1925]. 1991, S 193. "Eros [. I strolt dvojnoj most mezdu dvumja: o muzestvennostı odnogo relovečeskogo sušcestva $k$ Ženstvennosu drugogo 1 ot Ženstvennosti - $k$ muŽestvennosti vtorogo "

53 Ulla Link-Heer "Wird Androgyne normal? Zur Entfaltung ımaginierter Geschlechtlichkeıt zwischen zwei fins de siócles", in KultuRRewolution, $\mathrm{Nr} 27,1992, \mathrm{~S} 49$

54 Ebd. S 194 "| | Krasota - liš' oscututıelnaja forma Dobra i Istıny", i , esteuceskı prekrasnym 'on

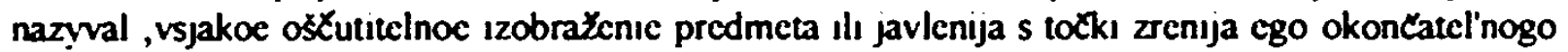
sostojanıja ıli v svete buduš̌ego mıra' Iną̌c govorja - prekrasno to chudožestvennoc proızvedenie. 
Gippius unterteilt diese Geschlechts-Ästhetik in drei Kategorien: 1. Darstellung der Liebe, wie sie existiert (Bunin) 2. Darstellung der Liebe, wie sie sein soll (Ibsen, Solv'ev) und 3. Darstellung der Liebe, wie sie existiert und wie sie sein soll (Goethe, Dostoevskij, Tolstoj, Bunin). Ibsens Liebeskonzeption kommt nach Gippius der idealisierten Liebe, wie sie Solov'ev vertritt, am nächsten, denn sie beruht auf der mystischen Vereinigung von Mann und Frau in einer neuen geheimnisvollen Ehe. Gogol' und Dostoevskij kommen Solov'ev auch nahe, da sie eine geistıge Körperlıchkeıt der Liebe (duchovnotelesnost' ljubvi) ${ }^{55}$ anstreben. Allerdings ist beiden die Vorstellung der Androgynie fremd. Tol'stoj kennt nur die diabolische und engelsgleiche Vorstellung von der Liebe. Bunins Erzählung Mitjas Liebe, der Gippius eine ausführliche Analyse widmet, rechnet sie zur real existierenden Liebe. Da sie sexuell vollzogen wird, endet sie immer tödlich. Gippius resümiert ihre Geschlechter-Ethik und Geschlechts-Ästhetik mit Solov'ev: "Der Sieg des ewigen Lebens - das ist der endgültige Sinn des Weltalls. Der Inhalt dieses Lebens ist die innere Einheit von allem oder die Liebe; ihre Form - die Schönheit, ihre Bedingung - die Freiheit." ${ }^{56}$ Damit wird die Kunst zur Verkörperung des Symbols im Fleisch, die metaphysische Definitionen dieser theurgischen Praxis unterordnet. ${ }^{57}$

In dem Aufsatz Die Arıhmetık der Liebe - Theorie, Wahrscheinlichkeit und Kombinatorik der Liebe - diskutient Gippius die persönliche Liebe als

kotoroe ,vedet k rcal'nomu uluščnıju dejstvitcl'nosti ${ }^{\cdots \cdots}$

55 Ebd S 197.

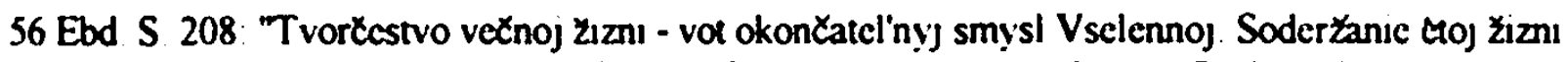
est' vnutrennec edinstvo vsego, ili Ljubov': ec forma - Krasota ee uslovic - Svoboda "

$57 \mathrm{Vgl}_{\mathrm{g}}$ in diesem Zusammenhang Andrej Belyj "Simvolızm", op cit. S 94/95 
Brücke zwischen zwei Persönlichkeiten und über die Grundlagen der Liebe als Grundlage der Persönlichkeit. Die ersten Grundlagen der Persönlichkeit sind "absolute Einmaligkeit, Unwiederholbarkeit, Potenz des absoluten Seins (der Ewigkeit)" 58 . Nach Solov'ev begreift Gippius den Eros, "als Wehen einer nichthiesigen Freude" ("vejanie nezdešnej radosti"). Wahre Liebe ist genau wie der Mensch immer "geistig-körperlich" ("duchovno-telesna") und jenseitig. Gippius geht von einer ursprünglichen Bisexualität des Menschen aus.

Sie entwirft eine Geschlechter-Ethik, die eine reziproke Geschlechtsrolleninversion impliziert:

[...] korennoe svojstvo Celoveka - androginizm [ . ] Živoe dušetelesnoe Celoveð̌eskoe suš̌estvo, real'nyj Zelovek, nikogda ne byvaet tol'ko muscinoj ili tol'ko Ženక̌̌inoj. Oba nacala, mužskoe i Ženskoe (M i Ž po Veijningeru), $v$ nem soprisutstvujut. No neobchodimo utverdit' i sledujušcee. ¿to ja osobenno podXerkivaju: $v$ kazdom real'nom Celoveke kotoroe-nibud' odno iz dvuch nacal, $\mathbf{M}$ ili Ž.,- preoblodaet Celovek takim obrazom, suš̌estvo ili mužeženskoe ili Ženomuzskos, priðem samo složenie dvuch natal v každom - ližno, to est' kak ližnosti edinstvenno i nepovtorimo Vo vsem etom, vmeste vzjatom, i zakljuðena potencija lið̌noj ljubvi. Dejstvitel'no bud' ljudi nositeljami ochnogo naČala, eti - mužskogo, te-Ženskogo, to každoe takoe cel'noe $M$ ravno vleklos' by $\mathrm{k}$ kazdoj poljarno protivopoložnoj cel'nostı - Zे (i obratno)

[ ...] Das ursprüngliche Merkmal des Menschen ist die Androgymtat [ ] das lebendige seelisch-korperliche Wesen, der Mensch ist niemals nur Mann oder nur Frau. Beide Prinzipien, das mannliche und das weibliche (nach Weininger $M$ und $W$.), koexistieren in ihm Aber man muß folgendes betonen: in jedem realen Menschen uberwiegt eines der beiden Prinzipien. Auf diese Weise ist das menschliche Wesen entweder mannweiblich oder weibmannhch, wobei die Verbindung der beiden Prinzipien in jedem personlich, das heißt in jeder Personlichkeit einmalig und nicht wiederholbar ist In allem zusammengenommen liegt die Potenz der personlichen Liebe begrundet Welches Prinzip der Mensch nun verkorpert, das mannliche oder das weibliche, es vereinigt sich doch jedes ganze $M$ mit jedem gegenuberliegenden ganzen $Z$ in seiner Ganzheit und umgekehs.

58 Guppius: "Arıfmetuka ljubvi" |zuerst Pans 1931], 1991, op cit., S 208 "Pervoosnoṿ liěnostu takie: absoljumaja edinstvennost'. nepovtorjaemost' i potencija absoljutnogo bytija (vocnosti)."

59 Ebd. S. $210 \mathrm{f}$ 
Gippius' Liebeskonzept bedeutet, daß bereits Androgyne, nämlich Mannweib und Weibmann, sich platonisch lieben und somit das Begehren begehren (statt das Begehren des Anderen Begehrens) ${ }^{60}$ :

[ ..] edinstvennoe "ty" [ ..] Ono, dlja suščestva mužestvennogo, budet drugim sušCestvom, v sootvetsvenno obratnoj mere ctvojnym Zenomužskm. No imenno v sootvetstuenno obratnoj mere. Ctoby ponjat' elu obratnost', predstavim sebe Celoveka v vide vos'merki Dve petli, $M$ i $Z$., nepremenno nerannye (preobladanie) Esli položit' vos'merka na rebro (kstati, ležacaja vos'merka v matematike - simvol beskonęnosti), to petlja M., mužskaja, budet pravoj, petlja Ž, Zenskaja, - levoj Poprobuem teper' vzgljanut' na otraženie etoj vos'merki $\vee$ zerkale. My uvidim druguju, soveršenno podobnuju, s petljami v toj Že mere meravnymi. Tol'ko pravaja u otražennoj vos'merka budet levoj, levaja - pravoj Obe petli obeich vos'merok sovpadajut no levaja każdoj s pravoj kazdoj Muzskaja kazdoj - s Ženskoj každoj Eti i est' sootvetstvennaja obratnost'

[ ..] das einzige "Du" fur ein mannliches Geschopf wird ein anderes Geschopf sein, das inm umgekehrt doppelt weibmannlich entspricht Aber genau in der entsprechend umgekehrien Form. Um diese Umkehrung zu verstehen, stellen wir uns einen Menschen in der Form einer Acht vor. Zwei Schlaufen, $M$ und $W$., unbedingt ungleiche (überwiegend) Wenn wir die Acht kippen (übrigens ist die liegende Acht in der Mathematik das Symbol fur Unendlichkeit), so ist die rechte Schlaufe M., mannlich, die linke Schlaufe W., weiblich Versuchen wir nun auf die Widerspiegelung dieser Acht im Spiegel zu schauen Wir sehen eine andere, vollkommen gleiche, mit ungleichen Schlaufen Nur die rechte Schlaufe der widergespiegelten Acht wird links sein, die jeweils linke rechts Beide Schlaufen der beiden Acht sind identisch die linke mit der jeweils rechten Die jeweils mannliche mit der mit der weiblichen Das ist die entsprechende Umkehrung. ${ }^{61}$

Die "umgekehrte Spiegelung" ("zerkal'naja obratnost"), die Gippius hier einführt, akzentuiert die narzißtische Selbstgenügsamkeit der androgynen Liebe, deren keusche Wollust sich als geschlechtliche >Identitätslust $<$ der Transsexualität konkretisiert. ${ }^{62}$ Die homosexuelle Liebe lehnt Gippius ab, da sie die

60 Annette Runte Biographische Operationen Diskurse der Transsexualistat, Munchen 1996, S 690

61 „Anfmetika ljubvi“, op cit.. S 211 If

62 Runtc. 1996, op cit. S 690 
Androgynităt eines Menschen und dadurch seine Persönlichkeit auslöscht. Aber auch, weil der Eros hier nur auf die "irdische Freude" gerichtet ist. Nur in der Kunst strebt der Mensch danach, das Bild der vollkommenen Liebe das heißt im Wortschatz der Gippius die göttliche Liebe - zu erschaffen. Hier endet Die Arthmetık der Liebe. Gippius stellt es signifikanterweise der $\mathrm{Zu}$ kunft anheim, die Frage nach der Erfüllung der Liebe (ispolnenija ljubvi) nach Solov'ev "die endgültigen Ziele der Liebe" - zu stellen. ${ }^{63}$

Resümierend könnte man Gippius' Metaphysik der Liebe als androgynales Phantasma bezeichnen, in dem transsexuelle Phantasien ausgelebt werden, denn die sogenannte ,priesterliche Geschlechtsliebe“, "Eros pontifex" - als Voraussetzung der Begegnung von "Mannfrau und Fraumann" - realisiert sich im Begehren des Begehrens und offenbart letztendlich die Phobie und die Flucht vor gegengeschlechtlicher Liebe. Sie ist gekoppelt an eine psychophysische Entdifferenzierung, d.h. die Feminisienung des Weiblichen beim Mann und der Verschleierung des Weiblichen bei der Frau und basiert damit auf einer autoerotischen Triebstruktur, denn der androgyne Mensch ist eine geschlossene Ganzheit, er ist zweigeschlechtlich und braucht das andere Geschlecht nicht mehr: "Der Androgyne liebt nicht, er erblickt sich in einem anderen Androgynen, um sich selbst zu sehen, rund, glatt ohne anderen. Als Verschmelzung an sich kann er nicht einmal verschmelzen: Er ist von seinem eigenen Bild fasziniert. ${ }^{\prime 64}$ Der androgyne Mensch, mit dem Gippius Rußland retten wollte, kann aber nicht "als Frau verkleideter Phallus", der die Differenz ignoriert und damit die hinterlistigste Maskerade für die Liquidierung

63 ..Arifmetuka ljubvi“, op cit., S. 215

64 Julia Kristcva Geschichien von der (sebe (Histoires d'amour), FrankfurtMain 1989, 572 
der Weiblichkeit" darstellt, sondern kann als Geschlechter-Ethik gelesen werden, die in der Verdoppelung des Weiblichen und Männlichen liegt. ${ }^{65}$ Sie basiert auf einer Liebessemantik, die auf der All-Einhelt aufbaut und die physische Seite der Liebe ausspart.

Die von Gippius vertretene Theorie des dritten Geschlechts als Grundlage der Religion des Dritten Testaments ist damit als Resultat des Zweifels an binärem Denken zu betrachten. In der oben dargestellten "dreieinigen Struktur der Welt" führt Gippius das Dritte ein, das niemals fixiert werden kann und folglich keine feste Gestalt annehmen kann:

Centr ee, sušžnost' korennogo mirosozercanija, $k$ kotoromu privel menja posledovatel'nyj put', - nevyrazyma "tol'ko v slovach". SchematiCeski, otCasti simvoliCeski, suš̌n nost' eta predstavljaetsja v vide vseob"emljušCego mirovogo Treugol'nika, v vide postojannogo soprisutstvija trech $\mathrm{NaCal}$, nerazdelimych i neslijannych, vsegda trech - $\mathrm{i}$ vsegda sostavljajuštich Odno (Autobiographische Bemerkung von 1914)

Das Zentrum, das Wesentliche der grundlegenden Weltanschauung, zu der mich ein konsequenter Weg führte, ist in 'bloßen Worten' nicht auszudrucken In schematischer, teils symbolischer Form prasentier sich dieses Wesentliche in Gestalt eines allumfassenden Welt-DREIECKS, in Gestalt standiger Koprasenz dreier PRINZIPIEN, untrennbar und unverschmolzen, immer drei - und immer EINES bildend. ${ }^{66}$

Der Dritte agiert immer auf einer theatralischen Metaebene und kommentiert dadurch seine eigene Position. Wie im folgenden dargestellt wird, agiert Gippius auf dieser theatralischen Metaebene, die man als paradigmatisch für das Geschlechtsverhalten innerhalb des symbolistischten Zirkels beschreiben kann.

65 Ebd S 73

66 Zit nach Grebcr, 1996, op cit. S 150 
Viele ihrer literaturkritischen Texte veröffentlichte Gippius unter männlichem Pseudonym, ein ,gender-shifi, der ihr weibliches Geschlecht vergessen macht und ihr textuell das anerkannte gender der Autorschaft verleiht." ${ }^{67}$ Indem sie den "Status der Frau-als-Zeichen" aufgab und in der "Sprache als Subjekt" ${ }^{68}$ auftrat, konnte sie in dieser Zeit ihre Gedanken über Sexualität und Liebe aussprechen. Aber nicht nur hinter der männlichen Schreibmaske probiert Gippius die Wirkung der Männlichkeit, sie trug auch Männerkleidung. Dieses Phänomen des Transvestismus bzw. cross-dressing wurde in der Genderforschung als Verwirklichung einer als Utopie wahrgenommenen Machtposition für Frauen dargestellt, die sich in der Vorstellung eines drıtten (jeschlechts als Möglichkeit der Frau, Ängste zu bekämpfen und Macht zu gewinnen, manifestiert. ${ }^{69}$ Transvestismus kann aber auch, wic Garber in ihrer Studie deutlich gemacht hat, auf homoerotische Weise nur den Mann ansprechen. In diesem Fall verschwindet die Frau vollkommen. ${ }^{70}$ Die Bedeutung des Transvestismus für Gippius scheint in der Subversion fixierter Definitionen von Geschlechtsidentität und in der parodistischen Form normabweichender Sexualität zu liegen. Das Phänomen des Transvestismus zeigt damit die kulturelle Gemachtheit von Geschlechtskategorien

67 Greber, 1996, op cit., S 152.

68 Judith Butler Das Unbehagen der (jeschlechter, Frankfurt/Main 1991, S 85

69 Vgl Sandra M Gilbert und Susan Gubar "Cross-Dressing and Rc-Dressing Transvestusm as Metaphor", in No Man's Land The Place of Women Writer in the Twenneth Century, Vol.II, Sexchanges, New Haven 1988, S 324-376

70 Majone Garber Vested Interests Cross-Dressing and ('ultural Anxoety, New York 1993, S. 10. 
auf. In dem er eine Kategorienkrise heraufbeschwört, subvertiert der Transvestismus die binäre Unterscheidung in männlich und weiblich: "Transvestism is a space of possibility structuring and confounding culture: the disruptive element that intervenes, not just a category crisis of male and female, but the crisis of category itself."

Das kulturstrukturierende und -begründende Element des Transvestismus in Zusammenhang mit Gippius' Theorie des Dritten Geschlechts zu stellen, erfolgt aus der Tatsache, daß gerade im Rußland der Jahrhundertwende die vorherrschende Sexualmoral infragegestellt wurde. Nicht umsonst hatten die Sekten einen so großen Zulauf, denn sie ermöglichten eine andere Ausübung

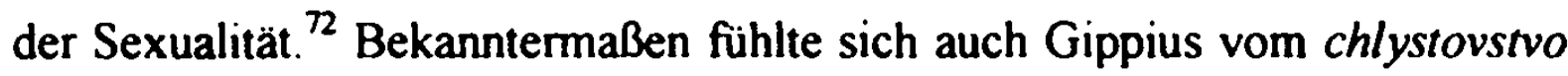
angezogen. ${ }^{73}$ Interessant ist in diesem Zusammenhang die Tatsache, daß der Transsexualismus (also die Verlagerung der Geschlechterzuordnung) innerhalb der russischen Sekten letztendlich auf die Doppelung der Geschlechtsidentităt verweist, genauso wie es das Phänomen des Transvestismus der Fall ist. Der Transvestit verweist dabei immer auf die Gemachtheit seiner eigenen Rolle. Dieses Mimikryverhalten ist auch paradigmatisch für das chlystovst$v o^{74}$, das sich im Falle der Gippius als "Chlystin" darin äußert, daß sie neben der Stilisienung einer männlichen Position geradezu eine Weiblichkeit

71 Ebd S 17 (Hervorhebung der Verfasserin)

$72 \mathrm{Vgl}$. Alexander Etkind. 1996. op.cit, S. 65

$73 \mathrm{Vgl}$. Dönng-Smirnov. "Sektanstvo i Literatura Sercbrjanyj golub' Andreja Belogo", in (hristianity and the Eastern Slaves, Vol 2.. Russian Culture in Modem Times. Ed Robert P Hughes and Irina Paperno. Berkeley, Los Angeles. 1994, S. 194-200. S 199. Filosofov ging sogar soweit zu behaupten. Gippius' erousch-mystische Liebeskonzeption sei schieres chlystovsivo

74 Aage A Hansen-Love "Allgemeine Haretik, russische Sekten und ihre Literansierung in der Modeme", in Wiener Slawistischer Almanach. Sonderband 41. Wien 1996. S 171-295 
betonte, die bei ihr gar nicht vorhanden war. ${ }^{75}$ Diese Maskerade der eigenen Geschlechtsidentität verdankte sie die Beinamen "Zinaida prekrasnaja" ("Die schöne Zinaida"), "Belaja D'javolica" ("Weiße Teufelin"), "dekadentnaja madonna" ("dekadente Madonna") und zahlreiche andere. ${ }^{76}$ Um die Komplexität des Geschlechtsverhaltens der virtuell androgynen Gippius beschreiben zu können, ist die unterschiedliche Wertung des Begriffs Maskerade aufschlußreich, die Butler aufgezeigt hat. ${ }^{n}$ Bei Lacan ist Maskerade dadurch gekennzeichnet, daß die Frauen den Schein, der Phallus zu sein, innerhalb der Komödie der Heterosexualität gezwungenermaßen inszenieren, während Rivière den Begriff der Weiblichkeit als Maskerade einfühn, um zu zeigen, daß (homosexuelle) Frauen eine weibliche Maske aufsetzen, um ihre Männlichkeit zu verschleiern. Nimmt man im vorliegenden Fall Rivières Interpretation der Maskerade als Angst vor der eigenen Männlichkeit an, so offenbart Gippius' transvestitische Mimikry den Wunsch, die Grenzen des eigenen Geschlechts aufzulosen, sie zu transzendieren, sich das andere Geschlecht einzuverleiben. Darauf deuten mehrere Faktoren. Die Tatsache, daß sie in ihren Gedichten mit Genusdifferenzen spielt, ihr lyrisches Ich

75 Nina Berberova beschreibt Gippius' Geschlechtsvcrhalten "Ona nesomnenno iskusstvenno vyrabotala v sebe dve vnešnic certy spokojstvic I zenstvennost' Vnutn ona ne byla spokojna I ona ne byla zenšxınoj " (Sie versuchie zweifellos kunstlich an sich zwei außerliche Zuge auszuarbeiten. Ruhe und Weiblichkeit Ihr Innenleben war nicht ruhig. und sie war auch keine Frau) In diesem Zusammenhang verweist sie auch auf Gippius' Hermaphroditusmus. den sic mit Gertrude Steins vergleıcht "Ja tožc viźu, čto v Gippius bylo mnogoc. cto bylo i v Gertude Stajn (v kotoroj tože nesomnenno byl germafrodituzm. no kotoraja sumela osvobodit'sja ı osušxestvit'sja v gorazdo bolec sil'noj stepenı [. I" (Ich sehe jetzt auch, daß dic Gippius vicles mit Gertude Stein gemeinsam hatte (zweifellos den Hermaphroditismus), von dem diese sich aber befreien und sich in viel starkerem Maße verwirklichen konnte). In Kursiv moj (Herworhebung won mir), New York 1954, S 282.

76 Andrej Belyj Nacalo veka (IDer Beginn des Jahrhunderts) [zuerst Moskau 1933], Moskva 1990, S 194. Vgl in diesem Zusammenhang auch Olga Mauchs Hinweis der Stılisierung Gippius als Klcopatra, Zit nach Doring-Smimov, 1994, op cit . S 200

77 Judith Butler Das Inbehagen der (ieschlechter, FrankfurtMain 1991, S 75-93 
abwechselnd in der maskulinen und femininen Form sprechen läßt. ${ }^{78}$ In ihrem Tagebuch Contes d'amour bespricht sie ihre zahlreichen Liebesabenteuer: Sie bevorzugt intime Begegnungen mit Frauen und bisexuellen Männern. ${ }^{79}$ Als maskierte Frau, die sich Männlichkeit wünschte, stieg Gippius unter männlichem Pseudodym in den öffentlichen Diskurs mit Männern, d.h. sie ist Teil eines männlichen homoerotischen Austauschs: "Gerade weil der männliche homoerotische Austausch eine Kastration beinhaltet, fürchtet die Frau Vergeltungsmaßnahmen, die auch die "Abwehr" des homosexuellen Mannes motivieren. Vielleicht ist die Weiblichkeit als Maskerade dazu bestimmt, von jener männlichen Homosexualität abzulenken, die die erotische Voraussetzung des hegemonialen Diskurses darstellt und die Irigaray als "Hommosexualität" bezeichnet hat." ${ }^{80}$ Die doppelte Funktion der Maske erlaubt es aber, daß man umgekehrt argumentiert und

78 Ein schr schónes Beispicl für das standige Spiel mit "Männlichkeit" und "Wciblichkeit" ist das Gedicht Ty (Du) von 1905, in. Srichorvorenija i piemy. Bd I. (Sohranic stichov Kniga vroraja (1903-1909) [zucrst Moskau 1910]), Munchen 1972, S 52/53

Ty - mo vesclyj I bespošcadnyj -

Ty - moja blizkaja i neizvestraja

Zdal ja I Zdu ja zan moej jasnol,

Ncutomimo tcbja poljubila ja.

Vstan' ze. moj mesjac sercbrjano-krasnyj.

Vyjdi. dvurogaja, - Milyj moj - Milaja

(Du bist mein lustiger und erbarmungsloser -

Du bist meine Nahe und Unbekannte

Ich warte [mask ] auf meine klare Abendrötc

Unermudlich liebte ich [fem.] dich.

Steıg' auf. mein silberroter Mond.

Komm' hervor, Zweihornige, mein Licber, meine Liebe )

79 Zinaida Gipplus Contes d'amour I-II, zit. nach Vozrozdente, Juli 1969, S 25-47, August 1969, S. $39-54$

80 Judith Butlcr, 1991, op cit., S. 87 
behauptet, Gippius setzt sich eine verschleiemde Maske auf, um gleichzeitig ihre wahre (Geschlechts-)Identität zu bewahren und die inszenierte Identität zu negieren. Das bedeutet, daß sie weder das weibliche noch das männliche Geschlecht inszeniert, sondern das eingeschlechtliche bzw. zweigeschlechtliche Geschlecht.

Zinaida Gippius und Dmitrij Merežkovskij verkörperten als Ehepaar ihre eigene Theorie der Ein- bzw. Doppelgeschlechtlichkeit. Diese schlug sich in der oben dargestellten Physiologie der "heiligen Ehe" nieder, die die physische Seite der Liebe und damit die Kinderzeugung ausschloß. Diese Theorie korrelierte untrennbar mit dem künstlerischen Schaffen, so daß man in dieser Partnerschaft von einer Doppelkünstlerschaft sprechen kann. Darin ubernahm Gippius den mannlichen Teil des "Zeugens", d.h. sie versorgte Dmitrij Merežkovskij mit philosophischen Ideen, während er den weiblichen Teil des Gebärens und Austragens übernahm, also ihre Ideen zu Papier brachte. $^{81}$ Auf ihre Weise verwirklichten Gippius und Merežkovskij das Solov'evsche Konzept der All-Einheit und jenes Prinzip der Verliehtheit, die sie als Voraussetzung für ein neues religiöses Bewußtsein deklarierten. ${ }^{82}$ Ihre

81 Anton Sergl "Literarisches Ethos. Implikationen von Literanzitat am Beispiel des konservativen Publizisten V V Rozanov Mit cinem abschließenden Exkurs zu A P. Cechov." In. Slavistische Beitrage, Band 322, Munchen 1994, S 308 "Für Rozanov war die Ehe zwischen Merežkovskij und Gippius eine der Vorlagen für den Gedanken .auf welchen bei mir alles errichtet ist' - die Theone des Geschlechts dic doppelte Inversion der mannlichen Frau und des weiblichen Mannes Gıppıus muß dabeı als dic Zeugende mit Merežkovskıj als dem Gebarenden korrespondieren Sie versorgt ithn mit fremdem Samen." Siche in diesem Zusammenhang auch Matich, 1972, S. 13

82 Viele Zeitgenossen sahen jedoch in Zinaida Gippius die tragende Kraft, die sich für den Ruhm ihres Mannes verdingte. $V_{g} l$ in diesem Zusammenhang Andrej Belyj NaZalo Veka (Der Beginn 
fünfzig Jahre dauernde Ehe war dadurch keine Ehe im herkömmlichen Sinne, denn sie basierte auf einer rein geistigen Partnerschaft: "Gippius enjoyed flaunting the sexlessness of her married life, plaiting her flaming red hair into one braid to indicate her virginity in spite of a ten-year-old marriage. ${ }^{83}$ Ähnlich Solov'ev, der sich mit seiner ewigen Freundın vermählt sah, stilisierte sich Gippius als Braut Christi. In der neueren Forschung wird vermutet, daß beide Ehepartner eine psychologische Abwehr gegen Sexualität im alltäglichen Sinne entwickelten. Schon zu Gippius‘ Lebzeiten munkelte man, sie sei Hermaphrodit. ${ }^{84}$ Tatsache ist jedenfalls, daß sie keine Kinder bekommen konnte. ${ }^{85}$ Auf diese Weise hatte Gippius zum Thema des Transsexualismus nicht nur eine theoretische Beziehung, sondern war auch persönlich davon betroffen. Retrospektiv gesehen könnte man Gippius' ständigen Grenzübertritt im mystifizierenden Spiel als Suche nach einer anderen geschlechtlichen Identität mit dem Phänomen des Transsexualismus in Verbindung bringen, denn offensichtlich konnte sie die ihr auferlegte biologische Geschlechtsrolle der Frau nicht akzeptieren. ${ }^{86}$ Diese Analogie könnte man auch für Gippius'

des Jahrhunder(s), Moskva/Leningrad 1933, S 434

83 Olga Matuch. 1972, op.cit., S. 12.

$84 \mathrm{Vgl} \mathrm{Anton} \mathrm{Sergl.} \mathrm{1994,} \mathrm{op} \mathrm{cit.,} \mathrm{S} 307$ "Im Herbst 1991 wurde im Kanal "Ostankıno" des Moskauer Fernsehens eine Portratsendung uber Zınaida Gippius gezeıgh die ich zufallig sah. Im Rahmen dieser Sendung wurde dic These als inzwischen wissenschaftlich überprüfte Wahrheit dargestellt."

$85 \mathrm{Vgl}$. M Kuzmins Erzahlung Vysokoe izkusstun (Hohe Kunst), Bd. 3, S.105ff Vgl. Gipplus autobiographische Prosa 1951, S. 36

86 Auch cross gender identity. gender identity disorder. Transposition der (jeschlechisidenntat. Syndrom der geschlechtlichen Idenntat genannt. "Bei Transsexuellen handelt es sich um Personen, die sich 1 . in Kenntnis ihres biologischen Geschlechts und ohne signifikante korperliche Anomalien psychisch dauerhaft dem Gegengeschlecht zugehong fuhlen, was sich auf thre Geschlechtsidentutat ["(core) gender identity"]. thr geschlechtsspezifisches Rollenverhalten ["gender role behaviour"] und eventucll thre sexuelle Orientuerung auswirkt. Diese Personen streben 2. eine hormonelle und chirurgische >Korrektur< thres Ausgangsgeschlechts an", Annette Runte. "Das Geschlecht der Engel Transsexualısmus in der Lacan-Schule (M Safouan. A Faure- 
Vorstellung eines Dritten Geschlechts ziehen, da es genauso wie das transsexuelle ein künstlich konstruiertes darstellt und herkömmliche Aussagen über Mann und Frau unterläuft. ${ }^{87}$ Gippius verkörpert auf diese Weise ihre eigene Theorie eines "Dritten Geschlechts", in dem sie sich immer in die Position eines „Dazwischen“ begibt: Sie ist weder ,Mann“ noch ,Frau" und füht dadurch als Person die kulturelle Gemachtheit von gender vor. Nicht nur in dem von ihr propagierten Androgynietätskonzept und zu realisierender gesellschaftlicher Utopie überschreitet sie den sexuellen Dimorphismus und bietet eine alternative sex/gender Klassifikation an, sondern auch in der Praxis, im gelebten Leben.

Oppenheimer, C Millot), in Psyche Zeitschnfi fur Psychoanalyse und ihre Anwendungen. 9, Septcmber 1985, S 830-862, S. 831

87 In der Lacan-Schule wurden Frau-zu-Mann-Transsexuelle in Ihrer transsexucllen Position zu Mann-zu-Frau-Transsexuellen verglichen Im Unterschied zu Mann-zu-Frau-Transsexuellen stellt man Frau-zu-Mann-Transsexuellen cine weniger spcktakulare Aufmachung fest. cinc Dissımulation weiblicher Merkmale cine Unterstreichen der phantasmierten Maskulinitat beı gleichzeitıger Integration des mannlıchen Organs bzw seines Sımulacrums. eine auffallige Neigung zur Askesc und Asexualitat. dem Wunsch, eınem fiktiven .,dritten Geschlecht" anaugchoren Ebd. S 857 


\section{Sophia-Projektion und schreibende Muse:}

\section{Zinov'eva-Annibals Tridcat'-tri uroda (Dreiundreißig Mißgeburten)}

Lidija Zinov'eva-Annibals (1866-1907) Texte sind zum Korpus der vernachlässigten weiblichen Literaturtradition der russischen Modeme zu rechnen. ${ }^{88}$ Als Ehefrau von Vjaceslav Ivanov hatte sie innerhalb des symbolistischen żznetvorcestvo zwei Funktionen zu erfüllen: Sie war sowohl "Sophia-Projektion" als auch "schreibende Muse". Die Erzählung Tridcat'-tri uroda (Dreiundreißig Mißgeburten) radikalisiert diese Position, indem sie gerade jene Urszene entwirft und travestiert, die für das ziznetvorčestvo paradigmatisch war, nämlich diejenige des "die Frau schreibenden (hier: malenden) Mannes". Der Text vervielfältigt diese Perspektive des Weiblichen in jeder Hinsicht: Eine Muse schreibt darüber, wie Männer Musen beschreiben. Damit verweist er auf die Idealisierung des Ewig Welblichen und auf die Konstruiertheit des Frauenbildes innerhalb der neuen Lebenskunst: Die

88 Siehe zu diesem Aspekt die neueren Arbeiten aus der gender-orientıerten Slavistik Kušlına. O B Zinov'eva-Annibal, Lidija" in: Russke Pisateli 1800-1917. Biograficeskj Slovar'. T.2., Moskva 1992. Ledkovsky, M Dictionary of Russian Women Writers, Westpon 1994, S 753, Pachmuss. Temira Women Wriers in Russian Modernism. An Anthology, Urbana 1978. S 191200, Danıcla Bayer Sichtungen. Zur Poelık won Lidija Zinov'eva-Annibal, Munchen 1995 (unveroffentlichte Magisterabeit). Gopfert. Frank "Dichterinnen und Schriftstellerinnen von der Mitte des 18 Jahrhunderts bis zum Beginn des 20 Jahrhunderts Eine Problemskizze", Slavische Betirage, Bd 289, Munchen 1992 Einen guten Uberblick zu Leben und Werk bietet Tat'jana Nikol'skajas Tworkeskij put' L. D Zinov'ewoj-Annibal. Tartu 1988 
körperliche Schönheit der Frau löst sich in der Ästhetik des symbolistischen Lebenskünstlers auf. Damit hinterfragt Zinov'eva-Annibal nicht nur die Poetik des žiznetvorčestvo, sondern auch die Rolle, die sie selbst darin spielte.

In der folgenden Analyse werde ich zunächst auf die Position Ivanovs im Rahmen seiner "Turm"-Gesellschaften zusammen mit dem Problemkreis der Homoerotik eingehen sowie die Rezeptionsgeschichte dieses Textes schildern, um dann die Frage eines genuin weiblichen Ortes in der Literatur des Silbemen Zeitalters an Zinov'eva-Annibals Text selbst zu diskutieren.

Im sogenannten "Turm", der Wohnung der Ivanovs im obersten Stock eines Hauses in der Tavriceskaja Ulica, wurde seit 1905 das "symbolistische Lebensschaffen" buchstäblich in Gang gesetzt. Die Versammlungen am Mittwochabend, an denen sich die Elite der Petersburger Intelligencija traf, hatten zum Ziel, neue Formen des Zusammenlebens zu finden: "Aus neuen Menschenzusammenklängen sollte, so hofften sie, eine neue Geistigkeit entspringen." $" 89$

Ausschlaggebend hierfür war Vjačeslav Ivanovs "Religion des Dionysos", ein "eigenwillig verstandener Nietzscheanismus", dem der Symbolist nicht die Idee des Übermenschen entlehnte, sondern die des Dionysos, des sterbenden und ewig wiederauferstehenden Gottes. ${ }^{90}$ Diese Religion des leidenden

89 Margarita Woloschin Die grine Schlange, Switgart 1987, S 184

90 Alexander Etkınd Eiros des (Inmoglichen Die (ieschichte der Psychoanalyse in Rußland, Leipzug 1996. S 62 
Gottes (ellinskaja relıgija stradajušcego boga) ${ }^{91}$ vereinigt Erotik und Ökumene, sohornost', das Prinzip innerer Liebes- und Lebensgemeinschaft. Sexueller Rausch und religiöse Ekstatik sollen nach Ivanovs Idealvorstellung die Grenzen des eigenen Ichs sprengen und ins fremde Ego vordringen. ${ }^{92}$ Ivanovs Ideal basierte auf einer Sexualität, die Keuschheit und Wollust als Eros des Unmöglıchen (eros nevozmožncgo) ${ }^{93}$ vereinte, während sein symbolistisches Programm lautete: Entindividualisierung des Ich und Du im kollektiven unsterblichen Wir und damit die Verschmelzung von Apollon und Dionysos, von Männlichem und Weiblichem im eingeschlechtlichen bzw. geschlechtslosen Ganzen. Ivanovs neuer Gott ist ein Gott, der Mann und Weib in sich vereint. Ivanovs Ziel, den einzelnen Menschen im kollektiven Wir aufzuheben, wollte er in der Dreierbeziehung als ideale, zwischenmenschliche Vereinigung verfolgen. Zwei Menschen verschmelzen vollkommen, sie werden eins. Dadurch können sie den Dritten aufnehmen: "Plavil'scik dal im primer, urok. Im nadležit $v$ svoe dvuedinstvo vplavit' tret'e sušcestvo - i ne tol'ko duchovno, no i telesno." 94 ("Der Schmelzer gab ihnen ein Beispiel, eine Lehre. Man muß in seiner Zweieinigkeit mit einem dritten

91 Vjaceslav Ivanov "Elınskaja religija stradajuščcgo boga", in: Novyj put', I (S 110-134), 2 (S 48-78), 3 (S 38-6I), 5 (S 28-40), 8 (S 17-26), 9 (S 47-70), Sankt-Petcrburg 1905 Ivanov entwickelt in diesem Text eine Dramenthcoric. die auf der Erschaffung eines neuen Theaters beruhte Sein Ziel war es. eine universelle Kunst zu etablieren. an der die Menschen teilhaben und nicht nur zuschauen Diese Idec leitet sich aus der Vorstellung ab, dab das Theater ursprunglich aus dem Dionysoskult entsprang Dabei steht dic Ekstase am Anfang des religiosen Empfindens, durch die dic Einheit mit dem Opfer erreicht werden kann, das durch den leidenden Gott verkorpert wird Diese Vereinigung ermoglicht es dem Opfernden. auch Opfer zu sein. denn die Ekstase bildet die Voraussetzang fur cine Dualitat des Scins, wo Leben und Sterben nebencinander existicren als zweı Aspekte eines universellen Mysteriums In diese dramatusche Urform der Opferhandlung greift das apollinische Prunzap ordnend ein Erst dadurch konnte die Tragodie entstehen

92 Ebd S 64

93 Ebd. Band 1. S 825

94 Vjaceslav Ivanov Sobranie Socinenij v irech tomach. Band 2, Brussel 1974, S 756 
Wesen verschmelzen, nicht nur geistig, sondern auch körperlich.") Neben der spirituellen Vereinigung wollte Ivanov die körperliche Vereinigung mit dem Dritten. In dieser doppelten Orientierung stellt seine Konzeption der Liebe als auf- und absteigende Liebe in Projektion auf die afrodita nebožttel'nica und der afrodita vsenarodnaja - eine Zwischenstufe dar zwischen der Solov'evschen All-Einheit, also der doppelten Inversion von "Weibmännlichen" und "Mannweiblichem", sowie Bachtins Volkskörper als Umstülpung des Weiblichen ins Männliche und des Männlichen ins Weibliche. ${ }^{95}$ Auf diese Weise wurden Ivanovs Mittwochgesellschaften zum Ort, an dem freie Formen der Liebe ausprobiert bzw. sexuelle Tabus wie Homosexualität umgangen werden konnten. ${ }^{96}$ Diese stehen im Mittelpunkt von Zinov'ev-Annibals Drelundreıßg Mißgehurten, aber nicht aus der Perspektive des die Frau schreibenden Mannes, sondern aus der Perspektive der schreibenden Muse.

Tridcat'-trı uroda erschien 1907 und wurde von der Kritik zerrissen. ${ }^{97}$ Vor allem die Darstellung lesbischer Liebe war den Zeitgenossen ein Dorn im Auge. ${ }^{98}$ Bogomolov macht auf die negative Reaktion der Symbolisten selbst aufmerksam:"[...] Indessen war 'Tridcat'-tri uroda' für die zeitgenössische

95 Doning-Smimov "Das zweigeschlechtliche Wort. Dic Autorisierung der Korrespondentun in zwet Brief-Werken der russischen Romantik", in Autorschafi Gemus und Genie in der Zeit um 1800, Berlin 1994, S 77-87, S 86

96 Etkınd. 1996. op cit., S 62

97 Zinov'cva-Annibal, L D. "Tndcat'-tn uroda", Sankt-Pcterburg 1907 Alle folgenden Textzitate entstammen dieser Ausgabe. sie uurden von mir ubersetzt Die Ausgabe wurde zunachst wegen "unsittlicher Darstellung" konfisziert dann aber doch ausgeliefert Vgl.. Literatumoe nasledsino, T 85, Moskva 1976, S 476 In einem Bnef vom 26 Februar 1907 schreibe Ivanov an Brjusov "Soeben habe ich Dir uber die Konfiszierung der zweiten Auflage von Zinov'eva-Annibals 'DreiundreiBig MiBgeburten' telegraphiert - wahrscheinlich. wie man aus der Setzereı mitteilt, wegen Paragraph 1001 (Beschuldigung der Unsitulichkeit)" ("Tol'ko cto telegrafiroval tebe o konfiskacı vorogo vypuska 'Or' - Tndcat' trech urodov' Zinov'evoj-Annibal - verojatno (kak telefoninuct iz upografii) po stat'c 1001 (obvinenie v beznraustvennost?")

98 Siche dazu Gopfert. 1992, op.cit S $171 \mathrm{ff}$ 
Kritik Objekt des Spottes und der Angriffe, in deren Chor sich auch Z. Gippius und A. Belyj einreihten. Das ist deswegen seltsam, weil ihnen, die sie auch in die Sphäre der symbolistischen Lebensschöpfung eingetaucht waren, klar sein mußte, daß die bekannte künstlerische Schwäche der Erzählung durch den Grad der Gegenwart des Autors in der Atmosphäre der Erzählung selbst kompensiert wurde. Es ist offensichtlich, daß die persönlichen Beziehungen ihr Bewußtsein für das trübte, daß unter den ziemlich hilflos beschriebenen Erlebnissen der Bücherhelden das echte, heiße Blut ihrer symbolistischen Kampfgefährten floß." 99

Obwohl gerade die Symbolisten bewußt oder unbewußt das Thema der Homoerotik wiederholt in ihren Texten aufgriffen, verurteilen sie erotische Beziehungen zwischen Frauen. Belyj schreibt darüber: "Das Intime des Symbolismus ist verloren; es wurde zu verlockend für die Damen und Herren, die Kuzmins 'Flügel' und Zinov'eva-Annibals 'Dreiundreißig Mißgeburten' gelesen haben." 100 Zinaida Gippius bezeichnet den Text als geradezu gefahrlich: "Warum mußte sie das alles schreiben. Sie ist doch weiß Gott keine dumme, sondern eine schöne, einfache Frau und kann sogar ganz gut schreiben, auf jeden Fall 'talentierter' als die 'Mißgeburten' geschrieben sind [...] aber die zeitgenössische [erotische] Literatur ist bitterer, erstens hat sie offensichtliche

99 Bogomolov, N.A : "My - dva grozoj zažennyc stvola Erotıka v russkoj poezi - ot simvolistov do obcnutov", in Isteraturnoe Obozrente, Moskva 1992. S 61 "l...] odnako dlja sovremennoj knukı 'Tndcat'-trı uroda' stalı ob'ektom glumlemja I napadok. pncem $k$ choru napadavšch prisoedinihs' Z Gippius ; A Bely. Eto bylo stranno tem bolec. to dlja nich, pogruzennych v sfenu simvolıstskogo zıznetvortestva, dolžno bylo byt' oxevidnym. Eto ızvestnaja chudožestvennaja slabost' povesti kompensıructsja stepen'ju vživlennost' avtora v samu atmosferu rasskaza. Orevidno. liěnye otnošemja zatcmnilı $v$ ich soznanic to, Eto pod dovol'no bespomošcno opısannỵmı percžıvanijamı knıžnıch getoev tckla nastojašcaja. gorjacaja krov' ıch žc soratnıkov po sımvolizmu "

100 Andrej Belyj "Simvolizm kak miroponımanic", [zuerst Moskva 1910) Moskva 1994, S 443 "Intimnoc simvolızma utraceno, ono stalo soblaznitcl'noju podmankoj dlja dam i junošcj. čtajušcich 'Krylja' Kuzmina i lesbianskic dvusmyslennostı Tndcat trech urodov' Zinov'cvoj-Annibal " 
Vorurteile gegenüber Kunst und zweitens ermuntert und erzieht sie eifrig zu einem unentschuldbaren Rowdytum, das den Menschen zerstört." ${ }^{101}$ Nicht nur diese beiden Kritiker, sondern auch alle anderen - bis auf Vjaceslav Ivanov selbst ${ }^{102}$ - übergehen, daß Tridcat'-trı uroda in der Darstellung der lesbischen Liebe gerade die Suche nach einer weiblichen Perspektive bzw. einem weiblichen Ort thematisiert. Im Scheitern dieser Suche verweist der Text darauf, daß es eine genuine "Weiblichkeit" nicht gibt, da diese immer schon durch die männliche Perspektive auf das Weibliche - also im männlichen Blick auf den weiblichen Körper - definiert ist. Das Besondere des Textes liegt meines Erachtens darin, daß Zinov'eva-Annibal die Diskursivität, d.h. die sprachliche Gemachtheit von "Männlichkeit" und "Weiblichkeit" vorführt.

101 Anton Krajnyj [Gippius. Z N ] "Bratskaja Mogila", in Vesy, Nr. 7, 1907, S 57-63, S. 62f: "I zacem ej bylo vse cto pısat" EJ Bogu. ona neglupaja, prekrasnaja. prostaja zenšx̌rina, 1 daze pisat' ona umect nedumo. vo vsjakom slučac 'talantlivec' neuzeli napisany 'Urody'| |No poslednaja |erouéeskaja literatural gorše. vo-pervych. potomu. Cto $\mathrm{v}$ nej zamctnye pretensu na iskusstvo, a vo vtorych - ona staratel'nee pooš̌r rjaet, vospityvaet bezpardonnoe chulıganstvo. raznušact celoveka " $V_{g l}$ in diesem Zusammenhang Nikol'skaja. 1988. op.cit, S. 136, die darauf hinwcist, daß dic negatuve Kntuk der Gippius in der Ablchnung des Dionysos-Kultes. Wic thn Vjaceslav Ivanov und seine Frau innerhalb der Turmgesellschaften pflegten. begrundet ist

102 Interessant ist in diesem Zusammenhang das Vorwort von Vjaceslav Ivanov, in dem er auf dic Besonderheit der weiblichen Perspektıve innerhalb des Textes anspiclt "Dic Tagebuchaufzeichnungen sind einfach. nuchtern und klug Zuweilen sind sic auf weibliche Art prosaisch, durchdrungen von weiblicher Anmut. Grazie und Poesie " ("Rec' ec zapisej prosta. trezva i umna. - poroj kak-to po-zenskı prozaicna, poroj zc pronıknuta zenstvennoju prelestju. gracıej i poezıej") In eınem Bnef vom 31 Julı 1907 schreibt er an scine Frau "I I prezde vsego podlınny jazyk strastı, I on ne možct ne potrjastı vsjakogo | | Tak intensıvno eto vpeładenie strasti. Cto glubokıj zamysel poxtu ne vidis' za krasnym pokryvalom eveta żivoj krovı Vera fantastıcna i prekrasna, kak istinnyj romantukeskıj up Izumitel'no, kak stol' otvlctennaja mysl' mogla oblaxit'sja v takuju żıvuju plot' " ("I .] vor allem die authentusche Sprache der Leidenschaft, die Eindrucke der Sprache sind so intensiv, daß man den uefen Sinn, der hinter dem Vorhang der roten Farbe lebendigen Bluts versteckt ist fast nicht bemerkt Vera ist phantastisch und schon Wie eine echte. romantische Figur. Es ist erstaunlich, wie cin abstrakter Gedanke sıch in Fleisch und Blut verwandeln kann "), zit. nach Nikol'skaja, 1988. op cit. S 130 
Der Text erzählt das kurze, aber sehr intensive Zusammenleben zweier Frauen. Eine Ich-Erzählerin schildert in Tagebuchform, dessen erster Eintrag vom ersten Dezember datiert und irgendwann im April endet, die Liebesbeziehung zu ihrer Freundin und Schauspielerin Vera. Beide Frauen verbindet der Wunsch nach einer neuen Familie, da die blutsverwandte nicht mehr existiert. Vera heiratet auf Wunsch der Mutter, die ins Kloster gehen wollte, bereits mit sechzehn Jahren. Der Ehemann stirbt nach zwei Jahren, Vera bleibt mit der zweimonatealten Tochter zurück, die ebenfalls kurz darauf stirbt. Vera versucht sich mit Friedhofswasser zu vergiften, was ihr mißlingt. Danach geht sie zum Theater. Die Ich-Erzählerin entstammt einer unehelichen Verbindung. Sie hat ihren Vater nie gesehen. Nach dem Tod der Mutter wird sie von der Großmutter versorgt, die fur sie den Brautigam aussucht. Am Abend vor der Hochzeit lernt sie im Theater Vera kennen. Sie verläßt ihren Bräutigam und zieht zu Vera. Ihre symbiotische und scheinbar ideale Liebesbeziehung wird von dreiundreißig Malern zerstört, die die ideale Schönheit der Ich-Erzählerin im Bild verewigen wollen: "Aber jeder der dreiundreißig Maler stellt seine Sicht der Natur dar, die nicht mit dem Ideal übereinstimmte, das Vera sich geschaffen hatte. Vera verkraftet den Verlust des Ideals nicht und bringt sich um." ${ }^{103}$

103 Nikol'skaja, 1988, op cit. S. 130 "No každyj iz tridcatı trech Zuvopıscev izobražl svoe videnie natury, ne sovpadajuštec s idealom, sozdannỵm dlja sebja Veroj Nc v silach perežt' utratu ideala. Vera kon'act zizn' samoubijstvom " 
Wie im folgenden gezeigt wird, inszeniert die Ich-Erzählerin in Dreiundreıßig Mißgeburten einen Raum, in dem eine ekstatische Körpererfahrung als weibliche Körpererfahrung möglich ist. Diese verweist wie die Verneinung familiärer Strukturen auf die Bruder-Schwester-Verhältnisse innerhalb der Sekten. Die hermetische Abgeschlossenheit des klosterähnlichen Raums und die selbstentworfene Kleidung erinnem an die Rituale der Chlysten und an die kollektiven erotischen Experimente, die im "Turm" stattfanden ${ }^{104}$ :

Éto moi chitony Nošu ich na goloe telo Mne eto nravitsja ja v nich takaja vysokaja i gibkaja, i legka, kak nagaja Na bosuju nogu nožu sandaly (S 9)

Das sind meine Chitonen Ich trage sie auf bloßer Haut Das gefallt mir darin bin ich so groß und so schlank, wie eine nackte Frau Am bloßen Fuß trage ich Sandalen

Die Vergöttlichung der Frau, bzw. die Erhebung der Frau in den Status der Gottesmutter innerhalb der (hlystengemeinde findet sich in Veras Wunsch wieder, aus der Freundin eine Göttin zu machen:

Ty dolzen ich pokinut' Ty ne ich Ja tebja naucu sama Ja tebja sdelaju prekrasnoj. potomu čto ja prekrasna. So mnoju ty budeš' boginej. (S 16)

Du mußt sie verlassen Du gehorst nicht zu ihnen Ich lehre dich selbst Ich mache dich uunderschon, weil ich wunderschon bin Mit mir wirst du eine Gottin

Auch der Hinweis auf ein italienisches Gemälde, das die heilige Agatha abbildet, während ihr die Brustwarzen herausgerissen werden, erinnert an das "Das Abendmahl mit der Brust der Gottesmutter"105, ein Ritual der Chlysten:

$104 \mathrm{Vgl}$. in diesem Zusammenhang Johannes von Gunther: Ein Leben im Ostwind: Zwischen Petersburg und Munchen. Ennnerungen. Munchen 1969, S 123 "Dic dritte in diesem Musenzurkel war Lydia Sinowjewa-Annibal, Iwanow's zweitc Frau. ene imposante Erscheinung Gross, ziemlich voll, mit einer rotblonden, uppigen Mahne und stets in farbenfieudigen griechischen Chitonen gekleidet. laut lustug, beweglich entschicden - und naturlich ebenfalls Dichterin. wenn sic auch nicht Lynk schrieb, sondem kleine und grosse Prosa und Theater Die gutuge Frau hatte ein warmes Herz fur junge Dichter, so gewann sic bald thre Zuneigung I . I man konnte sie als Motor bezeichnen, der die turbulente Geistigkeit der I wanowischen Mittwoch-Abende in Gang hielt."

$105 \mathrm{~K}$ Grass Die russischen Sekien Die (jottesleute oder Chlusten, Bd 1., Lapzig 1907, S 480ff 
Vspomnila kartinu - kopiju s kakoj-to ital'janskoj kartiny, kažetsja sv. Agata Ej vyryvaet zelezom soski, i dvoe mucitelej s takim ljubopytstvom odicalym zagljadyvaet $\checkmark$ glaza A glaza Agaty blazennye, blažennye.(S. 26/27)

Ich erinnere mich an die Kopie eines italienischen Gemäldes, scheinbar die heilige Agatha Ihr reißt man mit einem Eisen die Brustwarzen heraus, wahrend die zwei Peiniger ihr mit bestialischem Interesse in die Augen schauen Aber die Augen der Agatha strahlten Gluckseligkeit aus, Gluckseligkeit

Besonders deutlich werden die Anklänge an das Sektenwesen in jenen Teilen des Textes, in denen ekstatische Körpererfahrungen als Entgrenzung des eigenen Ichs dargestellt werden ${ }^{106}$, z.B. in dem Moment, als Vera aus "Lira v pustyne" ("Die Lyra in der Wüste") vorliest:

Bylo neponjatno slyšat' vopli Lira nad izmenivšeju ljubov'ju i videt' ego bezumnoe, stichijnoe lico tam, gde po gluchomu kovnu metalas' Vera, meždu laskovoju staroju mebel'ju ej materi-monachini.(S.23)

Es war merkwürdig, das Wehklagen der Lyra über die sich verandernde Liebe zu hören und sein wahnsinniges, unbeherrschtes Gesicht dort zu sehen, wo Vera sich auf dem oden Teppich hin- und herwälzte, zwischen den zärtichen, alten Möbeln ihrer Nonnenmutter

Aber auch die Stille, die auf die Ekstase folgt, verweist auf das häretische Ritual:

I mne pokazalos' eto molcanie masok samym strašnym i samym novym, cto ja kogdalibo znala Ja zakricala Vera, Vera, vernis' Etogo nel'zja delat' v komnate, tak blizka (S 23/24)

Und mir erschien dieses Schweigen der Masken das schrecklichste und das neueste. was ich jemals kennengelernt hatte Ich fing an zu schreien. Vera. Vera, komm' zunuck. Das darf man nicht im Zimmer machen, so nah

$106 \mathrm{Vgl}$ in dicsem Zusammenhang D.G Konovalov Religiozny ckstaz v nusskom misuceskom sekzanstue, Sergeev Posad 1908 
Das Wahrsagespiel des Silvesterabends kann ebenfalls unter dieser Perspektive gedeutet werden. Gemäß sektantischer Vorstellungen kann der Zustand der körperlichen Ekstase zu prophetischen Aussagen führen ${ }^{107}$ :

I vdrug Vera razrydalas' - sebe samoj, kažetsja, neozidanno, i vse zakoncila neponjatnymi slovami I $v$ tom moe raspjatie, cto ty ideš' $v$ sadom roz. $V$ nich vse stradanija, vse radosti, vse negi, i ty prinadleziš zizni Ja ze kricu tebe stoj [. ] I Vera smejalas' prjamo iz slez.(S 39)

Und plotzlich loste sich Vera in Tranen auf, was fur sie, wie es schien, ganz unerwartet war und alles endete mit unverstandlichen Worten Darin liegt meine Kreuzigung, daß du in den Rosengarten gehst Dort ist alles Leiden, alle Freude, alle Seligkeit, aber du gehorst dem Leben [..]. Ich schreie dich an bleib stehen [ ] Und Vera fing mitten unter Tranen as lachen an

Vera sieht in der Ekstase jenes Bild voraus, das sich im Wachsgießen fortsetzt: Die Passion Christi, die auch durch den zeitlichen Rahmen der Geschichte angekündigt ist. Das Geschehen erstreckt sich von Anfang Dezember bis Mitte April. Allerdings wird hier das Heilsschema umgekehrt. Der gekreuzigte Christus ist eine weibliche Erloserfigur:

\begin{abstract}
Vosk naš vylilsja do Cutkosti otCetlivo i krasivo Vere kurgan i krest s razpjatym na nem telom. Perekožennoe ot boli $v$ zmeistom naprjaženii muskulov. $\mathrm{Da}$, bylo strašno Mne vylilsja ploskij kusok. Vosk vsplesnulsja po ee poverchnosti vverch mnogimi tonkimi, prozraxnymi i lopnuvšimi bryzgami - rozami Eto byl rozovyj sad, obil'nyj, radostnyj, i posredi figura Ženšxiny (S 38)

Unser Wachs nahm bis zur Grausamkeit klare und schone Form an Vera goß einen Hugel und ein Kreuz mit ausgestreckten Leib, det durch die gewundene Anspannung der Muskeln vor Schmerz verzogen war Ja, es war schrecklich Ich goß ein flaches Stuck Das Wachs hatte sich auf seiner Oberfläche zu vielen feinen, aufgeplatzten, durchsichtigen Splittern - zu Rosen geflochten Das war ein voller und freudiger Rosengarten und mittendrin die Figur einer Frau
\end{abstract}

$107 \mathrm{Vgl}$ in diesem Zusammenhang Konovalov, 1908, op.cit., S 193 "Das automatische Sprechen m der Muttersprache oder in einer bekannten Sprache ist ein Ausbruch ekstatischen Wahrsagens" ("Avtomaticeskaja re飞' na rodnom jazyke pristup' ekstatikeskogo proroxestva") 
Die prophetische Dimension verbirgt sich in der postmortalen Wahrheit der Geschichte. Während die Ich-Erzählerin sich im Rosengarten wiederfindet, also ins Leben zurück, geht Vera, allein zurückgelassen, buchstäblich zugrunde.

Drelundreıßı Mıßgeburten verweist auch auf die Entstehung des perhorreszierten Weibs-Bildes durch die Kunst. Auf diese Weise wird das zerstückelte Bild der Frau zum Selbstbild der Ich-Erzählerin. Charakterisiert man den Unterschied zwischen männlicher und weiblicher Autorschaft, so kann man ihn darin bestimmen, daß er nicht in der Ästhetik des Schreibens selbst zu suchen ist, sondern in der Rezeption. Konstituiert sich männliche Autorschaft erst über den Blick auf den weiblichen Körper, so ist im Falle weiblicher Autorschaft die Angst vor diesem Blick konstitutiv. Der männliche Blick wird als Blick auf den unbedeckten, weiblichen Körper wahrgenommen und der Text selbst wird direkt mit dem Korper assoziier, "making the private attributes available to the public for a fee" ${ }^{108}$. Genau dieses konstitutive Element männlicher Autorschaft inszeniert Zinov'eva-Annibal in Dreiundreıßg Mißgeburten. Dreiundreißig Maler haben die Aufgabe, die absolute Schönheit der Freundin im Bild festzuhalten:

V tridcat' trech vnimatel'nych, vidjašxich parach glaz ty otrazisł'sja tridcat'ju tremja večnymi, stoijkimi, polnymi migami krasoty. (S 61)

In dreiundreißig aufmerksamen Augen wirst du dich durch dreiundreißig ewige, bestandige, erfullte Momente der Schonheit widerspiegeln

108 Siche Laura Engelstcin. The Keys to Happiness. Sex and the search for Modernity in Fin-desiècle Russia. Ithaca 1992. S $392 \mathrm{ff}$ 
Auf der anderen Seite beschreibt Vera die Enteignung der Schönheit durch die Kunstproduktion:

No potomu, čto ty voistinu prekrasna, - ja ne mogu ne davat' tebja ljudjam Oni smotrjat Vidjat krasotu Nirego net v zizni Iskra vspychnula i potuchla Tol'ko bol' i obida, i nel'zja ponjat', k remu I skuka I skuka No krasota (S 20)

Und weil du wirklich schon bist, muß ich dich den Menschen uberlassen Sie schauen Sehen deine Schonheit Nichts gibt es im Leben Der Funken ist aufgeflammt und verloschen Nur Schmerz und Scham und man versteht nicht wozu Und Langeweile Und Langeweile Aber Schonheit

Die Ästhetisierung des Weiblichen in der Kunst tilgt die reale Schönheit der Freundin und was übrigbleibt ist ihr zerstückelter Körper: Dreiundreißig perhorreszierte Weibs-Bilder, in denen die Ich-Erzählerin vergeblich nach dem eigenen Spiegelbild sucht:

Ja? Eto ja, kotoruju my s nej ljubili?

Eta? Eta? Eta?

Ja perebegala ot odnogo cholsta $k$ drugomu po vsej masterskoj

So vsech storon, kak sideli vokrug menja oni, pisavšie, ja videla sebja

Ili ja ne znala sebja szadi? Sboku? V tri cetvert'? V cetvert'? I prjamo v lico tože ne znala?

Eto drugie

Ne naši

Ich Ich Ich (S 68)

Ich? Das bin ich, die wir geliebt haben?

Diese? Diese? Diese?

Ich rannte durch das ganze Atelier von einer Leinwand zur anderen

Von allen Seiten, so wie sie mich gemalt haben, betrachtete ich mich

Oder habe ich mich nicht von hinten gekannt? Von der Seite? Dreiviertel? Vientel?

Oder direkt ins Gesicht. habe ich das auch nicht gekannt?

Das sind andere

Nicht unsere

Ihre Ihre Ihre 
Doch nach und nach wird genau das gemalte Bild zur Wirklichkeit der IchErzăhlerin. Sie verläßt den Raum, den sie mit Vera teilt und geht in die Welt der Künstler:

\begin{abstract}
Každyj iz tridcati-trech sosdal svoju ljubovnicu, ili svoju caricu I stalo mne zabavno ot $i t y v a t '$ ljubovnic ot Caric. No každyj den' ona putalas' snova, a kogda uchodila iz doma, leža u sebja na logtjach, staralas' ja pripomnit' každuju sebja, každyj svoj oskolozek tam, - putalis' ližny muritel'no, i ja smejalas' kak glupen'kaja (S. 72/73)

Jeder der dreiundreißig schuf seine Liebhaberin oder seine Zarin. Für mich war es komisch, die Liebhaberinnen von den Zarinnen au substrahieren Aber jeden Tag verheddente sie sich aufs Neue und wenn sie nachhause kam und sich auf ihr Bett legte, versuchte ich mich an jede zu erinnern, jedes meiner Splitterchen dort-, Masken verhedderten sich qualend und ich fing an zu lachen, wie eine torichte Person.
\end{abstract}

Die Verfahren, die Zinov'eva-Annibal anwendet, verschieben weibliche Perspektive und Perspektive des Weiblichen spiegelbildlich ineinander und verweisen auf die Maskerade als Mittel weiblicher Selbstdarstellung bzw. einer Inszenierung dessen, was auf die Frau projiziert wird:

Kak prekrasno tragicnoe pod maskoj, no kogda ono tak golo peredo mnoju i ... kogda vovlekaet menja nasil'no ..ja ne znaju chorošo li mne (S 44)

Wie schon ist das Tragische unter der Maske, aber wenn es nackt vor mir ist...wenn es mich gewaltsam anzieht .weiß ich nicht, ob es mir gut tut

Dabei verschiebt sich auch ständig die Grenze zwischen Kunst und Leben. Das weibliche Ich verschwindet hinter der Maske, die Opfer verlangt:

Da konečno, èto strašnaja żertva dlja nee No ona ljubit zertvy. Iš̌et. Ee maska trebuet ot nee zertvy. (S 50)

Ja. das war naturlich ein furchtbares Opfer fur sie Aber sie liebt Opfer Sucht sie. Ihre Maske verlangt von ihr Opfer 
In diesem Spiegelungsproze $B$ bekommt die symbolistische Dreierbeziehung eine ganz neue Dynamik. Sie besteht aus Vera, der Ich-Erzählerin und dem Ideal, dem Kunstwerk. Darauf deutet nicht nur die Beziehung zu den 33 Malern, sondern auch die Aneinanderreihung der Ziffer drei. Zinov'ev-Annibal verfremdet damit nicht nur das Ideal der symbolistischen Lebensschöpfung, sondern auch das Ideal der mystischen Liebe ${ }^{109}$, das sich in der Projektion des "die Frau schreibenden Mannes" realisiert. Das Resultat der männlichen Kunstproduktion ist der deformierte weibliche Körper, die Mißgeburt des Weiblichen. Alles was als Kunst-Schönes projiziert wurde, endet im grotesken, perhorreszierten Weibs-Bild. Dostoevskijs Formel Die Schönhelt rettet die Welt (krasota spasaet mir) als Vorlage der ewigen Schönheit (veðnaja krasota) der Religionssymbolisten, die den Tod überwindet, wurde hier eine groteske "Schönheit", die in den Tod führt.

Zinov'eva-Annibals Suche nach einem genuin weiblichen Ort in der Literatur bzw. einem weiblichen Schreiben kann man in dieser Erzählung als Prozeß der Restilisierung des Simulakrums "Frau" verwirklicht sehen.

109 Matuch. Olga "The Symbolist Meaning of Love Theory and Practice", in Papemo. I. Grossman. J D (Hgg.) ('reating L Lje. The Aesihenc Utopia of Russian Modernism. Stanford. 1994 


\title{
Kapitel II:
}

\section{Gottesverlangen und Minnedienst.}

\section{Der hysterische Mann im Silbernen Zeitalter}

\author{
"[...]Einstmals sahen wir die M o r g e n r ö t e; die \\ Morgenröte war etwas so Wichtiges, daß es uns nicht einmal \\ in den Sinn kam, ob d a s Kunst ist, oder nicht; \\ vornehmlich war es $\mathrm{d}$ a s, bald aber schon Zettelwerk. \\ Und glaube mir: Jetzt weiß ich, d a s war nicht nur Kunst; \\ vieles in unserem Schaffen kam nicht vom Formschmieden, \\ sondem von der $\mathrm{M}$ e dit a t i o n, d.h. von unbewußten, \\ oft okkulten Bewegungen in unserer Seele [...]." \\ Belyj an Blok (28.12.1912/10.01. 1913)
}

\footnotetext{
1 "Alcksandr Blok i Andrej Bely] Perepiska", in Slavsche Propylaien, Bd 65, [Nachdruck der Ausgabe Moskva 1940| Munchen 1969, S.311 "I. |nckogda my voleli z o r i, zon byli cem-to stol" vănym, cto u nas i ne voznykalo slov, iskusstvo c $t o$ ili ne iskusstvo. prežde vsego tto. a potom uze jarlyek I vor pover' mne ja teper' znaju. cto e to bujlo ne tol'ko iskusstvo: mnogoe v našem tvorkestve bylo ne ot koukj form. a o m e d i t a c i i, t.e or bessoznatcl'nych casto okkul'nụch duzzenij cego-to v svoej duse $[\ldots]^{n}$
} 


\section{Andrej Belyjs theurgischer Zeugungsakt: Die Silberne Taube}

So ist die Erinnerung an die Erinnerung, sie ist Rhythmus, sie ist die Spharenmusik des Landes, - wo ich vor der Geburt war'

Andrej Belyj, Kotık Letaev"

In seiner autobiographischen Schrift Zwischen zwel Revolutionen erklärt Belyj: "In dem Roman spiegelt sich ein persönliches Gefühl, das mich durch diese ganze Periode hindurch quälte: ein morbides Gefühl der 'Verfolgung', ein Gefühl von Netzen und drohender Zerstörung; das ist alles im Sujet der Silbernen Taube ${ }^{3}$ verankert. Indem ich meine 'Krankheit' im Sujet externalisierte, befreite ich mich von ihr." als körperlichen Prozeß, auf seinen Schreibakt als mögliches Mittel der

2 "Pamjat' o pamjat - takova. ona ntm, ona muzaka sfery, strany - gde ja byll do rożdenuja" Zit nach Andre, Belyj Konk letaev, [auerst Petrograd 1922), in. Slansche Propylicen. Bd 64, S 112

3 Serebrjany golub' kann als Belyjs polcmusche Antwort auf Brjusovs Roman Ognennyj angel (Der feunge Engel) getter, dessen Geschichte Betyjs gescheitertes "mystusches Expenment" behandelt de eleusinuschen Mystenen unter den Argonauten al etablieren Das Expenment scheiterte insofern, als Bety mit Nina Petrovskaja nicht die "hummlische" Lxebesbezchung verwirklichen konnte, sondern sich daraus cune scxucle Bezchung cntusckelte Vgl Mana Carlson "The Silver Dove", in Andrey Bely] The Spint of Symbolism. hi von John E Malmstad. S 60-96, S. 66 Siche auch Kapitel IIl dieses Buches

4 Andrey Belyj Meztu dusch rewoljucij (Zwischen zwel Rewolunonen), [Lenungrad 1934], Moskva 1989, S 354 . Belys autobrographische Schriften sowre seuxe Aufsatze tragen oft Titel. de cunen Umbruch bzw enc geschuchtliche Wende andzuten. we z B Na perewale (Auf dem Bergpaß). Na rubeže Aruch stolen) (An der (irenze zwischen zwel Jahrthunderien) usw Diese Posituon des "Dazwschen" ist auch signufikant fur Belyjs cigenc Position innertalb des symbolisuschen Zirkels 
Selbstheilung bzw. Selbsterlösung. In diesem Sinne kann der Text Die Silberne Taube als latenter Ort eines Sprechens gelten, in dem unverarbeitete physische und psychische Konflikte zum Ausdruck kommen und die Sujetstruktur bestimmen. Wie aus Belyjs Autobiographie hervorgeht, schien seine "Krankheit" in jenem "doppelten Bewußtsein" begründet gewesen zu sein, das paradigmatisch fur das hysterische Symptom bestimmt wurde. ${ }^{5}$ Der hysterische Körper lehnt eine eindeutige Differenzierung als Mann oder als Frau ab, er empfindet sich als bisexuell bzw. androgyn. In dieser Inszenierung ist er Zeichen einer sexuellen Prähistorie, die aus dem öffentlichen Diskurs ausgeschlossen bleibt. Wie auf den Fotografien aus Belyjs Kindheit zu sehen ist, akzeptierte Belyjs Mutter den kleinen Borja nicht als Jungen, sondem versuchte krampfhaft, aus ihm ein Mädchen zu machen: Als Kind trug er Mädchenkleidung. Sein Vater, Professor an der naturwissenschaftlichen Fakultät versuchte wiederum, aus ihm einen richtigen "Mann" zu machen. Auf diese Weise war Belyj von Kindesbeinen in einer Zwischenposition, er war Spielball im Machtkampf seiner Eltern": "Dies waren die primären Gefühle: Den Vater fürchtete und haßte er in einem heftigen Maße; [...] der lieben Mutter schenkte er sein Mitgefühl und sein Entzücken - letzteres fast bis zur sinnlichen Ekstase." ${ }^{7}$ Diese ödipale Ausgangssituation findet ihre Fortsetzung im Leben und Werk Belyjs. Er ist gleich in zwei Dreiecksbeziehungen verstrickt: mit Valerij Brjusov und Nina Petrovskaja und mit Aleksandr Blok und seiner Frau Ljubov' Dmitrievna: Seine Romane "sind $>$ fragmentarische Versionen eines Themas, einer im Kern einheitlichen

5 Maranne Schulke "Weibliche Neurose und Identutat Zur Diskussion der Histenc um die Jahrthundertwende", un: Die Wiederkehr des Korpers, hgg von Dietrnar Kamper und Chnstoph Wulf, FrankfurtMain 1982, S 180-192, S $184 \mathrm{Vgl}$ auch Regina Schaps Hystene und Weiblichkelt Wissen. schafismythen über die Frou. Frankfun 1982, S 55-82

6 Darauf verweist Magnus Ljunggrens Studie The Dream of Rebirth. Stockholm 1982

7 Alexander Edund Eros des Unmoglichen Die (ieschichte der Psychoanalise in Rußland, Leipzig 1996. $S 88$ 
Fabel<: des Dramas, welches sich einst in des Schriftstellers Familie ereignete. ${ }^{8}$

Belyjs Hysterie läßt sich am besten an seinem Veitstanz, seinem "tanzenden Körper"9 ablesen. Dieses körperliche Verhalten steht in engem Zusammenhang mit zwei Diskursmoden des Silhermen Zeitalters: Erstens mit dem DionysosKult, wie er von den Symbolisten im Anschluß an die Nietzsche-Rezeption literarisiert wurde ${ }^{10}$, zweitens mit der Chlystenbewegung, die sich gerade $\mathrm{zu}$ dieser Zeit großen symbolistischen Interesses erfreute. "Ein weiterer Grund für Belyjs Hysterie scheint aber auch die Angst vor Homosexualität gewesen zu sein. Kosofsky-Sedgewick hat darauf aufmerksam gemacht, daß dies zu einem Schreiben fuihrt, in dem sich diese Angst spiegelt. ${ }^{12}$ Sie charakterisiert dieses Phänomen als postromantisches Phänomen, das mit dem sogenannten paranord Gothic als literarischem Genre zusammenfält, in welchem die "Homophobie ihre gelungenste und verzweigteste Verkörperung" fand und für die "Grundlegung eines intensiven homosozialen Begehrens" steht. ${ }^{13}$ Auch Freud hat am Fall des Dr. Schreber auf die Verbindung zwischen männlicher Paranoia und

8 Ebd S. 88 Siche auch Vladislav Chodasevic Izbrannaja Proza [Ausgewahlic Prosa]. New York 1982, S 151ff

9 Unter den Zeitgenossen war wohl Maruna Zvetaeva dicjenige. de Belyjs Hystenc am eindeutugsten beschncb Lelomotivsch behandelt sie in Plenny chuch (Kin gefangener (jeist), |1934| Frankfurt 1989. S 167-242. den "tanzenden Korper" des Schnftstellers. der der .radenuja” den un Krets tanzenden Chlysten gleicht "So ist es fur mich auch geblicben der erste Belyj. der vor Goethe und Steinet tanze we Dand vor der Bundeslade Im Leben cunes Simbolisten ist alles Symbol Unsymbolisches gibt es nucht", "Belyjs tanzender Rucken", S 71, "Belyjs Vogelwesen", S 175. "Bely]. der hereingeflogen kam", S 178, "er flog fort", S 185 ctc

$10 \mathrm{Vgl}$ in diesem Zusammenhang Mana Deppermann "Nietzsche un Rußland", in Nietzsche Srudien. Bd 21, 1992, S. 211-252, S. 235ff

111908 war der Hohepunkt des symbolisuschen Interesses an Sekten Vgl in desem Zusammenhang Aage A Hansen-Love "Allgemeine Hareuk, russische Sekten und thre Literansienung in der Modeme", in Wiener Slawistischer Almanach. Sonderband 41, Wien 1996, S 171-295, "Dobroljubovs Ertrinken um russischen Wald der Sektanten", S. 242 und Alexander Etkund 1996, op cit., S 63

12 Eve Kosofsky Sodguick "Das Tier in der Kammmer Henry James und das Schreiben homosexueller Angst", in Dekonsinuktiver Feminismus Interaturwissenschafi in Amenka. $\mathrm{Hg}$ von Barbara Vinken, FrankfurtMain 1992. S 247-279

13 Ebd S. 252 
verdrängtem homosexuellen Begehren hingewiesen. ${ }^{14}$ Belyj beschreibt in seiner Autobiographie Zwtschen zwet Revolutionen eine ähnliche Situation, wenn er von seinem persönlichen Zustand als einem "Gefühl von Netzen und Verfolgung" spricht. Als er im Jahre 1909 seinen Roman zu schreiben begann, litt er zunehmend unter Verfolgungswahn und Depressionen. ${ }^{15}$ Wie in der folgenden Textanalyse gezeigt wird, spiegelt sich dieser innere Zustand in der Struktur Der Silbernen Taube wider, die durch ein signifikantes Netz (bzw. Netze) von Spaltungen und Verdoppelungen erzählerischer Verfahren (die Erzählerstimmen entpuppen sich als Masken des Autors, jede Figur hat ihren Doppelgänger, jeder Raum hat seinen Antipoden) jene Verstrickung bzw. jenen Verfolgungswahn im Text entfaltet, die Belyj körperlich beschreibt. Hinzu kommt die Tatsache, daß der Roman Die Silberne Taube den ersten Band einer geplanten Trilogie mit dem Titel (Osten oder Westen konstituiert, die Belyj nach kantianischem Schema konzipierte. Das Modell dieser Trilogie veranschaulicht Belyjs Rolle als "Prophet Rußlands"16, der in seinen Texten sowohl "die persönliche Gefahr der Vater-Sohn-Imitation" verarbeitet, als auch auf "die öffentliche Gefahr der politischen Usurpation" aufmerksam macht. ${ }^{17}$ In der Übertragung auf

14 Sigmund Freud Zwang. Paranoia. Perversion, Band VII. Studienausgabe. Frankfurt/Main 19691979

15 "[Bely] wandte sich der Theosophue zu. unsbesondere den Schnften von Elena Blavatskaja und trat dem thoosophischen Zirkel von Chnstoforova in Moskau bei Die gottsuchende Intelligencija, allen voran Ivanov und Munclova, bestarkten Belyj in seiner Neurose und seinem Verfolgungsuahn Wahrend eines Vortrags von Ivanov uber die mystusche Bezichung zuischen dem Volk und der Intellgencija am 27 Januar 1909 vor dem Moskauer Literatur- und Kunstlerzarkel brach er endgulag zusammen Er zog sich aufs Land zurick, wo er damt begann. die Ereignisse der vorausgegangenen Jahre, dxe zu dieser Knse fuhrten, zu 'banner' Er beschaftugte sich mut Astrologie und Okkulusmus. cnturckelte sein eigenes Horoskop und begann das erste Kapitel von Serebrjanyj golub' zu schreiben " Zit. nach Mana Carlson. "The Silver Dove", in Andrej Belyj The Spint of Symbolism, 1987, op cit., S 66

$16 \mathrm{Vgl} \mathrm{Manna} \mathrm{Zwetacua,} \mathrm{[1934],} \mathrm{1989,} \mathrm{S} \mathrm{195} \mathrm{"Ich} \mathrm{habe} \mathrm{den} \mathrm{Zusammenbruch} \mathrm{des} \mathrm{zanstuschen}$ RuBlands vorausgeschen, ich habe um Traum das Ende des Zaren geschen. schon 1905 hab ich's geschn, links die Sage, rechts die Axt "

17 Donng-Smumov "Scktanstvo i literatura Serebrjanyj Golub" Andreja Belogo", in "Chnstuanit and the Eastem Slaves Russian Culture in Modem Times (Vol 2)", Ed by. Robert P Hughes and Inna Paperno. Berketey 1994, S 194-200 
die innere Gespaltenheit Rußlands, sollte Die Silberne Taube als These die destruktive Kraft des Ostens darstellen, während Peterburg als Antithese, der zweite Band, das verwestlichte und damit kalte und leblose Rußland behandelt. Der dritte Band als geplante Synthese mit dem vielversprechenden Titel Die unsichıbare Stadt wurde nie geschrieben. Stattdessen erklärte Belyj Käterchen Letaev zum dritten Band der Trilogie. Dieser Roman handelt über die Entstehung des Bewußtseins und ist dem Kerngedanken der anthroposophischen Lehre - der Wiederverkörperung - gewidmet. In diesem Sinne steht Die Silbeme Taube am Anfang einer Triade von Wiedergeburtsphantasmen, die "im endlosen Konstruieren von Substituten des vorgeburtlichen Aufenthalts" ${ }^{18}$ mit dem Rückzug in die pränatale bzw. postnatale Geschlechtslosigkeit gleichzusetzen ist. Sie geht einher mit der Auflösung des Apoll-Dionysos-Konzeptes, des anthroposophischen Geist-Körper-Dualismus, der Vater-Sohn-Mythen, der verschiedenen Doppelgängerrollen, die die Figuren zu spielen haben. ${ }^{19}$ In dem der Text dicse Erlösungskonzepte parodiert, wird er zum On cines Schreibens, das in seiner grotesk-karnevalesken Inszenierung das symbolistische żızetvorČestvo, die "Lebensschöpfung", d.h. aus dem eigenen Leben ein Kunstwerk machen, dekonstruiert und damit das Scheitern des symbolistischen Romanmythos vorfuihrt.

In seinen Bemühungen um einen Ausweg aus der allgemeinen Kulturkrise und der Überwindung der gespaltenen Kultur Rußlands, die sich als status quo auf die russische Intelligencija übertragen hatte, entwarf der Schriftsteller ein neues

18 Luce Ingaray. Dhe Eihik der sexuellen Differenz. FrankfuruMain 1991, S 19

19 Renate Lachmann "Doppelgangerci", in Poenk und Hermeneunk. Band XVII. Munchen 1997, S $421-435, S 432$ 
Kulturkonzept, das aus seiner ästhetischen Theorie abgeleitet ist. ${ }^{20}$ Wie aus seinem 1909 verfaßten Aufsatz Die Emblematik des Sinns hervorgeht, betrachtete Belyj den Symbolismus als Verkörperung einer neuen Lebensform, "der Kunst der Zukunft", die die alte und neue Kultur in einer metaphysischen Einheit zusammenführt:

To dejstvitel'no novoe, čto plenjaet nas v simvolizme, est' popytka osvetit' glubocajšie protivorecija sovremennoj kultury cvetnymi lucami mnogoobraznych kultur My nyne kak by pereživaem vse prošloe. Indija, Persija, Egipet, kak i Grecija, kak i srednevekov'e. - oživajut, pronosjatsja mimo nas epochi, nam bolee blizkie ${ }^{21}$

Das wirklich Neue, das uns am Symbolismus fesselt, ist der Versuch, die tiefsten Widerspruche der zeitgenossischen Kultur mit den bunten Strahlen vieler Kulturen zu erhellen, heute erleben wir die ganze Vergangenheit noch einmal neu Indien, Persien, Griechenland, das Mittelalter werden ins Leben gerufen, wie jene Epochen, die uns näher stehen

Im "Dreieck vom Sinn und Wert der Existenz" konstruiert Belyj das Modell des Symbolismus als Weltanschauung. In der Darstellung von Maria Carlson sieht es folgendermaßen aus ${ }^{22}$ :

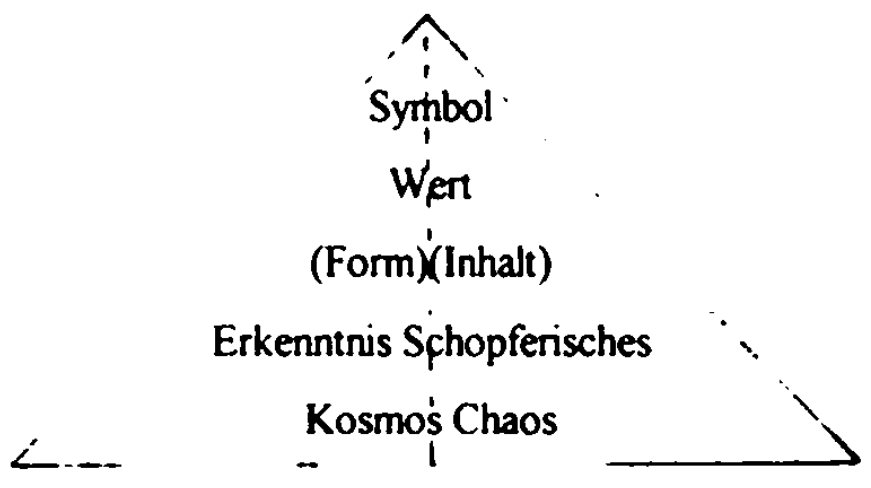

20 Belyjs asthetasche Theone von 1904-1908 steht ganz im Zeichen von Nietzsches Geburt der Tragodie, unterscheidet sich aber von der des deutschen Phulosophs "vor allem in der Haltung zur Religion Nach [Belyjs] Grunduberzeugung ist die Religion der Ursprung aller kunstlenschen Aktuvtat Er kntusert Nietzsche dann, daß er die Religion zwar in die Geburt der Tragodie engefuhrt habe. indem er den Ursprung des gnechuschen Dramas aus den eleusunuschen Mystenen herletect, aber daraus necht de Konsequenzen zog, den Platz der Religion in der Asthetik zu bestummen " Vgl Deppermann. 1992, op cit., S. 238

21 Andruj Belyj "Sumvolım", in Slavische Propylaen, Bd 62, S 49-143. S 51

22 Mana Cartson The ('onquesi of ('haos, Michugan 1983, S 105 
Das Dreieck als Emblem der symbolistischen Theorie veranschaulicht Belyjs Bemühungen, zu einer umfassenden Einheit, zur Synthese zu gelangen. Ihm unterstellt er das gesamte Spektrum menschlicher Erfahrung. An der Spitze des Dreiecks steht das Symbol. Belyj setzt es gleich mit „Antlitz“ (,lik“). Es verkörpert das Geheimnis, etwas, das man nicht wissen und nicht beschreiben kann, ein göttliches Prinzip, das alle Dinge in sich vereinigt und die Quelle für Sinn und Wert der Existenz ist. Das symbolische Sein des "lik" verkörpert das Sein-Sollen der Welt verkörpert und setzt den Glauben an seine Existenz voraus. Da es nicht direkt beschreibbar ist, ist es nur indirekt durch Symbolisienung erkennbar:

Kak Casto my vidim $v$ istorii, cto simvol izobražaet uslovnymi obrazami, v ponjatie o nem neobchodimo vvoditsja obraznoe soderzanie pri pomošci sredstv chudožestvennoj izobrazitel'nosti. Simvol ne možet byt' dan' bez simvolizacii, potomu- ¿to my olicetvorjaem ego $v$ obraze, obraz olicetvorjašcij Simvol, my nazyvaem simvolom $v$ bolee obščem smysle etogo slova ${ }^{23}$

Wie of sehen wir in der Geschichte, daß das Symbol sich durch gedachte Bilder darstellt. in dem Verstandnis uber das Symbol ist es unumganglich, unter Zuhilfenahme kunstlerischer Gestaltungsmittel, einen bildhaften Inhalt einzufuhren Das Symbol kann nicht ohne Symbolisierung gegeben werden, denn wir verkorpem es im Bild, das Bild. welches das Symbol verkorpert, nennen wir Symbol im weiteren Sinne des Wortes

Wie aus Belyjs ästhetischer Theorie weiter hervorgeht, erfolgt die Symbolisierung des Lebens durch drei Momente, die das symbolistische Sein bestimmen: šznetvorčestvo (Lehensschöpfung), teurglja (Theurgle), perextvanie (mysısches Eirlehen). ${ }^{24}$ Im żznetvorcestvo sind für den Autor Kunst und Leben unauflöslich miteinander verbunden. Gemäß der symbolistischen Vorstellung des Künstlers als Schöpfer eines neuen Universums, benennt der Künstler jedes Ding neu. Der Künstler als Verkörperung des Wortes schafft die "dritte Welt"

23 Andrej Belyj "Emblematuka smusla" (Dre Emblematik des Sunns), un Slavische Propsilaen. Bd 62. [zucrst Moskau 1910], S 49-143, S 105

$24 \mathrm{Vgl}$ Mana Carlson. 1987, op cit.. S 64 
(trett) mir), die Welt der Lautsymbole. Diese Worte sind kreative Worte als Ergebnis einer magischen Kombination von Lauten: "Aber jedes Wort ist in erster Linie ein Laut; der allererste Sieg des Bewußtseins." ${ }^{.25}$ Das schöpferische Wort des Künstlers ist das verkörperte Wort, der Wort-Leib. Nach Belyj ist das verkörperte Wort wahr, denn als sein Symbol erscheint der lebendige Leib des Menschen. In diesem Sinne kann man Belyjs Schreiben als körperlichen Prozeß beschreiben und seine Texte als dessen buchstäbliche Verkörpenung. Theurgie bedeutet im Wortschatz des Schriftstellers religiöse Kreativität. Sie basiert auf der mystischen Überzeugung, daß der Kosmos aus Lauten kreiert wurde: "Eine solche Bestätigung der Schaffenskraft in Worten ist eine religiöse Bestätigung." ${ }^{26}$ Perežrivanie bedeutet für Belyj, den Augenblick in mystischer Erhebung zu erleben.

In der folgenden Textanalyse wird gezeigt, auf welche Weise Belyj diese drei Elemente als Grundlage der symbolistischen Lebensform in dem Buch Die Silherne Taube integriert und auch parodiert. Denn gerade das Scheitern des lebensschöpfenden Projekts ist textgenerierendes Movens des Romans, der gleichzeitig das künstlerische und ästhetische Paradoxon der symbolistischen Theorie freilegt. Dabei verweisen die groteskkamevalesken Verfahren des Autors einerseits auf die Hysterie des żznetvorčestvo allgemein und andererseits auf die Hysterie des schreibenden Mannes im Silbernen Zettalter, der seine Weiblichkeit in der Maskerade der Männlichkeit versteckt. Das Sujet des Romans offenbart aber nicht nur die Verlagerung des privaten Theaters in ein öffentliches, dem des Textes, d.h. die Theatralisierung des Textuellen, sondem verweist auch auf die politische Gefahr der Chlystenbewegung für Rußland.

25 Andre Bely] "Magija slov" (Dic Magie der Worte). in. Slansche Propylaen. Bd 62, 1969, S 429. 453, S 430: "No vsjakoe s I o vo est' prezde vsego zvuk, pervejšaja pobeda soznanja "

26 Ebd S 448 "Tako utverzdenie sily tvortestva v slovach est' religioznoc utverzdenuc " 
Belyj nennt in seiner Autobiographie Zwischen zwei Revolutionen unter den von ihm vorausgeahnten Manifestationen des chlystovstvo auch Rasputin: "Die Silberme Toube ist ein Roman, der in vielem mißlungen aber in einem gelungen ist: aus ihm ragt ein Finger heraus, der jetzt noch auf einen leeren Ort verweist; aber diesen On wird bald Rasputin einnehmen." 27

Der Roman Die Silberne Taube spielt am Anfang des 20. Jahrhunderts. Die Geschichte handelt von dem russischen Intellektuellen Petr Dar'jal'skij, einem symbolistischen Dichter und Philologen, Kenner der Schriften Böhmes, Eckhardts, Svedenborgs, Marx ' und Lasalles. Dar'jal'skij ist auf der Suche nach der "Morgenröte". ${ }^{28}$ Bei dieser Suche gerät er in die Fänge einer geheimnisvollen Sekte, den Tauben (golubcen) ${ }^{29}$, die die Wiederkunf Christi, die Fülle

27 "Serebrjanyj golub' - roman, ncudačny vo mnogom, udaten $v$ odnom 12 nego torét palec. ukazyvajušcly na poka ešce pustoe mesto. no eto mesto skoro zajmet Rasputun" Rasputun wurde von dem homosexuellen Grafen Jusupov ermordet der genau we Belyj in Madchenkleider erzogen wurde Vgl "Felix Jusupoff" Eune Studic von Bons Groys. in Furst Felix Jussupoff Rasputans inde. FrankfurtMain 1990. S 9-41, S 12

28 Serebrjanyj golub' erschien erstmalig 1909 in Fortsctzoungen in der symbolisuschen Zeitschnft Vesy, $\mathrm{Nr}$ 3-4, 6-7, 10-11. 12 Als selbstandige Buchausgabe erschien der Roman 1910 bei Skorpion in Moskau Alk folgenden Textzitate entstammen dem Nachdruck der Berliner Ausgabe von 1922. in Savische Propylaen. Bd 38, Munchen 1967 Sie sind mit S G abgekurzt Die deutschen Zitate wurden von mir ubersetza Belyjs erster Roman markiert ene Wende in seiner Werkbiographie. Vgl in diesem Zusammenhang Konstantun Mocul'skuj Andrej Belyj, Pans 1955 Mocul'skuj bezeichnet den Roman als Wortrevolutuon. die durch die lynsche Prosa seiner Symphonien vorbereitet wurde: "Slovesnaja revoljucija podgotovlennaja linceskoj prozoj Simfonij nachodit svoc ṇrazenue v Serebrjanym golub'e Belyj nacinaet s urenjecskogo podrazanuja Gogol'ju On usvaivact vsc priemy ego stilistikj. dovodja ıch do krajnego emocional'nogo naprjazenuja Linka, ironja, grotesk, guperbola nagromozdenjja. kontrasty, stovesnuc kalambury, intonacil. kotont i ntm gogolevskoj prozy - pokazamy Belum skvoz' uveliętel'noe steklo " ("Dic Wortrevolution. die durch die lynsche Prosa der Simphonien vortoretet uurde. findent thren Ausdruck auch in dem Roman ."Die Silberne Taube“ Bely] beginnt mit der schulerhaften Nachahmung Gogol's Er eignet sich seine sulisuschen Verfahren an und fuhrt sie zur außersten emotionalen Spannung Lynk. Ironic. Groteske. Hyperbole, Kontraste. Wortspiele, Intonation. Kolont und Rhythmus der Gogol'sehen Prosa uerden von Belyj durch ein Vergrößenungsglas gezeigt"). S 157

$29 \mathrm{Vgl}$ in diesem Zusammenhang Aage A Hansen-Love "Belyjs (In-)sektenroman Serebrjanyj 
der Zeiten erwarten. Diese stellen sie sich entgegen der orthodoxen Lehre, nicht als Abstieg vom Himmel, sondern als Wiedergeburt im Fleisch vor: "Die Seligkeit nach dem Sterben interessiert die Häretik wie alle wahren Apokalyptiker nicht: Worum es geht, ist die Seligkeit $v$ o $\mathrm{r}$ und in dem leiblichen Leben, das kultisch und asketisch zu einem geistlichen verwandelt wird. Wenn alles Fleisch Geist geworden ist, herrscht Seligkeit und Jenseitigkeit, das im sektantischen Leben apokalyptisch vorweggenommen wird. Der Pneumatiker verwandelt sich in einen Engel schon zu Lebzeiten, daher ist eine Auferstehung des Fleisches, wie es die Orthodoxen als letzte Konsequenz ihrer Inkarnations-Christologie verlangen, für die Chlysten wie für alle Gnostiker undenkbar, weil unerwünscht. ${ }^{30}$ Bei dem Versuch, sich von der Taubensekte zu lösen, wird Dar'jal'skij ermordet. Eine Reintegration in die Orthodoxie ist damit gescheitert. Das Geschehen des Romans setzt bezeichnenderweise am Pfingstmontag ein und endet im September des gleichen Jahres, zum Fest Johannes des Täufers: "Die Chlysten waren überzeugt, daß sich die Offenbarung nicht als cinmaliges Pfingstwunder an den Apostel vollzogen hatte, sondern sich stets neu ereignete." ${ }^{31}$ Die Handlung spielt in dem fiktiven Dorf Celebeevo, auf dem Gut Gugolevo und in der Kreisstadt Lichov. Im ersten Kapitel wird das Dorf Celebeevo eingefuihn, Symbol für das ganze, heile Rußland. Hier leben das Haupt der Taubensekte, der Tischler Mitrij Mironyc Kudejarov und seine Magd Matrena. Die Figur des Tischlers ist wie jede Figur des Romans aus gegensätzlichen Elementen zusammengesetzt und wird dadurch ambivalent. In diesem Sinne ist die Rolle, die er im Roman einnimmt, mehrfach kodiert. Belyj verweist auf die ödipal motivierte Nachahmung des Vaters durch den Sohn, die dem

golub', 1996, op cit , S. 240, der auf die Widersprichlichkett der Verarbettung des "sektanstio" und hemetusch-gnosuscher und anthroposophuscher Mouve aufmerksam macht

30 Hansen-Love. 1996, op cit., S 209

31 Donng-Smimov, 1994, op cit. S 194 
Motiv der Usurpation entspringt, "das für bestimmte Phasen des historischen und kulturellen Selbstverständnisses Rußlands konstitutiv war" ${ }^{\mathbf{3 2}}$. Sein Name deutet auf den "Falschen Dmitrij", der sich im 17. Jahrhundert als Zar ausgab, um Macht über das Volk ausüben zu können, aber auch auf Rasputin, der sich die Zarenfamilie untertan macht: "Ich habe ihn in der Figur meines Tischlers phantasiert." ${ }^{33}$ Genauso wie Rasputin versucht der Tischler seine Kraft dazu zu benutzen, sich Andere vollkommen untertan zu machen. Der Tischler ist sowohl Teufel als auch Priester. Sein Aussehen ist mit einer Reihe von Assoziationen verbunden, die mit dem Teufel in Verbindung stehen. Er hinkt, hustet und hat einen bösen Blick. Sein Vorname verweist auf die Erdmutter Demeter. Im Rahmen des Taubenmysteriums fungiert Kudejarov als Priester des ErdmutterKults. Seine Nachname kann "koldun" (Oberpriester), "kudesnik" (Zauberer, Magier), "kudesnit"' (zaubern) und "kud"' (Böses, Geist, Satan) bedeuten, während "kudel"' (der fasrige Teil von Flachs oder Hanf), auf das Motiv der Spinnweben hinweist, das im Zusammenhang mit dem Tischler herausgearbeitet wird:

Stoljarovskaja pautina molitv', zatkannych solncem i t'moj $v$ odin vozdušnyj kover'. strannyj nevidimyj vid duša stoljara vytekaet naruzu pautinnymi nitjami, svetami. plamenami, vokrug ruk ego, vokrug ego golovy teper' - bagrovo zolotoj krug sonno vsjo to uvidala Matrena [ ...] (S G II, S. 107/108)

Man kann nicht mehr unterscheiden, was Sonnenlicht, was das Licht des Tischlers ist das Spinnengewebe aus den Gebeten des Tischlers, das sich mit Sonne und Dunkel au einem schimmernden Teppich verwebt In Spinnenfaden. Licht und Flammen dringt die Seele des Tischlers nach außen Um seine Hande. um seinen Kopf leuchtet ein rotgoldener Schein Matrena sieht das alles wie im Schlaf

Die böse Macht, die Kudejarov über Matrena und damit auch über Dar'jal'skij auszuüben vermag, wird sichtbar in Form der leuchtenden Fäden, in denen sich beide verstricken:

32 Lachmann. 1997, op.cit. S 429

33 "Ja ego sfantazroval v figurc svocgo stoljara", in Mezchu dunch rewoljucu, [zuerst Moskau 1934] 1989, op cit. S 354 
[. .] vsja ona v svetovoj, Zarkoj seti, a zelenye ugli nad nej l'jut vedra sveta, kjužkovatye pal'cy pletut zolotuju nit; vot stoljar otošel $i$ svetlaja ot nego polosa vytjagivaetsja, okancivajas' na Matrene, kak i v Matrene bol'sim svetovym klubkom [...] (S G II, S 108)

All das zieht jetzt wie ein Traum an Matrena voruber, ein gluhendes Lichtnetz umhullt sie; die grunen Kohlen uber ihr strömen Fluten von Licht aus, die krummen Finger spinnen goldene Fäden Der Tischler steht auf und tritt zur Seite ein goldener Streifen spannt sich zwischen ihm und Matrena

Das zweite Kapitel handelt von der Stadt Lichov, die als Schauplatz der Gebetstreffen der Tauben im Hause des Kaufmanns Eropegin stattfinden, das Unheilbringende verkörpert. Eropegins Frau benutzt die Abwesenheit ihres Mannes, um die Zusammenkünfte der Sekte im Badehaus zu veranstalten. Das reiche Kaufmannsehepaar Eropegin wird als Einheit dargestellt, die in zwei ungleiche Hälften zerfällt. Das Aussehen des Mannes, Luka Silyc, ist streng und ehrwürdig, aber seine Seele ist schlecht. Seine Frau, Thekla Matveevna, hat ein abstoßendes Äußeres, aber dafür eine gute Seele. Thekla deutet auf die erste Frau hin, die für Christus gemartert wurde, außerdem besteht eine Verbindung zu Theoclea, eine Seherin des Apollon-Orakels von Delphi. Beide Verweise unterstreichen die stark religiöse Ausrichtung der Figur. Luka deutet auf "lukavij" (hinterlistig, verschlagen), Sily $\mathcal{E}$ auf "sila" (Kraft). Damit ist vor allem die Brutalität des Kaufmanns gemeint, die sich im Umgang mit der alten Baronin Todrabe-Graaben äußert. Als Rache dafür, daß sie ihn in ihrer Jugend zurückgewiesen hat, will er sie jetzt finanziell zugrunde richten. Mit seinem Nachnamen wird "eropa" (selbstherrliche Person) assoziiert. Eine Verbindung besteht auch zu dem Verb "erepenit'sja" (widerspenstig sein, sich hartnäckig einer Sache widersetzen). Als Frauenheld und verschlagener Geschäftsmann verkörpert er die Welt des Scheins und der Materie, die von den wahrheitssuchenden Sektenmitgliedern überwunden werden will 
Das dritte Kapitel beschreibt das Gut Gugolevo, auf dem Dar'jal'skijs Verlobte Katja mit ihrer Tante, Baronin Todrabe-Graaben, lebt. ${ }^{34}$ Nach einem Zerwürfnis mit der Baronin verläßt Dar'jalskij das Gut und geht ins Dorf. Die alte Baronin Todrabe-Graaben, ihre Nichte Katja und ihr Sohn, Justizsenator in Petersburg, verkörpern im Roman den dekadenten Westen, den es zu überwinden gilt. Darauf weist ihr Name, der aus den deutschen Wörtem "Tod", "Grab" und "Rabe" zusammengesetzt ist. ${ }^{35}$ Der Rabe ist in der mythologischen und hermetischen Motivik (und in der Folklore) Symbolvogel der Weisheit, Prophetie und des Todes. Er steht in Opposition zur Taube. Die Baronin vertritt den alten, nach westlichem Vorbild erzogenen Adel; "gugnivost"', ihre näselnde Art zu sprechen, spielt auf die französische Sprache des Adels und damit auf ihre westliche Bildung an. Sie repräsentiert die Vergangenheit, die in der Gegenwart nur noch zum Schein existiert. Den Problemen der Zeit, wie dem Bauemaufstand und den Angriffen Eropegins steht sie hilflos gegenüber. Ihr Sohn Pavel Pavlovic verkörpert das apollinische Element, d.h. Erkenntnis, Logik, Vernunft und Ordnung. Dementsprechend begreift er den Epochenwandel, bleibt aber mit seiner Erkenntnis allein. Eine ernsthafte Gefahr sieht er in dem kommenden Sturm aus dem Osten. Er warnt Dar'jal'skij vor dem drohenden Untergang: "Prosnites', vemites' obratno", - i pokazyvaet po napravleniju k Gugolevu. "Kuda?" v ispuge vskidyvaetsja Petr. "Kak kuda? Na zapad: tam ved' zapad. Vy - celovek zapada; nu, cego ze vy pjalite na sebja rubašku? Vernites' obratno..." ("Wachen Sie auf, kehren Sie um" und zeigt in Richtung Gugolevo. "Wohin?" erwidert Petr voller Schrecken. "Wie wohin? Nach Westen: Dort ist doch der Westen. Sie sind doch ein

$34 \mathrm{Vgl}$ in diesem Zusammenhang Mana Carlson. 1987, op cit. S. 65 Carison weist darauf hin. daß Kafjas Bild von Belyjs neuer Liebe Asja Turgeneva inspinert wurde

35 Vgl. in diescm Zusammenhang Aage A Hansen-Love "Gogol" Zur Pocuk der Null- und Loerstelk. in Wiener. Nowisnscher Almanach. Band 39, Wien 1997, S 183-303, S 280 
Mensch des Westens; warum zichen Sie ihr Hemd an? Kehren Sie um", S.G.II, S.139) Aber die Umkehr nach Westen kann weder für Dar'jal'skij noch für Rußland eine Lösung bedeuten. Diesen Weg zu gehen würde bedeuten, den russischen Ursprung zu verleugnen.

Im vierten Kapitel beginnt die Dreierbeziehung zwischen Dar'jal'skij, dem Tischler und Matrena ${ }^{36}$ Nach dem Willen des Tischlers soll aus der sexuellen Vereinigung zwischen Darjjalskij und Matrena ein Kind des Geistes entstehen: Der neue Christus. Belyj überträgt die Rituale der Chlystenbewegung (der Name leitet sich von Christus ab) auf die Taubensekte und integriert sie in seinen Roman. ${ }^{37}$ Vor allem die "Aufhebung der genetischen Familien- und Verwandschaftsbande (Blutsverwandschaft)" und ihre Ersetzung durch pneumatische Formen der "geistlichen Bruderschaft" ist für die Sekten signifikant: Jeder ist zu jedem Bruder und Schwester. ${ }^{38}$ Das pneumatische Geist-Prinzip war für die Christologie der Sekte bestimmend: Jesus Christus wurde aus seiner historischen Einmaligkeit gelöst, er konnte immer wieder neu geboren werden als Verkörperung des Heiligen Geistes. Und in dem gleichen Maße wie Christus reduplizierbar gedacht wird, wird es auch die Gottesmutter. Diejenige Frau, die vom Heiligen Geist erfullt wird ("Sokatil") wird zu einer Gottesmutter. Die Rolle der Gottesmutter überträgt Belyj Matrena, einem häßlichen, pockennarbigen Weib, das männliche Attribute hat, während Dar'jal'skij, christusgleich, weiblich wirkt. Im fünten Kapitel warnt der Geheimwissenschaftler Šmidt seinen Freund Dar'jal'skij vor der kommenden Katastrophe. Šmidt, der jeden

$36 \mathrm{Vgl}$. in dresem Zusammenhang Mana Carlson. 1987, op crt., S. 65f. Carlson wetst darauf hin. daß Belyj in der Dreiocksbezichung von Dar'jalskj,. Matrena und Kudejarov seine exgenen Erfahnungen mt Blok und Ljubov' Dimitnevna, sowne sein seltsames Verhalenis mit Brjusov und Nina Petrovskaja Itteransiert

$37 \mathrm{Vgl}$. Manna Zvetaeva, [zucrst 1934], 1989, op.cit, S. 200: "[ ]aus der Stadt Tanussa m Gouvernement Kaluga. wo auf jedem Grab cune silbeme Taube ist. Ein Chlysten-Nest. dies Tanussa Tanussa? Schwesterherz' | | Mit Tarussa hat doch die Silberne Taube angefangen Mit den Erzahlungen von Serjosha Solowjow - uber jene Graber dort"

$38 \mathrm{Vgl} \mathrm{Aage} \mathrm{A} \mathrm{Hansen-Love.} \mathrm{1996,} \mathrm{op.cit.,} \mathrm{S} 206 \mathrm{f}$ 
Sommer in Celebeevo verbringt, ist eine ambivalente Figur. Er ist Russe und trägt einen deutschen Namen, er ist orthodox und glaubt nicht an Gott. Er beschäftigt sich mit Astrologie, die er wie eine konkrete Wissenschaft behandelt. Er ist Theo-soph und kennt sich im Okkultismus aus. Er ist Lehrer und Berater Dar'jal'skijs. Als Theosoph hat Šmidt lange Jahre den Lebensweg Dar'jal'skijs gelenkt: "On vspominaet prošlye gody, kogda Šmidt ego sudboj rukovodil, otkryvaja emu oslepitel'nyj put' tajnogo znanija; on byl uze cut' ne uechal s nim za granicu - $k$ nim, $k$ bratam, izdali vlijajušcim na sud'bu." ("Er erinnert sich an die ver-gangenen Jahre, als Šmidt sein Schicksal gelenkt hat und ihm seinen hellen Weg des geheimen Wissen eröffnet hat; er wäre ihm sogar fast bis ins Ausland gefolgt, zu ihnen, zu den Brüdem, die aus der Ferne sein Schicksal beeinflußt haben." S.G.II, S. 14). Šmidt warnt Darjjal'skij vor der drohenden Gefahr: "Kogda Saturn vojdet v sozvezdie Vodoleja, tebe ugrozaet beda; a vot teper', v eti dni - Saturn v Vodolee. Ja tebja v poslednyj raz govorju: beregis"" ("Wenn der Saturn mit dem Wassermann ein Sternbild eingeht, bedeutet das für dich Unglück; und jetzt ist Saturn mit Wassermann zusammen. Ich sage es dir jetzt zum letzten Mal, paß' auf dich auf" S.G.II, S. 14). Trotzdem vermag es Šmidt nicht, in das Schicksal des Helden einzugreifen: "Vot obertyvaetsja na prošloe svoe Dar'jal'ski: otvoracivaetsja ot okna, ot okna zovušcej i pogibajušcej Rossii, ot verchovnogo novogo vladyki ego sud'by, stoljara; i govorit' Šmidtu: Ja ne verju v sud'bu: vse vo mne pobedit tvorcestvo zizni...", (Ich glaube nicht an das Schicksal, in mir siegt der schöpferische Wille..." S.G. II, S. 15). Šmidt ist eine neutrale Figur im Roman. Er gehört weder dem Osten, noch dem Westen an, repräsentiert weder Chaos, noch Kosmos. Wenn auch sein Wissen, das er aus mündlicher Überlieferung erhalten hat, höher steht als die Erkenntnisse der konkreten Wissenschaften, werden seine Warnungen vor der Gefahr doch ausgeschlagen. Dar'jal'skij und mit ihm Rußland bewegen sich auf den Abgnund zu. 
Das sechste Kapitel handelt von Dar'jal'skijs Leben im Hause des Tischlers. Bei einer Andacht erscheint dort als Vision für kurze Zeit das Kind des Geistes. Später wendet sich die Taubengemeinde gegen Dar'jalskij als Erlöser. Daraufhin beschließt er, die Sekte zu verlassen und fährt mit dem Klempner Suchonkov nach Lichov. Als sich herausstellt, daß der Zug nach Moskau schon abgefahren ist, übernachtet er im Hause der Eropegins. Dort wird er von den Sektenmitgliedem erdolcht.

Belyj integriert das "Prinzip der Imitation und Wiederholung" ${ }^{39}$ der Chlystensekte gegenüber der Orthodoxie in seinen Roman. Wie der erste Apostel Simon-Petrus soll Dar'jal'skij einen neuen Grundstein für die Sekte legen. Petrus war derjenige, der Christus dreimal verleugnete. Dar'jal'skij verrät die Taubensekte durch seinen Versuch, sich von ihr abzusetzen. Sein Vorname Petr kann aber auch als Anspielung auf Peter den Großen verstanden werden, der Rußland "das Fenster zum Westen öffnete" und dadurch die Spaltung von intelligencija und narod herbeifürte. Diese kulturelle Spaltung versucht der Held Dar'jal'skij zunächst in sich zu überwinden. Darauf deutet die erste Silbe seines Nachnamens: "dar" bedeutet "Geschenk, Gabe, Talent, Begabung". Dar'jal'skij besitzt die Gabe, sich seinem "Geheimnis" zu nähern. Auf diesem Weg gerät er in die Macht unterschiedlicher Kräfte, die zur Spaltung seines Bewußtseins geführt haben:

No vidit Bog. ne lomalsja on on dumal. cto rabotaet nad soboj, $v$ nem zestokaja soveršalas' bor'ba izlišñej ogljadki slabosil'ja s predvkušenijem ešce ne naidennoj żzzni pobeden'ja, soveršalas' bor'ba vetchogo zverinogo obraza s novoj, podobnoj zverinoj. uze reloveceskoj zdravost'ju, $i$ on znal. čto raz vstupiv na etoj borby stezju, emu ne idti obratno. Eto stalo byt', $v$ bor'be etoj za budušcij lik žizni emu pozvoleno vse i nad nim nicego, nikogo, nikogda, (S G I, S 176)

$39 \mathrm{Vgl}$. Dorung-Smumov, 1994, op cit. . S 95 
Aber Gott zu sehen, zerbrach ihn nicht er dachte, daß er an sich arbeiten würde, in ihm fand ein schrecklicher Kampf statt wegen unnotiger Reue fur seinen schwachen Willen mit dem Vorgeschmack eines noch nicht gefundenen Lebensweges, es fand ein Kampf tierischen Ausmaßes in ihm statt mit einer neuen, tierahnlichen menschlichen Rechtfertigung. und er wußte, sobald er sich auf diesen Kampfesweg einließ, konnte er nicht mehr zuruckgehen, in diesem Kampf fur das zukunflige Antlitz seines Lebens war ihm alles erlaubt und daruber hinaus nichts, niemand, niemals

Dar'jal'skij will Katja heiraten, um in ihrer im 'Kosmos' verwurzelten Welt zu leben. ${ }^{40}$ Anfänglich sieht er in ihr die Verwirklichung seines neuen Lebensweges:

Ved' vremja eto - ne bolee kak včerašnij den', ešce on dumal vcera - tajna ego raskryvaetsja $\vee$ Kat'je, $v$ ee ljubvi i ee pocelujach Novyj ona ego put' i stolb nerušimyj istinoj żzzni. No pozemu ze i eto vとera - vremja uže nevozvratnoe (S G I, S 59)

Denn diese Zeit ist nicht mehr als der gestrige Tag Hatte er nicht gestern noch gemeint. das Geheimnis wurde sich ihm in Katja offenbaren, in ihrer Liebe, ihren Kussen? Hatte er nicht in ihr einen neuen Weg, die unerschutterliche Basis des wahrhaften Lebens gesehen? Aber warum ist auch dieses Gestem bereits unwiederbringliche Zeit

Unbekannte Kräfte entziehen ihm Katja. Sie offenbaren sich in der Magd des Tischlers Matrena. Ihrem "Zauberbann" kann Dar'jal'skij, der seit seiner Jugend auf der Suche nach der Morgenröte ist, nicht widerstehen. In Matrena glaubt er, dieses Geheimnis gefunden zu haben:

I kogda mimo nego prošel Darjjal'skij. tol'ko drognuli e guby da zagadoxno kak-to sverknuli glaza - u, kak oni zagorelis" Obernulsja, - obernulas' i ona u, kak ee opjat' ustavilis' na nego glaza' (S G I, S 62)

Und als Darjjal'skij an ihr vorbeischritt, zuckte es um ihre Lippen und geheimnisvoll funkelten ihre Augen, huh. wie sie funkelten' Er wandte sich um, und auch sie hatte sich umgewandt und starne ihn mit funkelnden Augen an

Die groteske Figur der Matrena wird zur Projektionsfläche jener Phantasien und Ängste, die Dar'jal'skij schon in seiner Jugend hatte. Sie bannen das Weibliche im Gut-Böse-Dualismus der heiligen Gottesmutter und der Hure:

$40 \mathrm{Vgl}$ in diescm Zusammenhang Mana Deppermann Andrej Belyjs asthensche Theone des schopfenschen Bewußiseins Symbolssienung und Knse der Kultur um 1900, Munchen 1983 
[..] budto tam, za oknom, stojala kakaja-to ženš̌̌na da rjaboe u nee bylo lico; i bezbrovoe -da vse êto bylo togda no raboe eto lico krivilos' gadkoj takoju ulybkoj, i takoj porok iskrivil to lico, gljanuvšee na nego besstydno, i vmeste neizglavimo zvavšee ego na bezstydstvo!. No otrego i tajna ego zakljutalas' v etom lice razve ego duši tajna zaklju飞ala grjaznyj. poroknyj smysl, kogda duša ulybalas' svetlym svetam zari? Da, zarja i ozarjala, i marala lico, cto pocudilos' emu za oknom. (S G I, S 132)

Es schien ihm, als hatte dort unter dem Fenster ein Weib gestanden, ja. und dieses Weib hatte eine blatternarbiges Gesicht, ja, und ohne Brauen war es gewesen, und dieses blatternarbige Gesicht hatte sich zu einem gemeinem Lachen verzogen ein lasterhafter Ausdnuck verzerrte das Gesicht, das ihn schamlos, zur Schamlosigkeit lockend, angesehen hatte' Sollte wirklich sein Geheimnis in diesem Gesicht begriffen sein schloß wirklich das Geheimnis seiner Seele einen schmutzigen lasterhaften Sinn in sich, während seine Seele der Abendrote zujauchzte? Die Rote des Himmels erhellte und verdunkelte zugleich das Antlizz, das ihm im Fenster erschienen war

Als doppelleibiges Fabelwesen repräsentiert sie sowohl das Gute und Mütterliche (ihr Vorname verweist auf das russische Wort mat', die Mutter) als auch das Böse (das durch die weibliche Verführung in die Welt gebracht wurde):

$V$ nich koli vzgljanes, vse ince zabudes' do vtorogo Christovo Prišestvija, utopaja. zabarachtaes sja v etich sinich morjach, molja Boga, toby tol'ko tebja skorej osvobodila ot plena morskogo zyžaja archangelova truba esli este u tebja ostanetsja pamjat' o Boge, i esli ty ne veriš v to, čto tu sinuju trubu ukral s neba diavol (S.G I, S.226)

Und schaust du in diese Augen, so vergißt du alles andere du versinkst in diesem blauen Meer und windest dich in seiner Umschlingung bis zar Wiederkehr Christi und betest zu Gott. daß die Posaunennfe der Erzengel dich moglichst schnell aus den Armen des Meeres befreien, wenn dir uberhaupt noch die Erinnerung an Gott geblieben ist und du nicht langst glaubst, daß der Teufel jene Posaunen des Gerichts aus dem Himmel entwendet hat

Matrena, die nicht von der westlichen Kultur beeinflußt ist und in der freien Natur lebt, symbolisiert das ursprüngliche Rußland, "Mütterchen Rußland" bzw. die Ungespaltenheit der Mutter-Kind-Symbiose, zu der es Dar'jal'skij, den "heimatlosen Intellektuellen", hinzieht:

Esli Ze ljuba tvoja inaja, esli kogda-to prošelsja na ee bezbrovom lice cernyj. ospennyj zud, esli volosi ee ry̌̌i, grudi otvisli, grjazny bosye nogi, i chotja skol'ko-nibud' vydaetsja Zjuot, a ona vse Že - tvoja ljuba - to, čto ty v nej iskal i našel, est' svjataja duši ot cisna i ej ty, ottizne ty, zagljanul vot $v$ glaza, $-i$ vot ty uže ne vidiš prežnej ljuby, $s$ toboj beseduet 
tvoja duß̌a, i angel-chranitel' nad vami snischodit', krylatyj Takuju ljubu ne pokidaj nikogda ona nasytit' tvoju dušu i ej uže nel'zja izmenit', v te že casy, kak pridet vozdel'enie, i kak ty ee uvidis takoj, kakaja ona est' to jaboe ee lico i ryże kosmy probudjat v tebe ne neznost', a żadnost', budet laska tvoja korotka i gnuba ona nasititsja vmig, togda ona, tvoja ljuba, s ukoriznoju budet gljadet' na tebja, a ty rasplaces'sja, budto ty i ne musCina a baba i vot tol'ko togda prigolubit' tebja tvoja ljuba, i serdce zab'estsja tvoe $v$ temnom barchate Cuvstv S pervoj nežnyj ty, chot' i vlastnyj mužcina, a so vtoroj’ Polno ne mužcina ty, no ditja. kapriznoe ditja, vsju-to budeś tjanut'sja zizn' za êtoj vtoroj, i nikto, nikogda tut tebja ne pojmet, da i ne pojmes' ty sam, eto vovse u vas ne ljubov', a nerazgadannaja gromada tebja podavljajušcej tajny (S G. I, S. 279/280)

Ist aber deine Liebste eine andere, ist ihr Gesicht von Blattemarben zerrissen, ist ihr Haar rot und hat sie eine Hangebrust, einen vorstehenden Bauch und nackte, schmutzige Fuße. so ist sie dennoch deine wahre Geliebte, - das, was du in ihr suchtest und fandest, ist die Seele deiner Heimat, und hast du der Heimat ins Auge geschaut, so hast du deine fruhere Geliebte vergessen; deine eigene Seele spricht aus ihr zu dir, und der Schutzengel breitet uber euch seine Schwingen Eine solche Geliebte verlasse du nie sie erquickt deine Seele und nimmer kannst du dich von ihr trennen In den Stunden sinnlicher Erregung erwecken ihr blatternarbiges Gesicht die roten Haarstrahnen nicht Zartlichkeit, sondern wilde Begierde in dir, kurz und grob wird deine Liebkosung sein und deine Begierde ist im Augenblick gestillt, dann wird sie, deine Geliebte, dich voruurfsvoll ansehen, und du brichst in Tranen aus, als warest du kein Mann sondern ein altes Weib und dann erst wird sie dich liebkosen, deine Geliebte, und dein Herz beginnt in süßer Wonne zu schlagen Mit der ersten warst du ein zartlicher, obwohl starker Mann Mit der zweiten bist du uberhaupt kein Mann, sondern ein Kind wie cin launenhaftes Kind wirst du dein Leben lang an dieser zweiten hängen, und niemand wird dich je verstehen konnen, ebensowenig wie du selbst verstehen wirst, daß nicht die Liebe euch verbindet, sondem die erdruckende Große eines unergrundlichen Geheimnisses

In ihr als seiner Schwester findet Dar'jal'skij seine wahre Erfüllung. Sie ist nicht nur die "Heimat seiner Seele"4l.

I vsja tebja ona stanet po otcizne sestriceju rodnenkoj, ešče ne vovse zabytoj v žizni snach - toju ona tebe stanet otciznoj, kotoraja gnustno greżtsja po oseni nam - v dni, kogda oranževye listy krutjatsja v sini prošcal'noj cholodnogo oktjabrja (S G I. S 282)

Und sie wird deine Schwester, deine Heimat, die du noch nicht ganz in den Traumen des Lebens vergessen hast - wird fur dich jene Heimat, von der man wehmutig im Herbste traumt, an jenen Tagen, wenn die orangerotgelben Blatter im sich verabschiedenden Blau des kalten Oktobers kreisen

41 Damut spielt Bely] auf Solov'cus ewige Freundin an Auch der Vomame Matrina konnte cin Zitat des gleichnamigen Solov'euschen Gedichts sein Vgl in diesem Zusammenhang Kapitel I 
Doch der anfängliche Zauberbann verflüchtigt sich schrittweise und zurück bleibt Matrena, das schielende, häßliche Weib, dessen Körper als negative, unmenschliche und kulturfeindliche Kraft eingesetzt wird ${ }^{42}$ :

A zakati glaza stoljaricha dva na tebja ustavjatsja zjjacich bel'ma Matreny Semenovny, tut pojmeš, ona-to tebja cužda i, kak ved'ma, prebezobrazno, a opusti dolu ona glaza i upris' imi v grjaz', solomu i strucki, da zaskonuzlye svoi ruki složla na żuot' - pobežit po licu ten', oðernjatsja skladki u nosa, javstvennyj $v$ rjabiny koža ee uglubitsja, - jabin-to mnogoe množestvo, - mjatym i potnym stanet lico, i opjat'-taki vypjatitsja żvot', a v uglach gub takaja zadrožit skladotka. Čo odna sramota budet tebe ona vsja - guljajuščj baboj (S G I. S 282)

Aber dann siehst du, daß ihre Augen schielen das eine Auge sieht dich an, das andere sieht an dir vorbei, und du mußt daran denken, wie heimtuckisch und falsch der Herbst ist Und richtet sie den Blick nach oben, so daß du das Weiße in ihren Augen siehst, dann erscheint sie dir fremd und abschreckend haßlich wie eine Hexe; und schlagt sie die Augen nieder und schaut auf den Schmutz, das Stroh und die Hobelspane am Boden, die Hande uber den Bauch geschlossen - dann gleitet ein Schatten uber ihr Gesicht, auf dem die vielen Blattemarben noch deutlicher werden, und noch mehr als sonst steht der Bauch vor, und um ihre Mundwinkel spielt ein Zug von Gemeinheit und du siehst in ihr nichts als ein grobes, liederliches Weib

Am Beispiel der Frauenfiguren Katja und Matrena setzt Belyj die klassische Dichotomisienung der Frau als femme fragile oder femme fatale, als Heilige oder Hure, fort. Sie steht im Zeichen der gespaltenen Kultur Rußlands und der in sich gespaltenen Intelligencija. ${ }^{43}$ Schon äußerlich unterscheiden sich beide Frauenfiguren vollständig. Katja ist schön und von adeliger Abstammung. Sie ist durch ihre französische Erziehung von der westlichen Kultur beeinflußt. Matrena dagegen ist ein häßliches, dickes, grobes, pockennarbiges Bauernweib. Katja (ihr Vorname erinnert an Katharina die Große) steht für das vom Westen beeinflußte Rußland, wie es sich in der Stadt Petersburg manifestier, Matrena

42 Belyj schreibt in Putevye zametka (Reisebeschresbungen), Moskva/Berlin 1929. S 99ff "Das Gehcimnus des Lachelns kennt unser Jahthundert nucht mehr, aber im Lacheln liegt der Anfang der Licbe, in ihm vereinugen sich Liebe und Soeke aber im Lacheln der Eva, die Adam den rotbackugen Apfel gab, entstand ein Riß in der Gantheit. durch Eva wurde dieser RAB verdrangt in der lacherlichen Verbundung der Köper im Koitus; um Ungestum des Geschlechts zeigt sich das Lachen. das Grauen. sowohl der Lacher als auch der Trauerer sind durch und durch Geschlecht. nur Geschlecht sie sind Halften, sie sind dic Gemeinhetten der Welt "

$43 \mathrm{Vgl}$ Regina Schaps. 1982, op.cit. S I30-138 
für das chaotische, ursprünglich Russische. Zwischen diesen beiden Welten ist der Intellektuelle Petr Dar'jal'skij hin- und hergerissen. Sein innerer Konflikt spiegelt zugleich den inneren Konflikt der gottsuchenden Intelligencija, die auf der Suche nach ihrer eigenen Identität und der Zukunft Rußlands im Kontext von Solov'evs apokalyptischen Visionen das mystische Rußland mit dem antichristlichen Westen vereinigen wollten.

Indem Belyj Dar'jal'skijs Geschichte auf der Folie der Christusbiographie beschreibt, parodiert er im Nachhinein die gesamte Paradigmatik des symbolistischen ziznetvorcestvo: Dar'jal'skij Bereitschaft, in die Sekte einzutreten, womit er unbewußt sein Todesurteil unterschreibt; seine Kopfbedeckung ([...] on vyšel; pjatiperstnyj bagrovyj venec ešče stojal vdaleke/[...] er ging hinaus; die rote funfzackig Strahlenkrone leuchtete immer noch in der Ferne." S.G.Il, S. 171); seine Ähnlichkeit mit dem verurteilten Christus, die Dornenkrone und der scharlachrote Mantel (vgl. Matthäus 27, 27); sein Zusammenleben mit dem Tischler Kudejarov und der Magd Matrena; scine Liebe zur Natur; das Mißtrauen der Dorfbewohner, die glauben, er plane einen Anschlag auf die Regierung ([...] delovye ljudi predpologali sperva, čto cel' est, cto cel' doľ̌na byt', i Cto cel' eta - protivopravitel'stvennaja/Geschäftsleute vermuteten anfangs, daß sein Aufenthalt einen Zweck haben müsse und daß dieser Zweck sich gegen die Regienung richte, S.G.I, S. 27); die Andacht im Hause des Tischlers, die an das letzte Abendmahl Christi erinnert (vgl. Matthäus 26, 26-29); auf dem Tisch steht ein Becher mit Wein ([...]v zestjnom kovše na stole zapuzyrilos' penoj tolko cto prolitoe vino/[...] auf dem Tisch - der umgeworfene Blechbecher, auf dem Fußboden Weinflecken, S.G.II, S. 148); seine Fahrt mit Suchorukov nach Lichov (Petr dumal o Kate [oblackov legkie strujki sgorali v ljubvi]; i net: Kati emu teper', kak vot tech oblačkov, ne dostat': net dlja nego Kati; i ščemit serdce/Peter denkt an Katja, aber er weist diese Gedanken von sich. Katja ist jetzt so unerreichbar für ihn wie diese roten Wölkchen am Himmel. Es gibt 
keine Katja mehr für ih! Sein Herz zieht sich schmerzlich zusammen, S.G.II, S. 174/175); der Verrat Suchorukovs, der Darjjal'skij in das Haus der Eropegins führt, wo seine Mörder schon auf ihn warten ([...] on pisal Kate, lichoradocno, spešno, točno želaja v odnom etom pis'me vyskazat' ej vsego sebja, ob"jasnit' ej vse êti dni sebe samomu neponjatnoe, a teper' vdrug stavšee jasnym do oxevidnosti povedenie/In fieberhafter Hast schrieb er an Katja, als wollte er sich ihr in diesem einen Brief ganz mitteilen, ihr sein Verhalten erklären, das ihm selbst die ganze Zeit hindurch vollkommen unbegreiflich und nun mit einem Schlag verständlich war, S.G.II, S. 240); der Mord durch die Glaubensbrüder ([...] on ved', - naš sobratik!/[...] er ist doch unser Bruder!, S.G. II, S. 245); die Anrufung Gottes (Gospodi, čto že eto takoe, cto že eto takoe?/O Gott, was ist denn das? Was wird mit mir geschehen, S.G.II, S. 242).

Durch dieses Verfahren verfremdet Belyj in dem Roman Die Silberne Taube nicht nur die Wiedergeburtsphantasmen des russischen "sektantstvo", die sich im Automessianismus der Chlysten widerspiegelt - Dar'jal'skij als "neuer Christus" - sondern auch das Gottesverlangen, das in der Liebessemantik des Religionssymbolismus als imaginierte Christusbrautschaft und Ewige Männlichkell (vecnaja mužestvennost') ${ }^{44}$ kodiert wurde, aber ebenso wie die Ewige Weiblichkeit androgyne Züge trägt. Das mystisch-erotische Durchspielen der jeweils anderen Geschlechtsidentität - also der neue Christus als weiblicher Mann (während die neue Gottesmutter als vermännlichte Frau erscheint) verweist damit auf das Phänomen des hysterischen Mannes: Die Ewtge Männlichkelt als Maskerade des effeminierten Mannes, dessen Geschlechtsverhalten ein homoerotisches Begehren offenbart. Der Text, der die Vater-SohnBeziehung in durch eine präödipale Mutter-Sohn-Beziehung ersetzt, bleibt, wie es die Annalyse gezeigt hat, im Vater-Sohn-Konflikt verhaftet, denn alle Vater-

44 Aage A Hansen-Love. "Zur psychopoetuschen Typologie der Russischen Modeme". in. Wiener Slawisnscher Almanach. Wien 1992, S 195-289, S 229 
funktionen werden auf das Mutterbild übertragen, das dadurch ambivalent wird. Auf diese Weise wird psychoanalytisch gesprochen der Versuch unternommen, einen symbolischen Mord am Vater zu begehen, jedoch nicht um seine Nachfolge anzutreten, sondem um die Stelle des Vaters als solche zu tilgen, damit eine Rückkehr in die präödipale Geschlechtslosigkeit möglich wäre. In diesem Sinne beendet der symbolische Vatermord jedoch nicht den Vater-SohnKonflikt, sondem perpetuiert ihn, ganz im Sinne der von Freud beschriebenen Urszene monotheistischer Religionen, die analog zur Kunstproduktion das Verdrängte zur Sprache bringt. ${ }^{45}$

Im Akt des Schreibens sublimiert Belyj sein homoerotisches Begehren auf ein auto(r)erotisches der Textproduktion. Der Text als Maske des effeminierten Mannes verweist damit auf den Kastrationskomplex, der sich nach Freud als Kastrationsangst artikuliert und sich im Blick auf den defizitären weiblichen Körper einstellt, die Angst vor dem "rien-à-voir" und die Angst vor dem Verlust

$45 \mathrm{Vgl}$ in diesern Zusammenhang das Kapitel "Der Kunstler als grober Mann und Held. Vaterersatz und Vatermorder" von Sarah Kofman in Die Kindhelt der Kunst Fine Interpretation der Freudschen Asthenk. Munchen 1993, S 28-36 Wichug in diesem Zusammenhang ist der Eunfluß Dostoevskujs (1821-1861), dessen Texte gewissermaßen als Pratexte Belyjs zu lesen sund. denn sie zeigen jene Verdoppelung der Frau als Hellige und Hure. de mit der Konzeption der heiligen Isebe im Silbermen Zetralier korrelien Gleschzeitig machen sie auch die odipale Inszenienung der Begehrensstruktur transparent und nehmen psychoanalytusche Ergebnusse vorueg Paradigmatusch dafur kann der Roman Podrostok (Der Jungling) gelten Gerade das uronusche Durchspieten odipaier Strukturen markıert das Romanguschechen Dic Suche nach dem Vater als Suche nach (geschlochtlicher) Identutat sucht m Mittelpunkt von Podrostok. dessen Titel auf die gescllschaftiche und damit sexuelle intuation des Helden Arkadj verweist Arkadjj Dolgonukij. Autor der Tagebuchaufzeichnungen, erzahlt dic Geschuchte seiner "zufäligen Familic" Dostoevskuj problemausken in diesem Roman jenen Moment der Kultur, der von Deleuze und Guartan als "wahnsinnige Odipalisicrung" in Frage gestellt wurde. in Gilles Deteuze und Felix Guattan Anth-()dipus Kaptlalismus und Schizophrente, Frankfurt/Main 1976, S 67 Als Reaktoonsbildung auf den Odipuskomplex fuhrt dieser Text das Durchspielen und Inszenueren von Geschlechiendentitaten vor Der Mann als Frau. dic Frau als Mann Vgl in dicsem Zusammenhang Aage A Hansen-Love "Der Diskurs der Konfession", in Fjodor Dostoewskj Der hingling. Munchen 1988, S 874-911, S 886 "Dic Eindeuugkett cuner klassischen Odipussituation ist dadurch aufgetober, daß der Sohn gleichzeitug mehrere Ziele verfolgte | | Diese odipale Blindhelt des Sohnes gegenuber dem Vater ist also in sich methrfach widerspnuchlich, ja der Odipusmỵthos selbst uurd in entscheidenden Punkten pervertuert Arkadju sucht mecht den phusisch-psychuschen Besitz der Mutter, sondern des ant der Mutter identufizierten Vaters. Arkadij totet kenneswegs den Vater wie der Odipus - im Gegentel er rettet Wersiloff, als dieser un der Schlußszenc de Waffe gegen de eigene Brust nchtet " 
des eigenen Phallus auf. ${ }^{46}$ Das weibliche Genital erscheint als zersetztes Gebilde, weil es zum Inbegriff des phallischen Mangels avanciert. In diesem Sinne steht die Wiederkehr der Ewtgen Mönnlıchkelt für die Verleugnung der Kastration als Mangel und für die Beglaubigung der eigenen phallischen Unversehrtheit: "Der metaphorische Schleier des ewig Weiblichen verhüllt dieses Geschlecht, das dem Blick kastriert scheint. Ein >strenges Über-Ich< wird als sein Erbe eingesetzt". ${ }^{47}$ Belyjs Schreiben kann damit als Ausdruck der männlichen Angst vor der übermächtigen Gegenwart des Nichts gesehen werden, die korrespondiert mit Furcht vor der Frau: der Text - Die Silberne Toube - travestiert die Ge-schlechtsangst. Nur die Schrift verwirklicht die Erlösung, nur darin kann die Spaltung überwunden werden:

My dol'žny zabyt' nastojašxee my dolžny vse snova peresozdat' dlja ètogo my doľ̌ny sozdat' samich sebja I edinstvennaja kruža, po kotoroj my možem ešce karabkat'sja, eto my sami $\mathrm{Na}$ veršine żdet naše ja Vot otvet dlja chudožnika esli on chocet ostat'sja chudoznikom, ne perestavaja byt' Celovekom, on dolžn stat' svoej sobstvennoj chudožestvennoj formoj. Tol'ko eto forma tvor estva eše sulit' nam spasenie Tut i ležit put' budušcego iskusstva ${ }^{48}$

Wir mussen die Gegenwart vergessen wir mussen alles noch einmal von vorne schaffen dazu mussen wir uns selbst schaffen. Und der einzige Hang, auf dem wir noch klettern konnen, sind wir selbst Auf dem Gipfel erwartet uns unser Ich. Hier liegt die Antwort für den Kunstler wenn er Kunstler bleiben will, ohne aufzuhoren, Mensch zu sein, dann muß er zu seiner eigenen kunstlerischen Form werden Nur diese Form der Schopfung verheißt uns die Rettung Hier liegt auch der Weg der Kunst der Zukunft

Der Text steht dabei konstitutiv für eine "Mystik des Postgeschlechtlichen", d.h. für Geschlechtslosigkeit einerseits und Doppelgeschlechtlichkeit andererseits. Er bildet die Voraussetzung für ein künstlerisches Schaffen, dessen Ästhetik auf der Usurpation und Tilgung des anderen (jeschlechts beruht und damit Geschlechter-Differenz emeut als binäre Opposition in Szene setzt.

$46 \mathrm{Vgl}$. Luce Ingaray Spiegel des anderen Geschlechis, FrankfurdMain 1980

47 Ebd S. 102

48 Andrej Belyy: "Budušca iskusstvo" (Dic Kunst der Zukunft, von 1907). in Slansche Propylaen. 1969, op cit., S 453. 


\title{
8. Idealisierte und/oder perhorreszierte "Weibs-Bilder":
}

\author{
Aleksandr Bloks Kult der Schönen Dame
}

Von der Volksseele und von unserer mit ith an Asche gewordenen Seele muß man mit schlichter und mannhafter Stimme sagen "Und sie wird auferstehen " Wir selbst mogen untergehen, doch die Morgenrote jener ersten Liebe bleibt.

Aleksandr Blok ${ }^{49}$

Besonders deutlich wird das Erscheinungsbild des hysterischen Mannes im Silhernen Zettalter an jenen Projektions-Dramen, die sich im Religionssymbolismus in der Auseinandersetzung zwischen den maskulinen Autoren und ihren idealisierten und/oder perhorreszierten "Weibs-Bildern" abspielten. Im folgenden Kapitel dient Aleksandr Bloks Kult der Schönen I Lame als weiteres Beispiel, dieses Phänomen darzustellen. Die Inszenienung privatester Verhältnisse im Sinne eines religiös-ästhetischen Mysterienspiels, in dessen Rahmen die religionskünstlerischen und ästhetischen Konzepte des Alltags ("byt") durchgespielt und durchgearbeitet werden, zeigt auf der einen Seite das Scheitern dieses großen Projekts im biographisch-existentiellen Bereich, was für die jeweils Beteiligten eine Tragödie war. Auf der anderen Seite enthüllt sie das kulturelle und ästhetische Paradoxon dieser Theoriebildung: Der Mangel - die

49 Aleksandr Blok ..O sovremennom sostojanı russkogo sumvolızma“ | 1910], in Sobranie Sičzinenuj v $v$ vos'mı romach. Moskva-Lenungrad 1962. Bd 5, S 425-436. S 435 "O narodnoj dušc i o našcj. vmeste s neju ispepelennoj. nado skazat' prostim I mužestvenn!m golosom Da voskresnet Možct byt. my sams i pogibnem, no ostanctsja zara toj penoj ljubv 
"Penia" - wird zum Movens für die Entstehung der "Fülle" des Künstlerischen. Gleichzeitig wird klar, daß die Inszenienung der jüngeren Symbolisten, deren Vorbild die dionysischen Feste waren, in direktem Zusammenhang mit der Hysterie zu sehen ist. Auf die Vergleichbarkeit zwischen Dionysos-Kult und Hysterie hat bereits Nietzsche in der (Götzen-Dämmerung aufmerksam gemacht. Er betrachtet beide Menschentypen als beständige Verwandlungskünstler, deren Schauspiele Inszenierungen des Sinnbildungsprozesses darstellen, die sich "als Ersatz eines Mangels an ursprünglichem Signifikat" ${ }^{50}$ vollziehen. Das Erscheinungsbild des hysterischen Mannes im Silbernen Zeitalter könnte man in dieser Engführung als Effekt einer Theorie des Performativen avant la lettre schlechthin beschreiben, so wie sie Žižek für Lacans Konzept einer selbständigen symbolischen Ordnung charakterisiert hat. ${ }^{51}$ Dabei ist die "Männlichkeit" als Maskerade eines effeminierten Mannes zu deuten, während das idealisierte "Weibs-Bild", die Schöne Dame und seine Perhorreszienung im Bild der Unbe-

50 Marianne Schuller "Weibliche Neurose und Identutat. Zur Diskussion der Hysterie um die Jahshundertuende", in Die Wiederkehr des Korpers, hgg von Dietmar Kamper und Chnstoph Wulf, Frankfurt/Main 1982. S. 180-192, S. 186f

51 Slavoj Zizck "Roberto Rossellini "Die Frau als Sumptom des Mannes", in: Lettre 12/Frihjahr 1991. "Die Frau als Symptom des Mannes" gilt als eune der notonsch frauenfeindlichen Außerungen des spaten Lacan Zizek weißt darauf hin. daß dieser Satz durch ein hohes Maß an Ambiguitat gekennzeichnet ist, denn et spicgelt den Wandel un Begnff des Symptoms in Lacans Theorie. Das Symptom galt berm fruhen Lacan als verschlusselte Botschaft. dementsprochend stellt das Frau-Symptom die Verkorpenung des ersten Sündenfalls dar, als ein Zeichen der Tatsache. daß der Mann seinem Begeturen nachgab Ebenso gilt bei Freud und Weininger de Frau als Verkorpenung der Sünde des Mannes, die nicht in sich selbst exustuen. Nach Weininger braucht sich der Mann nur von seinem Begehren nach der Frau zu renigen. damit ste ihren ontologischen Status vertien und in ihre Bestandteile zerfallt. Beim spaten Lacan bodeutete das Symptom eine signifizerende Position. die dem Subjekt seine spezelle ontologische Konsistenz verlehth indern es ithm ermoglicht. seine grundlegende. konstutuve Bezchung zur jousssance zu struktuneren Das Verhalmus des Mannes zu seinem Symptom verkehr sich folglich. dern wern sich das Symptom auflost. fällt das Subjekt als solches auseinander "In diesem Sinne bodeutet das Diktum, de Frau ist das Symptom des Mannes. daß der Mann nur durch die Frau, qua seines Symptoms exustuen: seine ganz ursprungliche Konsistenz verdankt sich seinem Symptom Mit anderen Worten, der Mann existnert buchstablich sen ganzes Wesen liegt außerhalb seuner selbse in der Frau Die Frau hingegen existien nicht. sie insistiert, weshalb sie nicht ausschließlich uber den Mann existiert In ihr ist etwas, was die Bezichung aum Mann flicht. den Bezug aum phallischen Signifikanten. Lacan versuchte bekanntlich. diesen Exzess mit dem Begriff eines nicht alles weibliches Genueßen - jouissance - zal fassen "* 
kannten zum Symptom des "die Frau schreibenden Mannes" wird. Žiž̌ek verweist im Rahmen seiner Untersuchung auf die besondere Rolle des Performativen für Lacans Theorie, die auch für die symbolistische Ästhetik paradigmatisch ist. Gemäß Austins Lehre, daß wir mit Worten Dinge tun können, wollten die Symbolisten mit ihren Worten die Wirklichkeit verändern und damit auch die Semiotik des zwischenmenschlichen Verhaltens. Das zeigen die maskulinfemininen Diskursspiele innerhalb des symbolistischen Zirkels sehr deutlich. Anders gesagt spielten die Symbolisten ihre Rolle als Lebensschöpfer derart authentisch, daß sie ihr gesamtes Privatleben unter diese "Ideologie" stellten. Thr Bestreben war es, einen Zustand absoluter Gleichzeitigkeit von Leben und Kunst und ihrer unauflöslichen Verquickung zu vergegenwärtigen. In diesem schicksalhaften Rollenspiel wurde ihre Maske zur Wirklichkeit: sie machte die Symbolisten zu dem, was sie vortäuschten zu sein. Darin bestand ihre symbolische Effizienz. Gleichzeitig wurde diese Inszenienung von einem Moment überlagert, das sich in der Theophanie als Gotteserscheinung äußerte. In dem hier vorliegenden Fall "erleuchtete" sie den jüngeren Symbolisten Aleksandr Blok und in dieser Erleuchtung fand er den Stimulus seiner Textproduktion: die Verse von der Schönen Iame.

1904 erschien Aleksandr Bloks (1880-1921) erster lyrischer Zyklus mit dem Titel Stichi o Prekrasnoj Dame (Verse von der.Schönen IJame) ${ }^{52}$. In diesen Ge-

52 Bloks lynscher Zyklus Sinchı o P'rekrasnoj Dame umfaßt unsgesamt 163 Godichte Sxe erschicnen zuerst in det Zetschnft Novyj Put' (Der neue Weg), dem Publikationsorgan der Merezkovskuschen Religions-Philosophischen (iemeinschaff Alle folgenden russischen Textzitate entstammen der Ausgabe Sobranie Soxinenij Tom pervyj Sichonorenija 1897 -1904, Moskva-Leningrad 1960. S 74-319, alle deutschen Textztate, falls nicht anders vermerkt wurde. entstammen der Herausgabe von Fntz Micrau Aleksandr Block Lynk und Prosa. Berlin 1982 Zur Problemauk des Zyklus sictie Ench Pọntuxt Die Zyklisterung lynscher Texle bet Aleksandr Blok. Munchen 1988 Im Rahmen dieser 
dichten aus den Jahren 1901-1903 ästhetisiert Blok seine mystischen Erfahrungen mit der Erscheinung der Ewigen Weıblıchkeit, die unter dem Einfluß der Darstellungen des Religionsphilosophen Vladimir Solov'ev über die göttliche Weisheit, der Sophia entstanden waren. ${ }^{53}$ Wie in Kapitel I dargelegt wurde, personifizierte Solov'ev die himmlische Weisheit in der Gestalt der heiligen Sophia als das Urbild der Schöpfung, das die Welt in ihrer idealen Gestalt und Schönheit umfaßt. ${ }^{54}$ Blok modifizierte jedoch die Visionen des Religionsphilosophen über die himmlische Sophia in zwei Punkten. Während Solov'ev die irdische Frau der himmlischen anpassen möchte, nimmt Blok die himmlische Frau als Ausgangspunkt seiner Mystifikation. Hinzu kommt die Tatsache, daß er den Troubadurkult als Matrix der höfischen Liebe und den Frauendienst des Minnesangs sowie die Symbolik der katholischen Kirche in seine Texte einfuihrt. ${ }^{55}$ Gerade Bloks Adaption des Marienphantasmas als Verkörperung einer Junggesellen- und Aufzeichnungsmaschine par excellence macht auf die Relevanz der Position des filialen Mannes innerhalb des symbolistischen そizne-

Arbet wurden nur die fur die Themenstellung der Arbeit signufikanten Godichte untersucht

53 Blok beschreibt in seiner Tagebucheintragung vom 25 Januar 1901 die Erscheinung der Schonen Dame "Guljan'c na Monctnoj $\mathrm{k}$ vetenu v soveršenno o s o b o m nastroenii $\mathrm{V}$ konce janvarja i nacale fevralja (este sine snega okolo polkovoj cerkv - tožc $k$ veteru) j a v n o j a v l j a e t s j a o n a" ("Ein Spazacrgang gegen Abend auf der Monetnaja-Straße in ener vollkommen besonderen Summung Ende Januar, Anfang Februar (blauer Schnoc umgab dic Regumentskurche - auch gegen Abend) crscheunt unverkennbar sie"). Zit. nach Konstantun Mocul'skuj Aleksandr Blok. Pans 1948, S 47. Mocul'skj unterstreicht die Echtheit der mystuschen Erfahrungen Bloks

$54 \mathrm{Vgl}$ in diesem Zusammenhang Rolf-Dieter Kluge Westeuropa und Rußland im Weltbild Aleksandr Bloks, Munchen 1967, insbesondere das Kapitel II "Das Ewz-Weibliche" Das Prinzap des Euzg-Weiblichen im Werke VI Solov'evs, in der westeuropauschen Mystlk und in der Dichtung Alcksandr Bloks, S 37-64

55 Der Minnesang ist der russischen-orthodoxen Kurche und Mystuk fremd Er stellt eine kulturelle Leerstelk dar, auch uird de Jungfrau Mana nicht auf diese Weise verehrt. uxe es dic katholische Kirche kthn In Simysl ljubvn (Der Sinn der ldebe) [1896] letunt Solov'ev die Troubadur- und Munnodichtung konsoquent ab, denn die "Minnesanger und Ritter [begnugen] sich bei threm starken Glauben und bet threr schwachen Vernunft mit der enfachen Ineinssetzung des Lietesideals mit der gegebenen Person und [verschließen] die Augen vor der offensichthichen Inkonsequenz beider", in Gesamiousgabe, Freiburg 1953, Band VII. S 201-272, S 232. Vgl in diesem Zusammenhang RolfDieter Kluge. 1967, op.ct, S 34. 
tvorcestvo aufmerksam. Die Position des filialen Mannes, von der her das Phantasma konzipiert ist, beruht auf einer besonderen Intimität des Mutter-SohnVerhältnisses; der Sohn ist exklusiv bei der Mutter ohne den Vater-Mann. Inbegriff des Phantasmas ist die filiale Autarkie, der Sohn-Mann, sein Endzweck der reine Selbstbezug des Mannes auf sich selbst, die spirituelle Monosexualität und die Rückbindung der Vater-Sohn-Symbiose, symbolisiert im Mutterkörper, der ein Jungfrauenkörper ist.

Gemäß den "Spielregeln" des symbolistischen žiznetvorčestvo ${ }^{56}$ mystifizierte und mythisierte Blok seine eigene Jugendfreundin, die reale Ljubov' Dmitrievna als Inkarnation dieses Phantasmas. ${ }^{57}$ In dieser wechselseitigen "Festschreibung" der Schönen Dame im Kunst- und Lebenstext produzierte Blok jene "doppelte Verschiebung", die Gyatari Spivak beschreibt als die "Ver-Entstellung" der Frau im Text und die Stelle der Frau als Entstellung für die (männliche) Theorie", in diesem Falle die symbolistische. ${ }^{58}$ Mit dieser "doppelten Verschiebung" inszenierte Blok seine Identität als symbolistischer Dichter und löste einen wahren Kult der Erscheinung der Schönen Dame innerhalb des symbolistischen Zirkels aus, deren Projektionsfläche die eigene Ehefrau darstellte. ${ }^{59}$ Umgekehrt hatte diese Mystifikation für Ljubov' Dmitrievna

56 Siche dazu ausfuhrlich Kapitcl III dieser Dissertation Hofische Lsebesspicle - Todliche Inszenieungen

57 'Tvorcestvo Bloka ob'edinjalos' | . 1, prizde vsego Lenost'ju avtora. $\propto$ vnutrennym obrazom. $\propto$ lejtmotavom v tekstc, $\propto$ duchovnoj i tvorceskoj sušcnost'ju. raznvajušcejsja v oprodelcnnom napravlenii. I samim napravlenuem $\propto$ evolucu", (Bloks Werk schloß sich zusammen | | vor allem durch die Personlichket des Autors. ihrem inneren Bild. ihrem Leitmouv im Text, threr geisugen und schopfenschen Eigenar. dic sich in exe bestummte Richtung enturckelec und durch dic Richtung threr Evolution setbst) Zit nach Dimitnj Maksumov Poezzja i prosa Al Bloka (Poesie und Prosa Aleksandr Bloks), Lenungrad 1975, S 329. Zum "herrschaftlichen Gebaren" unnertalb des symbolistuschen Zurkels siche cbd. S. 35

$58 \mathrm{Vgl}$ Gyatan Spivak "Verschucbung und der Diskurs der Frau", in Dekonsinuksiver Feminismus Isteraturwissenschafi in Amenka. (Hg von Barbara Vinken), Frankfure/Main 1992, S 183-219

59 Blok heiratete 1903 seine Jugundfreundin Ljubov Dmitrievna Mendelecva. Tochter des berihmten Chemikers Dimitriy Ivanoṿc Mendeleev (1834-1907) 
zur Folge, daß sie sich fortan im "Niemandsland" befand. ${ }^{60}$ Sie wurde durch diese doppelte Festschreibung funktionalisiert. In ihren Memoiren schreibt sie:

Oni znali, kakaja ja doľ̌na byt', potomu čto oni znali, remu ravna "funkcija" $v$ uravnenii poet i ego zena No ja byla ne "funkcija", ja byla celovek [ ..] Zizn' menja postavila s dvadcatiletnego vozrasta, na vtoroj plan, i ja etot vtoroj plan ochotno i otcetlivo prinjala pocti na dvadcat' let ${ }^{61}$

Sie >die symbolistischen Dichter, DR $<$ wußten, wie ich sein sollte, denn sie wußten, wem die Funktion in der Gleichung - der Dichter und seine Frau - glich Aber ich war keine "Funktion", ich war ein Mensch [ ] das Leben hatte mich seit meinem 20 Lebensjahr gezwungen, an zweiter Stelle zu stehen, und ich habe diese zweite Stelle gern und bereitwillig fast 20 Jahre eingenommen

In den Versen von der Schönen IJame verehrt und verherrlicht das lyrische Ich die angebetete Dame als weibliches Idealbild einer himmlischen Göttin. Es nimmt dabei jene Position ein, die charakteristisch ist für den Minnediener im Troubadurkult: die unstillbare, unbegrenzte Liebessehnsucht und sein Wissen um die Hoffnungslosigkeit der Werbung. Um sich seinem abstrakten Ideal ganz hingeben zu können, gibt das lyrische Ich vor, seinen eigenen Willen auszulöschen. In diesem Prozeß wird die Liebe zur Religion erhoben, die das Göttliche in Gestalt einer Frau oder Madonna offenbart. Die Geliebte verwandelt sich in eine Göttin, deren Erscheinung (svidanie) den Dichter aus der irdischen Welt erlöst und ihm die himmlische Welt öffnet ${ }^{62}$ :

$60 \mathrm{Vgl}$ desen Begnff des Niemandsland beı Gilbar und Gubert No man's land. Chicago 1990 und bei Myra Jctilen in Dekonsinukiver Feminismus, 1992, op cit. S 319-360

61 Ljubov' Dmutnevna Mendelecva-Blok Byll i nebylici (Wahrhett und Dichrung), in "Studien und Texte", Bremen 1977, S $5 f$

62 Diese Spintualisienung der Liebe stellt Kluge als de spezifische Leistung der Romantak dar "Zugnunde hegt ihr die problematusche Exustenz des Mannes, den es nach Erlosung verlangt", vgl RolfDieter Kluge. 1967, op cit, S. 32 
Vstuplenie

Otdych naprasen Doroga kruta,

Vexer prekrasen Stuču v vorota

Dol'nemu stuku Cužda i stroga.

Ty rassypaes' krugom Cemzuga

Terem sysok, i zarja zamerla

Krasnaja tajna u vchoda legla

Kto podzigal na zare terema,

Čto vozdvigala Carevna Sama?

Kazdyj konek na uzomoj rez'be

Krasnoe plamja brosaet $k$ tebe

Kupol stremitsja v lazumuju vys'

Sinie okna rumjancem zažglis'

Vse kolokol'nye vzory zvony gudjat

Zalit vesnoj bezzakatnyj najad

Ty li menja na zakatach zdala?

Terem zay.gla? Vorota otperla?

28 Dezember 1903 (S 74)

Ruhen nutzt schwerlich. Der Weg steilt empor

Der Abend gluht hertlich Ich klopfe ans Tor

Das irdische Klopfen fallt fremd an IHR Ohr,

Die rings tausend Perlen verstreute, verlor

Ihr Schloß, himmelhoch in die Feuer geturmt,

Ihr Eingang. den rot das Geheimnis beschirmt.

Wer setzte am Abend die Turme in Brand,

Die sie groß erbaute mit Eigener Hand?

Jedes Pferdchen auf gemustertem Schnitzwerk

Rotes Feuer wirft sich zu dir

Die Kuppel strebt in die lazume Hohe

Die blauen Fenster entbrannten in Rote 
Alles Glockenlauten drohnt

Uberflutet im Fruhling die untergangslose Kleidung

Hast du mich in der Morgenrote erwartet?

Die Gemacher erhellt? Die Tore geoffnet?

(S.22)

Bloks lyrisches Ich idealisiert die Schöne Dame als deva (Jungfrau), zarja (Morgenröte), Chranitel'nica deva (Beschützerin Jungfrau), als Velicavaja und Vecnaja zena (Großartige und Ewige Frau). ${ }^{63}$ In dieser Idealisienung metaphorisiert es seine imaginäre Männlichkeit, im Blick auf die Erscheinung der Ewigen Welblıchkeit, der Schönen Dame generiert es seine phantasmatische männliche Rolle. Die Verse von der Schönen Dame unterliegen dabei einem Signifikationsprozeß, dessen Signifikanten sich nicht selbst bedeuten können. Sie bleiben ohne Referenten und figurieren als 'Schleier', als screen für Bloks symbolistische Projektionen: "Der Schirm/screen verstellt die unheimliche Spiegelung des Anderen im Selben ebenso, wie er diese als Signifikant (erst) organisiert und strukturiert. Die Ambiguităt des $>$ Schirms $<$ als strukturierende Rhetorik der Sexualität ist dadurch gekennzeichnet, daß dieser trennt und verdeckt. Als Schirm bildet er gleichzeitig die Schranke, den Balken der Zensur gegen dieses unheimliche Moment der weiblichen Differenz, gegen die Andersheit im Männlichen und ermöglicht damit gerade die Instituierung von Männlichkeit und Weiblichkeit als selbstidentische Entitäten und sichert sie ideologisch ab. An (der) Stelle unheimlicher Selbstdifferenz werden $>$ Euphemismen $<$, Projektionen, Abwehrmechanismen, phantasmatische Konstruktionen, die die Grenze sichern, ausgebildet, wird der trennende $>$ Schirm $<$ zur Projektionsfläche, die die Ordnung von polar oppositiven und damit fetischisierten Bildern von Männ-

63 Die gnostischen Symbole "Rutter" und "Dame" entfalien sich innerhalb des stmbolistuschen Zirkels au Mythen Vgl in diesem Zusammenhang Zara Minc. "Simvol u Alcksandr Bloka" (Das Symbol bet Aleksandr Blok), in V mire Bloka. Shomik Statej (In der Well Aleksandr Bloks. Aufsatzsammlung), Heg Alcksandr A Michajlov und Stanislav S Lesnerskı, Moskva 1981, S 172-209. 
lichkeit und Weiblichkeit instituiert." ${ }^{64}$ Diese Rhetorik der "Verschleierung", des screen inszeniert das lyrische Ich als irdischen Sklaven, der gleich einem Schlafwandler einen beschwerlichen Weg auf sich nehmen muß, um dem verführerischen Gesang, der "schönen Stimme" seiner "Himmelskönigin" zu folgen. ${ }^{65}$ Dabei steht das "Glühen", das "Feuer" und der "Brand" - als Metapher des Weiblichen - metonymisch für die Suche des lyrischen Ichs nach Transzendenz seiner irdischen Existenz. Der Gesang der "Himmelskönigin", der "heiligen Frau" artikuliert sich in ihrer schönen Stimme und verweist damit auf das Jenseits (hinter dem Schleier), in das der Ritter eindringt:

\author{
Vchožs ja v temnye chramy, \\ Soveršaju bednyj obrjad \\ Tam そdu ja Prekrasnoj Damy \\ $\mathrm{V}$ mercan'i krasnych lampad \\ $\mathrm{V}$ teni u vysokoj kolonny \\ Drozu ot skripa dverej \\ A v lico mne gljadit, ozarennyj. \\ Tol'ko obraz, liš' son o Nej \\ 0 . ja privyk k etim rizam \\ Velicavoj Vexnoj zeny' \\ Vysoko begut po karnizam \\ Ulybki, skazki i sni. \\ O, Svjataja, kak laskovy svexi, \\ Kak otradny Tvoi certy' \\ Mne ne slyšny ni vzdochi, ni rexi. \\ No ja verju Milaja - Ty \\ 25 Oktober 1902 (S. 232)
}

64 Zit. nach Betune Mchnke "Dic Ver-Stcllung und die schonc Stumme", in Roum und Verfahren Intenventionen 2 ( $\mathrm{Hg}$ von Jorg Huber und Alas Martin Muller). Bascl/Zunch 1993, S 75 ff

65 Die Idac des Weges nummt um poctuschen Schaffen Bloks etre zentrale Rolle en Siche dazu Maksimov, 1975, op cit. S. 5-151. "Ideja putu v poeticeskom mire Alcksandra Bloka" und den Aufsatz "Duša pisatcl'ja" ("Die Socle des Dichters") von 1909, un .Sohranie Sičlinenij v vosmi tomach. Moskva-Lcningrad 1962. Bd 5, S. 369-370, sowic dic Nolizbucher (Zapisnye knigi) "|... Ja znaju. to soznatel'no idu po svoemu put. mne prodnaznaxennomu. i delžen idts po nemu ncuklonno", ("Ich weiß, daß sch bewußt meinen Weg getc. der mir vorherbestummt ist und ich muß thn unerschutterlich gchen") Euntragung von 1907, Bd 8. Moskva 1965, S 184 
In die Tempel tret ich glaubig.

Einfach ist mein Ritual.

Schone Dame, ich erwarte dich,

Flackert $\mathrm{Ol}$ in rotem Strahl.

Schatten stehn im Saulengange, Ich zittere beim Knarren der Tur Als Ikone schaut mich lange

An - ach nur ein Traum von ihr

In Silber gefaßt, du heilige Frau,

Tragst du nur Antlitz und Hande frei,

Hoch oben an den Gesimsen grau

Ziehen Lacheln, Marchen und Traume vorbei

Deine Kerzen, Ewige, sind zartich,

Trotz Worten und Seufzern vernehm' ich nur Ruh,

Deine Zuge, sie strahlen so tröstlich

Und ich glaube meine Liebe bist du (S.30)

In sich Zeitlosigkeit, Ewigkeit, Transzendenz vereinigend, übertritt das lyrische Ich die Grenze zur anderen Welt, um zum Geheimnis der Schönen Dame vorzudringen, denn "die semiotische Devise der Schönen Dame lautet Nichterkennbarkeit, Unenthüllbarkeit (symbolisiert durch ihr emblematisches Attribut, den Schleier) ${ }^{106}$. Der Schleier bezeichnet jene unlokalisierbare Stelle, jene Schwelle, an der sich das Konzept der Mimesis radikalisiert und za einer mimischen Nachahmung ohne Imitation wird, eine Referenz ohne Referenten darstellt, die Stelle der Unentscheidbarkeit des Textes markiert: weder draußen noch drinnen, weder Schleier noch Entschleierung.

Das Begehren des lyrischen Ichs äußert sich in dem Versuch, das Bild der Schönen Dame zu konservieren. Nur im Warten, im Triebaufschub, im eigentlichen Verfehlen des Begehrens scheint sich die Befriedigung zu erfüllen:

$66 \mathrm{Vgl}$. Enka Greber: "Mystufikation und Epochenschwelle (Cenubina de Gabriak und die Krise des Symbolismus)", in: Wiener Slawistischer Almanach. Band 32, 1993, S. 175-207, S. 195 
I tjažkij son Zitejskogo soznanja

Ty otrjachnes' toskuja, i ljubja

Vl. Solov'ev

PredCuvstruju Tebja Goda prochodjat mimo -

Vse v oblike odnom predcuvstvuju Tebja.

Ves' gorizont $v$ ogne - $i$ jasen nesterpimo.

I molca zdu, - roskuja i ljubja

Ves' gorizont v ogne, i blizko projavlenie,

No strašno mne izmeniš' oblik Ty,

I derzkoe vozbudeš' podozren'e.

Smeniv v konce privyčnye certy

O, kak padu - i gorestno i nizko.

Ne odolev smertel'nye mexty'

Kak jasen gorizont! I lư̌ezarnost' blizko

No strašno mne izmeniš oblik Ty

4. Juli 1901 (S 94)

Ind den schweren Traum des irdischen Bewußtseins

Schuttelst du im Sehnen und Lieben ab

I Tadımir Solov'ev

Ich spure Dich Vergeblich wandert Jahr um Jahr

Vorbei, und immer ahn' ich als Erscheinung Dich

Der Horizont flammt auf, wird unertraglich klar,

Mich sehnend, liebend, schweigend, warte ich

Der Horizont flammt auf und kundet Dein Erscheinen.

Doch mir wird angst Du anderst Dein Gesicht

Ich kann in mir nicht den Verdacht verneinen,

Du trugest die gewohnten Zuge nicht

$O$ abgrundtief, verzweifelt werd' ich fallen.

Denn ich bewaltige die Traume nicht

Wie klar der Horizont ist und wie nah die Strahlen,

Doch mir wird angst Du anderst Dein Gesicht (S 24) 
Das idealisierte weibliche Gesicht, das sich nicht konservieren läßt, kann folglich auch das Bild des idealisierten identischen Selbst nicht zurückgeben. In seiner Bewegung wird es zur Heterogenität des Mannes. Es trägt Fragmentierung und Aufsplitterung in das Bild hinein und stellt damit auch die eigene Repräsentation in Frage: Das Weibliche erscheint als die unheimliche Differenz des Mannes zu sich selbst. Das Paradigma des vielfach ver und aufgeschobenen Frauenkultes des "Troubadurs" war für diese Korrelation von Eros und Poesie vorbildhaft; umgekehrt verweist die bei den Symbolisten immer wieder gemachte Erfahrung der "Leere" des zu enthüllenden erotisch-mystischen "Geheimnisses" in die apophatische Tradition des nichtreferentiellen Diskurses zurück und vor auf die ungegenständlichen Tendenzen in der postsymbolistischen Kunst, wo die religiösen Motivationen jedoch ausgeblendet scheinen. Das lyrische Ich verfehlt letztendlich immer das Objekt seines Begehrens, denn die "blassen Schleier" und der "fremde, leere Blick" der "Himmelskönigin" erzeugen jenen screen, jene Differenz, die trennend die Opposition zwischen ihm, dem "Sklaven", und ihr, der Anderen, der Schönen Dame aufrechterhält. Diese Trennung wird verstärkt durch die Metapher des Nebels, der die Schöne Dame einhüllt bzw. versteckt und dessen Täuschung der "Sklave" unterliegt. Der "Schleier" muß aufrecht erhalten werden, denn das idealisierte Weibs-Bild könnte umkippen und bedrohlich werden: "Doch mir wird angst: Du änderst Dein Gesicht". Folglich realisiert sich das Begehren des lyrischen Ichs nur in seiner Nichterfüllbarkeit, denn auch im lockenden Gesang der Schönen Dame erkennt es nur Gefahr:

Pogibnet pesn', v bezbreznost' udaljajas'

Ne poj ty mne i sladostno i nezno.

Utratil ja davno s judol'ju svjaz'

25 Juli 1901 (S.114) 
Der Klang des Lieds jedoch ist Leidenschaft und Last und Luge burgt es unsichtbar Sing zartlich nicht und suß fur mich. Den Halt am Irdischen verlor ich lang (S.25)

Die "Himmelskönigin" steht als Metapher für die Weiblichkeit der Männlichkeit; in ihr kann sich der männliche Held spiegeln, in ihr vollzieht sich ein Spiel des Austauschs, eine metaphorische Transvestie: Der Signifikant, die Schöne Dame wird solange auf das fremde Signifikat, das lyrische Ich verschoben, bis dieses keine Bedeutung mehr hat. Auf diese Weise wird das Verhältnis zwischen Signifikant und Signifikat unbestimmt, denn der männliche Blick kann das weibliche Gegenüber nicht mehr bannen. Es offenbart seine eigene "trügerische Projektion, Halluzinationen an der Stelle einer die Identität bedrohenden Differentialität, die Irrfahrt stets aufgeschobener Signifikation"67. In diesen "trügerischen Projektionen" werden männliche und weibliche Geschlechtsidentität fragwürdig. Die Unbestimmtheit der Repräsentation - "dein Blick so fremd, so leer!" - der Fuphemismus der Schönen Dame impliziert die Angst des lyrischen Ichs vor dem Nichts: "Die Augen vor Angst zu schließen - ein Fluch", denn das Spiegelbild, das die Schöne Dame ihm zurückspiegelt, ist leer. Auf diese Weise reflektiert der Ont des Weiblichen das Nichts, in dem kein Geschlechtsverhältnis möglich ist. Die Reaktion der Schönen Dame auf die (Kastrations-)Angst des Mannes ist das Lachen: "Du hast mein junges Feuer selbst verlacht". Durch diese Euphemisierung wird der Schönen I Jame phallische Macht zugeschrieben. Ihre "Kerzen, Ewige" figurieren als phallisches Symbol, deren Funktion darin besteht, das bevorstehende Unheil abzuwenden.

67 Betune Menke "Dic Ver-Stellung und die schone Stimme", 1993, op cit.. S 84 
Bloks Poetik der Verschleierung beruht auf der Prosopopöeia, deren rhetorische Funktion darin besteht, mit sprachlichen Mitteln Körper, Gesicht und Stimme zu verleihen. Sie evoziert das Doppelgesichtige, das ">double screening $<$ als Euphemismen für die bedrohende (weibliche) Differenz und für ihre Verdrängung. ${ }^{.68}$ Durch den Schleier als Emblem der Nichterkennbarkeit und Unenthüllbarkeit verleiht Blok der Schönen Dame das Doppelgesichtige, ihre Maske. In ihr ist bereits im Ansatz jene Kippfigur zwischen Heiliger und Hure, Göttin und Teufelin enthalten, die in der Frauenfigur Die Unbekannte (Neznakomaja) ihre Vollendung findet: "Ty drugaja, nemaja, bezlikaja, pritailas' koldueš' v tiši" ("Du bist eine andere, stumme, gesichtslose, du hast dich verkrochen und treibst dein Hexenwesen in der Stille"). ${ }^{69}$

In diesem Frauenbild änderte Blok, der sich selbst immer fremder und unbekannter wird, das anfänglich idealisierte Frauenbild der Schönen Dame. Es wird zum Traummotiv der "unbekannten Frau", zum perhorreszierten "Weibs-Bild". Als das Andere schlechthin repräsentiert es den Schatten des Dichters, seinen Doppelgänger: der maskuline "Unbekannte" korrespondiert mit der "unbekannten Frau", die das Unbewußte personifiziert. ${ }^{70}$ In dieser Selbsterfahrung kann er die Grenzen des eigenen Ich-Bewußtseins überschreiten. ${ }^{71}$ Die Dekonstruktion der Schönen Dame im Neznakomka-Mythos offenbart dabei die Parallelen dieses Paradigmas zur jungianischen Anima-Psychologie: "[...] die symbo-

$68 \mathrm{Vgl}$. Bettune Menke "Die Ver-Stellung und die schone Stumme", op.cit S. 77ff

69 Aleksandr Blok Sobranie Soxinenl], Moskva-Lenungrad 1961, S. 72-102: Neznakomka (Die (Inbekannte) von 1906

70 Vgl Aage A Hansen-Love: "Gogol". Zur Poetik der Null- und Loerstelle. in: Wiener Slowisnscher Almanach. Band 39, Wien 1997, S. 183-305, S. 217

71 Ders . 1992, op.cit., S. 225 ff 
listische Sophiologie (bei Blok, Belyj und vor allem bei Ivanov) sind nicht nur homologe, sondern auch analoge Systeme der Personifizierung des (feminin besetzten) Unbewußten im Konflikt mit dem (maskulinen) Ich-Bewußtsein. Die Projektion der "Anima" als sublimes Über-Wesen (Personifizienung eines hochreligiösen, hochkulturellen oder hochethischen Über-Ich), wie sie dem apollinischen Typ des Religionssymbolismus entspricht, wird im dionysischen Selbsterlösungsmythos Jungs bzw. der Symbolisten ersetzt durch den ekstatischen Regre $\beta$ in ein feminines, aus der Sicht des Ich-Bewußtseins abgewertetes, erniedrigtes Anima-Bild, das mit den verdrängten Libido-Besetzungen negativ ausgestattet erscheint. Aus der Lichtgestalt des Himmlischen Weibes, das in Sonne gekleidet und mit Stemen gekrönt erscheint, aus der Immaculata-Maria und Gottes-Mutter wird der Aspekt der Oberen Geliebten abgespalten und ins Erdhaft-Unbewußte verdrängt, von wo dieses "Weibs-Bild" wiederaufersteht als animalische Anima, die das Pneumatisch-Religiöse im Erotisch-Triebhaften restinuiert." 72

Bloks Ehefrau Ljubov' Dmitrievna beschreibt in ihren Memoiren, daß Blok immer stärker unter Depressionen, Lebensüberdruß und Verfolgungswahn litt. ${ }^{73}$ Kurz vor seinem Tod fing er an, Dinge um sich herum, wie Bilder, Möbelstücke, Vasen usw. zu zerschlagen. Er zerschlug auch seinen kleinen Taschenspiegel, so daß dieser in tausend Stücke zersprang. Es scheint, als ob er mit diesem Akt der Zerstörung des eigenen Spiegelbildes im letzten Moment auch die eigene Poetik zerstören wollte, denn wenn in der symbolistischen Sophiologie das weibliche Ideal das Kunst-Schöne und die Selbsterlösung des männlichen Unbewußten repräsentiert, so steht das Bild der "Unbekannten", das perhorres-

72 Aage A Hanscn-Love "Zur psychopoctuschen Typologic", in Wiener. Nawistischer Almanach. Sonderband 31, Wien 1992, S 222.

73 Ljubov' Dmitnevna Mendelocva-Blok Byli i nebylici (Wahrhett und IIchtung). 1977, op cit. S 85 
zierte Weibs-Bild furr die Destruktion des Kunst-Schönen und damit für die Destruktion des männlichen Unbewußten und seiner Poetik. Damit verkehrte sich die Theophanie als Ausgangspunkt der Dichtkunst Bloks in ihr Gegenteil.

Im animalischen, perhorreszierten "Weibs-Bild" der Unbekannten als Kippfigur der Schönen Dame kulminiert jene männliche Hysterie innerhalb des symbolistischen Zirkels, die die abstrakte Weiblichkeit genauso ausschließt wie die körperliche Liebe. Damit machte sich die symbolistische Poetik ihrer eigenen Repräsentation verlustig und kündigt jenen Paradigmenwechsel an, jenes defacement, das die postsymbolistische Poetik des obnaženı prıma einleitet.

\section{Ver-Entstellung der $>$ Frau<:}

\section{Ljubov' Dmitrievnas Wahrheit und Dichtung}

1928 beklagte der Literaturkritiker Vladislav Chodasevic in einem Aufsatz. über den Symbolismus, daß keine andere literarische Epoche autobiographisches Material so nötig habe, wie der Symbolismus, denn "in den Schriften der Symbolisten selbst bleibt der Symbolismus unvollendet" ([...] "V pisanijach samich simvolistov simvolizm nedovoploščen"). ${ }^{74}$ Er begründete diesen Mangel mit der Tatsache, daß sich die symbolistische Poetik "ausschließlich in Wortformen rea-

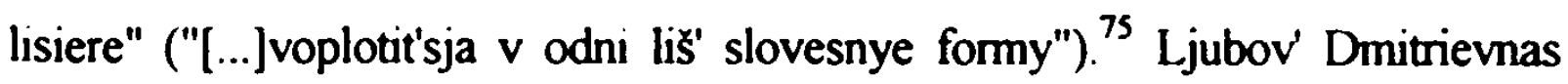
autobiographischer Text mit dem vielsagenden Titel Wahrhelt und Dichtung ${ }^{76}$ schließt diese von Chodasevic beklagte Lücke, indem er die Auswirkungen des

74 Vladislav Chodasevic Literatumye stati i usspominanija (Lsteransche Aufsatze und Erinnerungen), New York 1954, S. 155ff

75 Ebd S 155

76 Ljubov' Dmitnema Mendeloeva-Blok. "Bỵli i nebylisy", 1977, op cit.. S 5 Alke folgenden Textatate entstammen dieser Ausgabe Die russischen Zitate wurden von mur uberseta 
Žznetvorcestvo auf das häusliche Leben zeigt und die Kehrseite der symbolistischen Theorie offenbart:

Ja budu govorit' o storonach そ̇zni, o kotorych govorit' ne prinjato, znaja pocti navernjaka, čo budu obvinena $v$ cinizme No ja gluboko ubezdena - ili vovse ne pisat', ili pisat' to, o tem dumaes $\mathrm{V}$ takom sluðae est' kakoj-to šans skazat' blizkoe $k$ pravde, $t$ e nužnoe ( 11)

Ich werde uber Seiten des Lebens sprechen, uber die es sich nicht zu sprechen ziemt. Ich weiß im voraus, daß man mich des Zynismus beschuldigen wird Aber ich bin tief davon uberzeugt. man soll entweder uberhaupt nicht schreiben oder das schreiben, was man denkt In diesem Fall hat man die Chance, das zu sagen, was der Wahrheit nahe liegt, d.h das, was notig ist

Im Rückblick auf den Symbolismus verweist Ljubov' Dmitrievas Text auf die Inkonsistenzen des gesamten Sophia-Anima-Projekts und auf das verheerende Scheitem des žınetvořestvo auf der existentiellen Ebene. Der Text verdeutlicht somit die partiell verhängnisvolle Polarisierung von Kunst und Leben als Ziel der symbolistischen Theorie.

Bloks Verse von der Schönen Dame und der Kult, der sich daraus entwickelte, brachten Ljubov' Dmitrievnas eigene Stimme zum Schweigen. Erst nach seinem Tod begann sie mit der Rekonstruktion ihres Lebens:

Potom, predostavlennaja samoj sebe, ja postepenno privykla $k$ samostojatelnoj mysli, $t$ e vernulas' $k$ rannej molodosti, kogda ja $s$ takim Žarom iskala svoich putej i v mysli i v isskusstve (S 5)

Danach, als ich auf mich selber angewiesen war, habe ich mich Schritt fur Schritt an selbstandiges Denken gewohnt, das heißt, ich bin zu meiner fruhen Jugend zuruckgekehrt. in der ich so brennend meinen Weg im Denken und in der Kunst gesucht habe

Ljubov' Dmitrievna beschreibt zunächst die Spaltung der eigenen weiblichen Position und die Verlorenheit ihrer Situation, die für die Hingabe an fremde Ideale ausschlaggebend war: "Iz poteri sebja, iz nedostatka very $\mathbf{v}$ sebja" ("aus dem Verlust meines Selbst, aus Mangel des Glaubens an mich", S. 10). Diese "doppelte Spaltung des Ichs im Text und des Ichs des Textes" ${ }^{77}$ verweist auf die

$77 \mathrm{Vgl}$ in drescm Zusamminhang Betunc Menkc. "Verstellt - det Ont der >Frau<". in IRekonsinuk- 
Kehrseite der symbolistischen Theorie insofern, als sie das idealisierte Bild, das dem Kult der Schönen Dame unterliegt, infragestellt:

Ja byla po skladu duši, po sposobu oscuš̌cenija i po ustremlennosti mysli drugaja, cem soratniki Bloka epochi russkogo simvolizma S. 10

Meine Seele, mein Empfindungsvermogen und mein Gedankengut waren anders als das der Kampfgefahrten Bloks in der Epoche des russischen Symbolismus

Ljubov' Dmitrievna beschreibt genau jenes Phänomen, das sich in der Performanz der symbolistischen Lebensschöpfung niederschlug und damit auch das häusliche Leben der Bloks bestimmte:

I u nas srazu že, s pervogo goda našej obščj žzzni, načalas' kakaja-to igra, my dlja našich Cuvstv našli "maski", oknuzili sebja vydumannymi, no sovsem Zivymi dlja nas sušcestvami, naš jazyk stal sovsem uslovnyj Tak čto "konkretno" skazat' sovsem nevozmožno" [... $]$ (S 85)

Und gleich im ersten Jahr unseres gemeinsamen Lebens begann ein bestimmtes Spiel, wir fanden für unsere Gefühle "Masken", wir umgaben uns mit ausgedachten, aber für uns vollkommen lebendigen Geschopfen, unsere Sprache wurde vollkommen symbolisch, so daß es unmoglich war, etwas "Konkretes" zu sagen [...]

Die Beschreibung der Inszenienung des symbolistischen žınetvorcestvo im Eheleben der Bloks zeigt, inwieweit das Charakteristikum dieser literarischen Epoche in der endlosen Psychographie von Kunst und Leben selbst zu suchen ist. Auf diese Weise wurde die eigene Ehefrau zur Projektionsfläche symbolistischer Projektionen, die genauso ins Bild der Unbekannten umkippen konnte, wie das anfänglich idealisierte Bild, denn Blok selbst war sich ein "Unbekannter":

U Bloka bylo dve žizni - bytovaja, domašnaja, tichaja i drugaja - bezbytnaja, uličnaja, chmel'naja V dome u Bloka byl porjadok, razmerennost' i nnešnee blagopolucie Pravda, blagopoluzija podlinnogo i zdes' ne bylo, no dorožil ego vidimost'ju Pod maskoj korrektnosti i pedantizma tailsja strašnyj neznakomec (Hervorhebung von mir) - chaos ${ }^{78}$

nver Feminismus. Literaturwissenschaft in Amerika, hg von Barbara Vinken. Frankfurd Main 1992, S. 436-477, S. 472. Menke verwerst auf de Mans Spannung von kognutiver und performativer Dumension der Texte, deren Leitfigur die Prosopopoie ist.

78 Georgj Culkov Gody stransivij lz knigi vospominanij (Wanderjahre Aus den Memoiren). Moskva 1930. S. 143. Auf diesen Tatbestand verweast auch Zinada Gippius in thren Erinnerungen uber Blok Sie bezerchnet ihn als "meinen Mondfreund" ("moj lunnyj drug") "Cem dal'Še, tem vse jas- 
Blok fuhrte zwei Leben - ein alltagliches, häusliches, stilles und ein anderes - ein nichtalltagliches, betrunkenes Leben auf der Straße Im Hause Blok herrschte Ordnung. Gleichmaßigkeit und ein nach außen gekehrtes Glück Wirkliches Glück gab es auch hier nicht, aber Blok hutete seinen Anschein Unter der Maske der Korrektheit und des Pedantismus versteckte sich ein schrecklicher Unbekannter (Hervorhebung von mir, DR ) - das Chaos

Blok versuchte, in seiner Ehe wie in seinen Versen von der Schönen Dame, jene Vorstellung der höfischen Liebe zu verwirklichen, die in der mystischen Union als ideale Vereinigung der Geschlechter begründet lag:

On sejčas že prinjalsja teoretizirovat' o tom, cto nam i ne nado fiziceskoj blizosti, Cto eto "astartizm", "temnoe" i Bog znaet esce cto Kogda ja emu govorila o tom, cto ja-to ljublju ves' etot ešre nevedomyj mne mir, tto ja chołu ego - opjat' teorii takie otnošenija ne mogut byt' dlitel'ny, vse ravno on neizbežno ujdet ot menja $k$ drugim (S.51/52)

Er fing sofort an zu theoretisieren, daß wir keine physische Nahe brauchten, daß dies "Astartismus" sei, etwas "Dunkles" und weiß Gott noch was alles Als ich ihm erklarte, daß ich diese ganze, mir unbekannte Welt liebte, daß ich ihn will, emeut Theorien diese Beziehungen konnten nicht von Dauer sein, trotz allem konnte er es nicht vermeiden, noch $\mathrm{zu}$ anderen $\mathrm{zu}$ gehen

An diesem Zitat wird deutlich, daß das "Aufschub"-Problem (also die postmoderne Idee der "différence"/"différance") sowohl eine lebens- als auch eine kunsttexterzeugende Rolle spielt: Die Verbalisienung verhindert die aktuelle Realisierung des "Aktes", der "Akt" verhindert die religionskünstlerische Konzeptualisienung. Das häusliche Ehedrama der Bloks ist ein Beispiel fuir die Inszenienung dieses Paradoxon, denn das symbolistische ziznetvorCestvo basierte auf einem Geschlechtsverhältnis, in dem sich Mann und Frau ständig verfehlen. In diesem Sinne könnte man behaupten, daß das Zusammenleben der Bloks als Mann und Frau an der symbolistischen Lebensschöpfung gescheitert war:

noe prostupala dlja menja odna ¿crta v Bloke. - dvojnaja: ego Iragicnost', vo-pervych, I vo-vtorych. ego kakaja-to nezastistennost' o lego? Da ot vsego ot samogo sebja of drugich ljudej, - ot zizn i ot smert", ("Je methr ich Blok kenncnlernte, umso mehr knstallisierte sich fur mich cun Zug von ithm heraus. cen zweifacher Zug erstens seine Tragik und zweitens seine . Schutzlosigkell vor was? Nun. vor allem vor sich selbst, vor anderen Leuten. vor dem Leben und vor dem Tod"). in Zivye lica. Vospominanuja (lebendige Personen Linnnerungen), [auerst Prag 1925], Munchen 1971, S 7-73, S. 10 
Moja Żzn' s "mužem" /!/ vesnoj 1906 goda byla uze rašatannoj Korotkaja vspyška Cuvstvennogo ego uvlexenija mnoj $v$ zimu $i$ leto pered svad'boj skoro, $v$ pervye ze dva mesjaca pogasla, ne uspev vyrvat' menja iz moego deviceskogo nevedenija, tak kak instinktivnaja samozaščcita prinimalas' Sašej vser'ez (S.51)

Mein Leben mit dem "Ehemann" /!/ war im Frihling schon vollkommen zerruttet Das kurze Aufflammen seiner Gefuhle fur mich im Winter und Sommer vor unserer Hochzeit erlosch bald, nach den ersten zwei Monaten, ehe er mich aus meiner madchenhaften Unkenntis herausriß, da meine instinktive Selbstverteidigung von Saša ernst genommen wurde

Aber auch die sektantische Aufhebung der genetischen Familien- und Verwandschaftsbande und ihre Ablösung durch ein pneumatisches Geist-Prinzip, in dem Mann und Frau wie Bruder und Schwester zusammenlebten, sowie die sektantische Ablehnung der Fortpflanzung scheint hier eine Rolle gespielt zu haben. ${ }^{79}$ Beide Ehepartner lehnten es bekanntlich ab, Kinder zu bekommen. In seinem Notizbuch schreibt Blok noch vor der Hochzeit: "Esli u menja budet rebenok, to chuze stichov", ("Wenn ich ein Kind haben werde, so ist es schlechter als die Gedichte"). ${ }^{80}$ Auch I.jubov' Dmitrievna wollte keine Kinder. Sie hatte panische Angst vor der Mutterschaft:

S rannej, rannej junosti predel'nym užasom kazalas' mne vsegda vozmožnost' imet' rebenka Kogda stal približat'sja srok našej svad'by s Sašej, ja tak muxilas' etoj vozmożnost'ju, tak buntovala vse moe sušcestvo, tto daže resilas' skazat' vse prjamo Saše, potomu cto on zametil, tro ja o cem-to neponjatno terzajus'. Ja skazala, ¿to nicego tak ne navizu na svete, kak materinstvo, i tak ego bojus', cto byvajut minuty, cto gotova otkazat'sja ot braka s nim pri mysli ob etoj vozmožnosti. Saša tut Že uspokoil vse moi strachi detej u nego nikogda ne budet (S 64)

Von fruhester Jugend an war es fur mich der außerste Schrecken, ein Kind $z$ haben Als sich der Tag unserer Hochzeit naherte, habe ich mich mit dieser Moglichkeit so herumgequalt, mein ganzes Wesen rebellierte so sehr dagegen, daß ich mich dazu entschloß, Saša alles direkt au sagen, denn er bemerkte, daß ich mich mit etwas herumqualte Ich sagte ihm, daß ich nichts mehr auf dieser Welt haßte, als die Mutterschaft und ich sie so sehr furchtete, daß es Minuten gabe, in denen ich bei dem Gedanken an diese Moglichkeit bereit ware, von einer Ehe mit ihm abzusehen Sasa beruhigte sofort alle meine Angste er wurde niemals Kinder haben

$79 \mathrm{Vgl}$ Aage A Hansen-Love, 1996, op cit., S 206

80 Zit. nach dem Kommentar in Ljubov' Dmitnevnas Memotren. 1977, op.cit., S 98 
Wie aus Ljubov' Dmitrievnas Text hervorgeht, diente das Eheleben der Bloks im wesentlichen dazu, die Solov'evschen Thesen zur übermenschlichen, von allem Fleischlichen wegführende Liebe zu überprüfen: "Das Experiment zeitigte niederschmetternde Resultate. Was als philosophische Entsagung der Sexualität im Namen der weıßen Liehe begann und von Blok praktisch so vollzogen wurde, wandelte sich mit den Jahren in eine Serie von Fehltritten auf beiden Seiten und beschwor einen Konflikt zwischen der Frau und der Mutter des Dichters herauf." ${ }^{\prime 81}$

Ljubov' Dmitrievna, die das von Blok erschaffene Frauenbild während ihrer Ehe kultiviert und verinnerlicht hatte, sich aber von ihm und dem symbolistischen ziznetvorčestvo befreien wollte, wechselte in ein anderes Lager. Mithilfe von Freuds Lehre glaubte sie, ihre Konflikte lösen zu können, bzw. das zu verstehen, was sich in ihrem Leben ereignet hatte.

$81 \mathrm{Vgl} \mathrm{Alcxander}$ Etkind. 1996. op cit . S 72 


\section{Kapitel III}

Höfische Liebesspiele - Tödliche Inszenierungen

Kunst ist der Anfang des Leben-Schmiedens'

1 Andrej Belyj: "Teatr i sovremennaja drama", in: Arabesk. Slansche Propylden. Nr 63 [Moskva 1911], München 1969, S. 20: "Iskusstvo est' natalo plavlenija zizmi." 


\section{Märchen und Leben}

\section{I}

Marchen

Die Hexe Goderuna war wunderschon

Wenn sie aus ihrer Laubhutte herauskam. verstummten die Vogel und seltsam schienen zwischen den Zweigen die Tieraugen hervor

Goderuna war wunderschon

Eines Nachts ging sie am Ufer des schwarzen Sees spazieren, rief ihre Schwane zusammen Plotzlich sah sie unter einem Baum einen Jungling sitzen Seine Kleidung war reich und mit Gold genaht, eine wertvolle Krone schmuckte sein Haupt, aber die Brust des Junglings zeigte kein Atmen Das Gesicht war bleich, und in seinen Augen, die weit aufgerissen waren. spielten, sich widerspiegelnd, feme Steme

Und Goderuna vertiebte sich in den Toten

Sie besprengte ihn mit Zauberwasser, rieb ihn mit Heilkräutern ein und las drei Nachte Be-schworungsformeln

In der vierten Nacht stand der Tote auf, verbeugte sich vor der Hexe Goderuna und sagte

- Verzeih' mir, Wunderschone, ich danke Dir

Und Godenuna nahm ihn bei der Hand und sagte

- Lebe mit mir, toter Prinz, und bleibe bei mir, denn ich habe mich in dich verliebt

Und der Prinz kam mit ihr, und war immer bei ihr, aber seine Brust atmete nicht, sein Gesicht war weiß, und in seinen Augen, die weit aufgerissen waren. spielten sich widerspiegelnd ferne Steme

Niemals schaute er Godenuna an, und wenn sie sich zartich an ihn wandte, antwortete er immer nur "verzeih' mir" und "ich danke Dir"

Und Goderuna sagte voll Trauer und Schmerz au ihm

- Habe ich dich nicht zum Leben erweckt, toter Prinz?

- Ich danke dir, - antwortete der Prinz

- Wanum schaust du mich denn nicht an?

- Verzeih' mir, antwortete der Prinz

- Bin ich etwa nicht schon genug? Wenn ich im Mondschein tanze, scharen sich die Wolfe im Wald um mich herum und tanzen und die Baren jauchzen vor Freude und die Nachtblumen offnen ihre Zweige vor Liebe zu mir Nur du allein schaust mich nicht an

Und Godenuna ging zum Waldgeist und erzahlte ihm uber ihren toten Prinzen und ihren Liebeskummer

Der Waldgeist dachte nach und fing dann an zu achzen

- Dein Prinz ist deswegen gestorben, weil er sich am schwarzen See am Schwanengesang sattgeatmet hat Wenn du willst, daß er dich liebt, nimm' den goldenen Krug und weine drei Nachte uber ihm In der ersten Nacht beweine deine Jugend, in der zweiten deine Schonheit. und in der dritten Nacht beweine dein Leben, sammele die Tranen im goldenen Krug und bringe sie deinem Toten

Goderuna weinte drei Nachte, sammelte die Tranen im goldenen Krug und ging zum Prinzen

Der Prinz saß still unter dem Baum, seine Brust atmete nicht, sein Gesicht war bleich und in seinen Augen, die weit aufgerissen waren, spietten, sich wiederspiegelnd, ferne Sterne 
Goderuna gab ihm den goldenen Krug

- Das hier ist für dich, toter Prinz, alles, was ich habe. Schönheit, Jugend und Leben Nimm' alles, denn ich liebe dich

Und als sie ihm den Krug gab, starb Godenuna, und wahrend sie starb, sah sie, daß seine Brust atmete und sich das Gesicht errotete und die Augen schon nicht mehr vom Sternenfeuer brannten Und dann hörte Goderuna noch, wie er sagte

- Ich liebe dich!

\section{Auf geopfertem Blut wächst die Liebe.}

Das Leben

Marja Ivanovna war uberhaupt keine schlechte Frau Als sie bei den Limonins mit dem Oberleutnant Cubukov Padespan tanzte, applaudienten alle vor Entzücken und sogar die Kartenspieler unterbrachen ihr Spiel und die Hausherren krochen aus ihren Arbeitszimmern, um sich den angenehmen Anblick anzusehen

Eines Abends traf sie bei den Ljagunovs einen seltsamen jungen Mann. Er saß still da, trug einen Frack, seine Brust atmete nicht, das Gesicht war bleich, und in seinen Augen, die weit aufgerissen waren, spielten, sich widerspiegelnd, die Lämpchen des elektrischen Lüsters

- Wer ist das?

- Das ist Kulikov, Ivan Ivanyc.

Sie lud ihn $\mathrm{zu}$ sich ein. bewirtete ihn mit Tee und Petit Fours und gab ihm zum Abendessen Hummer, spielte auf dem Klavier einen neuen Twostep, sang so laut und frohlich, daß jemand aus der Nachbarwohnung kam und bat, ob es nicht etwas leiser ginge

Kulikov schwieg und sagte nur "Pardon" und "Merci".

Daraufhin ging Mar'ja Ivanovna zu ihrer Bekannten, der alten Wahrsagerin Antonina Pavlovna und erzahlte ihr alles über Ivan Ivany\& und über ihren Liebeskummer

- Was soll ich tun? Ich spiele, ich singe, ich bestelle das Abendessen, aber er sitzt da wie ein Kauz und außer "Pardon" und "Merci" kriegst du nichts aus ihm heraus

Die Wahrsagerin dachte nach und fing an zu krachzen

Ich kenne deinen Kulikov Im Klub hat er ihm anvertrautes Geld verspielt, deswegen sitz er jetzt da wie ein Kauz Ich weiß alles Er ist sogar schon zu Sofja Pavlovna gefahren, um sich dort etwas $z$ leihen, bei mir hat er auch schon Anstalten gemacht $\mathrm{Na}$ ja, bei mir ist nicht viel zu holen Aber wenn du wirklich so eine Idiotin bist, dann bringe seine Angelegenheiten in Ordnung und er wird wieder lebendig.

Marja Ivanovna bestellte Kulikov zu sich

Kulikov saß auf dem Diwan, sein Brust atmete nicht, sein Gesicht war bleich und in seinen Augen, die weit aufgerissen waren, spielten, sich widerspiegelnd, die Lampchen des elektrischen Lusters

Er saß da, wie ein Kauz

Und Marja Ivanovna sagte zu ihm

- Heute morgen habe ich meinen Verwalter gefeuert und jetzt habe ich niemanden mehr. der mir dabei hilf, das Haus auf der Kolomnenskaja Straße zu verwalten Wie froh wäre ich, wenn Sie das machen konnten Man muß eigentlich nicht viel machen, ein alter Hausmeister 
kümmert sich um alles Sie brauchten eigentlich nur zwei Mal im Jahr auf die Kolomnenskaja zu fahren, um danach zu schauen, ob das Haus noch auf seinem Platz steht oder ob es schon verfallt Als Gehalt wurden sie Dreitausend bekommen

- Funf' fragte Kulikov und das Licht in seinen Augen schimmerte seltsam

- Funf antwortete Marja Ivanovna errotend und starb

Aber als sie starb, sah sie, wie seine Brust atmete und sein Gesicht sich rotete und die Augen nicht mehr vom elektrischen Licht leuchteten

Und Marja Petrouna horte noch, wie er sagte

- Ich habe ganz vergessen Ihnen $2 u$ sagen Marusja, ich liebe Dich'

Auf geopfertem Blut wächst die Liebe 2

In dem oben zitierten Text der Schriftstellerin Teffi findet sich in nuce jenes Paradigma des symbolistischen žıznetvoř̌estvo, das sich in seiner Polarisienung von Leben und Kunst offenbart. Teffi unterteilt ihre Erzählung in legenda Märchen) und žzizn' (lehen). Beide Texte handeln von der Liebe der Heldin zu einem scheinbar toten Mann. Um ihn aus diesem Zustand zu erlosen und seine Gefuihle für sich zu erwecken, muß die Heldin im Märchen und im Leben sterben. Ihr Tod ist Voraussetzung für den Text: Auf dem "geopfertem Blut" der Heldin entsteht die Liebesgeschichte. Teffis Text dient hier als Paraphrase dessen, was im folgenden Kapitel behandelt wird: Die tödliche Inszenienung Nina Petrovskajas, einer der Musen des symbolistischen Zirkels, ist als Resultat der höfischen Liebesspiele zu sehen, wie sie innerhalb des symbolistischen ziznetvorcestvo modisch waren. An diesem Beispiel wird deutlich, daß sich die

2 Téffi (1872-1952) Pscudonỵm fur Nadežda Alexandronna Lochvickaja, spater Bučrnskaja. "Legenda I tum"' (Marchen und Leben). in Canca Poceluev Eronceske novelly i skazk russkach pisatele) (Die Konigin der Kusse Erotische Novellen und Marchen russischer. Schnfisteller), Moskva 1993. S. 278-280 (Der nussische Text wurde von mur ubersetz. D R). Die Farben wew und rot, die Teffi leionounsch venuendet. verueisen auf das hummlische Paar und de Vorstellung des Androgynen. uxe sie aus der Alchemie bekannt ist $\mathrm{V}_{\mathrm{g}} \mathbf{C} \mathrm{C}$ Jung Erlosungsvorstellungen in der Alchemke (Psychologic und Alchemuc 2), Olten 1985, S 15 
symbolische Präsenz des Mannes über die Abwesenheit der Frau, ihrem NichtSein herstellt, im Text wie im Leben. Auch hier steht die Repräsentation des weiblichen Todes für die mißglückte Verdrängung des Todes, die sich an dem "unumgänglichen Körper der Materialıtät-Mütterlichkeıt-Mortalität" ${ }^{3}$ niederschlägt. Der Freitod Nina Petrovskajas kann als Epilog des Romans Der feurıge lingel von Valerij Brjusov und damit ais logische Vollendung des żznetvorCestvo gelesen werden kann. In der Inszenienung ihres Lebens als Kunst folgte Nina Petrovskaja der Vor-Schrift dieses Textes bis zu seinem tödlichen Ende. Um diese These zu veranschaulichen, soll zunächst auf folgende Punkte eingegangen werden: 1. Auf das Mimikryverhalten der Symbolisten, das strukturelle Ähnlichkeiten mit dem Mimikryverhalten der russischen Sekten hat. Daraus ergibt sich der performative Charakter des ziznetvorcestvo. 2. Auf die höfischen Liebesspiele als Diskursmode der Symbolisten, die die Liebe selbst unmöglich machten. 3. Auf die konkrete ménage-à-trois von Valerj Brjusov, Nina Petrovskaja und Valerij Brjusov als eine Variation in der Grundstruktur der höfischen Liebe. 4. Auf ihre Literarisierung in Brjusovs Roman Der feurige Engel; aus der ménage-à-trois wurde ein text-à-trois.

Elisabeth Bronfen „Vom Omphalos zum Phallus Weibliche Todesreprasentanzen als kulturelles Symptom", in: Macht Geschlechter Differenz, Hrsg von Wolfgang Muller-Funk, Wien 1994, S. 128 151, S.128, sowne Nur über ihre leiche. Tod, Weiblichkelt und Ästhetik, Munchen 1994, S.551. Bronfen zeigt in Erweiterung von Frauds Interpretation des Odipusmythos und Lacans Geschlochtstheone. daß es un Odipuskomplex als Sujetmatnx det Litcratur nucht nur um de Usurpienung des vateriıchen Phallus geth um damit zur Mutter al gelangen und daß der Phallus nucht allen als privilegiertes kulturelles Zeichen getten kann. wenn die Uberwindung des Mangels auf etwas verweist. was noch fruhct anzusetzen ist, namlich auf de Uberuindung des Geburtstraumas, dessen anatomusches Zeichen der Nabel ist. Auf diese Weise. so Bronfen. geht es in der Odipussage nucht nur um den Vatermord, um die Uberschreitung des Inzestverbots und der Kastrationsangst. sondern auch um den Muttermord, darum, den mutterlichen Korper za uberwinden, um die Angst vor dern Tod au verdrangen Analog daza wird im symbolistischen ziznetwortestwo die Mutterfigur ambivalenth da ihr de Zuge des Vaters ubertragen werden 
10. Mimesis und Mimikry:

Das symbolistische riznetworčestvo.

A realıbus ad realiora

Vjaceslav Ivanov

Die russischen Symbolisten, allen voran die älteren Symbolisten (staršie simvolisty) Zinaida Gippius und Dmitrij Merežkovskij, Vjaceslav Ivanov und Lidija Zinov'eva-Annibal, sowie die jüngeren Symbolisten (mladšie simvolisty) Aleksandr Blok und Andrej Belyj lebten und arbeiteten unter dem selbstauferlegten Konzept des žlznetvorčestvo: "Aus neuen Menschenzusammenklängen sollte, so hofften sie, eine neue Geistigkeit entspringen. ${ }^{\text {.5 }}$ Vjaceslav Ivanov dachte dabei an einen einheitlichen Körper, in dem die unterschiedlichsten Menschen harmonisch vereint wären. ${ }^{6}$ Dies implizierte auch eine neue Art, das Geschlechtsverhältnis zu leben. Die Dreierbeziehung schien den Symbolisten wie auf den Leib geschneidert:

[ ] sie boten [ .] den einzelnen Protagonisten die Moglichkeit. mit sich selbst sowohl aktiv als auch passiv in Kontakt zu treten Daher auch V Ivanovs markantes Interesse am opfernden bzw geopferten Gott Dionysos, der Agens und Patiens. Subjekt und Objekt. Mann und Frau in einem ist Daruber hinaus ließe sich im Sinne von J Lacans Geschlechtstheorie annehmen, daß durch die Triangularitat eben jenes "Dritte" realisien werden sollte, das im Grunde das Symbolische ausmacht, also eigentlich den V a t e r, genauer sein Prinzip, seinen Namen [ . ] Die Selbst-Umbenennung des Dichters, der ein Pseudonym wahlt, wie dies im Symbolismus mehrfach zu beobachten ist (Belyj. Sologub

4 Vjaceslav Ivanov. "Dve stuchii v sovremennom sumvolizme" (Zwei Gudichte um zeitgenossischen Symbolismus), in Zolotoe nuno, 1908, 3/4, S 86-94

5 Marganta Woloschun Die gnune .X.hlange, Stutugar 1987, S 184

6 Vjaceslav Ivanov Sobranie Siclinenij, Bd I, Brussel 1971, S 95 Ivanovs Vorstellung eines ennheitlichen Korpers weist zunuck auf Solov'evs Konzept der All-Einhelt und vor auf Bachtuns Konzept des Volkskorpers 
etc.) ist dem Uberschreiten des Inzestverbots vergleichbar, also der Ausstreichung des "Namen-des-Vaters" und der autonomen Namen-Wahl, $d$ h der Ursurpienung des vaterlichen Phallus (Lacan) Das Abwesende, reale Urverdrangte ist es eigentlich, was vom Inzestverbot gewahr werden soll [ . ] der Urvater, der phallische Signifikant, der nach Lacan mit "Kreation, Schrift und Gesetz" gleichgesetzt wird. Die Schrift (mehr noch die Kunst) dient der Realisienung des Vollkommenheitsphantasmas, also einer Vermeidungsstrategie, den fundamentalen Mangel nicht zu akzeptieren Im Odipuskomplex wird die Illusion realisien, als ware das Verbot des Objekts des Begehrens (die Mutter-Geliebte) außer Kraft gesetz Das "Theater" als permanent inszenienter Odipuskomplex dient eigentlich der Vermeidung der Erfahrung, daß es das Objekt des Begehrens eigentlich nicht gibt [...]; das Symptom (bzw. die Symbolwelt) tritt an die Stelle des Unmoglichen ${ }^{7}$

In der Projektion auf die göttliche Dreieinheit, der mystischen Verschmelzung mit der Sophia wurde das Religiöse an das Sexuelle gekoppelt. Orgiasmus und die slavophile Idee der sobomost'(Ökumene) sollten als Vereintes gelebt werden. Die berühmten Mittwochsgesellschaften der Ivanovs gaben dafür einen ersten Anstoß. ${ }^{8}$

Ziel der Symbolisten war es, das vereinzelte leere Ich zum erfülten Selbst und das reale Leben in eine andere Welt (mir inoj) zu transformieren, die gleichzeitig Kunstwelt war. Gemäß diesem Streben nach der Vemetzung von Kunst und Leben trennten die Symbolisten die literarische nicht von der persönlichen Biographie, vielmehr erlebten sie die Ereignisse des Lebens als Teil ihrer inneren Welt und Teil ihres Schaffens. Umgekehrt wurden ihre Texte zu 'realen' Ereignissen für alle:

Simvolisti prezde vsego ne choteli otdelat' pisatelja ot celoveka, literaturmuju biografiju ot liznoj Simvolizm ne chotel byt' tol'ko chudozestvennoj łkoloj, literaturnym těceniem Vse vremja on poryvalsja stat' Ziznenno tvorteskim metodom (Hervorhebung von mir, D R.), i v tom byla ego glubołajšaja, byt' možet, nevypolnimaja pravda, i v etom postojannom stremlenii protekla, $v$ suščnosti, vsja ego istorija Eto byl rjad popytok, poroj

7 Aage A Hansen-Love "Zur psychopoctuschen Typologie", un Wiener. Slawistischer Almanach. Sonderband 31, Wien 1992. S. 195-289, S 224

$8 \mathrm{Vgl}$ in diesem Zusammenhang Nikolaj Berdjaev "Ivanovskue srody", in Russkaja Literatura XX veka. Kn 8, S. 97-100 und Alexander Etkund Eros des Unmoglichen Die (jeschichte der Psychoanalyse in Rußland. Leipzig 1996, S. 62 
istinno geroikeskich, najti bezukoriznenno vernyj splav Zizni i tvorkestva, svoego roda filosofskij kamen' iskusstva ${ }^{9}$

Die Symbolisten wollten vor allem den Schriftsteller nicht vom Menschen und die literarische nicht von der personlichen Biographie trennen Der Symbolismus wollte nicht nur eine kunstlerische Schule oder eine literarische Stromung sein Die ganze Zeit uber bemuhte er sich krampfhaft, eine lebensschöpferische Methode (Hervorhebung von mir, D R.) $2 u$ sein, und darin lag seine tiefe, vielleicht seine nichterfullbare Wahrheit, und in diesem standigen Bestreben vertief im Grunde seine ganze Geschichte Dies war eine Reihe zeitweise wahrhaf heldenhafter Versuche, eine einwandfreie, treue Legienung von Kunst und Leben zu finden, einen spezifischen philosophischen Stein der Kunst

Der Symbolismus sollte also die schöpferische Methode des Lebens sein. Auf diese Weise würden Kunst und Wirklichkeit gemeinsam geschaffen, als "authentischer Fall kollektiven Schaffens" ${ }^{10}$. Belyj definierte das žiznetvorčestvo auf folgende Weise:

'̌izn' est' litnoe tvořestvo Umenie žit' est' nepreryvnoe tvor ̌estvo eto mgnovenie, rastjanuvšeesja v veřnost' uslovija vnešnej neobchodimosti razryvajut tvorそeskij rjad $i$ mgnovenie Vexnost' raspadaetsja na vodopad migov, obraz Zuzni raspadaetsja na vodopad migov, obraz zizni razpadaetsja na tysjacy obrazov, forma zizni - na tysjacy form Eti formy togda - formy iskusstva, ic oblomki edinoj formy, odinaja forma - tvorEeski prożitaja zizn'"

Das Leben ist eine personliche Schopfung. Die Fahigkeit au leben ist ununterbrochene Kreativitat Es ist ein Moment, der sich in die Ewigkeit ausdehnt Die Bedingungen einer außeren Notwendigkeit reißen den kreativen Fluß und den Augenblick auseinander Die Ewigkeit zersplitter in einen Wasserfall von Augenblicken. das Bild des Lebens in tausende Formen Diese Formen sind Formen der Kunst, das heißt Fragmente einer einzelnen Form, und diese einzelne Form ist das kreativ gelebte Leben

Der literarische Text war für ihn nicht anderes als ein "weiteres Fragment des kreativ gelebten Lebens", die "Emanation des allumfassenden Lebenstextes"'2.

9 Vladislav Chodasevix "Konce Renaty" ("Renatas Ende"). (auerst Pans 1927). zt nach Russkj eros il filosofija Ijubv v Rossi (Der russische Eros oder die Philosophie der Lsebe in Rußland). Moskva 1991, S 337-350, S 338

10 Ebd S. $338 f$

11 Andrej Bely "Iskusstvo" (Dic Kunst). [zucrst Moskva 1911], in Arabeska Slavische Propylaen. Bd 63, Munchen 1969, S 211-219, S 216f

12 Zit nach A V Lavrov "Mifotvorkestvo 'Argonavtov"' (Die Mythenschopfung der Argonauten). in Mif. fol'klor. Itteratura Mythos, Folklore. Isteratur), hg von V G Bazanov, Lenungrad 1978. S 140 
Brjusov forderte vom Dichter, "er möge seine heiligen Opfer nicht nur den Gedichten bringen, sondern jeder Stunde seines Lebens [...] Möge der Dichter nicht seine Bücher schaffen, sondern sein Leben"13. Michail Kuzmin schrieb: "Die Wiederholung der Gefühle und Ereignisse ist wirklich ein zielloses Spiel der Geschichte, ein Rad der Maskerade menschlichen Lebens" ${ }^{\prime 4}$. Dieser Aspekt der "Maskerade" entlarvt neben der theairalischen Inszenienung und Fiktionalisienung des Lebens den innersten Kern des šznetvor ̌estvo: An der Maske, die die Symbolisten trugen, an dem Spiel, das sie spielten, an der Fiktion, der sie gehorchten.

Das Mimikryverhalten der russischen Symbolisten führte letztendlich auch zur Verfehlung von Mann und Frau und bewahrheitet damit genau jenen apodiktischen Satz Lacans, der lautet: "Es gibt kein Geschlechtsverhältnis." ${ }^{15}$ In diesem Zusammenhang spricht das verheerende Scheitern des ziznetvorčestvo auf der existentiellen Ebene Bände:

Simvolizm upomo iskal $v$ svoeij srede genija, kotoryj sumel by slit' zizn' i tvorcestvo voedino My znaem teper, tto genij takoj ne javilsja, formula ne byla otkryta. Delo svelos' k tomu, cto istorija simvoliztov prevratilas' v istoriju razbytich żznej, a ich tvorkestvo kak by nedovoplotilos' ${ }^{16}$

Der Symbolismus suchte in seiner Umgebung beharrlich nach einem Genie, das in der Lage gewesen ware, Leben und Kunst zusammenfließen $z$ lassen Heute wissen wir, daß dieses Genie nicht gefunden wurde, diese Formel nicht entdeckt wurde Die ganze Sache fuhrte dazu, die Geschichte des Symbolismus in die Geschichte zerstörter Leben (Hervorhebung von mir, DR.) zu verwandeln, ihr Werk jedoch verwirklichte sich nicht vollstandig

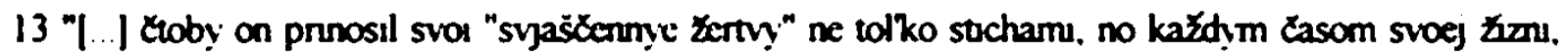
kaxtḥm Cuvstvom (...) Pust' poct tvont ne svoi knigi. a svoju zizn"', zt nach Grexıškin und Lavrov, in Isteratumoe nasledsmo. Valenj Brjusov, Bd 85, Moskva 1976, S. 331

14 Zit nach E.E Dmitrieva Russkaja Novella XX v. (Die russische Novelle), Moskva 1990. S. 5-14, S. 10

15 Jacques Lacan Radiophone Tëlèvision. Weinheim/Berlın 1988, S 66.

16 Vladislav Chodasevit. [1927] 1991, op cit. S. 338. 
Diese Verwandlung der Geschichte des Symbolismus in die Verwandlung der Geschichte zerstörter Leben gibt natürlich kein Erklärungsmodell für die künstlerische Relevanz des Gesamtprojekts ab und wurde auch nicht deswegen erwähnt. Es geht hier darum, zu zeigen, daß die Polarisienung von Kunst und Leben eine ganz spezifische Semiotik des Verhaltens erzeugte. Denn für die Symbolisten war Leben im Sinne von "Wirklichkeit" und Kunst nur in ihren Wunschträumen dasselbe; praktisch unternahmen sie wenig, um den Gegensatz zu überbrücken. Ihre Unfähigkeit, diese Aufgabe zu erfullen, äußerte sich vor allem darin, daß sie Kunst und Leben nur insofern vereinen konnten, als sie ihr Leben ganz der Kunst weihten. ${ }^{17}$ Der Literaturkritiker und Dichter Vladislav Chodasevic beschreibt im Nachruf auf den Freitod der Schriftstellerin Nina Petrovskaja (1884-1924) die Auswirkungen des symbolistischen žiznetvorCestvo auf das Leben der einzelnen Mitglieder folgendermaßen:

IAČmost' postepenno stanovilas' kopilkoj perełıvanij, meškom, kuda ssypalis' nakoplennye bez razbora emocij - "migi", po vyraženiju Brjusova "Berem my migi, ich gubja" [. ] neprestannoe stremlenic pereatraivat' mysl', tizn', otnošenija, samyj date obichod svoj po imperativu oxerednogo "perezivanija", vlekjo simvolistov $k$ neprestannomu akterstvu pered samimi soboj - $k$ razygrivaniju sobstvennoj žizn'i kak by $v$ teatre Żgucich improvizacij (Hervorhebung von mir, D R) Znali, cto igrajut No igra stanovilas' Zizn'ju Rasplaty byli ne teatral'nye "Istekaju kljukvennym sokom!" - kryčal blokovskij pajac No kljukvennyj sok inogda okazyvalsja krov'ju

Die "Person" wurde schrittweise zur Sparbuchse fur Erlebnisse, zum Sack, in den die angehauften Emotionen kritiklos hineingeschuttet wurden, "Augenblicke", wie sie Brjusov nennt "Nehmen wir die Augenblicke und richten sie zugrunde " Das unaufhörliche Bestreben, den Gedanken, das Leben, die Beziehungen, sogar seinen eigenen Beruf unter den Imperativ der zur Tagesordnung gehörenden Ertebnisse zu stellen, führte die Symbolisten zur unaufhörlichen Schauspieterei auch vor sich selbst - zum Durchspieten des eigenen Lebens im Theater nammender Improvisationen (Hervorhebung von mir, D R) Man wußte, daß man spielte Aber aus dem Spiel wurde Leben Die Bezahlung war nicht theatralisch "Ich verblute an Beerensaft", schrie der Bloksche Hanswurst Aber der Beerensaft erwies sich manchmal als Blut ${ }^{18}$

$17 \mathrm{Vgl}$ in diesem Zusammerhang Alcksandr Blok "O sovremennom sostojanj russkogo sumvolizma" [1910], (Uber die zetgenossische Situation des russischen Symbolismus). in .Sobranie Soxinenij $v$ vos'mi tomach. Moskva-Lenungrad 1962. Bd 5, S 425-436

18 Vladislav Chodasenc. [1927] 1991, op cit. S 341 
Aus diesem Zitat geht hervor, daß sich innerhalb des symbolistischen ziznetvorcestvo Mimesis, verstanden als Effekt der Darstellung einer bestimmten Rhetorik, und Mimikry, verstanden als theatralische Nachahmung derselben, wechselseitig bedingen und auf diese Weise ein intertextuelles Spiel zwischen Kunst und Leben evozieren. In seiner permanenten Theatralisierung der Lebensund der Textwelt verweist das ziznetvorcestvo damit auf einen vorkulturellen Ort, in dem Vollkommenheit imaginiert werden kann: auf den phallischen Signifikanten, der paradigmatisch für den Verlust des Urvaters, der ungehemmten joutssance steht. Auf diese Weise avancierte das żiznetvorčestvo zum Phantasma der All-Einheit, die Solov'ev als Sinn der Liebe einklagte.

\section{Eine Tragikomödie der Heterosexualität: \\ Die symbolistische ménage-à-trois}

Das żznetvorčestvo im Silbernen Zeitalter basierte auf einer (Diskurs-) Mode, mystisch-erotischer Liebesspiele, die das Verhältnis von Mann und Frau im Leben wie im Text prägten. Ihr Vorbild war die höfische Liebe. Sie erlebte im Rußland der Jahrhundertwende eine kulturelle Renaissance. Die Dreiecksbeziehungen der Symbolisten zeigen, daß in dieser Liebesökonomie einerseits das Objekt des Begehrens als stilisierte frouwe oder femme fatale unzugänglich gemacht und andererseits das Begehren endlos aufgeschoben wurde. Gleichzeitig wurde jene Geschlechtsambivalenz erzeugt, die dem Troubadurkult als Ausdrucksform der höfischen Liebe verpflichtet ist: "Die vom Troubadur durch Minne verehrte Dame nimmt (projektiv) jünglinghafte Züge an, wogegen der Minnediener leicht feminine Merkmale erhält." ${ }^{19}$

19 Aage A Hansen-Löve. 1992, op.cit. S 223 
Wie Slavoj Žižek gezeigt hat, kann man Logik und libidinöse Ökonomie der höfischen Liebe mit der "Heraufkunft des Masochismus, des masochistischen Paares gegen Ende des vorigen Jahrhunderts" erklären. ${ }^{20}$ Zižek argumentiert mit Lacan, daß die frouwe in der höfischen Liebe nicht als sublimes Objekt verstanden werden kann. Sie ist zwar abstraktes Ideal, hat aber keinen realen Hintergnund und dient nicht der spirituellen Läuterung. Ihr Wesen ist es kühl, distanziert und inhuman zu sein. Dabei gestaltet sich das Verhältnis des Ritters zur frouwe als Diener-Herrin-Verhältnis, wobei die frouwe das unmenschliche Gegenüber, das Andere repräsentiert. Als abstraktes Ideal kann die frouwe den Wünschen des Mannes aber nicht entsprechen, denn sie ist eine "Art Automat, eine Maschine, die willkürlich sinnlose Befehle ausspuckt." Dieses Zusammenfallen von absoluter, unergründlicher Andersheit und bloßer Maschine, verleiht der frouwe ihren unheimlichen, monströsen Charakter: die frouwe ist der Andere, mit dem keine Beziehung möglich ist. Die Verkörperung der frouwe als männliches Ideal, dem alle Vaterfunktionen übertragen sind, ist daher cin sekundäres Phänomen, sie folgt der primären Projektion der frouwe als Spiegel, in den das Subjekt sein narzißtisches Ideal projiziert.

Ein weiteres Charakteristikum der höfischen Liebe ist, daß sie "durch und durch eine Sache der Courtoisie und Etikette ist, und überhaupt nichts mit einer bestimmten elementaren Leidenschaft zu tun hat", denn "wir haben es mit einer streng kodifizierten Form zu tun, mit einem Gesellschaftsspiel des "Als ob", wenn wir vorgeben, unser Liebling sei die unerreichbare frouwe" ${ }^{21}$ Dieses Gesellschaftsspiel des "Als ob" war signifikant für das symbolistische żznetvorcestvo. Wie Žižek weiter mit Gilles Deleuze zeigt, kann die höfische Liebe damit in Bezug auf den Masochismus als einer spezifischen Form der Per-

20 Slavoj Žizek "Minne und Masochusmus Vom hofischen Liebesspicl zur todlichen Inszenierung", in: Iettre Intermational, Heft 25, II V / $194, S 76-79$, S 76 
version diskutiert werden, die in den literarischen Werken und in der Lebenspraxis Sacher-Masochs artikuliert wurde. ${ }^{22}$ Der Masochismus enthält jene Merkmale, die auch das zlznetvorcestvo charakterisieren: die Theatralisierung bzw. Fetischisienung der Realität; das heißt, Realität wird gespielt, Fiktionen werden zum Bestandteil der Alltagsrealität und umgekehrt. Und genau wie der masochistische Held unterwirft sich der symbolistische Held bzw. der Held des zıznetvorcestvo einem idealisierten Weibs-Bild, das ihm in mystischer Schau Zugang zum Übersinnlichen, dem anderen Leben (mır ınoj) gewährt. Dabei scheint es, "er (gemeint ist der masochistische Mann, D.R.) werde von der autoritären Frau erzogen und geformt, in Wahrheit aber ist sie es, die von ihm geformt und travestiert wird, und er ist es, der ihr die harten Worte eingibt, die sie an ihn richtet." ${ }^{23}$ Analog dazu wurde die Liebe im žznetvorcestvo entsexualisiert und der Diskurs über sie sexualisiert: "Die Lust selber wird verneint, indem der Masochist sie so lange hinauszögert, bis er genau im Augenblick der Lustempfindung ihre Wirklichkeit verneinen kann, um dem >neuen Menschen ohne Geschlechtsliebe> gleich zu werden." ${ }^{24}$ Damit wird auch das Objekt des Begehrens, die frouwe, unzugänglich, da es nur auf mäandrischem Wege, nur über Hindernisse erreichbar ist. Das Objekt der Erwartung wird zum Fetisch und das Begehren nach ihm permanent aufgeschoben: "Der Masochist erlebt das $>$ Warten im Reinzustand < [...], ebenso wie der Diabolist einem >leeren Adventismus $<$ verfallen ist, einer Verzögerung, Aufschiebung, Spannung, die vom

\section{Ebd S 76.}

22 Gilles Deleuze "Sacher-Masoch und der Masochismus", in. Loopold von Sacher-Masoch. Vemus im Pelz, Frankfurt/Main 1980. S 162-281, S 177

23 Ebd S 178.

24 Ebd. $S 187$.

25 Aage A Hansen-Love, 1992, op.cit. S 267 
Phantasma ausgeht." ${ }^{.25}$ Durch den endlosen Aufschub, das Warten und die Verzögerung bilden die zahlreichen und komplizierten Dreiecksverhältnisse der Symbolisten - sei es die zwischen Andrej Belyj, Nina Petrovskaja und Valerij Brjusov, oder zwischen Andrej Belyj, Ljubov' Dmitrievna und Aleksandr Blok, oder zwischen Zinaida Hippius, Dmitrij Filosofov und Dmitrij Merezkovskij ein Netz von Umwegen, Annäherungen und Beinah-Verfehlungen, deren Liebesobjekt nur als abwesender Bezugspartner erreichbar ist.

Neben der Geschlechtsambivalenz ist also das auffalligste Merkmal des Geschlechtsverhältnisses, das die symbolistische ménage-à-trois strukturiert, die Umleitung bzw. der endlose Aufschub des Begehrens über ein künstlich aufgebautes Hindemis, das den direkten Weg zum eigentlichen Liebesobjekt verzögert. Dabei kommt es zu einem ständigen Rollentausch bzw. doppelt verteilten Rollen, indem die beteiligten Personen damit spielen, wessen Stelle sie einnehmen, die des Liebenden, des Geliebten oder des Nebenbuhlers. Dies fuhrec daza, daß jeder Beteiligte innerhalb ciner symbolistischen ménage-à-trois den Platz des anderen einnehmen und damit sowohl "Mann" als auch "Frau" sein konnte. Jede Szene konnte praktisch auf mehreren Ebenen zugleich gespielt werden. Die Symbolisten erzeugten damit für sich die Illusion, daß es ein reales Liebesobjekt gäbe, das ihrem aus der symbolistischen Theorie entsprungenen idealisierten Bild entspräche. Das, was die Symbolisten mit dem Wort "Liebe" einforderten, war aber eine unmögliche Liebe, denn sie konnte nur auf jener Metaebene funktionieren, die das Leben als etwas Theatralisches gestaltete. Da sie einem fingierten Schauspiel unterlag, war es eine Liebe, die niemals vollzogen werden konnte:

Ot kazdogo, vstupavšego v orden (a simvolizm v izvestnom smysle byl ordenom), trebovalos' liš neprestannoe gorenie, dvizenie - bezrazlizno, vo imja cego Vse puti byli otkryty s odnoj liš objazannost'ju - idti kak možno bystrej i kak možno dal'še. Éto byl ego edinstvennyj dogmat Možno bylo proslavljat' i Boga, i D'javola, i čto ugodno Razrešalos' byt'

25 Aage Hansen-Love, 1992, op.cit. S 267 
oderżmym Cem ugodno trebovalas' liš polnota odertimostı Otsjuda lichoradocnaja pogonja za èmocijami, opjat'-taki bezrazlizno, za kakimi Vse "perezivanija" poxitalis' blagom, liš by ich bylo mnogo i oni byli sil'ny. Karestvo ich rešitel'no vytesnjalos' koliðestvom V svoju oxered' otsjuda vytekalo bezrazliznoe otnošenie $k$ ich posledovate'nosti, $k$ ich celesoobraznosti (celesoobraznosti i ne sprašivalos') ${ }^{26}$

Von jedem, der in diesen Orden eintrat - und der Symbolismus war gewissermaßen ein Orden -, forderte man ununterbrochenes Brennen, Bewegung - egal wofur Alle Wege waren offen, man mußte nur eine Bedingung befolgen - so schnell wie moglich und so weit wie moglich zu gehen Das war das einage Dogma Man konnte Gott verherrlichen oder den Teufel oder was auch immer. Man hatte sich dazu entschlossen, besessen zu sein, egal wovon man mußte nur wollkommen besessen sein Daher ruhrte die fieberhafte Jagd nach Emotionen, egal nach welchen Alle Erlebnisse sah man als Nutzen, Hauptsache es waren viele und sie waren stark Ihre Qualitat $20 \mathrm{~g}$ man entschlossen aus ihrer Quantitat. Daher ruhr auch die gleichgultige Beziehung zu ihren Folgen, ihrer Zweckmaßigkeit (nach der Zweckmaßigkeit wurde auch nicht gefragt)

Entsprechend diesem Schauspiel inszenierten die Symbolisten in der Maskerade ihrer eigenen Geschlechtsidentität eine Art "Tragikomödie der Heterosexualität": sie zeigten die Verfehlung von Mann und Frau, ihre NichtBegegnung. ${ }^{27}$

Wie Judith Butler in ihrer Analyse von Lacans und Rivières Definition der Maskerade dargelegt hat, kann die Maskerade sowohl "als performative Hervorbringung einer sexuellen Ontologie verstanden werden, d.h. als reine Erscheinung, die sich selbst überzeugend als Sein darstellt, als auch als Verleugnung eines weiblichen Begehrens gelesen werden, die eine vorgängige ontologische Weiblichkeit voraussetzt, die durch die phallische Ökonomie regelmäßig nicht repräsentiert wird." ${ }^{28}$ Übertragen auf die symbolistische ménage-à-trois bedeutet die permanente Inszenierung einer angeblich ge-

26 Vladislav Chodaseve. [1927] 1991, op.cit., S $340 \mathrm{f}$

27 Interessant ist in diesem Zusammenhang auch de Tatsache, daß gerade Puccinis Oper "Madame Butterfy" im Rußland der Jahrhundertwende sehr populär war (ste wurde zum ersten Mal am 25 Januar 1911 im Bol'šoj Teatr unter der Lettung von Zimin aufgefuihrt) Darauf verueist Nina Petrovskaja in ihren Memoiren, in: Literammoe Nasledsno Valenj Brjusov, Bd 85, Moskau 1976, S 783

$28 \mathrm{Vgl}$ Judith Butlers Kapitel "Lacan. Ruviere und dic Strategien der Maskcrade, in: Das Unbehagen der Geschlechter, FrankfurtMain 1991, S. 75-93, S 79f 
wünschten heterosexuellen Beziehung - zwei Männer kämpfen um eine Frau im Grunde nichts anderes als die Theatralisierung einer heterosexuellen Matrix, die man im Grunde ablehnt, sie aber letztendlich nicht überwindet aus Angst vor der eigenen männlichen oder weiblichen Homosexualität bzw. aus dem Antrieb heraus, den Mangel im anderen zu maskieren. Da sich nach Lacan die Beziehung zwischen den Geschlechtern um ein Sein und ein Haben zentriert (den Phallus haben $=$ Mann bzw . der Phallus sein $=$ Frau $)$, kommt es darin zwangsläufig zur Maskerade, die die Grenze zwischen Sein und Schein verschiebt. ${ }^{29}$ Analog dazu strukturiert sich die symbolistische ménage-à-trois. Denn da die "Frau" das maskiert, was sie eigentlich nicht ist und der "Mann" das maskiert, was er eigentlich nicht hat, kann es nur zu komischen Verfehlungen kommen, die das Geschlechtsverhältnis letztendlich zum Scheitern verurteilen. Dies verweist auf jenes Paradoxon der höfischen Liebe, das Lacan als "durch und durch raffinierte Weise" charakterisiert, der Abwesenheit des Geschlechtsverhältnisses zu supplieren, in dem fingiert wird, daß wir es sind, die hier ein I lindernis aufrichten." ${ }^{30}$ Es geht jedoch nicht danum, den Wert des Objekts durch ein zusätzlich eingebautes Hindernis zu erhöhen, sondern darum, die Illusion zu erzeugen, daß das Objekt ohne es erreichbar wäre. Was dadurch verschleiert wird, so Žižek, ist die Tatsache "der inneren Unmöglichkeit, zum Objekt zu gelangen, denn die Stelle der frouwe ist ursprünglich leer. Sie fungiert als narzißtische Projektionsfläche des Subjektes, als eine Art >schwarzes Loch<, um das herum sich das Begehren des Mannes strukturiert, sein Wunsch sich organisiert. Der Raum des Begehrens ist gekrümmt, nur indirekt ist das Objekt, die frouwe zu erreichen, nur auf gewundenem mäandrischen Wege. Sobald wir direkt darauf zugehen, verfehlen wir unser Ziel. Das ist es, was Lacan meint, wenn er im Kontext der höfischen Liebe auf die $>$ Bedeutung $<$ zu sprechen

29 Jacques Lacan "Dic Bodcutung des Phallus", in Schnfien II, Freiburg/1 Brg 1975, S 130

30 Ders Fincore. Das Seminar (Buch XX), Wenhuem 1986, S 20 
kommt, die wir der Absolvierung des Umweges in der psychischen Ökonomie beilegen müssen" ${ }^{\prime 3}$. Übertragen auf die Dreiecksbeziehungen der Symbolisten entspricht die Absolvierung des Umweges jeweils dem "Dritten", der gebraucht wird, um das Symbolische bzw. den "Namen des Vaters" zu realisieren. Nur noch in der Schrift, im Text, konnten die Symbolisten gemäß Solov'evs Vorstellung der All-Einhelt eins mit dem Anderen sein, was natürlich in letzter Konsequenz bedeutete, eins mit sich selbst zu sein.

Nachdem die Ökonomie der höfischen Liebe als theoretische Grundlage zum Verständnis des symbolistischen žınetvorčestvo erklärt wurde, wird jetż am Beispiel der Dreiecksbeziehung von Nina Petrovskaja, Andrej Belyj und Valerij Brjusov ihre konkrete Inszenierung veranschaulicht. Zunächst werden die biographischen Hintergründe dieser verstrickten ménage-à-trois geschildert, um dann im folgenden Abschnitt ihre Literarisierung in Brjusovs Roman Der feurige Engel zu besprechen.

Dic Bezichung zwischen Belyj und Brjusov begann ungefähr 1902. Brjusov schreibt in sein Tagebuch: "Vsech etich mel'kich interesnee, konežno, A. Blok, kotorogo ja lið̌no ne znaju, a ešce interesnee vovse ne mel'kij, a ocen' krupnyj B.N. Bugaev - interesnejšij Celovek v Rossij." ("Interessanter als alle die Kleinen ist natürlich Aleksandr Blok, den ich persönlich nicht kenne, aber noch interessanter ist der keineswegs kleine, sondern im Gegenteil sehr große B.N. Bugaev, der interessanteste Mann Rußlands"). 32 Boris Bugaev, der sich bald das Pseudonym Andrej Belyj (Andreas der Weiße) zulegte, war Brjusovs Schüler. ${ }^{33}$ In seiner autobiographischen Schrift Nacalo veka (Der Beginn des

31 Slavoj Žizck. 1994, op.cit. S 78

32 Zit. nach Konstantun Motul'skij. Valerij Brjusov, Pans 1962, S 134

$33 \mathrm{Vgl}$. den cunfuhrenden Artikel von S.S. Grexıškın und A.V Lavrov zum Briefwechsel Brjusov Belyj, der von 1902-1912 andauerte, in: Lteratumoe nasledsno (Das literansche Erbe) Valenj Brrusov, Bd 85, Moskva 1976, S. 327-348 Das Pseudonym Andrej Belyj (dt Andreas der Weiße) betont de Farbe Weiß als Symbolfarbe der Anuma-Sophua. "Das Weiße symbolisiert den "Immaculata"-Typus ebenso we das Prophetusch-Manusche der Hummelsgestalt, thr "Weissagen", dagegen 
Jahrhunderts) schreibt Belyj über sein Verhältnis zu Brjusov: "Ja objazan emu vsej kar'eroj svoej" ("Ich habe ihm meine ganze Karriere zu verdanken"). ${ }^{34}$ Jeden Brief an ihn unterschrieb er mit "gluboko ljubjaščij vas Boris Bugaev" ("ihr sie tief liebender Boris Bugaev"). ${ }^{35} 1903$ gründete Belyj den Kreis der Argonauten, der sich aus jungen Moskauer Dichtem, Philosophen und Künstlem reknutierte. Sie standen unter dem Einfluß der Solov'evschen Religionsphilosophie und Friedrich Nietzsches philosophisch-poetischen Werken und strebten danach, dem Leben durch eine apokalyptische Weitanschauung einen neuen geistigen Sinn zu geben: "Das Pathos des Argonautısmus bestand im wesentlichen in der Begeisterung an der Musik, im Blick und einer wilden, impulsiven Wiedergabe der emotionalen Befindlichkeit - des harmonischen Vorgefuhls künftiger Ereignisse." ${ }^{36}$ An diesem Kreis nahm auch Nina Petrovskaja teil, "Objekt der "theurgischen" Bemühungen Belyjs [...] die Frau des Verlegers von Grif: $<[\ldots]$ vollends gespalten, krank, gepeinigt von einem unglücklichen Leben, ausgeprägt psychopathisch, jederzeit bereit, sich Worten, die in ihrer Nähe fielen, schier bis zum Wahnsinn auszuliefern. $>$ "37 Belyjs Liebesexperi-

symbolisien das "Rote" die tellunsch-erousche Kchrsete des Weiblichen, das Vitale. Blutvolle - Liebe und Tod in einem In der erousch-mystischen Symbolik begegnet die Dualitat von WeiB und Rot als Lilie und Rose - beides zentrale Mouve der Manen-Minne des katholischen Mittelalters, die uber die hermetusch masonische Vermittlung und de Asthetusienung in der Romantuk auch in Rußland eingedungen war " Vgl. Aage A Hansen-Love, 1997, op cit, S 276/277 Mit der Farbe weß als Farbe des Lichtes und der Reinheit betont Belyj seine sexuelle Unschuld Der Titel des Romans Ognennyj angel verweist eunersets auf Belyjs "transsexuelles Wesen", andererserts verueist "ognennyj" auf das deutsche Wort Enge. Angst Es ist anzaunchmen, daß Brjusov, der gut deutsch sprach. sich bewußt dieses Wortes bedrente, um auf Belyjs Ginakophobic hinauwersen

34 Andrej Bely] Nacalo veka (IDer Beginn des Jahrhunderts) [Moskva-Lenungrad 1933] Moskva 1989, S. 159

35 "Pcrepiska s Andrcem Belym" (Bncfuvechsel mit Andrej Beby), in Literatumex nasledsroo (IDas literanische Erbe), Bd 85, Moskva 1976, S 349-427, S 384

36 "Upocnic muzykoj, vzor I stuchijnaja. umpul'sınnaja perodaca cmocional'naja sostojanja - gar-

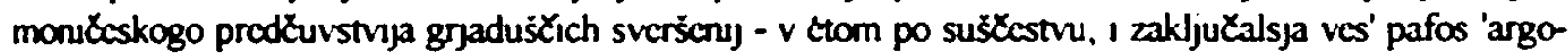
navtuzma' "Zit nach S S Grociškin und Lavrov, 1976, op cit, S $328 f$

37 Alexander Etkund Fros des (Inmoglichen Die (ieschichte der Psychoanalyse in Rußland. Leipzg. 1996. S 60 
ment mit Nina Petrovskaja zeigt, auf welche Weise der Schriftsteller seine Maxime des ziznetvorcestvo in die Tat umsetzen wollte. Seine beginnende Freundschaft mit dieser Frau verwandelte er in ein Mysterium; darin nahm er selbst die Rolle des "Himmelsbräutigams" ein, während er Nina Petrovskaja die Rolle "der Auserwählten Gottes" zuschrieb. Dieses "himmlische" Verhältnis entwickelte jedoch bald "irdische" Züge, tvas Belyj als Sündenfall und Scheitem seiner argonautischen Ideale auffaßte: Aus der heiligen Liebe hatte sich eine ganz profane, sexuelle Beziehung entwickelt. Belyj zog sich zurück und Nina Petrovskaja, enttäuscht von dieser Reaktion, näherte sich Brjusov an, der wiederum seine hypnotischen Experimente an ihr ausprobiert. Es entstand eine Dreiecksbeziehung, die ungefähr ein Jahr dauerte: Im Frühjahr 1905 versuchte Nina Petrovskaja während einer Vorlesung Belyjs auf Brjusov zu schießen, "doch die Browning versagt den Dienst..." ${ }^{38}$ Wie im folgenden gezeigt wird, ging es hier nicht um die Frau, sondem um die "Haßliebe" zwischen Belyj und Brjusov. Die Frau fungierte lediglich als Medium. ${ }^{39}$

Nach und nach verschlechterte sich das Verhältnis zwischen beiden Schriftstellem, zum einen dadurch, daß Brjusov die religionsphilosophischen Überzeugungen des jüngeren Symbolisten Andrej Belyj fremd blieben. Nach den Prinzipien des Materialismus und Atheismus erzogen ${ }^{40}$, fand Brjusov keinen

\section{Ebd}

39 "In gevissen Phasen dieser oft sechr dramatischen Dresecksbezachungen hatte es den Anschein, als würde der Licbende (etwa A. Belyj) dic Geliebte (Ljubov' Dmitnevna) primar als Medium seines Verhattusses zum Dntten (A. Blok) benutzen Ahnliches kannte fur das Dreteck A Belyj. V. Brousov und Nina Petrovskaja gelten (oder Merezkovskij, Zinaida Gippius und Filosofov) " Vgl Hansen-Love. 1992, op cit., S. 223

40 "Or skazok, of vsjakoj "Certovščiny" menja usendno oberegalı. Zato ob idejach Darvina i o prinzipach materializma ja uznal ranše, Cem nauxiljsja umnoženuju Netego govont', to o religii $v$ našem dome 1 pominu ne bylo [...]. Posle detskich knizek nastal kerez biografijj velikıch ljudej eti brografii prouzvelı na menja sil'nejsoc vpectatlente; ja nacal moxtat', čto sam nepremenno sodelajus' "velikim"..." ("Marchen, von jeglicher Teufelei hat man mich gewissenhaft femgehalten Stattessen wurden mir die Idoen von Danuin, die Prnzapien de Matenalismus beigebracht, noch bevor ich das Einmaleins lemte. Die Religion existierte in unserem Hause uberhaupt nicht [...] Nach den Kinderbuchem las ich Biographuen großer Leute. Diese Biographien hunterticken cunen großen Eundruck in mir. Ich begann 
Zugang zu mystischen Erlebnissen, wie sie sich in Andrej Belyjs Zoloto v lazuri (Gold in Lazur) und Aleksandr Bloks Stichı o Prekrasnoj Dame Nerse von der Schönen Dame) artikulierten: "Die jüngeren Symbolisten besangen die Erscheinung der Ewigen Weiblichkeit, sahen Blicke und hörten Laute, die er nicht sah und nicht hörte. Und er versteckte seinen $\mathrm{Haß}$ und seine Scham. ${ }^{(4)}$ Die konträren Ansichten zwischen beiden - Brjusov als Vertreter des l'art pour l'art, Belyj als Vertreter einer symbolistischen Religionskunst - führten bald zu offenen Auseinandersetzungen. Der Streit eskalierte in einem "geistigen Duell", was der Briefwechsel aus den Jahren 1904-1905, sowie die Widmungsgedichte und Karikaturen belegen. ${ }^{42}$ Ausschlaggebend dafür war auch die Tatsache, daß Brjusov zu dieser Zeit mit Hypnose experimentierte und die erworbenen Fähigkeiten in seiner Selbstinszenierung als Dämon innerhalb des symbolistischen Zirkels ausprobierte. Belyj schreibt darüber: "Brjusov stal dlja menja temnym, bezvestnym drugom-vragom" ("Brjusov wurde für mich zu einem dunklen, unbekannten Freund-Feind") ${ }^{43}$. Der Konflikt zwischen beiden erreichte seinen absoluten Höhepunkt, als Brjusov Belyj das Gedicht Bal'deru Loki schickte und das Papier in Form eines Pfeils faltete ${ }^{44}$.

davon as traumen, daß auch ich irgendwann "groß" werden wurde", Valeri Brjusov: Avtobiografija. Moskva 1914, S 102-103, zt. nach Russkie Pisatel"i Bibliograficeskjj Slowar'v cturch romach, hg von P. Nikolacv et al., Moskva 1990, S 119-123, S.119.

41 "Mladžse simvolısty vospeli javlenuc Večnoj Žensmennos", videlı vzory i zvuku. kotoryj on ne vdel I ne slyšal I on skril svoju nenavist' i styd " Vgl. Konstantun Mocul'skuj. 1962, op.cit.. S. 134.

42 Die Tatsache, daß Belyj schr enge Kontakte mit den Merežkovskuss führtc, uurde von Brjusov nucht gutgeheißen Bet enem Besuch in deren Haus begann er. die Merełkovskujs al beschumpfen. Belyj schickte ithm daraufhen cunen Bricf, in dem er thn als "rugatel"' charaktensiert Danach forderte Brjusov Bely] in encm Brief vom 20 Februar 1905 zum Duell auf, weil er sich von Bely] "beuußt beleidigt" fülte In seunen Memoiren veruetst Bely] darauf, daß es keinen wirklichen Grund al einem Duell gegeben habe "Oxevidno. te Brjusov iskusstvenno stroit duel"' ("Es ist offensichtlich. daß Brjsuov das Duell kunstlich konstruiert"), un. "Perepiska s Androem Belym" ("Bnefwochsel mit Andrej Bely"), in Isteratumoe Nasledsno, 1976, op.cit, S 383

43 Zit. nach Groxiškin und Lavrov, 1976, op cit. S 336

44 Ebd S 336 Balder und Lokı getoren der germanischen Göttenwelt an Balder ist der Licht- und Jugendgoth der Sohn des Odins und der Fngg. charaktensusch fur thn ist seine Rolle als passives Opfer Lokj ist ein chaotischer, velgesichtger Todesdamon. der de anderen Gotter mit Spott und 
Svetlyj Bal'der! Mne navstrecu

Ty, kak solnce, vznosiš lik

Cem lucam tvoim otvecu?

Opalennyj ja ponik

Ja vzbegu $k$ snegam na kruci

Ty smees sja s vysoty'

Ja vznesus' bagrjanoj tucej

Kak zvezda, sijajes ty!

Pripadu na tajnom lože

$\mathrm{K}$ aloj laskovosti gub

Ty metnes strelu, - i cto ze!

Ja, droza, szimaju trup

No mne javlen Nertoj mudroj

Prizrak budušzich viemen

Na tebja, o zlatokudryj,

Luk volšebnyj naveden

Lichter Balder Mir entgegen

haltst du wie die Sonne, dein Gesicht

Antworte ich Deinen Strahlen?

Versengt neige ich mein Haupt

Ich renne zum Schnee auf den Hugel!

Du lachst aus der Hohe!

Ich jage der purpurnen Wolke nach

Wie ein Stern strahlst du!

Ich gerate in die geheime Loge

zur purpurnen Zartlichkeit der Lippen

Du wirfst den Pfeil, und was wohl!

Zitternd presse ich den Leichnam

Aber mir erscheint der weise Nertoj

Der Schatten kunftiger Zeiten

Auf dich, oh, Goldgelockter,

ist der Zauberpfeil gerichtet

Am 14. Dezember folgte Belyjs Antwort: Das Gedicht "Starinnomu vragu v znak ljubvi i uvaženija" ("Einem alten Feind als Zeichen der Liebe und Hochachtung"):

Ja byl $v$ ušcel'e Demon gormyj

Vzmachnul krylom - zatmilsja svet

On mne grozil borboj upornoj.

Ja znal $v$ borbe poscady net

Sctmahungen uberschuttet Lokıs unsuhnbares Verbrechen ist die Totung Balders. eune Tat, die schon auf das bevorstethende Ende der Gotter hunweist Nerthus ist ein Naturgott der Zweigeschlechtlichkeit. mit ihm wird der Kult der heligen Hochzeit vertunden 
I dlan' vozdel. I oblak belyj

$V$ lazur' menja - v lazur' unes.

Opjat' v efirach vol'nyj, smelyj,

Omytyj laskovost'ju ros!

Ty nessja wys' so mnoju rjadom,

Podobnyj dikomu orlu

No oprokinut tjałkim gradom.

Ty pal, bessil'nyj, na skalu

Ty pyl'ju vstal, no pyl', no kopot'

Spalit ogon', rasseet grom

Net, ne vzletis bescel'no chlopat'

Svoim rastrepannym krylom

Moja bronja gorit požarom

Kop'e mne - moln'ja. Solnce - šxit

Ne približajsja: $v$ gneve jarom

Tebja groza ispepelit

Ich war in der Schlucht Ein Bergdamon

schlug mit seinem Flugel und versperte die Sonne

Fr drohte mir mit einem hartnackigen Kampf

Ich wußte in diesem Kampf gibt es keine Gnade

Und ich hob die Hande empor Und die weiße Wolke trug mich ins Lasurblau for

Zunuck im Ather frei, mutig

Von Zartlichkeit umhullt bin ich gewachsen!

Du bist mit mir in die Hohe geflogen,

ahnlich einem wilden Adler

Aber von einem schweren Hagel niedergerissen,

bist du, kraftlos, auf den Felsen gefallen

Voll Staub bist du aufgestanden, aber Staub, Ruß

versengen das Feuer, saen Zorn

Nein du fliegst nicht in die Hohe ziellos

schlagst du mit deinem zerrissenen Flugel

Mein Panzer brennt vor Feuer

Der Speer ist mir Blitz Die Sonne - ein Schild

Komme nicht naher im rasenden Zorn

legt dich der Donner in Schutt und Asche

(Interlinearubersetzung von mir, D R ) 
Brjusovs inszenierter Zweikampf enthält Züge dessen, was Kosofsky Sedgwick an anderer Stelle als paranold Gothic bezeichnet. Damit verbindet sie ein postromantisches Phänomen, das für die "weitverbreitete, endemische männliche Angst vor Homosexualität" ${ }^{\text {45 }}$ steht. Sie versteht unter diesem Phänomen "Romane der Romantik, in denen ein Held in einer engen, gewöhnlich mörderischen Beziehung zu einer anderen männlichen Figur steht, die in mancherlei Hinsicht sein "Double", sein "Doppelgänger" ist" ${ }^{46}$. Kosofsky Sedgwick siedelt dieses Phänomen in der Zeit an, als sich "die moderne, vom Kapitalismus gezeichnete, ödipale Familie" ${ }^{\prime 47}$ herauskristallisierte, in der das weibliche Element ausgestoßen wird. In ihrer Studie Between Men verweist sie darauf, daß männliche homosoziale Beziehungen die gesamte Kultur strukturieren, die nach Lévi-Strauss eine globale Tauschbeziehung darstellt. Diese stellt sich nicht zwischen einem Mann und einer Frau her, sondern zwischen zwei Gruppen von Männem, wobei die Frau dabei die Rolle eines Tauschobjekts einnimmt und nicht die eines Partners, zwischen denen der Tausch stattfindet. ${ }^{48}$ Obwohl das symbolistische Ziznetvorčestvo für sich die Schaffung von neuen Lebenszusammenhängen in Anspruch nahm, die auch das Verhältnis zwischen Mann und Frau neu definieren sollten, konstituierte sich der Symbolismus als literarische Schule über eine Gruppe von Männem, während der Großteil der Frauen weiterhin die traditionelle Rolle der Muse übernahmen, mit Ausnahme der problematischen Zinaida Gippius. ${ }^{49}$ Brjusovs Begehren galt nicht der Person Nina Petrovskajas, sondern den mystischen Erfahrungen, die sie mit Belyj teilte:

45 Eve Kosofsky Sodguick: "Das Tier in der Kammer: Henry James und das Schreiben homosexueller Angst", in: Dekonstruktiver Feminismus. Literaturwissenschaft in Amerika, $\mathrm{Hg}$ Bartara Vunken. FrankfurdMain 1992, S. 247-278, 252.

46 Ebd. S. 275.

47 Ebd S. 252.

48 Eve Kosofsky Sedguick: Between Men. English Literarure and Male Homosocial Desire, New York 1985, S. 83-96

49 Siche Kapitcl I dieser Dissertation 
[Brjusov] odno vremja postavivšego sebje devizom menja "SRAŽAT"; etot sport dlilsja v epochu 1904-1906 godov, i odnako est' ukazanija ego o strannom fakte, cto on scital sebja pobezdennym mnoju "MIFIZACIJA" 1905 godov ego romane "OGNENNYJ ANGEL", gde on menja "UDOSTOLL" roli grafa Genricha

[Brjusov] hatte es sich einmal zur Devise gernacht, mir eine "Niederlage beizubringen", diesen Spott betrieb er von 1905-1906, und doch gibt es ein Faktum, daß er sich von mir als besiegt betrachtete seine "Mythisienung" unserer Beziehung in der Zeit von 1904 bis 1905 in seinem Roman Der feurige Iingel, wo er mich der Rolle des Grafen Heinrich für wurdig erachtete ${ }^{\text {so }}$

Nina Petrovskaja, die als Vermittlerin den Konflikt zwischen Brjusov und Belyj mit ausgetragen hatte, charakterisierte das Verhältnis als „Mythos einer provinziellen Legende über ein dämonisches Thema, das von Belyj erfunden wurde" $^{\text {"51 }}$. In ihren Erinnerungen wird deutlich, daß Brjusov das gemeinsame Leben als Inspirationsquelle für seinen Roman betrachtete:

[...] grudy istoriðeskich issledovanij i materialov perekovyvalis' v plastiðeski-prekrasnuju plamennuju fabulu Iz etich gnud listov, gde każaja krochotnaja zametka strogo sootvetstvovala istoriceskoj pravde, vstavali obrazi grafa Genricha. Ruprechta i Renaty Emu byli nužny podlinnye zemnye podobija tetich obrazov (Hervorhebung von mir, D.R.) [ ] I ja nužna byla Brjusova dlja sozdanija ne fal'šivogo, ne vymyšlennogo v kabinete, a podlinnogo poxti obraza Renaty iz "Ognennogo angela" Potomu ljubopytstvo ego, vnacale ljubopytstvo poťi cto naurnoe, vozrastalo s každym dnem [ ] ${ }^{\text {s2 }}$

[ .. ]die Massen an historischen Forschungen und Materialien verwandelte Brjusov in eine plastisch-wunderschone feurige Fabel Aus dieser Menge von Blattern. wo jede kleinste Anmerkung der historischen Wahrheit entsprach, entstanden die Bilder des Grafen Heinich, Ruprechts und Renatas Brjusov brauchte dazu authentische, irdische Ebenbilder (Hervorhebung von mir, D R ) [ ] Brjusov brauchte mich fur die Schaffung

50 Andrej Belyj. (Poxemu ja sial simwolistom i mikogda perestal im byr' wo usech fazach moego idejnogo i chudožestrennogo razvinja (Wanum ich ein Symbolist bin und warum ich nie aufgehort habe. einer zu sein), (handschnftliches Onginal von 1928). Ardis. Ann Arbor. Michigan 1982, S 23/24 Deutsche Ubersetzang Ich, ein Symbolist, Munchen 1987, S 42

51 "Iz vosporminanj" ("Aus den Ennnerungen"), in Isteraturnoe nasledsiwo (Das literansche Erbe). Valenj Brjusov, Moskva 1976, S 789 Nina Petrovskaja versuchte 1924 in Berlin vergeblich, diesen Text in den Verlagen Petropolis. Beseda und Russkj. Sovremennik zu publizieren Nach threm Tod blicb der Text in den Handen threr Berliner Freundin Gallop-Rempel, die thn 1934 dem Staatichen Literaturarchiv der UdSSR (CGALI) ubergab Dort licgt er als Autograph - allerdings nur in Fragmenten - vor Fur die Untersuchung des Geschlochtsverhaltusses innerhalb des symbolistuschen Zirkels ist er von besonderer Bodeutung. denn er stellt als weibliche Gegenstumme die Bezichungen zwischen den einzelnen Mitgliodem des symbolısuschen Zirkels auf eundrucksvolle Weise dar

52 Ebd S 791 
seines, nicht im Arbeitszimmer ausgedachten, sondern nahezu authentischen Bildes der Renata aus dem Feurigen Engel. Deshalb wuchs seine Neugier, die am Anfang wissenschaflich war, mit jedem Tag [. ]

Wie Chodasevic gezeigt hat, interessierte sich Brjusov vor allem für die Hysterie Nina Petrovskajas. ${ }^{53}$ Aus der "dekadenten Hysterikerin" macht er im Text eine vom Teufel besessene "Hexe", die an den Folgen der Inquisition stirbt:

Brjusov v tu poru zanimalsja okkultizmom, spiritizmom, cernoju magiej,- ne veruja, verojatno, vo vse eto po sušcestvu, no veruja v samye zanjatija kak v Żest, vyrazajuščij opredelennoe duševnoe dvizenie. Dumaju, čto i Nina otnosilas' $k$ etomu točno tak ze. Vrjad li verila ona, cto ee magiceskie opyty pod rukovodstvom Brjusova $v$ samom dele vernut ej ljubov' grafa Genricha. No ona perežjvala èto kak podlinnyj sojuz s d'javolom Ona chotela verit' v svoe vedovstvo. Ona byla isterickoj, i eto, byt' možet, osobenno privlekalo Brjusova: iz novejšich nauxnych istoxnikov (on uvazal vsegda nauku) on ved' znal, Cto v "velikij vek vedovstva" ved'mami poxitalis' i sami sebja poxitali - istericki. Esli ved'my XVI stoletija "v svete nauki" okazalis' isterickami, to $v$ XX veke Brjusovu stoilo popytat'sja prevratit' istericku v ved'mu. ${ }^{\text {s4 }}$

Zu dieser Zeit beschaftigte sich Brjusov mit Okkultismus, Spiritismus und schwarzer Magie. wahrscheinlich glaubte er an das alles nicht wirklich Aber er glaubte an diese Beschaftigungen als Geste, die eine ganz bestimmte seelische Bewegung ausdrückt. Ich denke, daß Nina genau die gleiche Einstellung dazu hatte Sie glaubte wohl kaum daran, $\mathrm{da} \mathrm{ß}$ ihre magischen Erfahrungen unter Brjusovs Anleitung ihr tatsachlich die Liebe des Grafen Heinrich zuruckbringen wurden Aber sie erlebte sie als authentische Verbindung mit dem Teufel. Sie wollte an ihr Hexentum glauben. Sie war eine Hysterikerin und das zog Brjusov wohl besonders an aus neuesten wissenschaftlichen Quellen (er verehrte die Wissenschaft immer), wußte er, daß im großen Jahrhundert der Hexerei man die Hexen als Hysterikerinnen betrachtete und sie sich selbst auch als Hysterikerinnen ansahen Wenn die Hexen des 16 Jahrhunderts im Lichte der Wissenschaft als Hysterikerinnen gatten, so schien es Brjusov fur lohnenswert, im 20 Jahrhundert aus einer Hysterikerin eine Hexe $2 \mathrm{~s}$ machen

53 Aus dern Entuurf zu den autobiographuschen Kapiteln des Romans Der Feunge Engel geht hervor, daß Brjusov Nina Petrovskaja von allem Anfang als Hysterikerin einstufte "Ponjal, cto œ ljubov" istenja, ne ko mne, ne k B N. (Bons Nikolaevic. gemeint ist Belyj, D. R.), a voobške." ("Ich begriff, daß thre Luebe cine Hysterie ist, de weder mur noch B.N gilt)". Zit. nach Grexiškun und Lavrov, "Biograficeskic istotniki romana Brjusova Ognennyj angel ("Die biographuschen Grundlagen des Romans Der Feurige Engel von Bjusov"), in Wiener Slawistischer Almanach. Bd I, Wien 1978, Teil I, S. 79-108; Bd 2. Wien 1979, Teil II S.73-96, 1978, S.79.

$54 \mathrm{Vgl}$ Chodasevix [1928] 1991, S 345 Der Litcraturkritaker spict auf die wissenschaftichen Veroffentlichungen von Charcot an die in Rußland rezipiert wurden 
Eine Textpassage aus dem Roman Der Feurige Engel weist daraufhin, daß Brjusov Charcots Texte gekannt haben muß, zeigt sie doch deutliche Parallelen zu der Art, wie Charcot die Hysterikerinnen beschrieben hat:

Nikogda to togo dnja ne videl ja takich sodroganij i ne podozseval. cto celoveceskoe telo možet izgibatsja tak neverojatno! Na moich glazach ženš̌xina to vytjagivalas' muCitel'no i protiv vsech zakonov prirody, tak ť šeja ee i grud' ostavalis' tverdymi, kak derevo, i prjamimi kak trost', to vdrug tak sgibalas' vpered, cto golova i podborodok sblizalis' s pal'cami nog, i žli na še cudovišňno naprjagalis', to, naprotiv, ona udivitel'no otkidyvalas' nazad, i zatylok ee byl vyvorocen vnutr plex, $k$ spine, a bedra vysoko podnjaty ${ }^{s s}$

Nie bis zu jenem Tage hatte ich solche Zuckungen gesehen, und nie hatte ich vermutet, daß der menschliche Korper zu derartigen Verrenkungen fahig sei Gegen alle Gesetze der Natur reckte sich die Frau vor meinen Augen so, daß ihr Hals und Brust fest wie Holz und gestreckt wie ein Stecken blieben, oder sie beugte sich dermaßen weit vor, daß das Kinn die Zehen berürte, wahrend die Adern am Halse unnaturlich anschwollen, oder daß inr Hinterkopf zwischen den Schulterblattern auf dem Rücken lag. während die Huftknochen weit vorragten

Während Nina Petrovskaja das Bild der mittelalterlichen Hexe verkörperte, stand Belyj wiederum Brjusov Modell für die Figur des Grafen Heinrich und des Engels Madiel:

[...]on, brosivšij plašx na menja, zastavljal neproizvol'no menja $v$ mesjacach emu pozirovat', stav'ja voprosy iz svoego romana i zastavljaja na nich otvexat', ja Že, ne znaja romana, ne ponimal, zaxem on, za mnoju - točno gonjajas', vysmatrivaet moju podnogotnuju $i$ ekzamenuet voprosami o sueverii, o magii, o gipnotizme, kotoryj-ze on praktikuet, kogda stali pečatat'sja glavy romana "Ognennyj angel", ja ponjal "stilistiku" ego voprosov ko mne" Avtor rasskaza - Brjusov Graf Gejnrich luð̌šaja Cast' menja, svet, kotoryj bor-etsja s mrakom, Renata soveršennaja kopija Niny Petrovskoj ${ }^{\text {s6 }}$

[...] er zwang mich, nachdem er mir den Mantel übergeworfen hatte, ihm unfreiwillig monatelang Modell zu stehen, stellte mir Fragen aus seinem Roman und ich mußte sie beantworten Ich. der ich den Roman nicht kannte, verstand nicht, warum er buchstablich hinter mir herjagte, mein tiefstes Inneres ausspahte und es mit Fragen uber Aberglauben. Magie. Hypnose, die eigentlich er praktizierte, untersuchte Als erste Kapitel des Feurigen Fingels gedruckt wurden, verstand ich die "Stilistik" seiner Fragen Der Autor der Erzahlung ist Brjusov, Graf Heinrich ist der beste Teil von mir, das Licht, das mit dem Dunkel kampft, Renata ist die vollständige Kopie von Nina Petrovskaja

55 "Ognennyy angel", in . Savnsche Propylaen. Bd 88, |zuerst 1909|. Munchen 1971, S. 18ff

56 Andrej Belyj. NaCalo Veka (Der Beginn des Jahrhunderts), [auerst Moskva 1932] Moskva 1989, S. 284 
Aus diesem Zitat wird deutlich, das Brjusov Lebenssituationen mythisierte und ästhetisierte, ein Faktor, der ausschlaggebend wurde für den innersymbolistischen Konflikt und zur Krise des Symbolismus im Jahre 1910 führte. Die Besonderheiten dieses Konflikts lagen im wesentlichen darin begründet, daß Brjusov aus dem Symbolismus eine literarische Schule machen wollte und den herrschenden Konflikt zwischen jüngeren und älteren Symbolisten nicht öffentlich austrug, weil er nach außen hin die Einheit des Symbolismus wahren wollte. Aus diesem Grund wurde der Konflikt mit in die Literatur getragen. ${ }^{57}$ In einer Reihe von Briefen aus den Jahren 1906-1908, die Brjusov an Nina Petrovskaja adressiert, wird dieses Dilemma sehr deutlich. Immer wieder beklagt er seine innere Leere und die Unfähigkeit, zu schreiben. Ein Brief vom 14. Juli 1906 offenbart Brjusovs Schaffenskrise:

[...] Pomnju, verno pomnju: ja perežjval togda imenno to, čto i teper' iznemoženie, bessilie, nesposobnost' k tvorŁestvu, Zelanie ubezat', skryt'sja, utait'sja Cto-by menja ne sostavili dumat', dejstvovat', a prezde vsego Cuvstuovat' [...] I vdrug prisla - ty, kak to-to novoe, neozidannoe, nesbytołnoe, o rem mextalos' davno i čto vdrug osušcestvilos'. Priß̌la ljubov', o kotoroj ja tol'ko pisal $v$ stichach, no kotoroj ne znal nikogda; prišla zenšcina o kotorych ja tol'ko Cital v knigach ( $v$ tvoem Pšibyševskom), no ne vidal nikogda. Ty mne casto govorila, to tot god byl voskreseniem dlja tebja; no on byl i dlja menja voskreseniem U menja vdrug otkrylis' glaza, sdelalis' v sto raz bolee zorkimi; v rukach ja cuvstvovala novuju silu. Ja vdrug uvidal vokrug vnov' sokroviš̌a, kotorych moj prežnij vzor ne razlizal, [ . ] No ja ošibsja Rudnik moj byl vse ze uže opustošen. Skoro ołen' skoro podnjal ja poslednjuju blestku, - $i$ vot opjat' stoju v pustote, v razorennoj, opustošennoj šachte [. .] Ja ne mogu bol'se žit' ižrtymi verovanijami, temi idealami, 'rerez kotorye ja perešagnul Ne mogu bol'še žit' "dekadentsvom" i "nicšeanstvom" [ . ] ${ }^{\text {s8 }}$

[...] Ich erinnere mich ganz genau, damals litt ich genauso, wie ich jetzt leide: an Erschopfung. Kraftlosigkeit, an der Unfähigkeit zum künstlerischen Schaffen, dem Wunsch wegzurennen, mich zu verstecken, zu verbergen, damit man mich nicht zwingen konnte, zu denken, zu handeln, aber vor allem, zu fühlen [...] Und plözlich bist du gekommen du als etwas völlig Neues, Unerwartetes. Unerfullbares, von dem man lange geträumt hatte und das sich plotzlich verwirklichte Die Liebe ist gekommen, über die ich nur in Gedichten geschrieben habe, die ich aber niemals gekannt hatte, es kam eine Frau, über

57 Zara Minc "Graf Gennich von Ottergejm i Moskovskjj Renessans" ("Graf Heunnch von Siati i unspominanuja, Moskva 1989, Hgg Stanuslav Lesnevskij und Aleksej Michajlov, S Ofterdingen und die Moskaucr Renaissance"), in. Andrej Belyj. Problema nortesna, Moskau 1990, 115-240

58 Lteratumoe nasledsruo (Das literansche Erbe). Valerij Brjusov, Bd. 85, Moskau 1976, S. 791 
die ich bisher nur gelesen hatte (in Deinem Pšybyševskij), aber nie gesehen hatte Du hast mir oft erzählt, daß dieses Jahr fur dich eine Auferstehung war; aber auch fur mich war es eine Auferstehung Mir wurden plotzlich die Augen geoffnet, sie wurden hundertmal wachsamer, in den Handen spurte ich eine neue Kraft. Ich sah plotzlich ringsherum wieder Schatze, die mein fruherer Blick nicht wahrnahm [. ] Aber ich habe mich geim Mein Bergwerk war dennoch bereits vollkommen leer. Bald, schon sehr bald erhob sich der letzte Funke, - und jetzt stehe ich emeut in der Leere, in dem verwusteten Schacht [ ...] Ich kann nicht langer mit toten Uberzeugungen leben, mit jenen Idealen, die ich schon uberschritten habe. Ich kann nicht mehr in Dekadenz und Nietzschetum leben [...]

Brjusovs Roman Der Feurige Engel entspricht damit Belyjs Interpretation des literarischen Textes und stellt auf seine Weise ein "Fragment des kreativ gelebten Lebens" dar, das letztendlich gescheitert ist:

Dlja menja éto byl god buri, vodovorota Nikogda ne perežival ja takich strastej, takich mucitel'stv, takich radostej Bol'šaja Cast' pereżvanij voplošena v stichach moej knigi "Stephanos" Koe-cto vošlo i v roman "Ognennyj Angel" Vremenami ja vpolne iskrenno gotov byl brosit' vse preznee moej zizni i pereijti na novye, nacat' vsju zizn' snova Literaturno ja potti ne sušcestvoval za etot god, esli razumet' literaturu v Verlenovskom smysle Poxti ne rabotal "Zemlja" napetatana s cernovyka Poxti so vsemi porval snošenija, v tom זisle s Bal'montom i Merežkovskimi Nigde ne pojavljalsja. Svjaz' ostavalas' tol'ko s Belym, no skoree svjaz' dvuch vragov Ja ego vyzyval na duel', no delo ustroilos' on izvinilsja Vesnu 1905 goda ja provel v Finljandii, na beregu Sajmy. S oseni nacalos' kak by vyzdorovienie. Ja vnov' obrel sebja "s9

Fur mich war das ein sturmisches Jahr, voller Umbruche Niemals vorher habe ich eine solche Leidenschaft erlebt, solche Qualen, solche Freuden Einen großen Teil meiner Leiden habe ich in den Gedichten meines Buches "Stephanos" verewigt. Etwas davon ging in den Feurigen tingel Zeitweise war ich aufrichtig bereit, alle Brucken hinter mir abzubrechen und ein neues Leben zu beginnen. In der Literatur habe ich in diesem Jahr uberhaupt nicht existiert, wenn man die Literatur im Sinne Verlaines versteht Ich habe fast nicht gearbeitet "Die Erde" ist vom Entwurf gedruckt worden Mit fast allen habe ich gebrochen, unter anderem mit Bal'mont und Merezkovskij Bin nirgendwohin gegangen In Verbindung stand ich nur mit Belyj, aber das war eher eine Verbindung zweier Feinde Ich habe ihn zum Duell aufgefordert, daraus wurde nichts Er hat sich entschuldigt. Den Fruhling habe ich in Finnland verbracht, am Ufer der Sajma Seit Herbst fing so etwas wie Gesunden an. Ich hatte mich wieder gefangen

Der Roman Ognennyj angel (Der feurige Engel) ist ein Schlüsseltext des russischen Symbolismus, denn er spiegelt jenen "authentischen Fall kollektiven Schaffens" wieder, der von Vladislav Chodasevic als paradigmatisch fur das symbolistische żznetvorčstvo beschrieben wurde. Das "kollektive Schaffen" 
der Symbolisten resultierte in einer spezifischen Semantik des symbolistischen Zirkels, der sogenannten zirkulären Semantik (kruzkovaja semantika), die für die Frage nach der Semiotik des Verhaltens zwischen Mann und Frau eine ganz eigene Dynamik offenlegt. Gleichzeitig wird deutlich, auf welche Weise sich das Konzept dieser kunstreligiösen Existenz verselbständigte und wie es sich auf Autorschaft und Textproduktion auswirkte.

\section{Text-à-trois:}

\section{Valerij Brjusovs Roman Der Feurige Engel}

Als Ognennyj angel (Der feurige Engel) im Jahre 1908 erscheint, gerät der Roman ins Kreuzfeuer der zeitgenössischen Kritik. ${ }^{60}$ Brjusovs Kritiker werfen ihm "Ideenimpotenz" vor, die sie auf das "Bankrott einer einsamen Seele" zurückfüren. ${ }^{61}$ Die eigentliche Bedeutung des Romans liegt aber gerade in seiner Vervielfältigungsstruktur von Kunst und Leben, die sowohl die Spielregeln des symbolistischen žznetvorčestvo als auch die Matrix der höfischen Liebe entblöBt. ${ }^{62}$ In einem intertextuellen Spiel mythisiert und ästhetisiert

59 Übersetza nach Mocul'skij, 1962, S. 102.

60 Ognennyj angel wurde erstmals 1908 in Moskau veröffentlicht. Alle folgenden russischen Zitate entstammen dem Nachdruck der revidierten Ausgabe von Moskau 1909, in. Slavische Propyldien, Band 88, München 1971. De deutschen Zitate entstammen det Ausgabe Der Feurige Engel, Koln 1990

$61 \mathrm{Vgl}$. Konstantin Mocul'skij. 1962. S. 133. Mocul'skj selbst fuihrt den Tatbestand der polemischen und strengen Kritik der Zeitgenossen an dem Roman darauf zurück, daß er au keinem Genre gehöre, das in der russischen Literatur gangig war Für einen histonschen Roman sei er zu phantastisch, für eunen psychologischen al unwahrheitsgemaß, keiner schätze das Bemühen des Autors, das Genre des westeuropauschen Abentcurerromans auf russischen Boden al verpflanzen. Man kann Mocul'skjj alstummen, wenn es darum geht, cine kulturelle Loerstelle innerthalb der russischen Literatur zu füllen. Allerdings handelt es sich nicht um das fehlende Genre des Abenteuerromans, sondern um die höfische Luebe und ihre Inszenienung innerhalb des symbolistischen Zirkels.

62 Diesem Aspekt ist bisher in der slavistischen Forschung keine Rochnung getragen worden. Grociskin und Lavrov verweisen auf den brographischen Hintergrund des Romans. Vgl. S.S. Grectiskin und A.V. Lavrov, op.cit. Holthusen sicht das eigentliche Thema det histonischen Romane Brjusovs in 
Brjusov Bloks Kult der Schönen Dame, sowie Belyjs Konzeption, die "Eleusinischen Mysterien" unter den Argonauten zu etablieren. ${ }^{63}$

Als Brjusov mit der Niederschrift seines Romans begann, hatte er als Wegbereiter und Führer des Symbolismus schon uneingeschränkten Ruhm gelangt, denn er konzentrierte alle seine Fähigkeiten auf die Schaffung dieser neuen literarischen Schule, deren Führung er sich von vorneherein reservierte. In seinem Tagebuch schreibt er am 04. März 1893:

Talant, daže genij, cestno dadut tol'ko medlennyj uspech, esli dadut ego. Eto malo! Mne malo Nado vybrat' ince Najti putevodnuju zvezdu $v$ tumane. I ja vižu ee eto dekadentsvo Dal C'to ni govorit', ložno ni ono, smešno li, no ono idet vpered, razvivaetsja, i budušce budet prinadležat' emu, osobenno kogda ono najdet dostojnogo voždja A étim vożem budu Ja! Da, Ja!"

Talent, sogar Genialitat fuhren nur langsam zum Erfolg, wenn überhaupt Das ist wenig' Das ist mir zu wenig. Ich muß etwas anderes auswählen Ich suche einen gewissen wegweisenden Stern im Nebel Und ich sehe ihn das ist die Dekadenz Ja! Was man auch uber die Dekadenz sagt. wie verlogen sie auch ist, wie komisch sie ist, wird sie trotzdem weiterbestehen, sich entwickeln, die Zukunft wird ihr gehören, besonders wenn sie einen wurdigen Fuhrer findet Und dieser Führer werde ich sein' Ja, ich' ${ }^{64}$

Als Reaktion auf jene Situation, die Brjusov in seiner selbstgeschaffenen Führungsposition destabilisierte, löste der Roman Der Feurige Engel eine dramatische Wechselwirkung zwischen Kunst und Leben aus, die sich daran zeigt, daß der Tod der Heldin als Voraussetzung des Textes zum Tod der realen Frau führte. Der Roman erzählt die Geschichte der Dreiecksbeziehung zwischen

\footnotetext{
der Bedrohung der Gesellschaft von innen, $\mathrm{d} h$ dem Auftreten von mystuschen und okkulten Sekten. dem Wirken der Magie, der Verblendung und Hystene. dem Niederreißen moralischer und sexuelier Schranken Fur ithn sund samtliche Personen in thren Reaktionen Angetionge der dekadenten Gesellschaft des fruhen 20 Jahrhunderts Vgl Johannes Holthusen: Studien zur Asthenk und Poerik des russischen Symbolismus, Gotungen 1957, S 70 Flickunger greift zwar den masochustischen Aspket auf, arteitet thn aber nucht aus. Bngitte Flickinger Valerij Brousov. Dichtung als Magie Kritische Analyse des 'Feungen Engels', Munchen 1976

63 Die Eleusinischen Mystenen getoren zu eunem alljahrlichen religiosen Ritus, de im alten Gnochenland zu Ehren der Gottun Demeter gefeiert wurden und von Tanzen und Theaterauffuhrungen begletet waren

64 Valenj Brjusov Dnevnika 1890-1910 (Tagebucher), Moskau 1927, zt nach Russke pisatell, op cre, S. 120
} 
Brjusov, Belyj und Petrovskaja, die von 1904-1905 dauerte. Die Hexe Renata (Nina Petrovskaja) ist zwischen der "heiligen" Liebe zu Graf Heinrich bzw. dem Engel Madiel (Andrej Belyj) und der "irdischen" Liebe zu Ruprecht (Valerij Brjusov) hin- und hergerissen. Folgendes Schema zeigt die grundlegenden Parallelen des Sujets zu den realen Episoden in den Beziehungen zwischen Belyj, Brjusov und Petrovskaja. Es verdeutlicht die Brüche und Verschiebungen, die sich aus der Polarisierung von Kunst und Leben ergaben ${ }^{65}$ :

\begin{tabular}{|c|c|}
\hline $\begin{array}{l}\text { 1. Andrej Belyj ist das Haupt der Argo- } \\
\text { nouten, die ihn als ihren Propheten ansehen }\end{array}$ & $\begin{array}{l}\text { 1. Graf Heinrich ist das Mitglied einer ge- } \\
\text { heimen mystischen Gesellschaft, die es sich } \\
\text { zur Aufgabe gemacht haben, den Weg zur } \\
\text { Wahrheit und zum Licht zu finden. }\end{array}$ \\
\hline $\begin{array}{l}\text { 2. Nina Petrovskaja, die als "Hohe } \\
\text { Priesterin" stilisiert wird, beginnt mit Andrej } \\
\text { Belyj eine mystische Beziehung, die auf den } \\
\text { Grundlagen einer Bruder-Schwester-Ge- } \\
\text { meinschaft basieren sollte }\end{array}$ & $\begin{array}{l}\text { 2. Graf Heinrich nähert sich Renata, die ihn } \\
\text { - wie den Engel Madiel - in ehrfurchtsvoller } \\
\text { Haltung anbetet, aber nicht nur himmlische, } \\
\text { sondern auch irdische Liebe sucht. }\end{array}$ \\
\hline $\begin{array}{l}\text { 3. Andrej Belyj sieht, daß seine mystischen } \\
\text { Erwartungen in Bezug auf seine Elysischen } \\
\text { Mysterien gescheitert sind. Seine argoncu- } \\
\text { tische Weltanschauung gerat ins Wanken }\end{array}$ & $\begin{array}{l}\text { 3. Graf Heinrich mißachtet die Regeln der } \\
\text { geheimen Gesellschaft, seine Erwartungen } \\
\text { vom Leben beginnen sich zu andern. Er } \\
\text { flüchtet vor Renata }\end{array}$ \\
\hline 4 Nina Petrovskaja nähert sich Brjusov. & $\begin{array}{l}4 \text { Renata, von bösen Geistem befallen, triff } \\
\text { Ruprecht und erzahlt ihm die Geschichte } \\
\text { ihres Lebens; Ruprecht verliebt sich in Re- } \\
\text { nata, hilf ihr aber bei der Suche nach Graf } \\
\text { Heinrich }\end{array}$ \\
\hline $\begin{array}{l}\text { 5. Andrej Belyj beendet die Beziehung mit } \\
\text { Nina Petrovskaja und fluchtet aus Moskau. }\end{array}$ & $\begin{array}{l}\text { 5. Renata findet Graf Heinrich, aber ist ei- } \\
\text { frig bemüht, sich vor ihr zu verstecken }\end{array}$ \\
\hline
\end{tabular}

65 Zit. und übersetza nach Grociskin und Lavrov, op.cit. S. 85. 


\begin{tabular}{|c|c|}
\hline $\begin{array}{l}6 \text { Brjusov fordert Belyj nach einem langen } \\
\text { "geistigen Duell" zum "richtigen Duell". }\end{array}$ & $\begin{array}{l}\text { 6. Ruprecht erscheint auf Renatas Forde- } \\
\text { rung bei Graf Heinrich mit der festen Ab- } \\
\text { sicht, ihn zu beleidigen, um ihn damit zum } \\
\text { Duell auffordem m konnen }\end{array}$ \\
\hline $\begin{array}{l}\text { 1. Bruch } \\
\text { 7. Andrej Belyj schickt Brjusov einen erkla- } \\
\text { renden Brief Brjusov akzeptien die Ent- } \\
\text { schuldigung }\end{array}$ & $\begin{array}{l}\text { 7. Graf Heinrich macht einen Versuch aur } \\
\text { Versohnung, den Ruprecht ablehnt }\end{array}$ \\
\hline $\begin{array}{l}8 \text { Brjusov betrachtet Belyjs Widmungs- } \\
\text { gedicht Stannnomu vragu (Finem alten } \\
\text { Feind) als eine Niederlage im "geistigen } \\
\text { Duell", Brjusov hat einen Traum, in dem er } \\
\text { von Belyj im Duell besiegt wird. }\end{array}$ & $\begin{array}{l}8 \text { Im Duell besiegt Graf Heinrich Ruprecht } \\
\text { mit dem Degen }\end{array}$ \\
\hline $\begin{array}{l}9 \text { Brjusov und Nina Petrovskaja führen eine } \\
\text { Licbesbeciehung }\end{array}$ & $\begin{array}{l}9 \text { Renata pflegt Ruprecht nach dem Duell; } \\
\text { sic licben sich. Renata fluchtet vor } \\
\text { Ruprecht, tritt in ein Kloster ein und fallt in } \\
\text { die Hande der Inquisition } \\
\text { II. Bruch } \\
\text { Ruprecht versucht Renata zu retten, aber sie } \\
\text { stirbt }\end{array}$ \\
\hline $\begin{array}{l}\text { 10. Belyj und Brjusovs freundschaftliche } \\
\text { Beziehungen sind ab } 1906 \text { wiederhergesellt }\end{array}$ & $\begin{array}{l}10 \text { Ruprecht trifft nach dem Tod von Rena- } \\
\text { ta Graf Heinrich und versohnt sich mit ihm }\end{array}$ \\
\hline
\end{tabular}

Das Geschehen des Romans spielt in Köln 1534/35 zwischen zwei sich ablösenden Epochen vor dem Hintergrund des mittelalterlichen Aberglaubens, Okkultismus, dem Fanatismus der Inquisition und des Klerus einerseits und dem Humanismus und dem Streben nach exaktem Wissen andererseits. Der histo- 
rische Rahmen, das deutsche Mittelalter in seinem Übergang zur Renaissance, dient Brjusov als ästhetisches Verfahren, im Roman selbst hat er keine weitere Funktion. Nach dem Tod Renatas schreibt der Landjunker Ruprecht seine Erlebnisse auf. Seine Erinnerung ist geprägt von der Distanz zwischen erlebendem und erzählendem Ich und bildet die Nahtstelle zwischen der doppelt fiktiven Welt des Romans. Dem eigentlichen Erzählkem des Romans ist ein Doppelrahmen vorangeschickt, der seinen symmetrischen Aufbau bedingt und dadurch jene Polarisienung von Kunst und Leben erzeugt, die für das symbolistische ziznetvorCestvo charakteristisch ist: Durch die Einführung dieser beiden Rahmen wird die Illusion der Grenze zwischen Kunst und Leben ständig aufgebaut und wieder zerstört. Der äußere Rahmen, der die als Beichte ausgegebene Erzählung Ruprechts umgibt, besteht aus dem Vorwort des fiktiven Herausgebers und seinen kritischen Anmerkungen zur Edition:

Ognennyj Angel ili pravdivaja povest', v kotoroj rasskazyvaetsja o d'javole, ne raz javljavsemsja v obraza svetlogo ducha odnoj devuske i soblaznivšem ee na raznye grechovnye postupki, o bogoprotivnych zanjatijach magiej, astrologiej, goetejej i nekromantiej, o sude nad odnoj devuske pod predsedate'stvom ego prepodobija archiepiskopa Trirskogo, a takž o vstrexach i besedach $s$ rycarem i trizdy doktorom Agrippoju iz Nettesgejma $i$ doktorom Faustom, napisannaja otevidcem (O.A. S. IX) ${ }^{66}$

Der feurige Engel oder eine wahrhaftige Erzahlung, in welcher berichtet wird vom Teufel, der mehr denn einmal einer Jungfrau in Gestalt eines lichten Geistes erschien und sie al mannigfachen sundhaften Handlungen verleitete, von der gottwidrigen Beschäftigung mit der Magie, der Astrologie, der Kabbalistik und Nekromantie, von der Verurteilung jener Jungfrau unter dem Vorsitze seiner Eminenz des Erzbischofs von Trier, gleicherweise von den Begegnungen und Gesprachen mit dem Ritter und dreifachen Doktor Agrippa von Nettesheim und mit dem Doktor Faust, verfaßt von einem Augenzeugen

Dieser Kunstgriff relativiert und verfremdet den zweiten Rahmen, die Vorrede des Erzählers, in welcher er von seinem Leben bis zu seiner Rückkehr in

66 Mit Agnippa von Nettesheim spielt Brjusov auf Vjaceslav Ivanov an. der un Nettesheims Schriften auf dic Prophezeiung gestoßen ist, daß im Jahre 1900 ein großer histonscher Umschwung stattfinden und cine neuxe Epoche beginnen wurde Diese Epoche werde. wie alke vorangegangenen $490 \mathrm{Jahre}$ dauen und eanem der sieben kosmischen Damonen unterstehen $\mathrm{Vgl}$ Vadeslav Ivanov: "Iz oblasti sovremenmych nastroenj" (Aus dem Gebict zeitgenossischer Stummungen). in: Vesy 1905, 6, S 35f. 
deutsche Lande berichtet (Amico lectori. Predislovie avtora, gde rasskazyvaetsja ego ̌̌izn' do vozvrašcenıja v nemeckie zemli):

Menja privlekaet takže vozmoznost' - otkryt', na ètich stranicach, svoe serdce, slovno v nemoj izpovedi, pred nevedomym mne sluchom, tak kak bol'se ne k komu mne obratit' svoi pečal'nye priznanija, i trudno molæat' celoveku, ispytavšemu sliškom mnogo (S. 5)

Mich lockt nicht minder die Moglichkeit, auf diesen Seiten wie in einer stummen Beichte vor mir unbekannten Zuhorem mein Herz zu enthullen, denn ich weiß keinen, an den ich meine traurigen Bekenntnisse berichten konnte, und schwer fallt es jenem zu schweigen, der zuviel erleiden mußte (S 11)

Fanatische Hexenprozesse charakterisieren die Zeit, in der die Geschichte von Renata, Graf Heinrich und Ruprecht spielt. Die Folgen des im Jahre 1486 erschienenen Hexenhammers der Dominikanermönche Jakob Sprenger und Heinrich Institoris stempelten Zauberei als spezifisch weibliche Form der Häresie und machte aus Frauen als "Trägerinnen von Geheimwissen, Agentinnen des Bösen, vom Satan zur Zerstörung der göttlichen Weltordnung gesandt. ${ }^{.67}$ Die hieraus entstandene Dämonenlehre mit ihren Elementen Teufelspakt, Hexensabbat, Geschlechtsverkehr sind spezifische Erfindungen des Mittelalters. Brjusov literarisiert den misogynen Diskurs dieser Epoche, der das wachsende Mißverhältnis zwischen Mensch und Natur widerspiegelt und eine Diffamienung des weiblichen Geschlechts mit sich brachte. Die tief verwurzelte Sexualangst des Klerus und die damit verbundenen Intrigen über sexuelle Ausschweifungen offenbaren ein Ritual, das durch den Frage- und Antwortkatalog des Hexenhammers bestimmt ist und den Prozeß der Inquisition charakterisiert:

67 Heidemanc Bennent Galantene und Verachrung. Frankfurt/Maun 1985, S 34 Bennent wetst daraufhun. daß de Genese des Pnvatbereichs und des dazugchongen Ideals der guten Hausfrau und Mutter an ene der blutrunsugsten Massenvernuchtungskampagnen unerhalb der abendlandischen Geschichte gekoppelt war. Die daraus resultuerenden Hexenprozesse zeigten auch, daß de Durchsetaung dieser neuen Sozalvertaltususse nicht ohne massive Widerstande und Opfer von statten ging. 
Posle étogo brat Foma dostal iz karmana knižxku, v kotoroj, po razlienym priznakam uznal "Malleus Maleficarum in tres partes divisus" Sprengera i Institorisa, i, spravljajas' s etim rukovodstvom, stal zadavat' Renate obstojatel'nye voprosy, kotorye ja, ravno kak i sledovavsie za nimi otvety, dolžen byl zapisyvat', chotja poroju sžimal zuby ot otcejanija (S. 292)

Hierauf holte Bruder Thomas aus seiner Tasche ein Buchlein hervor, das ich als das "Malleus Maleficarum in tres partes divisus" von Sprenger und Institoris erkannte, anhand dieses Werkes stellte er Renata sehr ausfuhrliche Fragen, die ich, gleich wie aufschreiben mußte, obwohl ich von Zeit zu Zeit die Zahne vor Verzweiflung zusammenbiß (S. 357).

In der hier zitierten Anspielung auf das chlystovstvo integriert Brjusov auch die häretische Lebensweise, die das Ziznetvorとestvo prägen. Dies wird deutlich in der Anspielung auf Belyjs Tänze ("Alle Bewegungen Heinrichs schienen nicht im Laufe, sondern zum Fluge zu drängen", O.A., S. 202/203), die ihn genau wie seine äußere Erscheinung ("Er pflegte sich weiß zu kleiden, seine Augen waren blau, seine Haare wie feingesponnene Goldfäden", O.A., S. 194) als chlyst entlarven. Aber auch die Anspielung auf Nina Petrovskajas stilisierte Rolle als "Hohe Priesterin" innerhalb des Argonautenkreises verweist auf das chlystovstvo. Im Roman ist Renata "Auserwählte Gottes", die durch den Engel Madiel die Gottesnachricht, das fleischgewordene Wort Gottes empfängt ${ }^{68}$ :

Bylo Renate let vosem', kogda vpervye javilsja ej v komnate $v$ solnexnom luce, angel, ves' kak by ognennyj, $v$ belosneznoj odezde Lico ego blistalo, glaza byli golubye, kak nebo, a volosy slovno iz tonkich zolotych nitok. Angel nazval sebja - Madiel [...] Kogda Renata neskol'ko podrosla. Madiel vozvestil ej. cto ona budet svjatoj, kak Lotarinskaja Amalija, i to imenno zatem on i poslan $k$ nej On mnogo govoril ej o Zertve lususa Christa, o blažennoj pokomosti Devy Marii, o sokrovennych putjach $k$ zapexatlennym vratam zemnogo raja o svjatoj Agnesse, nerazluenoj s krotkim agncem, svjatoj Veronike, verno predstojastej pred obrazom Spasitelja, i o mnogich dngich licach i vešcach, kotorye mogli navesti tol'ko na blagocestivye razmyšlenija (S 21/22).

Renata muß etwa acht Jahre gewesen sein, als ihr zum ersten Mal in ihrem Zimmer in einem Sonnenstrahl ein Engel erschien Sein Antlitz erstrahlte, seine Augen waren blau wie der Himmel, und seine Locken schienen aus lauter feingesponnenen Goldfaden zu sein Der Engel nannte sich Madiel [. ] Als Renata alter geworden war, verkundete ihr Madiel, sie würde eine Heilige werden, wie Amalie von Lothringen, und deswegen sei er zu ihr entsandt worden Er redete haufig uber den Opfertod Jesu Christi, uber den gebene-

$68 \mathrm{Vgl}$. un diesem Zusammenhang Manfred Schneider Lsebe und Betrug Die Sprachen des Verlangens, Müchen Wien 1992. 
deiten Gehorsam der Jungfrau Maria, uber die vertorgenen Wege zu den versiegelten Toren des irdischen Paradieses, er erzahlte ihr von der heiligen Agnes, die sich von ihrem frommen Lammchen nicht trennt, von der heiligen Veronica, die ewig das Bild des Erlosers vor Augen tragt, und von vielen anderen Personen und Dingen, die nur zu den frommsten Betrachtungen anleiten konnten (S 35).

Brjusov zitiert hier die biblische Verkündigungsszene (Luk.1, 26-38) und das dadurch entstandene Phantasma der Verkündigung, der Szene der Schriftwerdung als Schrifterscheinung der Gottesnachricht am weiblichen Körper. Der Engel Madiel, der Renata das Gottesverlangen überträgt, zwingt sie, mit Gott zu kommunizieren. Sie muß in seiner Sprache sprechen, in der Sprache der Körperwunden:

Ona nacala sobljudat' vse postnye dni, ustanovlennie svjatoj Cerkov'ju, posešcat' každyj den' messu i mnogo molit'sja naedine, v svoej komnate, pered izobražniem Razpjatija Neredko Madiel zastavljal Renatu podvergat' sebja Zestokim ispytanijam vychodit' obnaZennoj na cholode, golodat' i vozderł̌vat'sja ot pit'ja po neskol'ku sutok podrjad, bicevat' sebja uzlovatymi verevkami po bedram ili terzat' sebe grudi ostrijami. Renata provodila po celym nocam na kolenjach, a Madiel, ostavajas' podle, ukrepljal iznemogajušcuju, kak angel Spasitel'ja v sadu Gefsimanskom. Po usilennoj pros'be Renaty kosnulsja Madiel ee ruke, i u nee na ladonjach oznacalis' jazvy, kak by znaki Christovych krestnych muk, no ona eti rany skryvala ot vsech ljudej tšctatel'no (S. 22)

Von nun an hielt sie alle von der heiligen Kirche festgelegten Fastentage ein, ging jeden Tag in die Messe und betete stundenlang in ihrem Zimmer vor dem Bild des Gekreuzigten Haufig drangte Madiel sie, sich schweren Prufungen zu unterziehen Sie mußte nackt in die Kalte hinausgehen. hungern und einige Tage hintereinander sich jeglichen Trankes enthalten, sich mit knotigen Stricken die Oberschenkel peitschen und die Brust mit spitzen Gegenstanden zerfleischen Renata lag nächtelang auf den Knien, und Madiel, der in ihrer Nahe blieb, leistete ihr Beistand. wie der Engel des Heilands im Garten Gethsemane Auf Renatas instandige Bitte beruhrte er ihre Hand, und ihre Handflachen wurden von eiternden Wunden gezeichnet, den Leidensmalen des gekreuzigten Christus gleich (S 36)

Ein weiteres häretisches Merkmal zeigt sich in der Anspielung auf den Transsexualismus. Die Velagerung der Geschlechterzugehörigkeit innerhalb der Sekten wird in der Figur des "Engels" deutlich. Engel sind transsexuelle Wesen, sie stehen zwischen den Geschlechtem. Und auch Belyj stand immer dazwischen. Nicht nur zwischen Brjusov und Petrovskaja, sondern auch zwischen Blok und Ljuobov، Dmitrievna. Aber auch die Bruder-Schwester-Beziehung, die Belyj zu 
Nina Petrovskaja aufbauen wollte, deutet auf ein häretisches Merkmal: die Ablösung des genetischen Blutsprinzip durch das pneumatische Geist-Prinzip. Das

Scheitem einer solchen Beziehung führte zum Bruch, den Brjusov im Roman rückwirkend verfremdet:

Madiel' żvo opecalilsja, kogda Renata vyskazala emu svoi strastnye poželanija ego lico tak ona rasskazyvala - stalo pri ee slovach pepel'no-ognennym, slovno solnce, na kotoroe smotriš skvoz' zakopłennuju sljudu On tverdo vozpretil Renate daže dumat' o plotskom, napominaja ej o bezmernom blaženstve pravednych duš $v$ raju, kuda ne možet' vstupit' nikto, predavivšijsja plotskim soblaznam Renata ne posmev nastaivat' otkryto, poresila dostix' svoej celi chitrost'ju. Kak v dni detstva, uprosila ona Madielja provesti s neju noc' v posteli, i tam, obnjav ego i ne vypuskaja iz ruk, vsemi putjami prinuždala soedinit'sja soboj. No angel, ispolnjas' velikim gnevom, razvilsja ognennyj stolp $i$ iscez, opaliv Renate pleci i volosy (S.23)

Madiel wurde tieftraurig, als Renata von ihren leidenschaftlichen Wünschen sprach Er verbot Renata aufs strengste, an die Lüste des Fleisches auch nur zu denken, er erinnerte sie an die unermeßliche Glückseligkeit der gerechten Seelen im Paradiese, in welches keiner käme, der den Versuchungen nicht widerstanden hätte. Da Renata nicht wagte, offen auf ihren Wünschen zu beharren, beschloß sie, ihr Ziel durch eine List at erreichen. Wie in den Tagen der Kindheit bat sie Madiel, eine Nacht mit ihr im Bett zu verbringen, sie umarmte ihn, ließ ihn nicht los und war mit allen Mitteln bestrebt, eine Vereinigung at erzwingen. Aber der Engel, voller Zorn floh vor Renata, versengte ihr Schultern und Haare (S.37)

Belyj selbst betrachtete die Beziehung mit Nina Petrovskaja und damit sein mystisches Experiment als gescheitert ${ }^{69}$.

[. ] proizošlo to, cto nazrevalo uze $v$ rjade mesjacev - moe padenie $s$ Ninoj Ivanovnoj; vmesto grez o misterii, bratstve i sestrinstve okazalsja prosto roman Ja byl $v$ nedoumenii: bolee togo, ja byl ošelomlen, ne mogu skazat', cto Nina Ivanovna mne ne nravilas', ja ee ljubil bratski, no glubokoj, istinnoj ljubvi $k$ nej ne cuvstvoval, mne bylo jasno, čto vse, proizsed šee mezdu nami, est' s moej storony dan' Cuvstvennosti Vot po¿emu roman s Ninoj Ivanovnoj ja rassmatrivaju, kak padenie, ja videl, cto u nee ko mne - glubokoe Cuvstvo, u menja že - bratskoe otnošenie preobladalo; k nemu primešalas' čuvstvennost'; ne srazu mne stalo jasno, poetomu ne srazu vse eto mog postavit' na vid Nine Ivanovne; Cuvstvovalos' nedoumenie, vopors, i glavnym obrazom - Cuvstvovalsja sryv ja ved' tak staralsja pojasnit' Nine Ivanovne, cto mezdu nami - Christos; ona - soglašalas', i potom, vdrug, - "takoe" Moi poryvanija k misterii, k "teurgii" poterpeli poraženie ${ }^{70}$

69 Siche Kapitcl II dieser Dissertation

70 Zit. nach Groxiskin und Lavrov, 1978, op.crt., S. 85. 
[...] es passierte das, was in einer Reihe von Monaten herangereif war - mein Fall mit Nina Ivanovna, statt Träumereien uber das Mysterium, über Bruderlichkeit und Schwesterlichkeit ereignete sich einfach ein Verhältnis. Ich verstand es nicht noch mehr Ich war betaubt, ich kann nicht sagen, daß mir Nina Ivanovna nicht gefiel; ich liebte sie bruderlich, aber ich empfand keine tiefe, echte Liebe fur sie; mir war klar, daß alles was zwischen uns passient war, meinerseits Zins einer Sinnlichkeit war Deswegen betrachte ich das Verhaltnis mit Nina Ivanovna als Fall, ich sah, saß sie fur mich ein tiefes Gefuhl empfand, bei mir aber die bruderliche Beziehung überragte, daza kam die Sinnlichkeit, mir war das nicht sofort klar, deswegen konnte auch Nina Petrovskaja nicht sofor alles klar sein, man spüre Unverstandnis, Fragen, und in der Hauptsache spurte man einen Bruch. Ich habe mich doch so bemuht, Nina Ivanovna zu erklaren, daß zwischen uns Christus steht; sie willigte ein, und danach plotzlich 'so etwas' Mein Drang zum Mysterium, zur Theurgie waren erschuttert "

Nach diesen Ereignissen zog sich Belyj aufs Land zurück. Hier begann er mit der Niederschrift seines ersten Romans Serebrjanyj golub' Die Silberne Taube), seine Antwort auf Brjusovs verschlüsselten Roman.

Renata und Ruprecht (bzw. Nina Petrovskaja und Valerij Brjusov) verkörpern in der Inszenienung des symbolistischen ziznetvorcestvo das masochistische Paar, das der Ökonomie der höfischen I iebe unterstellt ist. Ruprecht ist das Opfer, das den Launen seiner unumschränkten Herrscherin und ihren Beleidigungen scheinbar hilflos ausgeliefert ist. Gerade das Motiv der Leidenschaftslosigkeit ("besstrastie") symbolisiert die Geliebte als Verkörpenung männlicher Projektionen. In ihrer Gefühlskälte und Erstartheit, die den Mann wiederum zum Warten, zur Reflexion zwingt, konstituiert sich sein theoretisches Ideal, in dem er sich (schriftlich) verewigen kann. ${ }^{71}$ Das Herr-KnechtVerhältnis ist jedoch vorgetäuscht, denn der Diener inszeniert sein eigenes Sklaventum. Er ist der Regisseur, der das Drehbuch schreibt und der Frau ihr Tun diktiert: "Genau diese Logik der Fiktion erlaubt es uns, das fundamentale Paradox in der masochistischen Haltung zu erfassen. Denn wie sieht die typische masochistische Séance aus? Der Mann-Diener bestimmt kühl und business-like die Punkte des Kontrakts mit der Frau-Herrin: was sie mit ihm tun

71 Vgl Hanscen-Love. 1992, op cit., S 267 
soll, welche Kleidung sie tragen soll, wie weit sie in Richtung realer, physischer Tortur gehen soll (wie stark sie ihn peitschen, in welcher Weise genau sie ihn in Ketten legen soll usw.). Wenn sie schließlich zum eigenen masochistischen Spiel übergehen, bewahrt der Masochist die ganze Zeit über eine Art von reflektierter Distanz, er läßt nie seinen Empfindungen wirklich freien Lauf, gibt sich nie dem Spiel vollkommen hin. Mitten im Spiel kann er plötzlich mit dem Ton eines Regisseurs präzise Anweisungen geben. [...] der innerste Kern des Seins des Masochisten tritt in dem inszenierten Spiel, dem gegenüber er die ganze Zeit Distanz wahrt, zutage." ${ }^{72}$ In diesem inszenierten Spiel erhält die frouwe ihre Rolle als Doppelgängerin. Sie ermöglicht dem Mann, seine Beziehung zum Begehren zu strukturieren. In diesem Sinne ex-istiert der Mann nur in der Frau, während die Frau nicht ausschließlich über den Mann ex-istiert, sie in-sistiert und entzieht sich damit der Macht des phallischen Signifikanten. Die Frau für sich genommen verkörpert folglich für den Mann den Todestrieb. Darin erhält sie nach Lacan ihre eigene ethische Position. ${ }^{73}$ Dieses beschriebene Verhältnis von Ruprecht und Renate setzte sich als Lebenstext von Nina Petrovskaja fort. Als Muse des żınetvorcestvo verlor sie schließlich die lebensnotwendige Distanz.

\section{Der Tod der Muse:}

Renatas Ende

Nina Petrovskaja führte in Sankt-Petersburg einen literarischen Salon und nahm selbst regen Anteil am künstlerischen Leben dieser Zeit. Ihre ersten Erzählungen erschienen 1903 im Almanach Grif, ihre Rezensionen, Feuilletons und

72 Vgl. Slavoj Żizck. 1994, op cit., S 77

73 Jacques Lacan The Eshics of Psychoanalysis, London 1992 
Erzăhlungen in verschiedenen Zeitschriften und Zeitungen, u.a. in Vesy Die Waage), Russkaja Mysl' (Der russische (jedanke) und (Ttro Rossij (Der Morgen Rußlands). Brjusov selbst schätzte Petrovskajas literarisches Talent in einem Brief vom 11. (24.) Dezember 1908 folgendermaßen ein:

So vsej otkrovennost'ju i so vsem bespristrastiem mogu skazat' tebe, čto zdes' v literature, est' dlja tebja budustee i zizn'. Ty znaes, cto ja ne ocen' vysoko cenju vse, cto ty sdelala do sich por Troju knigu, po-gimnaziteski, ja ocenivaju "tri s pljusom", tvoi recenzii - "tri $s$ minusom" No ja bol'še drugich znaju vse susčestvujušctie dlja tebja vozmožnosti $U$ tebja duša samobytnaja, u tebja original'nyj. svoj vzgljad na vse, u tebja ostraja metkaja. tonkaja nabljudatel'nost', u tebja ponimanie stija Tvoj razgovor vsegda interesen, tvoi sużdenija samostojatel'ny i gluboki, tvoj slog prinadleżt tebe [. .] Nado rabotat', i mnogo i oten' mnogo eto ja utverzdaju bezpovorotno."

Mit aller Offenheit und Objektivitat kann ich Dir sagen, daß es hier in der Literatur tatsachlich eine Zukunft und ein Leben fur dich gibt. Du weißt, daß ich nicht alles hoch schatze, was du bisher gemacht hast Dein Buch bewerte ich mit einer gymnasialen "drei plus", deine Rezensionen mit "drei minus" Aber ich kenne am besten alle deine dir offenstehenden Moglichkeiten Du hast eine originelle Seele, deine eigene, originelle Perspektive auf alles, eine scharfe, treffende, feine Beobachtungsgabe, du hast Verstandnis fur Stil Deine Unterhaltung ist immer interessant; deine Itrteile sind eigenstandig und tief: du hast einen eigenen Stil [ ] Du mußt arbeiten, viel, sehr viel arbeiten das betone ich unwiderruflich

In den folgenden Ausführungen stütze ich mich auf die Errmnerungen von Petrovskaja, um aus weiblicher Perspektive die Ästhetisienung und Theatralisierung des Lebens innerhalb des symbolistischen ziznetvorcestvo und seine spiegelbildliche Fortsetzung im Text darzustellen. "In mir fand er (gemeint ist Brjusov, D.R.) vieles, was er für das romantische Bild von Renata brauchte", schreibt die Autorin, "Verzweiflung, eine tote Sehnsucht nach einer phantastisch-wunderschönen Vergangenheit, die Bereitschaft, meine eigene wertlose Existenz in jedes beliebige Feuer zu werfen, vernückte, religiöse Ideen (die

74 Valenj Brpusov Literatumoe nasledsno (Das literansche Eirbe), Band 85, Moskau 1976, S 773

75 Nina Petrowskaja konnte thre Begabung rucht wirklich realisieren Ihre Texte - der Erzahlband Sancrus Amor und de Finnnerungen - geraten in Vergessenheat Erst in der Gorbacev-Ara uund de Erzahlung Brodjaga (IDer Vagabund) aus og. Band veroffentlicht. Vgl Russkaja Novella XX veka (Dre nussische Novelle des 20 Jahrhunderts), Moskva 1990 
Elysischen Mysterien!...), vergiftet von dămonischen Verimungen, die Entfremdung vom Leben und von den Menschen, $\mathrm{Haß}$ gegen alles, eine organische, seelische Heimatlosigkeit, das Verlangen nach Untergang und Tod - mit einem Wort, alle seine geliebten poetischen Hyperbole und Gefuhle waren in einem Wesen konzentriert, einer kleinen debütierenden Journalistin und entgegen dem gesunden Menschenverstand die Frau des erfolgreichen Verlegers S. Krecetov. Aber auf alle diese Eigenschaften bin ich nicht stolz, viele sind in den Jahren abgestorben, einige gingen vorüber, wie Kinderkrankheiten. Einige haben sich nicht nur verstärkt, sondem sind für immer organische Grundlage meiner Seele geworden. Damals aber blühten sie in mir alle als reicher BlumenstrauB in einem wunderschönen Rahmen des müBigen Lebens, wo sogar Einzelheiten des Kummers ästhetisch umrahmt wurden (Hervorhebung von mir, D.R.). ${ }^{76}$ Diese Polarisierung von Kunst und Leben - ein Gesellschaftsspiel das den Regeln des "Als ob" folgte - , hatte für Petrovskaja reale Konsequenzen. Nach der Publikation des Feurigen Engels im Jahre 1908 kultivierte sie ihr Leben nach dem literarischen Vorbild und machte daraus ein künstlerisches Ritual. Sie durchlebte „,buchstäblich“ den Prozeß der Verwandlung der ,realen“ Frau in das literarische Frauenbild. In einem Brief an Brjusov schreibt sie: "Ich möchte sterben, damit du Renatas Tod von mir übernommen hast und damit ich Modell dieses letzten schönen Kapitels sein kann." ("Ja choču umeret' [...] ctoby

76 [ . I vo mne on vošel mnogoc iz togo. tho trebovalos' dlja romantikeskogo oblika Renaty ottajanie, mertvuju tosku po fantastuceski prekrasnomu prošlomu. gotovnost' svymut' svoe obestencnnoe sušcestvovanue $v$ kakoj ugodno koster. wyernutoe naiznanku. otravlennye demoniteskimi soblaznami religiozmye ide i Cajanuja (Elevzinske misteni!..). otonannost' $\alpha$ byta i ljudej, poctu cto nenavist' $k$ predmetnomu muru, organiceskuju dušcennuju bezdomnost', zaztu gibel I smerti. slovom. vse svoi ljubimye

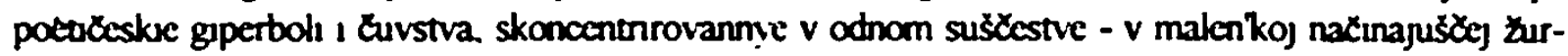
nalıstke I naperekor zdravomu smyslu, zenc S Krocetova, blagopoluǩnogo redaktora knigoizdatel'stva "Grif" Ni odnim iz etach morch katestv ja ne gorzus' Mnogie iz nuch oumerlis godam. nekotone

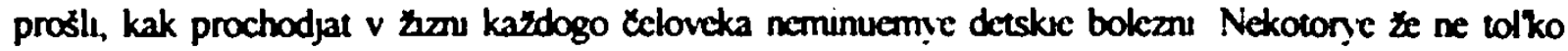
ukrepilus', no ošutulis' kak onganiceskaja osnova dušı navsegda Togda te use oni cvelı vo mne pysinum buketom i k tormu ze v prekrasnoj rame barstvennoj zumu. gde date detal gorja obstavljalis' esteticeski. in Literatumoe nasledsno (Das literansche Erhe) 1976, op.cit . S 782 
smert' Renaty ty s menja, ctoby byt' model'ju dlja poslednej glavy.") ${ }^{7}$ Im Jahre 1908 fährt sie von Paris aus nach Köln, um sich vollständiger als "Heldin" des

Romans zu fühlen. Sie schreibt an Brjusov:

Cuvstvovala sebja odnoj vo vsem mire - zabytoj pokinutoj Renatoj Ja lezala na polu sobora, kak ta Renata kotoruju ty sozdal, a potom zabyl i razljubil [.] Na plitach Kel'nskogo sobora ja perežila vsju našu żzn' minut za minutoj [...] A v temnych svodach drožali volny organa, kak nastojašzaja pochoronnaja pesn' nad Renatoj

Ich fuhlte mich so einsam in der Welt, genauso wie die vergessene und verlassene Renata Ich legte mich auf den Boden des Doms, genau wie es Renata getan hat, die du geschaffen hast, dann aber vergessen hast und nicht mehr liebtest [...] Auf den Steinplatten des Kölner Doms erlebte ich noch einmal unser Leben, Minute fur Minute [...] Und in den dunklen Gewolben erzitterten die Wellen der Orgelmusik wie das authentische Todeslied auf Renata.

Auch die Rolle der Renata als Mystikerin und Empfängerin der Gottesnachricht verinnerlichte Nina Petrovskaja auf derart perfekte Weise, daß sie die Romanfigur als Vorlage für das eigene Verhalten einsetzte: "[...] ona načala igrat' svoju Hizn' kak akter pered zerkalom" ("sie fing an, ihr I eben wie ein Schauspieler vor dem Spiegel zu spielen"). ${ }^{79}$ Das Sujet des Feurigen Engels realisierte sich in dem Moment, als sie 1910 zum Katholizismus übertrat, den Namen Renata annahm und 1927 in Paris mit ihrem Freitod den Roman buchstäblich zu Ende schreibt:

Żizn' ee byla liriðeskoj improvizaciej, v kotoroj, liš primenjajas' $k$ takim Ze improvizacijam drugich personažej. Nina staralas' sozdat' nexto celostnoe - "poemu iz svoej liłnosti" Konec ližnosti, kak i konec poemi o nej, - smert'. V suščnosti, poema byla zakonとena v 1906 godu, v tom samom, na kotorom sjužetno obryvaetsja "Ognennyj Angel". S tech por v Moskve, i v zagranižnych stranstvijach Niny dlilsja muŽtel'nyj, strašnyj, no lišennyj dvižnija epilog Dopisat' poslednuju frazu i postavit' tocku Nina ne bojalas', no ne mogla

Ihr Leben war eine lyrische Improvisation. Indem sie sich nach den Improvisationen anderer Personen richtete, bemuhte sich Nina Petrovskaja etwas Ganzes zu schaffen, ein "Poem aus ihrer Person". Das Ende der Person war wie das Poem über sie der Tod. Im Grunde war das Poem 1906 abgeschlossen, im gleichen Jahr, in dem die Sujetlinie des

77 Zit. nach Groxiskin und Lavrov, 1978, S. 79

78 Ebd

79 Chodasene [1927) 1991, op.ctt. S 343 
Feurigen Engels abbricht. Seit dieser Zeit zog sich in Moskau und in Ninas Wanderchaften im Ausland ein qualender, schrecklicher und bewegungsloser Epilog hin. Den letzen Satz zu schreiben und einen Punkt zu setzen, davor hatte Nina keine Angst, aber sie konnte es nicht tun ${ }^{80}$

Aus diesem Zitat geht hervor, daß Nina Petrovskaja die Distanz zum symbolistischen Gesellschaftspiel final und unwidemuflich aufgehoben hatte. Indem sie das Frauenbild, das eigentlich keine reale Substanz hatte, zu ihrem eigenen machte, erfülte sie die Musenfunktion absolut und realisierte damit die symbolistische Lebensschöpfung auf perfekte Weise: sie setzte Brjusovs Aufforderung "Berem my migi ich gub'ja" ("Nehmen wir die Augenblicke und richten sie zugrunde") vollständig in die Tat um. Gemäß dem "Dogma" an etwas leiden zu müssen, jagte Nina Petrovskaja Diskursemotionen nach und verkehrte ihr Leben dadurch in eine endlose Psychographie. Ihre Hysterie ist als Resultat dieser Psychographie zu sehen, denn die höfische Liebe, die die Symbolisten sozusagen als Pfand einsetzten, basierte, wie oben gezeigt wurde, auf einer unmöglichen Liebe, einer Liebe, die niemals vollzogen, eben nur als fingiertes Schauspiel realisiert werden konnte. Auf diese Weise machte sich Nina Petrovskaja zum Medium des symbolistischen Experiments schlechthin. Der damit offensichtlich einhergehende Realitätsverlust erscheint in dieser Konstellation als Lustgewinn an einem Ort, "wo die Arbeit mit und über ein erhaltenes Objekt es erlaubt, dessen Aufdruck und Spur selbst zu inszenieren"81. Nina Petrovskajas Selbstinszenierung als "Hohe Priesterin" im Kreise der Argonauten und danach als "Renata" markiert "einen Zwischenraum zwischen Körper und Sprache, wie vom Begehren gemacht"82. In diesen Zwischenraum gelangte durch das auferlegte Gottesverlangen das Geschriebene und schreibt sich als enteignetes $\mathrm{Be}-$

\section{Ebd S 348}

81 Vgl in dresem Zusammenhang Eva Meyer "Schreben aus Licbeswut. Mystak und Hysterie", in Frauensprache und Frauenliteratur? Für und Wider einer Psychoanalyse literanscher Werke. Tubungen 1986, S. 1-17, S. 13

82 Ebd S. 15 
gehren in den mystifizierten Körper ein. Mit ihm ließ sich Nina Petrovskaja schreiben, indem sie selbst verstummte und sich damit dem Verschwinden entzog. Wenn die Hysterie des Mannes im Silbermen Zeitalter in der Selbstzensur des Begehrens zu beschreiben ist, so kann man die Hysterie der Frau, in diesem Falle der Nina Petrovskaja in der Enteignung ihres Begehrens sehen. In diesem Sinne äußert sich die symbolistische Ästhetik als eine Ästhetik der Gewalt, die sich am weiblichen Körper manifestiert und auf das Schreibens des Mannes verweist: Er wird zum Grab des männlichen Zeichens. ${ }^{83}$

$83 \mathrm{Vgl}$ in diescm Zusammenhang Jaan Baudnllards Konzepuon des "Gezeichneten Körpers", der das Grab der Zeichen und das Zeichen als das Genppe des Sexus darstelle. in. Der symbolische Tousch und der Tod, Munchen 1991, S. 155ff 


\section{Kapitel IV:}

\section{Liebesverluste. \\ Sankt-Peterburg - Petrograd - Leningrad}

Once upon a time there was a little boy. He lived in the most unjust country in the world. Which was ruled by creatures who by all means should be considered degenerates. Which never happened. And there was a city.

The most beautiful city on the face of the earth [...] which ceased to exist. Joseph Brodsky' 


\section{Der Petersburger Text:}

\section{Ein männlicher Stadttext}

Im Jahre 1703 gründet Peter der Große die Stadt Sankt-Petersburg. Sie wird aus dem Nichts geschaffen, mit der Intention des Zaren, von allen europäischen Hauptstädten das Wesentliche zu kopieren, um gewissermaßen das Substrat der westeuropäischen Kultur nach Rußland zu transplantieren. Damit sollte ein Signal gesetzt werden, der fundamentalen Rückständigkeit des Landes ein Ende zu bereiten. Vladimir Solov'ev sieht in Peter dem Großen eine der großen Gestalten der russischen Geschichte, die als Wegbereiter der russischen Idee zur kollektiven religiösen und historischen Rettung Rußlands beigetragen und damit auf entscheidende Weise das nationale Bewußtsein geprägt zu haben: "Da tauchte plötzlich aus diesem Chaos der Barbarei und des Elends die kolossale und einzige Gestalt Peters des (iroßen auf. Den blinden Nationalismus von Moskau verwerfend, von einem aufgeklärten Patriotismus durchdrungen, der die wahren Bedürfnisse des Landes sieht, läßt er sich durch nichts abhalten, Rußland die Zivilisation aufzudrängen, die es verachtete, die ihm jedoch notwendig war; er ruft nicht allein die fremde Zivilisation als ein mächtiger Protektor herbei, sondem sucht sie selbst bei ihr daheim auf als ein demütiger Diener und fleißiger Lehrling; und trotz der großen Mängel seines persönlichen Charakters bietet er bis zum Schluß ein bewunderungswürdiges Beispiel der Hingebung an seine Pflichten und der bürgerlichen Tugend. Wohlan! Wenn man sich an dies alles erinnert, sagt man sich: Es muß doch sehr groß und sehr schön sein in seiner endgültigen Verwirklichung, dies nationale Werk, das solche Vorläufer gehabt hat."

2 Vladimur Solov'cv "Dic russische Idoc" [1889], in Sobranie Sixınenı Vladımira Sergeeviča Solov'eva (Gesamtansgabe der Werke' un Wladimir Solowjew), [crstmalig Sankt-Pcterburg 1873-1900]. 
Das Werk Peters des Großen gelingt. Mit der Gründung von St. Petersburg schafft er eine vollkommene Kulisse westeuropäischer Kultur, die Rußlands prinzipielle Mangelposition verdeckt und auf diese Weise auch seine kulturellen Leerstellen kaschiert. Als ein solches transplantiertes Kultur-Über-Ich hält Petersburg das russische Denken in seinem Bann, "im Bann des unendlichen Zitierens einer fremden Kultur" ${ }^{3}$. Von Puškin bis Dostoevskij erscheint diese fremde Kultur als Phantom, als Ungeheuer, als Dekoration der Leiden oder in den Gedichten von Aleksandr Blok als Schauplatz für die Erscheinung der Ewlgen Weiblıchkeit, der Schönen Dame bzw. der Unbekannten. ${ }^{4}$ Auf diese Weise entsteht ein für die russische Kultur spezifischer Text: "Der Petersburger Text der russischen Literatur spiegelt die Quintessenz des Lebens an der Peripherie, am Abgrund, am Rande des Todes und es werden Wege der Rettung aufgezeigt. Gleichzeitig darf man die prophezeiende und prognostizierende Rolle dieses Textes nicht vergessen, der als Vergöttlichung und Prophezeiung der russischen Geschichte auftritt, betrachtet sub specie von Petersburg. Gerade in dieser Stadt hat die Schwierigkeit und Tiefe des politischen, ökonomischen, alltäglichen Lebens, die zur Entwicklung der Gefuihle, der intellektuellen Möglichkeiten und Ideen im Bereich des Symbolischen gehört, jenes hohe Niveau

Nachdruck Brissel 1966, Band XI, S 89-118, S 97/98: "[... mezapno v etom chaose varvarstva i bestvi podymautsja kolossal'my] I odinstvenny] v svoem rode obraz Petra Velikogo: otbrosiv slepoj nacionalizm Moskvy, proniknutyj prosveštennım patriouzm, vidjašxim istunnye potrebnosti svoego naroda, on ne ostanavlivaetsja ni pered $\mathrm{ccm}$, ctoby unest, chotja by nasil'stvenno, $v$ Rossiju tu civilizaciju, kotonuju ona prezarala, no kotoraja byla ej noobchodimo; on ne tolko prizavaet ctu cužtuju civilizaciju. kak mogucij pokrovitel', no sam idet $k$ nej. kak smirennyj služtel' i prilezmyj utenik; i nesmotrja na knupnye nodoxety $v$ ego charaktere, kak tastnogo lica, on do konca javlajet dostojnyj udivlenija pnmer prodannost dolgu i grazdanskoj doblest. - i vot, vspominaja vse eto, govons' sebe skol' veliko i prekrasno dolžno byt' v svoem konớnom osuš̌estvlenuja nacional'noe delo [. .] " Die deutsche Übersctzung entstammt der Gesamtausgabe, Hg. Wladimur Szylkarski, Freiburg/Brg. 1953, Band III, S 30-91, S. 45

3 Boris Groys: "Petersburg/Petrograd/Leningrad Eune Stadt und ihre Namen", aus: Petersburger Trciume. Ein literansches lesebuch, Hg. von Peter Lange. Munchen 1992, S. 291-302, S. 294.

$4 \mathrm{Vgl}$. in diesem Zusammenhang das Kapitel "Poet I gorod" (Der Dichter und die Stadt) in Vladimir Orlov Zdrowsinujte, Aleksandr Blok. Leningrad 1984 
erreicht, wo man nur noch auf authentische Antworten auf die wichtigsten Fraugen hoffen darf. $\mathrm{Zu}$ der Zeit, als der Petersburger Text entstand, gab es in Rußland keine zweite Stadt dieser Art."

Im Petershurger Text als spezifischem Phänomen der russischen Literatur ist die Frage nach der Geschlechter-Differenz prinzipiell eine Frage, die der Topologie des Ortes unterliegt: "[...] geschaffen von der männlichen Hand Peters des Großen, der in einem gewaltsamen Akt der Selbstkolonialisienung die weibliche Seele Rußlands versklavte und sie der Geometrie des westlichen Denkens unterwarf", spiegelt sich "Männliches" und "Weibliches" in erster Linie in der geographischen Lage der Stadt und ihrer Architektur. ${ }^{7}$ Die geraden Formen dieser Architektur, im Gegensatz zu den nunden Moskaus charakterisieren diesen Stadttext als männlich, der auf die weiblichen Züge seines russischen Ursprungs verweist. Auch die besonderen klimatischen Verhältnisse, die sich vor allem im Nebel, in Schnee und Eis artikulieren, fließen in die Poetik des Petershurger Textes und bewirken seine transparente, schleierhafte Struktur. Unter diesen Bedingungen wird das Motiv des Doppelgängers, des Phantoms, des Ungeheuren zum Leitmotiv der Schriftsteller des Petershurger Textes. Angefangen mit Puškin, Gogol' und Dostoevskij bis hin zu den Autoren, deren

5 V.I. Toporov. "Peterburg a Peterburgskj Tckst Russkoj Literatury" ("Petersburg und der Petersburger Text in der nussischen Literatur", in Trudy po znakovym sistemam (Arbetten zu Zeichensystemen), Nr 18, 1984, S. 4-30, S 30: "V P tekste russkoj literatury otrazena kvuntesscencija zuzn na kraju, nad bezdnoj. na grani smert i namocajutsja put k spaseniu Vmeste s tem nel'zja zabyvat' o prognozanujušcej I prodskazujuščcj rolı ctogo tcksta. vystupajuščcgo kak dinnacija i prorotestio na temu russkoj istoni. rassmatnvacmoj sub spocic P Imenno v ctom gorode sloznost' 1 glubina zizn gosudarstverno-politubeskoj. chozjajstvenno-skonomileskoj. bytovoj. omosjašcejsja k razviuju Cuvstv, intellektual'nych sposobnostej, idcj, $k$ sfere simvoliceskogo i bytujstvennogo. - dostugla togo vyssego urovnja, kogda tol'ko i možno nadejat'sja na polucenie podlunnych otvetov na samye važnye voprosy $V$ to stolete, kogda skladyvalsja P. tckst. drugogo takogo goroda v Rossii ne bỵlo"

6 Bons Groys, 1992, op.cit., S. 294

$7 \mathrm{Vgl}$. Signd Weigel Topographien der (jeschlechter Kulturgeschichiliche Siuctien zur Literatur, Hamburg 1990 Weigel untersucht den Zusammenhang von Schnft und Korper, Wildns und Stadt in Bezug auf das Verhaltinis von Geschlocht und Sprache. den On von Frauen Rolle des Weiblichen in den traditionellen Praktiken der Bodeutungskonstitution 
Texte Analysegrundlage dieser Dissertation bilden, spiegelt diese Poetik den besonderen Umgang mit der eigenen (Geschlechts)-Identität. Sie wird immer in Bezug auf die Stadt und in Bezug auf Rußland problematisiert. Auf diese Weise unterliegt sie der prinzipiellen Gespaltenheit bzw. Doppelung der russischen Kultur. Gerade der Traum vom Dritten Geschlecht in der russischen Moderne, der im Bild des Gottmenschen Solov'evs bzw. des androgynen Künstlermenschen kulminierte, macht deutlich, auf welche Weise diese Autoren im Text versuchten, Rußland wieder als Ganzheit und damit sich selbst als Ganzes zu erfahren. Der Versuch, zum ursprünglichen Rußand zurückzukehren, es im Text neu zu erschaffen und damit die Gespaltenheit der eigenen Kultur und des eigenen Selbst zu überwinden, wird mit Beginn des 20. Jahrhunderts zum zentralen Stimulus der Petersburger Intelligencija. ${ }^{8}$ Sie identifizieren die russische Literatur und damit ihre eigene Identität als Zitate der westlichen Kultur, denn "Sankt-Petersburg, als außer- und posthistorisches Zitat, hatte von Anfang an gewissermaßen keine Geburt und war folglich venurteilt zu einer geisterhaften Unsterblichkeit jenseits von Leben und Tod - wie die zeitgenössische Kunst, die gleich fürs Museum gemacht wird und sich die permanente Bewahrung eben durch ihre Totgeborenheit sichert"".

Im Petershurger Text taucht die verdrängte und "versklavte weibliche Seele Rußlands" als symbolisierter Sprachkörper wieder auf. Der Text reinszeniert Peters initiierte Zivilisationsarbeit und verweist damit auf jene Schnittstelle innerhalb der nussischen Kultur, die sich in der Gegenüberstellung von slav-

\footnotetext{
8 Paradigmatisch fur die Suche nach der eigenen Kultur und der damut einhergehenden Bewußtsennsveranderung ist der Roman Peterburg (Erstausgabe 1913-1914) von Andrej Belyj. in dem der Autor noch vor Joyce und Döblin den stream of consciousness in die Literatur einfuhrt, sowie das lyrische Poem Snežnaja maska (1907) von Aleksandr Blok. dessen Sujet als Folge des sich uandelnden Bcuußtseinszustandes zu verstehen ist. In beiden Werken entsprechen sich Wirklichkeit und Maskerade. hinter der sich die andere Welt als leere Transzendenz verbirgt. Dementsprechend loer und leblos sind auch die Figuren. Sic agieren als Manonetten bzw. leblose Puppen
}

9 Bons Grows: "Petersburg/Petrograd/Leningrad", op ctt, S. 293 
janofilstvo und zapadnicestvo außert. Betrachtet man das slavjanofilstvo als Artikulation des Semiotischen und das zapadnicestvo als Artikulation des Symbolischen, so wiederholt der Text jenen Moment des Übergangs von Natur und Kultur, der die Überblendung zwischen Gewesenem und Heutigem aufzeigt und psychoanalytisch gesprochen den Eintritt in die symbolische Ordnung bedeutet. Das heißt der Petersburger Text thematisiert die Frage nach der russischen Identität, die an die Frage der Geschlechter-Differenz gekoppelt ist und damit einerseits die Sehnsucht nach der Konservienung des ursprünglichen, heiligen Rußland (also des pränatalen bzw. postnatalen Rußlands) offenbart, andererseits die in der fortschrittlichen westeuropäischen Entwicklung liegenden "Wiedergeburt" Rußlands, die mit einer eindeutigen Geschlechts(-Identität) verknüpft ist, problematisiert. Auf diese Weise verkörpert der Petershurger Text die Verdoppelung der Geschlechter-Differenz: Er ist männlich und spiegelt weibliche Züge wider, denn die Kulisse der Stadt verweist auf einen leeren Ort, das Nichts, das als weiblich assoziert wird. Diese Erkenntnis prägt das Psycho(patho)gramm der Petersburger Autoren, deren künstlerischer Projektionsakt jene Metapoetik der Verschleierung bzw. Maskierung erzeugt, jenen Diskurs des Mangels, der den Verlust des Ursprünglichen beklagt und es durch die Textproduktion substituieren möchte 


\title{
5. Die Erotik der Autor-Stadt:
}

\author{
Konstantin Vaginovs Kozlinaja pesn ${ }^{\prime 0}$
}

Konstantin Vaginov als Petersburger Autor und Angehöriger der alten Petersburger Intelligencia steht am Ende dieser langen Tradition innerhalb der russischen Literatur. Als letzte Petersburger Märchen konzipiert, schreibt Vaginov mit seinen Texten den Petershurger Text zu Ende und schreibt ihn gleichzeitig von seinem Ende her. Sein Schaffen beschließt das Petersburger Thema in der russischen Literatur: Petersburg existiert nicht mehr. Es existiert Petrograd und danach Leningrad." Damit handeln Vaginovs Texte von ihrer eigenen Entstehung, deren Verfahren zum eigentlichen Thema werden und den Autor in Bezug zu seiner Autorschaft problematisieren. Der (quasi)-erotische Diskurs, wie er seit Petr Caadaev über Rußland gefuihrt wurde, wird zum auto(r)erotischen Diskurs als Teil von Petersburg und vice versa.

10 Alle Textztate von Kozlinaja Pesn' (Ziegenlied. Bocksgesang) wurden von mir ubersetzt. Sie entstammen der Ausgabe Zabyraja Kniga (Das vergessene Buch), (Nachdruck der Ausgabe Leningrad 1928], Moskva 1989. Vaginov ließ man seit seinem Tod 1934 in 'Vergessenheit' geraten Seine Texte wurden erst in der Gorbatev-Ara weder publizaert Einge von ihnen sind bereits ins Deutsche ubersetzs:

- Trudy i dni Sinstonova, [Leningrad 1929], Moskva 1989, Werke und Tage des Sivistonov, übersetzt von Gerhard Hacker, Munster 1992.

- Der Stern won Bethlehem. Zwet Erzahlungen, übersetat von Peter Urban, Berin 1992.

- Garpagoniana |Lcningrad 1933], Moskva 1991, Auf der Suche nach dem Gesang der Nachrigall, übersetz von Ulrike Zernme, Frankfurt/Main 1993

- Bambocciada, [Lenungrad 1931], Moskva 1989, Bambocciade, übersetzt von Andreas Le1tnet, Lempag 1993

11 Vaginov gilt generell als zakrywatel'(Beschließer) des Petersburger Textes, während Andrej Belyj und Alcksandr Blok als zowersiteli Vollender) gelten Vgl. in diesem Zusammenhang V.I. Toporov, 1984, op.cit, S. 15. Erst in den siebager Jahren wird das Petersburger Thema von dem Schnftsteller Andrej Bitov in seinem Roman Puskinskaj dom (Das Puskanhous) emeut aufgegriffen In jüngster Vergangenhest uurde von der Schriftstellenn Manna Palej diese Tradituon fortgefuhrt Auch hier steht der Text als gersuges Ideal, das Wege der Retuing aufzeigt 
Für Vaginov, der 1919 von der Sibirischen Front zurückkehrte, wurde das durch den Kriegskommunismus in Trümmer liegende, heilige, antike Petersburg zum Schlüsselerlebnis seiner Textproduktion. Vaginovs erster Gedichtband von 1921 trägt den bezeichnenden Titel Reise ins ('haos (Putesestvie v chaos). Als Identifikationsfigur seines lyrischen und epischen Ichs wählte Vaginov den griechischen Sophisten und Redner Philostrat aus, der auch in den ersten beiden Erzählungen von 1922 Der Stern von Bethlehem (Zvezda hetlegema) und Das Kloster unseres Herm Apoll (Monastyr' našego gospodına Apolla) diese Rolle beibehält und später in Kozlınaja pesn' intratextuell verarbeitet wird. Im Rückgriff auf die Antike verfolgt Vaginov den Weg seiner eigenen Kultur bis zu ihrem Untergang. In dem er im Text das alte Petersburg und die Petersburger Intelligencija wiederauferstehen läßt, wirkt Vaginov dem Verlust kultureller Identität und der Herausbildung des geschlechtslosen homo sovietıcus entgegen, der sich als Resultante der gerade in den zwanziger Jahren forciert betriebenen Angleichung der Geschlechter zum Aufbau der sozialistischen Gesellschaft formierte. Der Versuch, Rußland im Text wiederzugewinnen, zu seinem Ursprung zurückzukehren, vollzieht sich in seinen Texten mittels eines Projektionsaktes, der über die Eninnerung getragen wird, während er in symbolistischen Texten auf die Zukunft gerichtet war. Die Selbsterlösung des Religionskünstlers, der sich seiner eigenen selbsterschaffenen Sophia-Anima gegenübersieht, die ihn zur Selbsterlösung erlöst, wird transformiert und mutiert zur grotesken Auto(r)soteriologie des sich durch den Text selbst gebärenden Autors, dessen 'Wiedergeburt' sich in der 'Todgeborenheit' seiner Kultur und Identität vollzieht. Beiden künstlerischen Systemen ist der auto(r)erotische Diskurs gemeinsam, der in den vorliegenden Fällen das Psycho(patho)-gramm der abstrakten Autoren bestimmt, deren Projektionsakt das verlorene (Liebes-)-Objekt - die tote bzw. wiederzugebärende nussische Kultur - auto(r)-soteriologisch bzw. auto(r)erotisch substituiert. Rußland bzw. Petersburg wird zum introjizierten Objekt, 
mithilfe dessen sich die abstrakten Autoren erst im zweigeschlechtlichen Wort konstituieren. $^{12}$

Kozlınaja pesn' von Konstantin Vaginov (1899-1934) gehört der späten russischen Avantgarde an (der Text wurde erstmalig in dem Leningrader Joumal Zvezda (Der Stem/ im Jahre 1927 gedruckt). ${ }^{13}$ Er ist damit Teil jenes Werkkorpus der russischen Modeme, der vor dem Hintergrund eines doppelten Paradigmenwechsels - als Ergebnis der sogenannten Kunstrevolution von 1910/1913 und der Oktoberrevolution von 1917 - entsteht. Der vollkommene Traditionsbruch und ganzheitliche kulturelle Systemwandel wird zum Ausgangspunkt für jene narrative Verfahren, die in der Textproduktion dieser Zeit eine Konfrontation von Symbolismus und Avantgardismus bedingte. ${ }^{14}$ Entsprechend lassen sich in KP sowohl narrative Verfahren aus dem künstlerischen System des Symbolismus finden als auch avantgardistische Verfahren, die in den Manifesten der verschiedenen Gruppierungen propagiert wurden. ${ }^{15}$ Folgt man der Einteilung von Certkov, so entstand Kozlinaja pesn' in Vaginovs "dritter" Schaffensperiode, der sogenannten oberiutisch-formalistischen Periode, die die

12 Vgl in diesern Zusammenhang Doring-Smmov, 1994, S 79

13 Tat'jana Nikol'skaja "Konstantin Vagunov, ego vremja i kngi" ("Konstantun Vaginov, seine Zcit und seune Bucher"). un Vaginov, K. K.: Kozlinaja Pesn' Romany, Moskva 1989, S. 5-18, S 10 Kozlinaja Pesn' wird um folgenden KP abgekura Die Anfangsbuchstaben KP spielen auf KP $=$ Kommunustikeskaja Partua an. Vaginovs Text ist als Parodic auf diese au lesen

$14 \mathrm{Vgl}$ Ingold. 1981, S 26

15 Vaginov nahm an velen Gruppierungen und Zirkeln der zwanziger Jahre teil - er arbeitete mit den Obenuten (Oberiuty) Charms und Vvedenskuj zusammen, gehörte der Gruppe Die Insulaner (Ostrovifane) und Der Klingenden Muschel (Zvitascaja rakovna) an, stand mit den Lenungrader Imaginisten (Imazinisty) und Vertretern der Formalen Schule wie Junj Tynjanov und Bons Ejchenbaum in Verbindung Trotz allem Enthusiasmus. mit dem er am literarischen Leten dieser Jahre teilnahm, bleibt er, wic sein Werk, ein Außenseiter 
Jahre 1926-1930 umfassen. ${ }^{16}$ Bestimmend fur die formale Struktur des Textes ist die satira menippea: Die gleichzeitige Verwendung von wort- und erzählkünstlerischen Verfahren, die beliebige Verknüpfung heterogener Stilschichten und Genres bis hin zur Textcollage. KP besteht aus einer Montage von Zitaten, die die Verfahren literarischer Schulen der zehner und zwanziger Jahre zitiert und sie auf diese Weise "entblößt". Sie dienen als Masken, um die Diskursmoden dieser Schulen zu inszenieren. Die von den russischen Formalisten entwickelte Theorie der Entblößung des Verfahrens (obnazente priema) wird in zahlreiche Handlungen gekleidet zum eigentlichen 'Helden' des Romans. Michail Bachtin und seine Arbeiten werden in KP als metaliterarischer Diskurs zu textintemen Verfahren integriert: "Neben Michail Bulgakov war Waginow einer der ersten russischen Autoren die "bachtinisch" schrieben, das heißt, im Roman nicht mehr mit "Vorrang auf die Kohärenz einer erzählten Geschichte und auf die lineare Logik von Handlung, Raum und Zeit abstellte [...]." ${ }^{17}$ Unter diesen Bedingungen der Konfrontation von Symbolismus und Avantgardismus ist im künstlerischen System Vaginovs ein Eklektizismus an narrativen Verfahren und ihrer Selbstthematisienung zu konstatieren, die durch folgende Faktoren geprägt sind: 1. Der 'tabula-rasa conditio' einer postrevolutionären Apokalypse: die ehemals florierende Stadt St. Peterburg - verwüstet durch den Kriegskommunismus - gleicht jetzt einer Geisterstadt. 2. Der Erinnerung an das vorrevolutionäre Rußland und der damit verbundene Heils- und Erlösungs-

16 Loonid Certkov "Zugige Weite und Ungemuthchkent" Konstantan Vaginov, der Lynker, in Schreibheft Zettschnff fur Isteratur, Nr. 40, S 104-109

Certkov unterscheidet vier Pernoden in Vaginovs Schaffen

I Eune sumbolisusch-romantusche Penode von 1919-1923

II Eine antak-groteske Periode von 1922-1925, mit der er seinen Durchbruch schafft

III Eine obcriutusch-formalistusche Penode von 1926-1930

IV Eine synthetusche Penode von 1931-1934

17 Reinhard Lauer "Kauze und Kunositaten oder Vom Sinn der Kultur Zu Konstantun Waginous <Bambocciade>", in: Konstanun Waginow Bambocciade, Leipzag 1993, S 183. 
wunsch, der sich mit der Frage nach dem russischen Ursprung verbindet: die Anspielung auf den Religionssymbolismus. 3. Der intertextuellen Rezeption jener Kunstverfahren, die in den zwanziger Jahren von den verschiedenen literarischen Schulen entwickelt wurden: die formale Schule.

Vaginov konserviert den Moment dieses kulturellen Paradigmenwechsels, indem er als Autor gewissermaßen den Weg des symbolistischen "Religionskünstlers" zum absurdistischen "Erinnerungskünstler" nachzeichnet, um an einer absoluten Nullstelle anzukommen, die gleichzeitig den Ausgangspunkt seiner Texte bildet: Der sich in Entstehung befindende homo sovietıcus, dem nichts mehr bleibt, als "tote" Erinnenung zu sammeln. Als ein solcher "Schwellentext" ist KP Poesie und Politik objekaloser Liebe zugleich, denn er beruht auf einem auto(r)erotischen Akt des Schreibens und spiegelt das Auslöschen von Geschlechter-Differenz auf zweifache Weise wider: als religionsphilosophische Utopie des Dritten Geschlechts der Symbolisten und als realisierte quasireligiöse Utopie des geschlechtslosen homo sovieticus der Kommunisten. Auf diese Weise kommt es in KP zu einer Transformation des autosoteriologischen Modells als eine der zentralen Konzeptionen symbolistischer Textproduktion. Der künstlerische Akt beruht hier, wie im folgenden ausgefuihrt wird, auf einem grotesk-soteriologischen Konzept. Erinnem wird dabei zum wichtigsten Stimulus der Textproduktion des abstrakten Autors. Im Abschreiten der Stadt Leningrad als Gedächtnisraum der verlorenen Literatenwelt der zehner und zwanziger Jahre von St. Petersburg wird sie zum auto(r)erotischen Zeichen. In diesem Sinne steht KP für Auto(r)erotik als Konsequenz von Ideologien des "Postgeschlechtlichen" bzw. "Postnatalen", die jeweils kunstreligiösen Ursprung haben: "Immer erscheint eine neue Religion an der Peripherie einer Kulturwelt" ("vsegda novaja religija pojavljaetsa na periferii kul'turnogo mira", KP, S.38), sagt Teptelkin, einer der Helden von Kozlınaja pesn'. 
Die Geschichte von KP spielt in der NEP-Zeit der zwanziger Jahre. ${ }^{18}$ Erzählt wird der Untergang der Stadt Petersburg, den der im Vorwort erschienene Autor (pojavivšijsja avtor) beklagt: "Jetzt gibt es Petersburg nicht mehr", („Teper' net Peterburga“, S.20) und der im Vorwort erscheinende Autor (pojavljajušxijsja avtor) stellt melancholisch fest: "Ich liebe Petersburg nicht, mein Traum ist zu Ende", ("Ne ljublju ja Peterburga, končilas' mečta moja", S.19). Im Mittelpunkt des Geschehens stehen der Gelehrte Teptelkin und sein Kreis - der unbekannte Dichter (nelzvestnyj poet), dessen Barockgedichte nur Kennem zugänglich sind, der Dichter Trojcyn, der an den Untergang des Abendlandes $^{19}$ glaubt, der Dichter September, Sergej K., Miša Kotikov, der

18 NEP ist die Abkurzung fur Novaja ckonomiceskaja Politika (Nave Okomonische Politik). cune Polituk kapitalıstuscher Ausnchtung. die Lenin auf dem 10. Parteikongreß durchsetzte, um das für die Wirtschaft katastrophale Expenment des Kricgskommunismus in den Gnff au bekommen

19 Oswald Spenglers umfassende Schnft Der Untergang des Abendlandes war um nachrevolutoonaren Rußland schr popular Vaginov zutert drese Schnift. um sic mit dem Untergang der Petersburger Kultur al analogisieren Interessant in diesem Zusammenhang ist Spenglers Charaktensierung des nachrevolutionaren Rußlands. das ir mit dem Rest Europas vergleicht "Hier licgen heute uxe in Sinen zar Zett Jesu zwei Wirtschaftswetten ubereinander, cunc obcre, fremde. zuvilisierte, de von Westen cengedrungen ist und zu der als Hefe der ganz abendlandische und unrussische Bolschewismus der ersten Jahre gehort, und eine stadtlose. nur unter Guter leberde in der Tiefe, die nucht rechnet. sondem thren unmittelbaren Bodarf eintauschen mochte. Man muß die Schlagworte der Oberflache als eune Stumme auffassen. aus uclcher der ganz mit seiner Soele beschaftugte einfache Russe den Willen Gottes heraushort Der Marxismus unter Russen beruht auf eunem inbrüstugen Mibverstandnus Man hat das hohere Wirtschaftsleben des Petrnismus ertragen, aber woder geschaffen noch anerkannt Der Russe bekampft das Kapital nicht, sondern er begreift es nicht Wer Dostoeuskij zu lesen verstcht. wird her eune junge Menschhett ahnen, für dre es noch gar kein Geld gibt. nur Güter in Bezug auf en Leben. dessen Geurcht nicht auf der Wirtschaftsseite liegt Die "Angst vor dem Mechrwert", dic vor dem Knege manchen bis zum Selbstmord getneten hat, ist eine unverstandene hteransche Verkle1dung der Tatsache, daß der Gelderwerb durch Geld fur das stadtlose Guterdenken en Frevel ist, aus der werdenden russischen Religion godacht eine Sunde. So wie heute die Stadte des Zarentums verfallen und der Mensch in thnen moder wie im Dorfe lebt. unter der Kruste des stätrisch denkenden. rasch hunschuindenden Bolscheuismus, so hat er skch von der westlichen Wirtschaft befret. Der apokal!pusche $\mathrm{Haß}$ - der auch das cinfache Judentum aur Zeit Jesu gegen Rom beherrschte - richtet sich neche nur gegen Petersburg als Stadt. als Sitz ener politischen Macht westlichen Stils, sondern auch als Mitte eines Denkens in westlichem Geld, was das ganze Leben vergiftet und in eine falsche Bahn 
Material über den kürzlich verstorbenen Dichter Zaefratskij sammelt, Kostja Rotikov, der Kitsch sammelt. Sie träumen davon, ihr Leben ausschließlich der Kunst zu widmen und versammeln sich in Peterhof in einem Holzturm, um auf ihre Weise dem Untergang der Kultur zu begegnen. Der unbekannte Dichter (neizvestnyj poét) schlägt die innere Emigration vor, als einzige Möglichkeit innerhalb des totalitären Regimes zu überleben:

- Ja predpolagaju napisat' poemu, - govoril neizvestmyj poet (kogda videnie rassejalos'): $v$ gorode svirepstvuet metafiziceskaja cuma, sin'ory izbirajut grexeskie imena $i$ uchodjat $v$ zamok Tam oni provodjat vremja $v$ izučenij nauk. $v$ muzyke, $v$ sozidanii poeticeskich. zivopisnych i skul'pturnych proizvedenij No oni znajut, cto oni osuždeny, cto gotovitsja poslednyj sturm zamka Sin'jory znajut, to im ne pobedit; oni spuskaetsja v podzemel'e. skladyvajut $v$ nem svoi lưezarnye izobraženija dlja buduščich pokolenij $i$ vychodjat na vermuju gibel', na osmejanie, na besslavnuju smert', ibo inoj smerti dlja nich sejcas ne sušcestruet.(S 78)

Ich schlage vor ein Poem zu schreiben, sagt der unbekannte Dichter (nachdem die Erscheinung sich aufgelost hatte) in der Stadt herrscht metaphysische Pest, die Herren suchen sich griechische Namen aus und gehen ins Kloster Dort verbringen sie ihre Zeit mit dem Studium der Wissenschaften, der Musik, schaffen Poesie, Malerei und Skulpturen Aber sie wissen, daß sie verurteitt sind, daß der letze Sturm auf das Schloß vorbereitet wird Die Herten wissen, daß sie nicht siegen werden, sie begeben sich in die Unterwelt und legen dort ihre glanzenden Darstellungen nieder fur zuküntige Generationen und gehen hinaus in den sicheren Untergang, in das Belachtwerden, in den ruhmlosen Tod, denn einen anderen kann es furr sie nicht geben

In diesem maskierten Rückzug bilden Teptelkin und sein Kreis, der die Hoffnung auf eine künftige Wiedergeburt Rußlands nicht aufgibt, eine letzte Insel der Renasssance (poslednyj ostrov Renessansa, S.75). Die hier implizierte Konzeption Bachtins über den Kameval als gebärenden Tod wird zum zentralen Verfahren innerhalb der dargestellten Welt von KP als Ausdruck für den fundamentalen Rettungswunsch des Autors, der Verneinung des Subjekts in

gelenkt hat Das Russentum der Tiefe laßt heute eine noch pnesterlose. auf dem Johannesevangelnum aufbaukende dritte Art des Chnstentums entstehen, die der magischen unendich viel naher steht als der faususchen, die deshalb auf ciner neuen Simbolik der Taufe beruht und weit enternt von Rom und Wituenberg, in cuner Vorahnung kunfuger Kreuzzuge uber Byzanz hunweg nach Jerusalem blickt Damit alleun beschätugt. uurd sich die Wirsschaft des Westens wioder gefallen lassen. we der Urchnst de romusche. der gotische Christ die jüdische, aber es beteiligt sich nucht mehr an ihr", in Der Untergang des Abendlandes. Umnsse einer Morphologie der Weligeschichte, Munchen 1923, S. $617 \mathrm{ff}$ 
der sich etablierenden totalitären Kultur entgegenzuwirken. Dabei ist die Funktion des Grotesken als Überwindung der Angst und Entfremdung für den sich durch die Erinnerung rettenden Autor paradigmatisch. Seine Autobiographie liegt in seiner Schrift, "im Raum des Gelebten, der den Beschreiber als die Technik seiner Beschreibung ergreift und in dem Maße ein neues Leben ergreift und in dem Maße ein neues Leben gewinnt, wie diese Technik die Autobiographie in Gang setzt" ${ }^{\prime 2}$. Diese Technik ist die der Kamevalisienung, der Maskierung als Travestie der Tragödie (Kozlinaja Pesn' ist die direkte Übersetzung des griechischen Wortes 'Tragödie'; tragos=Bock, ode=Gesang). ${ }^{21}$ In ihr dient der Kult des Dionysos, Symbol göttlicher Inspiration, als Mittel zur Eleminierung der Grenzen zwischen Hellenismus und dem zeitgenössischen Sowjetrußland. ${ }^{22}$ Aber nicht nur der Kult des Dionysos, Orpheus, Philomene, Philostrat, Phönix bevölkem den Gedächtnisraum von Teptelkins Kreis, dessen unstillbare Wißbegierde die fleischliche Begierde ersetzt und auf diese Weise einen künstlerischen Produktionsvorgang in Gang setzt, in dessen Mittelpunkt die lustvolle Beziehung zwischen Text und Prätext steht. Prätexte und deren Verfahren werden vom abstrakten Autor als narrative Diskursobjekte in den hermetisch abgeschlossenen Wort-Körper einverleibt, um einen kulturellen Kontext zu bewahren, der angesichts des sich etablierenden totalitären Systems verloren geht. So besteht KP aus einer Sammlung von Zitaten, die im Rückgriff auf die Antike und den Symbolismus historisiert werden: "Vaginov setzte die "Porträthaftigkeit" - portretnost, wie die Russen sagen - bewußt und mit solcher

20 Eva Meyer: Die Aurobiographie der.Schnfi, Berlin 1989, S. 9

21 Ol'ga Sindina spricht in diescm Zusammenhang von einem "metatextuellen Modell. eunem neakn Typus der Beziehungen zuzschen dem Akt des kunstlerischen Schaffens und den ithn beschreibenden Text auf der einen Seite. zuischen Kunst und Wirklichkeit auf der anderen Seite", von einer "Theatralisienung des Erzahlens" in Kozlinaja Pesn': "Teatralizacija povestvovanija v romane Vaginova Kozlinaja pesn"', in: Teair, Nr. 11, 1991, S 161-171.

22 Anthony Anemone Konstantin Vaginov and the leningrad Avant-Carde: 1921-1934, Berkeley 1985, S 157 
Dichte ein, daß das Buch als "Szenenroman" gelesen und verstanden werden konnte, als Roman über eine im Verschwinden begriffenen Literatenwelt, die der Autor, wie es im Vorwort heißt, gleich einem Sargmacher einsargte, um sie zu bewahren." 23

Teptelkin verkörpert den Typ des vorrevolutionären russischen Intellektuellen, der nachts an seinem Lebenswerk Die Hierarchie der Sinngebungen arbeitet und kostenlos Unterricht in alten Sprachen gibt, um dem Verfall der Kultur entgegenzuwirken:

Posmotrel Teptelkin na letnee kreslo-kacalku i našel, cto ono ne menee udobno, cem vol'terovskoe kreslo, resil prodolzat' osnovnoj trud svoej zizni, otkryl sunduk, sunduk byl vsegda pokryt zelenoj pljuševoj skatertju i izobražal - neizvestno cto izobražal Dostal tetrad'

Na pervoj stranice bylo vyvedeno "Ierarchija smyslov. Vvedenie $v$ izucenie poeticeskich proizvedenij" (Hervorhebung von mir, D.R.) Na vtoroj stranice $v$ nizhem uglu (Teptelkin ljubil original'nost') pomešalos' posvjašcenie "Moej EDINSTVENNOJ" (edinstvennoj $s$ bol'soj bukvy) i fotograficeskaja kartocka Metty $\mathrm{Na}$ tret'ej stranice rimskaja cifra I, na Cetvertoj posredine vystupalo odno slovo: "predislovie", na pjatoj.

Trud byl nacat solidno Dal'se pod osnovnym tekstom \$li primecanija na francuzskom jazyke iz vidnejšich sovremennych lingvistov, bez perevoda na russkij jazyk (trud byl javno naštitan na nastojastich urenych, a ne na glupych studentov). Osnovnoj tekst, kazalos', tože byl napisan na inostrannom jazyke i tol'ko soglasovan nusskimi okonzanijami Tut namekalos' na vozmožnost' dat' novye opredelenija ponjatiju romanticeskogo i ponjatiju klassiteskogo, tut govorilos' o poetiłeskich sposobach okrašivat' nastojašce vremja $v$ prošedšee i budušcee i razrušalos' nelepoe predstavlenie, ť to smysly gnezdjatsja v slove, i davalos' opredelenie estetileskogo kak fantazma, kak garmonizacii prirody i istorii

"I esli by istinnyj chudožnik, - dumal Teptelkin, - zagljanul v etu knigu, on ne smog by otorvat'sja ot nee; na nego podejstvoval by zavoracivajušij pafos etich stranic chudoŻestvennoe proizvedenie vsegda liťno, principial'no liťno nel'zja videt' chudožestvennoe proizvedenie bezlizno, delo ne v imeni, a v tom, čto liěnost' v proizvedenii otražatsja" (S. 517)

Teptelkin schaute auf den sommerlichen Schaukelstuhl und fand, daß er nicht weniger komfortabel als ein Voltairesessel sei Er entschloß sich dazu, das Hauptwerk seines Lebens fortafuhren, offnete die Truhe, die immer mit einer grunen Plüschtischdecke bedeckt war und stellte. - stellte wer weiß was dar Er holte sein Heft heraus

Auf der ersten Seite stand: "Die Hierarchie der Sinngebungen. Einfürung in das Studium poetischer Werke". Auf der zweiten Seite (Teptelkin liebte Originalitat) stand

23 Anthony Ancmone. 1985, op. cit. S. 184 
unten eine Widmung "Meiner EINZIGEN" (groß geschrieben) und eine Fotographie seines TRAUMS. Auf der dritten Seite die romische Ziffer I, auf der vierten in der Mitte stand nur ein Wort: "Vorwort", auf der funften.

Die Arbeit war solide begonnen Unter dem Haupttext kamen Anmerkungen in franzosischer Sprache von den bedeutendsten zeitgenossischen Linguisten, ohne sie ins Russische zu übersetzen (die Arbeit war augenscheinlich fur richtige Gelehrte bestimmt und nicht fur dumme Studenten) Der Haupttext, schien es, war auch in einer Fremdsprache geschrieben und stimmte nur in den Endungen mit dem Russischen uberein Hier besprach er Moglichkeiten, den Begriff des Romantischen und den Begriff des Klassischen neu au bestimmen, don uber das poetische Können, die Gegenwart mit der Vergangenheit und Zukunf zu verschonem und er zerstorte die absurde Vorstellung, daß der Sinn im Wort wurzelt, und definierte das Asthetische als Phantastisches. als Harmonie zwischen Natur und Geschichte

Und wenn ein echter Kunstler in dieses Buch schauen wurde, dachte Teptelkin, dann konnte er sich nicht davon losreißen, denn auf ihn wurde das verzaubernde Pathos dieser Seiten einwirken das kunstlerische Werk ist immer personlich, prinzipiell personlich, man darf das kunstlerische Werk nicht als unpersönlich ansehen, denn es kommt hier nicht auf den Namen an, sondern darauf, daß die Personlichkeit sich im Werk widerspiegelt

Die Entfaltung des Sujets schafft aber gerade einen Gedächtnisraum, in dem die Hierarchie der Sinngebungen aufgelöst wird. Dieser dient dem abstrakten Autor dazu, die ursprüngliche Vollkommenheit von Petersburg wiederherzustellen, denn das beabsichtigte geschlossene, vollkommene Werk soll den $\mathrm{Ob}$ jektverlust, den Untergang von Petersburg, substituieren. Die konsequente Verneinung der sowjetischen Realität innerhalb des Textes, dieses Nicht-zur-Kenntmis-Nehmen des neuen Kultur-Über-Ichs entspricht jener archaistischen bzw. neoprimitivistischen Kulturverweigerung der Avantgarde und damit psychoanalytisch gesprochen der Verweigerung, durch den "Namen-des-Vaters" in die Kultur eingeführ zu werden. ${ }^{24}$ Hansen-Löve bezeichnet diesen Diskurs als depressiv narzißtischen bzw. neurotischen, denn er reflektiert genau jenen psychischen Zustand, den Freud mit dem neurotischen Symptom benennt. ${ }^{25}$ Nach Freud wird die Neurose durch die Versagung des Objekts herbeigefuihrt und impliziert den Verzicht auf das reale Objekt: "Die dem realen Objekt entzogene

24 Hansen-Love. 1992. S 203

25 Ebd S 230 
Libido geht auf ein phantasiertes zurück (Introversion) ${ }^{\prime 26}$. Übertragen auf den Schreibakt des abstrakten Autors von Kozlinaja pesn' bedeutet diese Introversion eine Desexualisienung der Außenwelt. Das Künstler-Ich interpretiert alle Objekte dieser Außenwelt als Produkte seines libidinös besetzten Ichs und damit als kommunikationslos. In der Folge davon befindet sich es sich in permanenter autoreflexiver Selbstbespiegelung, die fur den abstrakten Autor in KP paradigmatisch ist. Sein Projektionsakt löst sich in unendlichen Spiegelungen bzw. Masken seines Autoren-Ichs auf: Im Bild des Autors lobraz avtora), im unbekannten Dichter (neizvestnyj poet), im Bild des Gestalt gewordenen Autors (ustanovivšlysja avtor), in seinen "Helden". Vaginovs Helden sind, wie er selbst als Autor, Sammler. Sie versammeln sich, um auf allen Ebenen kulturelles Wissen zu sammeln und es in der Erinnerung am Leben zu erhalten. Auf diese Weise wird das Sammeln libidinös besetzt und avanciert zum eigentlichen Triebobjekt, das durch den Erinnenungsvorgang vereinnahmt wird. Das Vergangene wird somit zum selbstwertigen Zeichen für Vaginovs auto(r)erotisches žiznetvorčestvo: Durch die Aneinanderreihung der Worte des unbekannten Dichters ruft er eine neue Welt hervor (vot i nikomu ne izvestnyj poet posredstvom sopostavlenija slov vyzyvaet novyj mir dlja nas, KP S.48), denn er weigert sich, das totalitäre System und dessen Implikation auf die russische Kulturpolitik wahrzunehmen. Für ihn ist Kunst ein objektiver Zustand des Seins, ein Zustand, der Begeisterung auslöst:

$V$ esteticeskom net ni prirody, ni istonii, eto osobaja sfera i ne logiceskaja, i ne estetixeskaja, i ne summa ich. Skolko by ne tital chudoknik, ne otstupno zvucal by $v$ ego ušach lejtmotiv knigi iskusstvo est' bytie voschišcennoe. fantazija est' ob"ektivnyj fazis bytija (S 52)

Im Asthetischen gibt es keine Natur, keine Geschichte, das ist eine besondere Sphare weder eine logische. noch eine asthetische, oder die Summe beider Was immer der

26 Sigmund Freud: "Zur Einfuhnung des Narzßmus" (1914), in Das lch und das Es und andere metapsychologische Schnifien, Frankfurt/Main 1978. Bd I. S 29. 
Künstler gelesen hat, unerlaßlich tönt das Leitmotiv des Buches in seinen Ohren: die Kunst ist ein Sein der Begeistenung, die Phantasie ein objektiver Zustand des Seins.

Der unbekannte Dichter lehnt die Revolution mit allen ihren Konsequenzen ab. Für ihn, den intelligenten Menschen kann es keine Umstürze, keine Revolutionen geben, die etwas in den Grundzügen verändern:

- Ne stoit filosofstvovat', - uklonilsja neizvestnyj poet, - my davno - ja iskusstvenno, vy literaturno - perežli gibel', i nikakaja gibel' nas ne udivit Intelligentnyj Celovek duchovno žvet ne $v$ odnoj strane, a vo mnogich, ne $v$ odnoj epoche, a vo mnogich i možet izbrat' ljubuju gibel', on ne grustit, a emu prosto skưno, kogda ego gibel' zastaet doma, on tol'ko promyčit ešce raz s toboj vstretilsja, - i emu stanet smešno (S 49)

- Es hat keinen Sinn zu philosophieren, wich der unbekannte Dichter aus, - wir haben schon lange den Untergang durchlebt und kein Untergang kann uns noch verwundern Ein intelligenter Mensch lebt geistig nicht nur in einem Land, sondern in vielen, nicht nur in einer Epoche, sondern in vielen und kann sich einen beliebigen Untergang heraussuchen, er wird nicht traurig, ihm ist nur langweilig, wenn ihn plözlich der Untergang zu Hause überfallt, et brült nur noch einmal habe ich mich mit dir getroffen, und er findet es komisch

Dementsprechend scheitert auch der Versuch des Autors, seinen Helden Teptelkin zu retten, denn eine Rettung kann es angesichts dieser Weltauffassung nicht geben:

\section{POSLESLOVIE}

Avtor vse vremja pytalsja spasti Teptelkina, no spasti Teptelkina emu ne udalos' Sovsem ne $v$ bednosti posle otrexenija zil Teptelkin Sovsem ne maloe mesto zanjal on $v$ zizni, nikogda ego ne ochvatyvalo somnen'e $v$ samom sebe, nikogda Teptelkin ne dumal, cto on ne prinadležit $k$ vysokoj kulture, ne sebja, a svoju mextu scel on lož'ju

Sovsem ne bednym klubnym rabotnikom stal Teptelkin, a vidnym, no glupym činovnikom. I nikakogo sadika vo dvore ne razvodil Teptelkin, a, naprotiv, - on krical na bednych činovnikov i byl strašno rečist i gord dostignutym položeniem. (S. 205)

\section{NACHWORT}

Der Autor versuchte die ganze Zeit, Teptelkin zu retten, aber Teptelkin zu retten, gelang ihm nicht Nach dem Verzicht lebte Teptelkin keinesweg in Armut Er nahm einen großen Platz im Leben ein, niemals hatte er Selbstzweifel, niemals dachte Teptelkin, daß er nicht zur hochsten Kultur gehor, nicht sich, sondern seinen Traum hielt er für eine Luge Teptelkin wurde uberhaupt kein armer Klubarbeiter, sondern ein angesehener aber 
dummer Beamter. Und Teptelkin legte keinen Garten in Hof an sondern im Gegenteil, er schrie die armen Beamten an und war schrecklich redselig und stolz auf die Position, die er erreicht hatte

Teptelkin und sein Kreis konnten in dem neuen Regime nicht mehr lange existieren. Auch die ehemals gute Beziehung zu dem unbekannten Dichter zerbricht an dem totalitären System und seiner Kulturpolitik:

Kazalos' emu, razušaetsja gosudarstvo, a cistyj junoša poét o svobode ducha, poet skrytno, kak by stydjas', a vse slušjut i chvaljat za neponjatnye metafory, za sijanie, voznikajuscee ot sopostavlenija slov.(S.39)

Es schien ihm [gemeint ist Teptelkin, DR.], während der Staat zerstort wird, singt der reine Jungling [gemeint ist der unbekannte Dichter, D.R.] uber die Freiheit des Geistes, singt zuruckhaltend, als ob er sich schame, und alle hören ihm zu, loben ihn für die unverstandlichen Metaphern, fur das Strahlen, das von der Zusammenstellung der Wörter ausgeht

Die Sorge um materielle Absicherung gewinnt Priorität über geistige Fragen. Teptelkin heiratet, läßt seine Arbeit über die Hierarchie der Sinngebungen im Stich und beginnt, seinen Lebensunterhalt mit Vorlesungen für das neue Regime zu bestreiten. Miša Kotikov wird Zahnarzt und heiratet die Witwe seines Idols, des verstorbenen Dichters Zaefratskij. Der unbekannte Dichter - unfähig Kompromisse zu machen - begeht Selbstmord. Der (jestalt gewordene Autor rettet seinen "Text-Körper" über die Travestie, über das žıznetvorČestvo als groteskes, in der Ästhetisienung bzw. Theatralisienung des Lebens, wie es für die symbolistische Lebensschöpfung signifikant war:

No pora opustit' zanaves Konzilos' predstavlenie Smutno i ticho na scene Gde obešcannaja ljubov', gde obestannyj geroizm? Gde obešcannoe iskusstvo?

I petal'nyj trechpalyj avtor vychodit so svoimi gerojami na scenu i rasklanivaetsja

- Smotri, Mit'ka, kakie urody, - govorit zritel' - nu i nu, ekij prochvost, kakuju pochabšcinu zagnul

Ach, ty užas kakoj, neuzeli vse takie ljudi? Znaete, Ivan Matveevic, v vas est' necto teptelkinskoe

- Uz, ja razdelajus' zavtra s nim. Uz ja podvedu pod nego minu Už ja 
Avtor mašet rukoj - tipografsxiki nacinajut nabirat' knigu

- Spasibo, spasibo, - celuetsja avtor s akterami

Snimaet percatki, razgrimirovyvaetsja Aktery i aktrisy vypramljajutsja i tut ze na scene stirajut grim

I avtor so svoimi akterami edet $v$ deševyj kabačok Tam oni pinjut sredy butylok $i$ opustoß̌aemych stakanov Avtor obsuždaet so svoimi akterami plan novoj p'esy, i oni sporjat i gorjazatsja i proiznosjat tosty za vysokoe iskusstvo, ne bojašceesja pozora, prestuplenija i duchovnoj smerti

Uze naborš̉xiki nabrali polovinu "Kozlinoj pesni" i avtor so svoimi nastojaščmi druz'jami vychodit iz kabackka v prelestnuju peterburgskuju vesennjuju not. vzmetajušcuju dušu nad Nevoj, nad dvorcami, nad soborami, nox' selestjašcuju, kak sad, pojušcuju, kak molodost', i letjaščuju, kak strela. dlja nich uł̌e proletevšuju. (S. 205/206) ${ }^{27}$

Aber es ist Zeit, den Vorhang zu senken Die Vorstellung ist zu Ende. Wirr und still ist es auf der Büne. Wo ist die versprochene Liebe, wo ist das versprochene Heldentum? Wo ist die versprochene Kunst?

Und der traurige dreifingrige Autor geht mit seinen Helden auf die Buhne und verneigt sich

- Schau, Mitja, was fur Mißgeburten, sagt ein Zuschauer Na, na, was fur ein Halunke. was fur eine Zote ist da hereingekommen

- Ach, was fur ein Schrecken, sind das denn wirklich Leute? Wissen Sie, Ivan Matveeic, sie haben etwas teptelkinsches

- Schon Morgen werde ich mich davon trennen Morgen schon werde ich eine Mine unter ihn legen Ich

27 In der Ausgabe Kozlinaja Pesn' Romany, Moskau 1991 im Verlag Sovremennik (Der Zellgenosse) feht dieses Stuck am Ende von KP Der Text condet dort folgendermaßen "Bol'šaja luna osvešcala Dom iskusstv, uze ne sušcestvovavšij Sluzutel' s licom poslodncgo imperatora gotovilsja zaperet' dveri Teptelkın I Mar'ja Petrovna spustilıs' vnuz po Eernomu chodu i vysh v pustoj pereroždajušcijsja gorod

Cert voz'mi. kak ćto bylo davno!

Svet stojal nad proplevannymu zdan'jam. kogda Teptelkın I Marja Petroina šlı vmeste I v predrassvetnom tomkeni szumalos' serdec. I cholodnyj veter rval, i prišcelkival, i prisvistyval.

Avtor smotnit v okno V uschach ego zventl, i poét, i voct. I opjat' poet, i opjat' zvenit I, perochodja v ncjasnyj ścpol zamolkact Kozlinaja pesn'

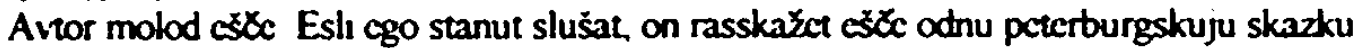

Itak. do slectujušrej noxı, drug "

("Ein großer Mond beleuchtete das Haus der Kunst, das schon necht mehr existierte. Eun Diener mut dem Gesicht des vergangenen Herrschers schuckte sich an. die Tür zu schlseßen Teptelkun und Mana Petrovna gingen den schwarzen Flur hununter und heraus in die loere. sich whodergebarende Stadt

Hols der Tcufel. we ist das lange her'

Das Licht stand auf den uberschwemmten Gebauden. als Teptelken und Maja Petrovna zusammengingen. Und in der Sonnenaufgangsmudigkett zog sich das Herz zusammen und der kalie Wind heulte. schnalzte und pfiff

Der Autor schaut uns Fenster In seinen Ohren tont es und sungt und rauscht und sungt woder und tont moder und geht uber in ein unklares Flustern und das Ziegenliod verstummt Der Autor ist noch jung Wenn man thm zuhort. crzahlt er noch ein Petersburger Marchen Und somit bis zur nächsten Nacht. Fround "KP, S 161) 
Der Autor winkt mit der Hand Die Drucker beginnen das Buch zu setzen.

- Danke, danke, - der Autor küßt die Schauspieler

Zieht die Handschuhe aus und beginnt sich abzuschminken Schauspieler und Schauspielerinnen richten sich auf und schminken sich noch auf der Buhne ab

Und der Autor fahrt mit seinen Schauspielern in eine billige Kneipe Dort feiem sie zwischen Flaschen und leer gewordenen Glasern Der Autor erörtert mit seinen Schauspielem den Plan fur ein neues Stuck, und sie streiten und regen sich auf und erheben Trinkspruche auf die hohe Kunst, die keine Blamage furchtet, keine Verbrechen und keinen seelischen Tod

Die Setzer hatten schon die Halfte des Ziegenlieds gesetzt, und der Autor kommt mit seinen wirklichen Freunden aus der Kneipe heraus in die herrliche Petersburger Fruhlingsnacht uber der Neva, uber den Palästen, uber den Kathedralen, eine Nacht, die die Seele in Aufruhr bringt, rauschend wie ein Garten, singend wie die Jugend, fliegend wie ein Pfeil, fur sie schon vorbeigeflogen

Die Klage um das verlorene Objekt St. Petersburg und seine "Wiedergeburt" als phantasiertes bestimmen die mnemotechnischen Verfahren in KP und damit den künstlerischen Prozeß als grotesk-soteriologischen, der dem Monströsen, dem Unheimlichen entgegenwirkt:

Peterburg okrašen dlja menja s nekotorych por $v$ zelenovatyj cvet, mercajušcij i migajuščij, cvet užasnyj, fosforiłeskij I na domach, i na licach, i v dušach drožit zelenovatyj ogonek, echidynj i podchichikivajušcij Mignet ogonek - Petr Petrovið pered toboj, a lipkjj gad, vzmetnetsja ogonek - i ty sam chuže gada, i po ulicam ne ljudi chodjat zagljanes pod ふapku - zmejnaja golova, smotrišsja v starušku - Žaba sidit i Žvotom dvižet. A molodye ljudi každyj s mextoj osobennoj: inžener objazatel'no chocet gavajskuju muzyku uslyకat', student - poeffektnee povesit'sja, škol'nik rebenkom obzavestis', ctob silu mužskuju dokazat' Zajdes' v magazin - byvšij general za prilavkom stoit i zaucenno ulybaetsja; vojdes" v muzej - voditel' znaet, čto lžet, i lgat' prodolzaet Ne ljublju ja Peterburga, koncilas' mecta $\operatorname{moja}($ S 19)

Petersburg ist fur mich seit einiger Zeit in eine grüe Farbe getaucht, eine flackernde. blinzeinde, eine schreckliche, phosphorizierende Farbe Auf den Hausern, auf den Gesichtern, in den Seelen zittert ein grunes Feuer, giftig und kichernd Es blinzelt ein Feuer, und es steht nicht Petr Petrovic vor dir, sondern ein klebriges Reptil; das Feuer flackert auf und du bist noch schlimmer als das Reptil, und auf den Straßen gehen keine Leute schaust du unter die Mütze - ein Schlangenkopf; schaust du eine Alte an, sitzt da eine Krote 
und bewegt den Bauch. Und die jungen Leute, joder von ihnen hat einen besonderen Traum: ein Ingenieur will unbedingt Musik aus Hawai hören, ein Student sich besonders effektvoll authangen, ein Schuljunge sich ein Kind anschaffen, um seine mannliche Stärke zu zeigen Gehst du in ein Geschaft, steht da ein ehemaliger General und lachelt wie wenn er es auswendiggelernt hatte, gehst du in ein Museum - weiß der Führer, daß er lügt und fahrt fort zu lügen. Ich liebe Petersburg nicht mehr, mein Traum ist zu Ende gegangen.

Dabei resultient die Haltung des abstrakten Autors in der Melancholie als Zeichen unbewältigter Trauer, denn er kann den Verlust seines Liebesobjektes, den Untergang der Stadt Petersburg nicht überwinden. Nur in der Groteske kann er seine Angst bannen. Hierbei greift Vaginov Bachtins Karnevalskonzeption auf, um sie noch einen Schritt weiterzufuihren. Er hypertrophiert die Subjekthaftigkeit in unendlichen Spiegelungen seines Autoren-Ichs im Bild des Autors (obraz avtora), im unbekannten Dichter (neizvestnyj poet), um sie im monströsen Bild des an (jestalt gewonnenen Autors (ustanoviv̌̌egosja avtora) kulminieren zu lassen:

Ja dopisal svoj roman, pudnjal ostrokonexnuju golovu s glazami, poluzakrytimi zeltymi pereponkami, posmotrel na svoi urodlivye ot rozdenija ruki na pravoj ruke tri pal'ca, na levoj- cetyre (S 188/189)

Ich schrieb meinen Roman zu Ende, hob den spitzen Kopf mit den von den gelben Fältchen halbgeschlossenen, schaute auf meine von Geburt an mißgestalteten Hände: auf der rechten Seite drei Finger, auf der linken - vier

Das Monströse, das Ungeheure ist zum Subjekt selbst geworden. Damit steht Vaginovs KP im Spannungsfeld zwischen russischer Moderne und Postmodeme: "Das Ungeheure ist in der Postmoderne nicht mehr eine Möglichkeit des Menschlichen (Freud, Bachtin u.a.), etwas, das sich zurückweisen ließe (Christentum) und einem in der Verschmelzung mit dem Nicht-Ungeheuren Aufgehobenes (totalitäre Kultur). Das Subjekt ist ein Monster und nichts als das." ${ }^{28}$ Das Monströse und Unheimliche assoziiert der abstrakte Autor in seinen

28 Igor Smimov: "Dic Evolution des Ungetcuren Versuch uber Mamloev", in .Schreibheff. Zeitschnff fur Literatur, Nr. 40, November 1992, S 150-155, S 151 
Selbstbespiegelungen mit Leningrad als pervertierter Frau, der er entfliehen will und die er in einem Spektrum von gynäkophoben und misogynen Projektionen in die dargestellte Welt bannt. In seinen Masken vollzieht der abstrakte Autor den Übergriff auf das Monströse als Weibliches und Gegengeschlechtliches und sublimiert dieses durch den Prozeß des Schreibens. Auf diese Weise wird das Monströse als das kulturelle Über-Ich (die sich etablierende totalitäre Kultur) entmachtet und in den Text eingeschlossen. Der in der Maskerade vollzogene Geschlechtswechsel als gender-shifi offenbart damit die Umverteilung von Macht, denn "mit gender-shifis kann ich Allmacht erlangen: wenn ich mich des Anderen be-mächtige, ihn besitze als mich selbst. Hier wird die ganze Extension der gender-shifi-Problematik deutlich - sie ist ebenso psychologisch wie politisch bestimmt" ${ }^{29}$.

Die Umverteilung der Macht im Kommunistischen System wird in KP an der Figur des (jestalt gewordenen Autors deutlich, der sich $\mathrm{zu}$ gleichen Teilen allmächtig und ohnmächtig fühlt. Seine deformierte Hand symbolisiert die Deformation seines Geschlechts, denn die Hand spielt eine signifikante Rolle bei der Herausbildung der (Geschlechts-)Identität, sie wird zum Zeichen des Geschlechts. ${ }^{30}$ Die deformierten Hände des an Gestalt gewonnenen Autors werden auf diese Weise zum Zeichen des deformierten Gesellschaftssystems, das folglich nur ein deformiertes Geschlecht zeugen kann, den homo sovieticus. Paradigmatisch für Vaginovs Textproduktion ist das Verschwinden des wahren Ursprungs: "Jeder meiner Finger - eine verschwundene Stadt, die Handfläche ein Ozean der Trauer, wahrscheinlich deshalb liebe ich so sehr Deine Hände,

29 Johanna-Renate Doring-Smimov "Gender Shifts in der Russischen Postmodeme", in: Psychopoetik Bettrage zur Tagung Psychologie und Lterarur. Wiener Slowisnscher Almanach. Sonderband 31 , Wren 1992. S. 557-563, S. 557

30 Jacques Dernida: Geschlecht (Heidegger). Sexuelle Differenz. ontologische Differenz. Heideggers Hand (Geschlecht II). Wien 1988, S. 59. 
schreibt Vaginov in den Petersburger Nachten und weiter heißt es dort": "Ein Dichter, nicht von Hand geschaffen bin ich, ich liebe die langen Hausmeisterwohnungen, wo man Buchweizengrütze ißt und Kokain schnupft. Mich verachten sie, mein Gesicht, meinen Gang, sie errichten die neue Religion, morgens kehren sie die Höfe nicht." ${ }^{32}$ In KP hinterfragt der (jestalt gewordene Autor seine Identität als Schriftsteller, denn er muß sich seiner Autorposition ständig aufs Neue versichem: "Ja eto pisal ili ne ja? I vdrug podnošu svoju ruku k gubam i celuju. Dragocennaja u menja ruka. Sam sebja chvalju ja". ("Habe ich das jetzt geschrieben oder nicht. Und plötzlich fuihre ich meine Hand zum Mund, küsse sie. Eine wertvolle Hand habe ich", S. 192). Für ihn wird Schreiben zum körperlichen Akt der Selbstreinigung: "Ich glaube, daß Schreiben ein körperlicher ProzeB ist, eine besondere Art der Säuberung des Organismus" ("Ja polagaju, cto pisanie - nexto vrode fizilogiceskogo processa, svoeobraznogo oxišcenija organizma", KP, S. 191), schreibt der Gestalt gewordene Autor und deutet damit die Verbindung von Körper und Schrift an, die er in Bezug auf seine (Geschlechts-)Identität problematisiert. Indem er einen Text über das verlorene (Liebes-)Objekt schaff, gewinnt er es in sich und für sich wieder zurück:

Vo mne, pod vlijaniem nebleklych cvetov i travy, snova prosnulas' ogromnaja ptica, kotoruju soznatel'no ili bessoznatel'no Zuvstvovali moi geroi Ja vižu svoich geroev stojašcimi vokrug menja $v$ vozduche. ja idu $v$ soprovożdenii tolpy v Novyj Petergof, sazus u morja. $i, v$ to vremja kak moi geroi stojat nad morem $v$ vozduche, pronizannye solncem. ja naxinaju perelistyvat' rukopis' i besedovat' s nimi (S . 189)

In mir erwachte erneut, unter Einwirkung der nichtverblaßten Blumen und Graser, der gewaltige Vogel, den meine Helden bewußt oder unbewußt fuhlten Ich sehe meine Helden um mich herum in der Luft stehen, ich gehe in Begleitung der Menge nach Neu-Peter-hof,

31 Konstantun Vaginov, "Petersburger Nachte", in Der Siem von Bethlehem Zwei Eirzahlungen, Bertin 1992. S. 28. Dieser Godichtzaklus von 1921/1922 konnte als Buch nucht erschenen

32 Konstantun Vaginov. Der. Siem won Bethlehem Zwel Erzählungen. Berlin 1992. S 5 . Anspiclung auf das berühmte Godicht Alcksandr Puškins "Ein Denkmal, nucht von Menschenhand geschaffen. baut ich mir " 
setze mich ans Meer, und während meine Helden uber dem Meer in der Luft stehen, von der Sonne durchdrungen, beginne ich das Manuskript durchaublattern und mich mit ihnen a unterhalten.

Ähnlich dem Melancholiker will der Gestalt gewordene Autor das verlorene Liebesobjekt im Ich wieder aufrichten, eine Objektbesetzung durch eine Identifizierung ablösen, deren Introjektion fiktionalen Charakter hat: "Die Objektbesetzung erwies sich als wenig resistent, sie wurde aufgehoben, aber die freie Libido nicht auf ein anderes Objekt verschoben, sondem ins Ich zurückgezogen. Dort fand sie aber nicht eine beliebige Verwendung, sondern diente dazu eine Identifizlerung des Ichs mit dem aufgegebenen Objekt herzustellen." ${ }^{33}$ Doch diese Identifizienung mit dem verlorenen Objekt macht einen emeuten Zugriff nur punktuell möglich. Immer wieder wird der Gestalt gewordene Autor von einem Gefühl der völligen Ohnmacht verfolgt, denn der Objektverlust geht mit dem Verlust seines Ichs einher: "Inogda ja smotrju na svoi urodlivye pal'cy i udovletvorenno smejus': - Ved' vot kakaja ja urodina! Ruki moi vlažny, izo rta pachnet malinoj." (S.190) ("Manchmal schaue ich auf meine mißgestalteten Finger und lache erstaunt: Was bin ich doch fuir eine Mißgeburt! Meine Hände sind immer feucht, aus meinem Mund riecht es nach Himbeeren.") Er beginnt sein soeben geschaffenes Werk zu verbrennen und entkleidet sich dabei. Da er aber nur durch sein Werk lebt, nur durch es "Gestalt" wird und auf diese Weise auch seine Identität bekommt, verliert er durch diesen Verbrennungsakt beides:

Vozvrativšis' v gorod, ja chocu raspast'sja, isceznut', i, ostanovivšis' u pexki, ja naxinaju brosat' $v$ nee listy rukopisi i podżgat' ich

Zara

Ja medlenno razdevajus', golyj podchožu $k$ stolu, raskryvaju okno, rassmatrivaju prochożich i gorod i nacinaju pisat' (S 189)

33 Sigmund Freud "Trauer und Melancholie", in Das Ich und das Es. Und andere melapsychologische. Schnfien, op cit. S 110. 
Zuruckgekehrt in die Stadt, mochte ich zerfallen, verschwinden und wahrend ich am Ofen stehen bleibe, beginne ich, die Blatter des Manuskripts hineinzuwerfen und sie au verbrennen

Glut

Ich ziehe mich langsam aus, gehe nackt auf den Schreibtisch zu, offne das Fenster, schaue auf die Vorubergehenden und die Stadt und beginne zu schreiben

Damit artikuliert der Gestalt gewordene Autor ein zirkuläres (Text-) Begehren. Indem er seine Texte immer wieder verbrennt, d.h. seine Objekte letztendlich verneint, vollzieht er auch immmer wieder den Akt des auto(r)erotischen Schreibens. Die kurzfristig entstandene Triade Subjekt - Trieb - Objekt wird durch den Verbrennungsakt wieder zur Dyade von Subjekt und Trieb. Dem Gestalt gewordenen Autor gelingt es folglich nicht, eine eindeutige Geschlechtsidentität bzw. Machtposition zu entwickeln. Er bleibt in der Situation des "Postgeschlechtlichen" bzw. "Postnatalen" verhaftet.

Kozlınaja pesn' als logisches Ende des Petersburger Textes beginnt mit dem Ende der Petersburger Kultur, mit dem Zusammenbruch der Familie, mit dem symbolischen "Tod" von Mann und Frau. Die Geschichte entfaltet eine Möglichkeit, dieser Ideologie der Entdifferenzierung entgegenzuwirken. Sie endet im gender-shıfi der postrevolutionären Utopie, in der deformierten Hand des (jestalt gewordenen Autors als Symbol seines deformierten Geschlechts: Der neue Mensch, der seinen wahren Ursprung verloren hat. 


\section{Zusammenfassung}

Die vorliegende Dissertation stellte sich die Aufgabe, mit den Einsichten der poststrukturalistischen feministischen Literaturwissenschaft nach der $\mathrm{Ge}$ schlechter-Differenz in Lebens- und Kunsttexten russischer Philosophen und Schriftsteller zu Beginn der Modeme zu fragen, vor allem während der sogennanten (zweiten) religionsphilosophischen Formation des Symbolismus. Die Themenstellung orientierte sich damit an einer allgemeinen kulturtheoretischen Problematik (der Stelle des weiblichen Diskurses in der Literatur) und an der spezifischen "gender"-Problematik im Silbernen Zeitalter vom Ende des 19. Jahrhunderts bis zum Ende der russischen Moderne. Der Untersuchungszeitraum ist doppelt gerechtfertigt: Erstens brachte die gescheiterte Revolution von 1905 ein disziplinär ganz neu formuliertes Interesse an sexuellen Triebproblemen, die die dominierenden Diskurse durch psychoanalytische und psychiatrische Erkenntnisse erweiterte. ${ }^{34}$ Zweitens entwickelte sich in dieser Zeit ein reformuliertes Literaturverständnis heraus: Literatur wird zum Religionsersatz und bietet - durchaus vergleichbar mit dem psychoanalytischen Weg - soteriologische Modelle an. Hier ging es also nicht um die Evolution der Konzeptionen des Symbolismus, sondern um die Rekonstruktion einer Genealogie, d.h. das aktuell historisch rekonstruierende diskursanalytische Untersuchungsspektrum um wesentliche hochkulturelle ästhetisch funktionale und funktionierende Modelle zu erweitern.

Die russische Religionsphilosophie ausgehend von Vasilij Rozanov, aber auch von Merežkovskij und dessen Frau Zinaida Gippius verbanden die Frage

34 Wic das Laura Engetstein in threr Studie zeigen konnte. Vgl The Keys to Happiness. Sex and the Search for Modemiry in Fin-de-Siècle Russia. Ithaca 1992. 
nach dem Platz - der "Leerstelle" - des Weiblichen in der Konfiguration der Geschlechter mit der Frau nach Gott und Religion. Die uralte gnostisch-mystische Idee einer weiblichen göttlichen Hypostase in der Sophiologie vor allem bei Vladimir Solov'ev wurde in den Texten der Religionssymbolisten mit der apokalyptischen Vorstellung von einem "Dritten Reich" des Geistes verknüpft, in dem die Geschlechter-Differenz wie alle Dichotomien in der Restitution einer "All-Einheit" aufgelöst sind. Vladimir Solov'evs Ideal eines "Gottmenschen" wurde vor allem von Zinaida Gippius und Dmitrij Merežkovskij zum Konzept eines "Dritten Geschlechts" ausgeweitet, dessen Androgynität den ausweglosen Kampf der Geschlechterkampf, wie ihn Nietzsche postulierte, beenden sollte. Diesem Idealbild des neutralisierten Androgyn liegt also die Verwerfung des Geschlechter-Binarismus zugnunde. Sie führt zu einer spezifischen Geschlechter-Ethik und Geschlechter-Ästhetik, die sich in der Besessenheit nach androgyner Liebe offenbart. Gerade die Betonung der Zweigeschlechtlichkeit bei Solov'ev und bei Gippius impliziert eine Art "keusche Wollust", die sich als geschlechtliche Identitätslust des transsexuellen Phänomens konkretisiert. Die sophiologische Idealisierung der Frau in der hermetischen Tradition Rußland (wie man sie in den Texten Gogol's findet) und in der Romantik, aber auch die Überkompensation des idealisierten Weiblichen im Bruder-Schwester-Ideal beim jungen Dostoevskij haben für die Sujets der symbolistischen Kunsttexte große Bedeutung und verweisen auf ihre ödipale Ausgangssituation, die sich im Lebenstext der Schriftsteller (in den zahlreichen Dreiecksbeziehungen) fortsetzte. Gerade die Feminisierung des Männlichen und die darauffolgende Virilisierung des Weiblichen und der damit partielle Rollentausch zwischen Mann und Frau offenbart die Inkonsistenzen und die Hysterie der gesamten symbolistischen Lebensschöpfung, wie sie sich beispielsweise an Aleksandr Bloks Kult bzw. Kultivienung der Schönen Dame zeigen läßt. Während die Hysterie des Mannes im Silbernen Zeitalter als Maskerade der Männlichkeit zu ver- 
stehen ist, läßt sich die Hysterie der Frau in der Selbstinszenierung des eigenen Lebens beschreiben, die im Falle der Nina Petrovskaja der Vor-Schrift bis zu seinem tödlichen Ende folgt.

Die "Frau", um die in den höfischen Liebesspielen der Religionssymbolisten vorgeblich rivalisiert wird, dient als ein "screen", als Projektionsfläche für die idealisierten bzw. perhorreszierten Weibs-Bilder, die spiegelverkehrt das Fremde des Eigenen und das Eigene des Fremden zeigt. Als Anderes wird die Frau damit gelöscht. Diese Poetik verweist aber auch auf den Nicht-Ort der Frau als Nichts, also die von den Symbolisten immer wieder gemachte Erfahrung der "Leere" des zu enthüllenden erotisch-mystischen "Geheimnisses", die auf das Paradigma des vielfach ver- und aufgeschobenen Frauenkultes des "Troubadurs", sowie auf die apophatische Tradition des nichtreferentiellen Diskurses zurückgreift. Für die Frau aus "Fleisch und Blut" bedeutete das, wie es die Textanalysen gezeigt haben, die Löschung des symbolistischen Frauenbildes und die Suche nach einem eigenen weiblichen Bild und Ort in der Literatur, wie es Ivanovs Frau Lydia Zinov'eva-Annibal getan hat, oder aber die absolute "Übererfüllung" des Frauenbildes, die Mortifikation der realen Frau im Falle der Petrovskaja, bzw. die Kultivierung des Frauenbildes im Falle von Bloks Ehefrau Ljubov'-Dmitrievna und die Maskerade der Weiblichkeit bzw. die Virilisienung der eigenen weiblichen Position im Falle von Zinaida Gippius. Wenn die Geschlechter-Ethik und Geschlechts-Ästhetik der symbolistischen Lebensschöpfung im Silbernen Zeitalter als Geschlechter-Indifferenz lesbar wurde und damit auf einen Ort verweist, in dem sich Mann und Frau verfehlen, so wird an Konstantin Vaginovs Text aus der späten Avantgarde deutlich, daß sich das Geschlechtsverhältnis als groteskes gestaltet. In beiden Fällen ist die physische Seite und damit die Prokreation ausgespart, d.h. die Geschlechter-Ethik und Geschlechts-Ästhetik der Kunst- und Lebenstexte propagieren eine pränatale bzw. postnatale Ein- bzw. Doppelgeschlechtlichkeit. 


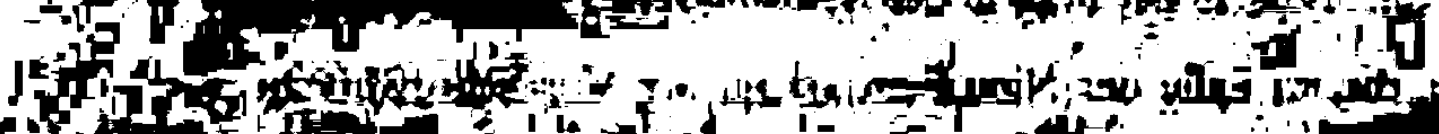

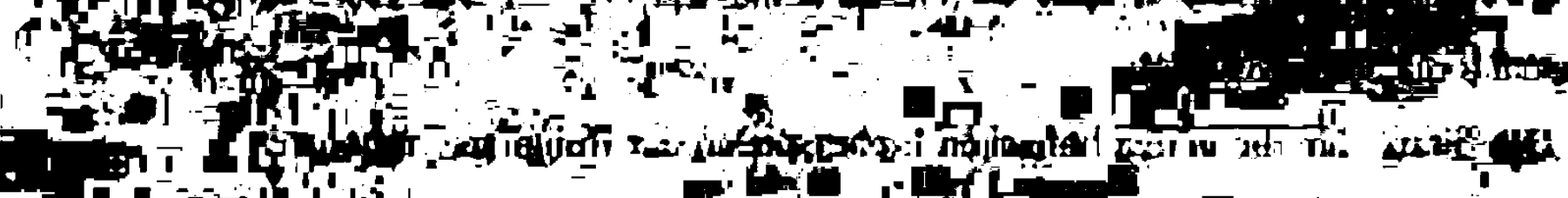

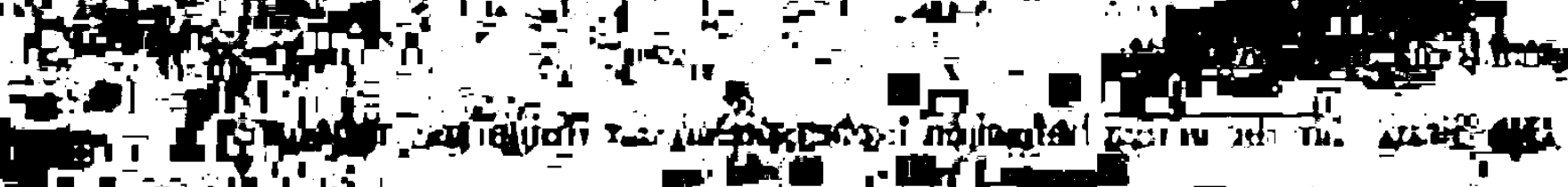

If 'F 正

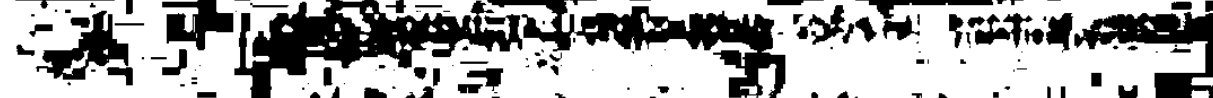

-

4h Fot III

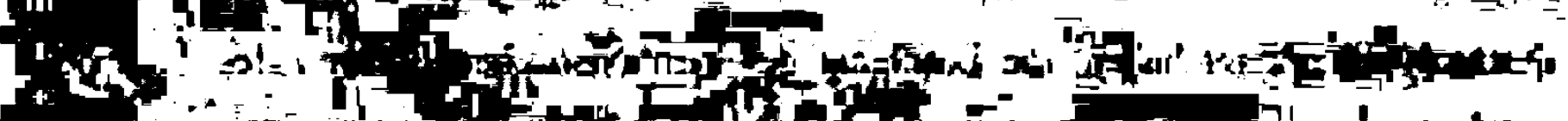

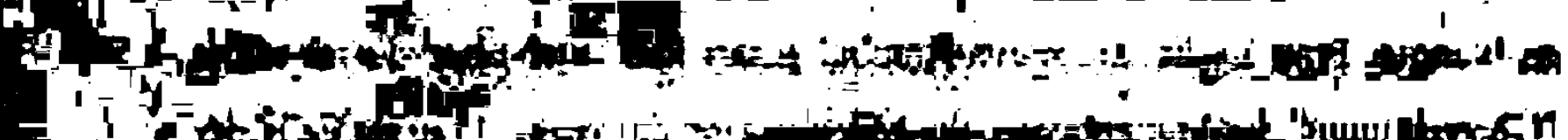

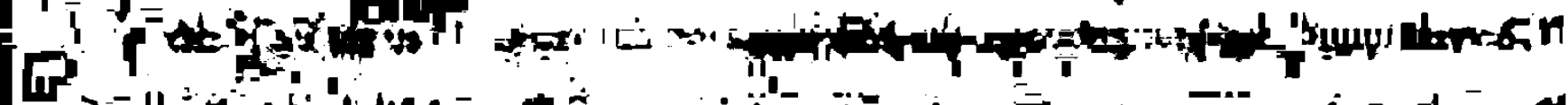
C If a

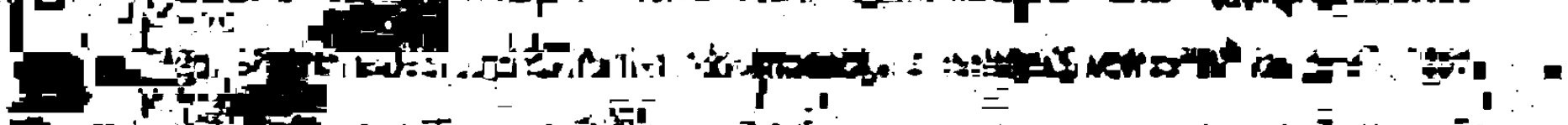

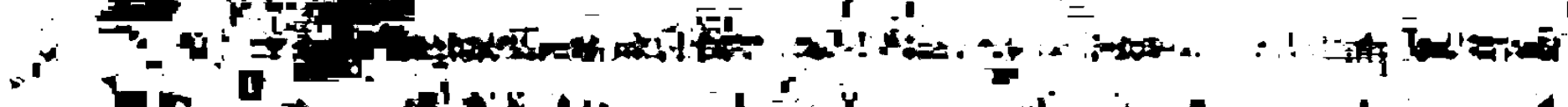

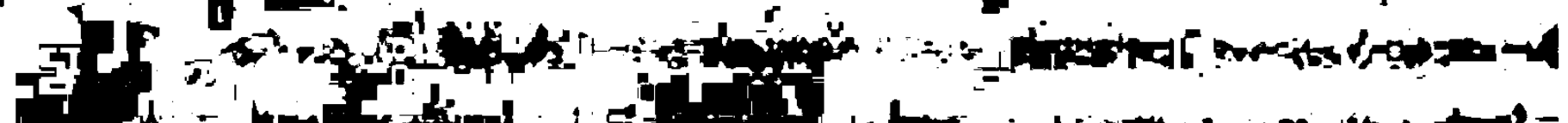
最

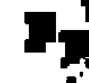

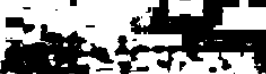

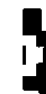

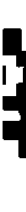

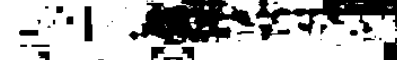

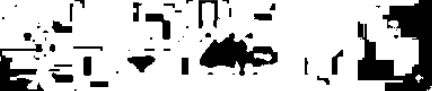

i 


\section{Literaturverzeichnis}

\section{Primärliteratur}

\section{Andrej Belyj:}

- Serebrjanyj golub'(1909), in: Slavische Propyläen [Nachdruck der Berliner Ausgabe von 1922], Band 38, München 1967.

- Kotik Letaev [Petrograd 1922], in: Slavische Propyläen, Band 3, München 1964.

* Simvolizm, in: Slavische Propyläen [Nachdruck der Ausgabe Moskau 1910], Band 62, München 1969.

- Arabeskl, in: Slavische Propylaen, Band 63, München 1969.

- Pocemu ja stal simvolistom i pocemu ja ne perestal im byt' vo usech fasach moego idejnogo i chudožestvennogo razvitija (handschriftliches Original von 1928). Dt. Übersetzung von Gisela Drohla, Ich, ein Symbolist, Frankfurt/Main 1987.

- Aleksandr Blok i Andrej Belyj. Perepiska, in: Slavische Propyläen, Band 65, München 1969 (Nachdruck der Ausgabe Moskau 1940).

- Meždu dvuch revolucij (Leningrad 1934), Moskva 1989.

- Načalo veka (Moskva-Leningrad 1933), Moskva 1989.

- Na rubeže dvuch stoletij (Moskva 1930, 1931), Moskva 1990. 


\section{Aleksandr Blok:}

- Sobranie socinenij v vos'mi tomach, Band 1, 2, 4, Moskva/Leningrad 1962.

- Literatumoe nasledstvo. Aleksandr Blok. Novyje materialy i issledovanija, tom 92, kniga pervaja, Moskva 1980, kniga vtoraja, Moskva 1981, kniga tret'ja, Moskva 1982.

\section{Valerij Briusov:}

- Literaturnoe nasledstvo. Valeri Brjusov, tom 85, Moskva 1976.

- Ognennyj angel' in: Slavische Propyläen Band 88, München 1971, Nachdruck der revidierten Ausgabe Moskva 1909. Deutsche Übersetzung von Reinhold von Walter, Köln 1990.

\section{Marina Cvetaeva:}

- Mein weiblicher Bruder. Brief an eine Amazone, München 1985.

5. Zinaida Gippius:

* Sobranie Stichov. Kniga Vioraja, Moskva 1910, in: Slavische Propyläen, München 1972.

- Literatumyj dnevnik (Anton Krajnij), Petersburg 1908.

- Živye lica, [zuerst Prag 1925 in zwei Bänden], in: Slavische Propyläen, München 1972.

- Dmutry Merezkovskı, [zuerst Paris 1951], Tiflis 1991.

* Contes d'amour, in: Vozrożdenıe II, Juli/August 1969.

6. Vjaceslav Ivanov:

- Sohranie Socinenij v trech tomach, Brüssel 1974 


\section{Vladimir Solov'ev:}

- Sobranie Socinenij Madimira Sergejvica Solov'eva, Bd.III-IV, Bd, VIIVIII, Bd.IX-X, Bd. XI-XII, Sankt-Peterburg 1873-1905, Nachdruck Brüssel 1966. Deutsche Gesamtausgabe der Werke von Wladimir Solowjew (18 Bände), Bd. I und VII, Hg. von Wladimir Szylkarski, Freiburg/i.Brg. 1953.

* Stichotvorenija i šutocnye p'esy, in: Biblioteka Poèta, Leningrad 1974.

\section{Téffi:}

* Legenda i ṫizn' [1904], Carica Poceluev. Erotiteskie novelly i skazki russkich pisatelej, Moskva 1993.

\section{Konstantin Vaginov:}

* Kozlinaja Pesn'(Leningrad 1928), in: Zabytaja Kniga, Moskva 1989.

* Werke und Tage des Svistonov, Dt. Übersetzung von Gerhard Hacker, Münster 1992.

* Der Stern von Bethlehem. Zwei Erzählungen, Dt. Übersetzung von Peter Urban, Berlin 1992.

- Auf der Suche nach dem (iesang der Nachtigall, Dt. Übersetzung von Ulrike Zemme, Frankfurt/Main 1993.

* Bambocciade, Dt. Übersetzung von Andreas Tretner, Leipzig 1993.

\section{Lidija Zinov'eva-Annibal:}

* "Tridcat'-tri uroda", Sankt-Peterburg 1907. 


\section{Sekundärliteratur}

1. Forschungsliteratur zu den Autoren:

\subsection{Andrej Belyi:}

CARLSON, Maria: The Conquest of (.haos, Michigan 1983.

CASTELLANO, (harlene Ann: Synesthesia: Imaginatıon's Semıotic in Andreı Bely's Peterburg, Ann Arbor, Michigan 1981.

DEPPERMANN, Maria: Andre Belyjs Ästhettsche Theorie des Schöpferıschen Bewrßtseıns, München 1982.

HARRIS, Jane Gay: "Andrej Belyj's Memories of Fiction", in: Autobiographical Statements in Twentıeth Century Russian Literature, Princeton, New Jersey 1990.

LESNEVSKIJ, Stanislav und Aleksandr MICHAJLOV (Hgg.): Andrej Belyj. Problema tvorčestvo. Stat'i i vospominanija, Moskva 1989.

LJUNGGREN, Magnus: The Dream of Rehırth, Stockholm 1982.

MALMSTAD, John E.: Andrey Bely. Spirıt of Symbolısm, Ithaca/ New York 1987.

\subsection{Aleksandr Blok:}

BEKETOVA, Maria, A.: Aleksandr Blok. Biograficesk!) ()cerk, Den Haag, Paris 1969 [Nachdruck der Ausgabe Petrograd 1922].

EJCHENBAUM, Boris M.: Sud'ba Bloka, Letchworth 1979.

GROSSMAN, J.D.: "Blok, Brjusov and the Prekrasnaja Dama"', in: Alexander Blok. Centennial Conference, Hg. W. Vickery u. B. Sagatov, Columbus 1984, S. 159-177. 
KLUGE, Rolf-Dieter: Westeuropa und Rußland im Weltbild Alexander Bloks, München 1967.

ders.: "Alexander Bloks 'Schneemaske' oder: Wie funktioniert ein symbolistisches Gedicht", in: Zeitschrift für Slavische Philologie 42, 1982, S. 261273.

MAKSIMOV, D. E. : Poezija i proza Aleksandra Bloka, Leningrad 1981.

MENDELEEVA-BLOK, Ljubov D.: Byli i Nebylicy, Bremen 1977.

MICHAJLOV, Aleksandr und Stanislav LESNEVSKIJ (Hgg.): $V$ mire Bloka. Sbomik Statej, Moskva 1981.

MOČULSKIJ, Konstantin: Alexander Blok, Paris 1948.

PETERS, Johanna.: Farbe und Licht. Symbolik bei Alexander Blok, München 1981 .

POYNTNER, Erich: Die Zyklisierung lyrischer Texte bei Aleksandr Blok, München 1988.

ORLOV, Vladimir: Hamayun. The Live of Alexander Blok, Moskau 1980.

\subsection{Valenij Briusov:}

ABRAMOVIC, S.D.: "Voprosy istorizma $v$ romane Valerija Jakovlevica Brjusova 'Ognennyj Angel'", in: Voprosy Russkoj Literatury 2, 1973, S. 8894.

ARTHUR, D.B.: Love, Death and World's End. Themes in Brjusov's Prose, Texas 1976.

BAER, J.T.: "Symbolism and Stylized Prose in Russia and Poland: Valerij Brjusov's 'Ognennyj Angel' and W. Berent's Zywie Kamenie", in: American Contribution to the 9th International Congress of Slavists, Kiev, September 1983, Hg. P. Debreczeny, Columbus 1983, II, S. 19-38. 
BURLAKOV N. St.: Valerıj Brjusov. Ocerk tvorcestva. Moskva 1975.

FLICKINGER, Brigitte: Valerij Brjusov. Dıchtung als Magie. Kritische Analyse des 'Feurigen Engels', München 1976.

GERASIMOV, K.S.: "Naučnaja Fantastika Brjusova", in: Brjusovskie ctenija 1971 goda, Erevan 1973.

GROSSMAN, J.D.: Valerij Brjusov and the Riddle of Russian Decadence, Berkeley 1985.

MINC, Zara: "Graf Genrich von Ottergeijm i "Moskovskij Renessans", in: Andrej Belyj. Problemy tvorcestva, Hg. Al. Lesnevskij et al., Moskva 1993.

RICE, M.P. : Valerij Brjusov and the Rise of Russian Symbolısm, Ann Arbor, Michigan 1975.

SETSCHKAREFF, V.: "The Narrative Prose of Brjusov", in: Intemational Congress of Slavic Linguistics and Poetics 1/2, 1959, S. 237-265.

ZAKRZEVSKIJ, A.: "Karamzovšcina. Psichologiceskie paralleli. Dostoevskij. Brjusov. Rozanov. Arcybałev" (Kiev 1912), in: Sobranie socınenij, 8 Bde., Moskva 1963-1967, Bd.1, S. 430-439.

ZAYM, R.: Die historischen Romane V.J. Brjusovs, Wien 1973.

\subsection{Zinaida Gippius:}

MATICH, Olga: The Relıgıous Poetry of Zınaida (iippius, München 1972.

PACHMUSS, Temira: Zinaida Hippius. An Intellectual Profile, London, Amsterdam 1971.

\subsection{Vladimir Solov'ev:}

GEORGE, M.: Mystische und religıöse lirfahrung ım I Denken Vadımır Solov'evs, Göttingen 1988. 
GROYS, Boris: "Weisheit als weibliches Weltprinzip. Die russische Sophiologie des Wladimir Solowjew, in: Alleida Assmann (Hg.) Weisheit, München 1990.

KLUM, Edith: Natur, Kunst und Liebe in der Philosophie Vladimir Solov'evs. Eine relıgionsphilosophische Untersuchung, München 1965.

MOCUL'SKIJ, Konstantin: Vladimir Solov'ev. Žizn' i uCenie, Pariz 1951.

MÜLLER, Ludolf: Das relıgıonsphilosophische System Vadimir Solov'ev, Berlin 1956.

MUNZER, E.: The prophet of Russian Western Unity, London 1956.

SESTOV, L.: Umozrenie i otkrovenie: Relgioznaja filosofija Vladimira Solov'eva, Paris 1964.

\subsection{Konstantin Vaginov:}

ANCIFEROV, N.P: "Tri glavy iz vospominanij", in: Pamjat', 4, Paris/New York 1978.

ANEMONE, A.: Konstantin Vaginov and the Leningrad Avant-Garde: 19211934, Berkeley 1985.

dies.: "Konstantin Vaginov and the Death of Nikolaj Gumilev", in: Slavic Review, 4, 1989, S. 631-636.

CERTKOV, Leonid: "Zugige Weite und Ungemütlichkeit." Schreibheft. Zeitschrift für Literatur, Nr. 40, S. 104-109.

ZUKOVSKIJ, N.: Literatumye Vospominanija, Moskva 1989.

ERL', V.: "Konstantin Vaginov i Aleksandr Vvedenskij v Sojuze Poetov", in: Wiener Slawistischer Almanach 27, 1991, S. 219-222.

GERASIMOVA, A.: "Oberiu. Problema smešnogo", in: Voprosy lıteratury 4, 1988 , S. $48-49$. 
dies.: "Trudy i dni Konstantina Vaginova", in: Voprosy literatury 12, 1989, S. 131-166.

JUDINA, M:: Stat'i, vospominanija, materıaly, Moskva 1978.

LAUER, Reinhard: "Käuze und Kuriositäten oder Vom Sinne der Kultur. $\mathrm{Zu}$ Konstantin Waginows <Bambocciade>", in: Konstantin Waginow: Bambocciade, Leipzig 1993, S. 181-190.

LUKNICKIJ, P.: "O Vaginove", in: Literaturnoe obozrenie 5, 1989, S. 71- 72.

MOREV, G.: "Konstantin Vaginov: Obretenie citatelja", in: Novoe literaturnoe obozrenie 1, 1992, S. 232-235.

NIKOL'SKAJA, T: "K voprosu o russkom ékspressionizme", in: Tynjanovskij sbomik. Cetvertyje Tynjanovskie ctenija, Riga 1990, S. 173-180.

ŠNDINA, O.: "Teatralizacija povestvovanija $v$ romane Vaginova Kozlinaja Pesn"', in: Teatr 11, 1991, S. 161-171.

\subsection{Zinov'eva-Annibal:}

GÖPFERT, F.: "Dichterinnen und Schriftstellerinnen von der Mitte des 18. Jahrhunderts bis zum Beginn des 20. Jahrhunderts. Eine Problemskizze", in: Slavtstische Beitrd̈ge, Bd. 289; München 1992.

KUŠliNA, O.B.: Russkie Pisateli 18(1)-1917. Biograficeskıj Slovar', Moskva 1992.

LEDKOVSKY, M.: Dictionary of Russian Women Writers, Westport 1994.

NIKOL'SKAJA, T.L.: Tvorceskı Put' I.D. Zinov'evoj-Annıhal, Ucenye Zapiski Tartuvskogo Gosudarstvennogo Universiteta, Vypusk. 813, 1988. 
2. Slavistische Forschungsliteratur

ANDREW, Joe: "Not daring to desire: Male/Female and Desire in Narrative in Puskin's Bachcisarajskij Fontan"', in: Russian Literature XXIV (III), 1988, S. 259-275.

ders.: Women in Russian Literature, 1780-1863, New York 1988.

ders.: "The Blind will see": Narrative and Gender in Taman', in: Russian Literature XXXI (IV), 1992, S. 449-477.

AVERINCEV, S.S.: "Analiticeskaja psichologija K.G. Junga i zakonomemosti tvorceskoj fantazii", in: O sovremennoj burzuaznoj éstetike, Moskva 1972, S. 110-155.

BAYUK, Milla: "The submissive wife stereotype in Anton Cechov's Darling"', in: College Language Association XX/2, 1976, S. 533-538.

BARKER, Adele Marie: The Mother Syndrome in the Russian Folk Imagination, Columbus, Ohio 1986.

BELKNAP, Robert L.: Russianness: an examination of Russia and the West, Ann Arbor, Michigan 1990.

CHODASEVIC, Vladimir: Literatumye stat'i $i$ vospominanija, New York 1954.

COSTLOW, J., SANDER, S., VOWLES, J. (Hgg.): Sexuality and the Body in Russian (.ulture, Stanford 1993.

DEPPERMANN, Maria: "Nietzsche in Rußland", in: Nietzsche Studien 21, 1992, S. 211-252.

DERING-SMIRNOVA, J.R.- I.P. SMIRNOV: "Poeticeskij avangard $s$ tocki zenija évolucij chudožestvennych system", in: Russian Literature VIII, 1980, S. $403-468$. 
DÖRING-SMIRNOV, J.R.: "Dämonologische Vorstellungen in zwei anonymen russischen Erzählungen des XVII. Jahrhunderts", in: IJSLP XXXI$X X X I I, 1980$, S.101-112.

dies.: "Metaphysik des Geschlechts", Nachwort in: Leo Tol'stoj, Anna Karenina, München 1993, S. 979-993.

dies.: "Sektanstvo i literatura. Serebrjanyj Golub' Andreja Belogo", in: Christianity and the Eastern Slaves (Vol.2). Russian Culture in Modern Times, Ed. Robert P. Hughes and Irina Paperno, Berkeley, Los Angeles 1994, S. 194-200.

EBERT, Christa: Symbolismus in Rußland. Zur Romanprosa Sologubs, Remisows, Belys, Berlin 1988.

EDMONDSON, Linda Harriet: Feminism in Russia, London 1984.

ENGELSTEIN, Laura: The Keys to Happiness. Sex and the Search for Modernity in Fin-de-Siècle Russia, Princeton 1992.

ETKIND, Alexander: Eros des Unmöglichen. Die Geschichte der Psychoanalyse in Rußland, Leipzig 1996.

EVDOKIMOV, Pavel: Die Frau und das Heil der Welt, München 1960.

ders.: Der Abstieg in die Hölle. (jogol und Dostojewski. Salzburg 1965.

ders.: Gotteserleben und Mönchstum, Wien/München 1967.

ders.: Chrıstus im Russischen Denken, Trier 1977.

GRASS, K.: Die russischen Sekten. Die Gottesleute oder Chlüsten, Bd. I, Leipzig 1907.

GREBER, Erika: "Mystifikation und Epochenschwelle. (Čerubina de Gabriak und die Krise des Symbolismus)", in: Wiener Slawistischer Almanach, Bd. 32, 1993, S. 175-207, S. 195. 
HANSEN-LÖVE, Aage A: Der Russische Symbolismus. System und Entfaltung der Motive, Bd.1, Wien 1985.

ders.: "Zur Typologie des Erhabenen in der russischen Moderne", in: Poetica 23, 1991, S. 166-216.

ders.: "Pecorin als Frau und Pferd und Anderes zu Lermontovs 'Geroj nasego vremeni"' (1.Teil), in: Russian Literature XXXI IV), 1992, S.491-545.

ders.: "Zur psychopoetischen Typologie", in: Wiener Slawistischer Almanach, Sonderband 31, Wien 1992, S. 195-288.

ders.: "Allgemeine Häretik, nussische Sekten und ihre Literarisienung in der Moderne", in: Wiener Slawistischer Almanach, Sonderband 41, Wien 1996, S. 171-295.

ders.: "Gogol"'. Zur Poetik der Null- und Leerstelle, in: Wiener Slawistischer Almanach 39, Wien 1997, S. 183-305.

HARRIS, Jane Gary: Autobiographical Statements in Twentieth-Century Russian Literature, Princeton/New Jersey 1990.

HELDT, Barbara: Terrible Perfection. Women and Russian Literature, Bloomington 1987.

HOLTHUSEN, Johannes: Studien zur Ästhetik und Poetik des russischen Symbolismus, Göttingen 1957.

HUBBS, Joanna: Mother Russia. The Feminine Myth in Russian Culture, Bloomington 1988.

INGOLD, Felix Philip: "Kunst- und Lebenstext. Thesen und Beispiele zum Verhăltnis zwischen Kunstwerk und Alltags-Wirklichkeit im nussischen Modemismus", in: Die Welt der Slaven 26, 1981, S. 37-61.

KONOVALOV, D.G.: Religioznyj ekstaz v russkom mistıCeskom sektanstve, Sergeev Posad 1908. 
LACHMANN, Renate: (jedachtnts und Literatur, Frankfurt/Main 1990.

"Doppelgängerei", in: Poetik und Hermeneutik, München 1997, S. 421-435.

LANGAN, Janine: "Icon versus myth: Dostoevskij, feminism and pornography", in: Religion and Ltterature 18, 1986/1, S.63-72.

LANGE, Wolfgang (Hg.): Petersburger Trçume. Ein literarisches Lesebuch, München 1992.

LEDKOVSKY, Marina: Dictıonary of. Russian Women Writers, Westport 1994.

LEVIN, Eve: Sex and Society in the World of the Orthodox Slavs, London 1989.

LOTMAN, Jurij M.: Aufsätze zur Theorıe und Methodologie in der Literatur und Kultur, Kronberg 1974.

deMAEDG-SOEP, Carolina: The Emancipation of Women in Russian Literature and Society, Gent 1978."

dies.: Chekhov and Women, Columbus, Ohio 1987.

MAMONOVA, Tat'jana: Women and Russta. Feminist Writings from the Soviet Union, Boston/Mass. 1987.

dies.: Russıan Women Studies, New York 1988.

MATICH, Olga: "Androgyny and the Russian Religious Renaissance", in: Anthony Mlikotin: Western Philosophical Systems in Russian Literature, Los Angeles, Cal., 1979, S. 379-407.

dies.: "A Typology of Fallen Women in Nineteenth Century Russian Literature", in: American Contributions to the ninth International Congress of Slavtsts, Ohio, 1983, S. 325-345. 
dies.: "The Symbolist Meaning of Love. Theory and Practice", in: Paperno, I., Grossman, J.D. (Hgg.): Creating Life. The Aesthetic Utopia of Russian Modemism, Stanford 1994, S.

MIERAU, Fritz: Zwolf Arten die Welt zu beschreiben. Essays zur russischen Literatur, Leipzig 1988.

MINC, Zara: "Ponjatie teksta i simvolistskaja estetika", in: Materıaly vsesojuznogo simposiuma po vtoricnym modelinujušcim systemam 1(5), Tartu 1974. MULLER DE MOROGUES, Inès: Le problem féminin et les portraits de femmes dans l'oeuvre de Nikolaj Leskov, Bern, Frankfurt/Main, New York, Paris 1991.

NIKOLAEV, P.A.: Russkie Pisatelı 1800-1917. Biograficeski slovar', Moskva 1992.

PACHMUSS, Temira: Women Writers in Russian Modermism. An Anthology, Urtana/llinois 1978.

PAPERNO, Irina: Chemyshevskij and the Age of Realısm, Stanford, Cal. 1988.

PAPERNO, I., GROSSMAN, J.D. (HGG.): Creating Life. The Aesthetic Utopia of Russian Modemism, Stanford 1994.

RANCOUR-LAFERRIÈRE, Daniel: Russian Literature and Psychoanalysis, Amsterdam/ Philadelphia 1989.

SCHERRER, Jutta: Die Petershurger Religıös-Philosophischen Vereinigungen, Berlin/Wiesbaden 1973.

. ŠESTAKOV, V.P.: Russkij éros ili filosofija ljubvi v Rossii, Moskva 1992.

SMIRNOV, Igor: Na putı k teorii literatury, Amsterdam 1987.

ders.: "Die Evolution des Ungeheuren. Versuch über Mamleev", in: Schreibhefi. Zettschrift für Literatur, Nr. 40, November 1992, S. 150-155. 
TOPOROV, V.N.: Neomifologizm $v$ russkoj literature nacala $X X$. veka, Trento 1990.

ders.:"Peterburg i peterburgskij tekst russkoj literatury", in: Semıotıka goroda i gorodskoj kul'tury. Peterburg. Trudy po znakovym sistemam, 18, 1984, S. 4-19.

WIENER SLAWISTISCHER ALMANACH, Mythos in der Slawischen Moderme (Sonderband 20), Wien 1990.

Psychopoetik. Betträge zur Tagung Psychologie und Literatur (Sonderband 31), Wien 1992.

Periodisierung und Evolution (Sonderband 32), Wien 1993.

Orthodoxien und Häresien in den Slavischen Literaturen (Sonderband 41), Wien 1996.

\section{Forschungsliteratur zur Geschlechter-Differenz}

ALLEN, Virginia: The Femme Fatale. Erotic Icon, New York 1983.

ALTHOFF, Gabriela: Weiblichkelt als Kunst, Stuttgart 1991.

APPELT, Hedwig: Die leibhaffige Literatur. Das Phantasma und die Präsenz der Frau in der Schrift, Weinheim/Berlin 1989.

ARIES, Philippe, BEJIN, André: Die Masken des Begehrens und die Metamorphosen der Sinnlichkeit. Zur (jeschichte der Sexualität ım Abendland, FrankfurtMain 1984.

BADINTER, Elisabeth: Die Mutterliebe. (jeschichte eines (jefühls vom 17. Jahrhundert bis heute, München 1981.

dies.: Ich bin chu. Die neue Bezlehung zwischen Mann und Frau oder Die androgyne Revolution, München 1987. 
BAJBURIN, A.K., KON, I.S.: EtniCeskije stereotipy mužskogo i Ženskogo povedenija, Sankt-Peterburg 1991.

BASSEIN, Beth: Woman and Death: Linkages in Westem Thought and Literature, Westport, Conn. 1984.

BECKER-CANTARINO, Bartara: "Frau Welt und Femme Fatale. Die Geburt eines Frauenbildes aus dem Geiste des Mittelalters", in: Poag, James F. und Scholz-Williams, Gerhild (Hg.), Königstein 1983.

BENHABIB, Seyla/ BUTLER, Judith/ CORNELL, Drucilla/ FRASER, Nancy:

Der Streit um Differenz. Feminismus und Postmodeme in der Gegenwart, Frankfurt/Main 1993.

BENJAMIN, Jessica: Die Fesseln der Liebe. Psychoanalyse, Feminismus und das Problem der Macht, Frankfurt/Main 1993.

BENNENT, Heidemarie: Galanterie und Verachtung. Eine philosophiegeschichtliche Untersuchung zur Stellung der Frau in Gesellschaft und Kultur, Frankfurt/New York 1985.

BOVENSCHEN, Sylvia: Die imaginierte Weiblichkeit. Exemplarische Untersuchungen zu kultungeschichtlichen und literarischen Präsentationsformen des Weiblichen, FrankfurtMain 1980.

BRAUN, Christina von: Logik, Liebe, Libido, Frankfurt/Main 1985.

dies.: "Ceci n'est pas une femme. Betrachten, Begehren, Berühren - von der Macht des Blicks, in: Lettre International, Nr. 25, 1994, S. 80-84.

BRONFEN, Elisabeth: Nur über ihre Letche. Tod, Weiblichkeit und Ästhetik, München 1994.

dies.: "Vom Omphalos zum Phallus", in: Macht Geschlechter Differenz, Hg. Wolfgang Müller-Funk, Wien 1994. 
BUSCH/RUGE/WITTSTOCK: "Den Körper neu denken/Gender Studies", Neue Rundschau 4, 1983.

BUTLER, Judith: Das Unbehagen der Geschlechter, Frankfurt/Main 1991.

dies.: Körper von Gewicht. Die diskursiven Grenzen des Geschlechts, Berlin 1995.

CAVARERO, Adriana: Der Mensch ist zwei: Das Denken der Geschlechterdifferenz, Wien 1989.

CHASSEGUET-SMIRGEL, Janine: Psychoanalyse der wetblichen Sexualität, Frankfurt/Main, 1976.

CHODOROW, Nancy: The Reproctuction of Mothering: Psychoanalysis and the Sociology of Gender, Berkeley, Cal. 1978.

dies.: Feminism and Psychoanalyic Theory, New Haven/London 1989.

DERRRIDA, Jacques: Die Schrifi und die Differenz, Frankfurt/Main 1989.

ders.: Geschlecht, Wien 1988.

DUJKSTRA, Bram: Idols of Perversity: Fantasies of feminine evil in fin-desiècle culture, New York 1986.

DIDI-HUBERMAN, Georges: Erfinctung der Hysterıe, München 1997.

ERHART, Walter und Britta HERRMANN: "Feministische Zugänge -

$>$ Gender Studies<", in: (irundzüge der Literaturwissenschafi, Hgg. von Heinz Ludwig Amold und Heinrich Detering, München 1996.

FELMAN, Shoshana: Itterature and Psychoanalysis. The Questıon of Reading Otherwise, Baltimore, London 1982.

dies.: "Woman and Madness: The Critical Phallacy", in: Diacritics 5/2 (1975), S. $2-10$.

FOUCAULT, Michel: Sexualıät und Wahrhett, Frankfurt/Main 1989. 
GARBER, Marjorie: Vested Interests. Cross-Dressing and Cultural Anxiety, New York 1993.

GILBERT, M./ GUBAR, S.: No Man's Land. The Place of the Women Writer in the Twentieth Century, New Haven 1988.

GUTHKE, Karl S.: Die Herkunft des weltliterarischen Typus der femme fatale aus der deutschen Volkssage, in: Germanisch-Romanische Monatsschrif, Neue Folge 6, 1956.

HAHN, Barbara: "Feministische Literaturwissenschaft - Vom Mittelweg der Frauen in der Theorie", in: Neue Literaturtheorien, Opladen 1990, S.218234.

HERDT, Gilbert (Hg.): Third Sex, Third Gender. Beyond Sexual Dimorphism in Culture and History, New York 1994.

HILMES, Carola: Die Femme Fatale. Ein Weiblichkeitstypus in der nachromantischen Literatur, Stuttgart 1990.

HENICZ, Heidi: Die weiblıche (jeschlechtlichkeit im männlichen Bild von der Frau, Oldenburg 1988.

HORNEY, Karen: Psychologie der Frau, Frankfurt/Main 1985.

HUBER, Jörg (Hg.): Interventionen 2, Basel/Frankfurt/Main 1993.

IRIGARAY, Luce: Das Geschlecht das nicht eins ist, Berlin 1979.

dies.: Speculum. Spiegel des anderen (jeschlechts, Frankfurt/Main 1980.

dies.:Genealogie der Geschlechter, Freiburg (Breisgau) 1989.

dies.: Ethik der sexuellen Differenz, Frankfurt/Main 1991.

dies.: Zur Geschlechterdıfferenz. Interviews und Vorträge, Wien 1987.

JOHNSON, Barbara: The Critical Difference: BarteS Bal Zac, Baltimore 1980. KRISTEVA, Julia: Die Revolution der poetischen Sprache, Frankfurt 1978.

dies.: (jeschichten von der Liebe, Frankfurt 1989. 
dies.: Fremde sind wir uns selbst, Frankfurt 1990.

LAQUEUR, Thomas: Auf den leib geschrieben. Die Inszenierung der Geschlechter von der Antıke bis Freud, Frankfurt/Main/New York 1992.

LINK-HEER, Ulla: "Wird Androgynie normal? Zur Entfaltung imaginierter Geschlechtlichkeit zwischen zwei fins de siècle", in: KultuRRevolution, $\mathrm{Nr}$. 27, 1992, S. 46-49.

dies.: "Geschlechts-Palimpseste. Die >Hommes-Femmes< bei Marcel Proust", in: KultuRRevolution 9, 1985, S. 63-66.

MEYER, Eva: "Schreiben aus Liebeswut. Mystik und Hysterie", in: Frauensprache und Frauenllteratur' Für und Wider einer Psychoanalyse literarischer Werke, Tübingen 1986.

dies.: Die Autobiographie der Schrift, Bertin 1989.

OPITZ, Claudia: Weiblichkeit oder Feminısmus, Weingarten 1984.

dies.: Evatöchter und Bräute (hristi. Weiblicher Lebenszusammenhang und Franenkultur im Mittelalter, Weinheim 1990.

PRAZ, Mario: Liebe, Tod, Teufel. Die schwarze Romantik, München 1970.

ROHDE-DACHSER, Christa: "Unbewußte Phantasie und Mythenbildung in psychoanalytischen und psychoanalytischen Theorien über die Differenz der Geschlechter", in: Psyche 3, 1989, S. 193-219.

ROEBLING, Imgard: Lulu, Lilith. Mona Lisa...Frauenhilder der Jahrhundertwende, Pfaffenweiler 1989.

RUNTE, Annette: "Das Geschlecht der Engel. Zur Theorie des Transsexualismus in der Lacan-Schule", in: Psyche. Zeitschrift für Psychoanalyse und ihre Anwendungen, 9, 1985, S. 830-862. 
diess.: "Die Reise ins andere Geschlecht. Männlichkeits- und Weiblichkeitsmuster in autobiographischen Diskursen Transsexueller", in: KultuR-Revolution, 9, 1985, S. 11-14.

diess:: ">Das Selbe im Anderen (Geschlecht). Über Diskurse zum transsexuellen gender breakdown", in: Hans-Ulrich Gumbrecht, Pfeiffer, K. Ludwig (Hgg.): Paradoxien, Dissonanzen, Zusammenbrüche. Stationen offener Epistemologie, Frankfurt/Main 1991.

diess.: Biographische Operationen. Diskurse der Transsexualität, München 1996.

SCHABERT, Ina/ SCHAFF, Barbara: Autorschaft. Genus und Genie in der Zeit um 1800, Berlin 1994.

SCHAPS, Regina: Hysterie und Weiblichkeit. Wissenschafismythen über die Frau, Frankfurt 1982.

SCHLESIER, Renate: Mythos und Weiblichkeit bei Sigmund Freud. Zum Problem von Entmythologisierung und Remythologisienung in der psychoanalytischen Theorie, Frankfurt/Main 1990.

SEIFFERT, Edith: "Was will das Weib?" Zu Begehren und Lust bei Freud und Lacan, Weinheim/Berlin 1987.

STEPHAN, Inge u. C. PIETZKER: Frauensprache - Frauenliteratur? Für und Wider einer Psychoanalyse literarischer Werke, Tübingen 1986.

STEPHAN, Inge, WEIGEL, Sigrid: Feministische Literaturwissenschaft. Dokumentation der Tagung in Hamburg vom Mai 1983, Berlin 1984.

dies.: Weiblichkeit und Avantgarde, Berlin/Hamburg 1987.

dies.: Die verborgene Frau, Berlin 1988.

TAEGER, Annemarie: Die Kunst, Mectusa zu töten. Zum Bild der Frau in der Jahrhundertwende, Bielefeld 1987. 
THEWELEIT, Klaus: Mönnerphantasten, Frankfurt/Main 1977.

VINKEN, Barbara (Hg.): Dekonstrukaver Femınısmus. Literaturwissenschaft in Amerika, Frankfurt/Main 1992.

WARNER, Marina: In weiblicher Gestalt. Die Verkörperung des Wahren, Guten und Schönen, Hamburg 1989.

WEIGEL, Sigrid: Topographien der Geschlechter, Hamburg 1990.

ZIZEK, Slavoj: The Sublime (Object of Ideology, London 1991.

ders.: "Roberto Rosselini:. Die Frau als Symptom des Mannes", in: Lettre Intemational 12, 1991.

ders.: "Minne und Masochismus. Vom höfischen Liebesspiel zur tödlichen Inszenienung", in: Lettre International. Europas Kulturzettung 25, 1994, S. 76-79.

\section{Forschungsliteratur zu Psychoanalyse und Literatur}

BATAILLE, Georges: Der hellige Eros, FrankfurdMain, Berlin, Wien 1974.

DELEUZE, Gilles: "Sacher-Masoch und der Masochismus", in: SACHERMASOCH, Leopold von: Venus ım Pelz, FrankfurtMain 1980, S. 163-281. FREUD, Sigmund: Studienausgabe Band I-X, (Frankfurt 1969-1979), Frankfurt/Main 1982.

JUNG, Carl Gustav: Erlösungsvorstellungen in der Alchemie. Psychologie und Alchemie 2, Bd.6), Olten 1985.

LACAN, Jacques: Schrifien I-III, Weinheim/Berlin 1986.

ders.: Die vier Grundhegriffe der Psychoanalyse, Weinheim/Berlin 1987. 
ders.: Freuds technische Schrifien. Das Seminar Buch $I$, Weinheim/Berlin 1990.

LANG, Hermann: "Freud - ein Strukturalist?", in: Psyche 10, 1980, S. 865-884.

RUHS, August: "Die Schrift der Seele. Einfuihrung in die Psychoanalyse nach Jacques Lacan", in: Psyche 10, 1980, S. 885-909.

SCHÖNAU, Walter: Einfuihrung in die psychoanalytische Literaturwissenschafi, Stuttgart 1991.

WEBER, Samuel: Jacques Lacans Entstellung der Psychoanalyse, (Frankfurt, Main, Berlin, Wien 1978) Wien 1990.

WIDMER, Peter: Die Subversion des Begehrens. Jacques Lacan oder Die zwelte Revolution des Begehrens, Frankfurt/Main 1990.

\section{Texte zu Literatur- und Kulturwissenschaft}

AUSTIN, John L.: Zur Theorie der Sprechakae (How to do things with words), (Stuttgart 1972), Stuttgart 1979.

BARTHES, Roland: $S / Z$, Frankfurt/Main 1976.

ders.: Die Lust am Text, Frankfurt/Main 1977.

ders.: Fragmente einer Sprache der Liebe, Frankfurt Main 1988.

BAUDRILLARD, Jean: Der symbolische Tausch und der Tod, München 1991. ders.: Die fatalen Strategıen, München 1991.

BOHRER, Karl Heinz: Mythos und Moderne. Begriff und Bild einer Rekonstruktion, FrankfurtMain 1983.

ders.: Ästhetik und Rhetorik. Lektüren zu Paul de Man, Frankfurt/Main 1993. 
CULLER, Jonathan: On Deconstruction: Theory after Structuralism, Ithaca, New York 1982.

DERRIDA, Jacques: Iiperons. Les Styles de Nietzsche, Venedig 1976.

GREENBLATT, Stephen: Schmutzige Riten. Betrachtungen zwischen Weltbildern, New York 1991.

MAN, Paul de : Allegorien des Iesen, Frankfurt/Main 1988.

RORTY, Richard: Eine Kultur ohne Zentrum. Vier philosophische Essays, Stuttgart 1993.

SCHNEIDER, Manfred: Erkaltete Herzensschrift. Der autohiographische Text im 20. Jahrhundert, München/Wien 1986.

ders.: Liebe und Betrug. Die Sprachen des Verlangens, München/Wien 1992.

SENNETT, Richard: Die (iroßsstadt und die Kultur des Unterschieds, Frankfurt/Main 1991.

SPENGLER, Oswald: Der Untergang des Abendlandes. Umrisse einer Morphologie der Weltgeschiche, München 1923.

VOGL, Joseph (Hg.): (jemeinschafien. Positionen zu einer Philosophie des Politischen, Frankfurt/Main 1993.

WÜNSCH, Marianne: Regeln erotıscher Beziehungen in Erzähltexten der Frühen Moderne und thr theoretischer Status, in: Spiel Jg.9, 1990, S.131172. 